\title{
ENGINEERING
}

CENC 1194

SUPPLEMENT

NO. 1

VOLUME IV

\section{LMFBR \\ DEMONSTRATION PLANT \\ STEAM GENERATING \\ SYSTEM}

AEC CONTRACT AT(11-1)-3031
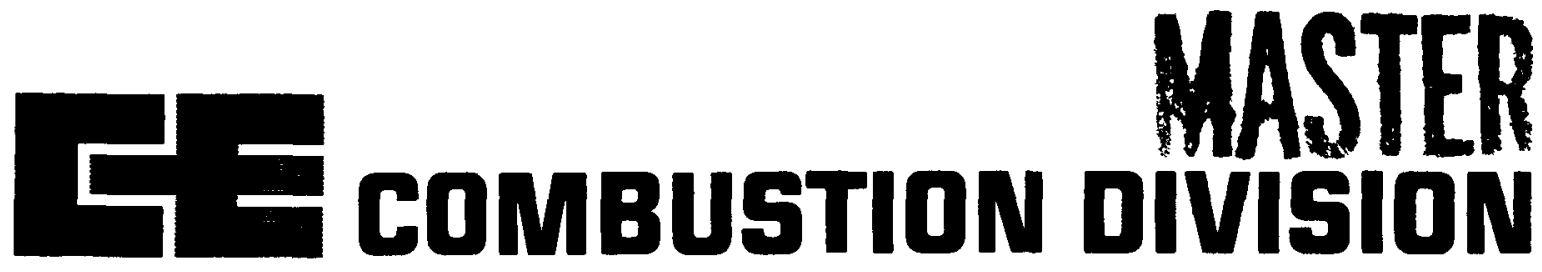

COMBUSTION ENGINEERING, INC. 


\section{DISCLAIMER}

This report was prepared as an account of work sponsored by an agency of the United States Government. Neither the United States Government nor any agency Thereof, nor any of their employees, makes any warranty, express or implied, or assumes any legal liability or responsibility for the accuracy, completeness, or usefulness of any information, apparatus, product, or process disclosed, or represents that its use would not infringe privately owned rights. Reference herein to any specific commercial product, process, or service by trade name, trademark, manufacturer, or otherwise does not necessarily constitute or imply its endorsement, recommendation, or favoring by the United States Government or any agency thereof. The views and opinions of authors expressed herein do not necessarily state or reflect those of the United States Government or any agency thereof. 


\section{DISCLAIMER}

Portions of this document may be illegible in electronic image products. Images are produced from the best available original document. 


\section{APPENDIX G}

\section{THERMAL TRANSIENT MODEL CALCULATION}

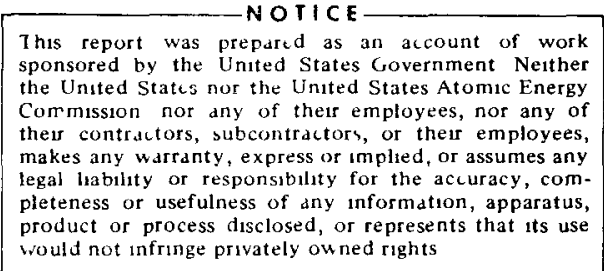

would not infringe privately ou ned rights 
COMEUSTION ENGINEERING. INC.

WINDSOR, CONN.

AEC

CONT. NO

made oreflefaranis/72

OWG. No.

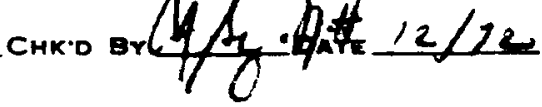

All calculations fon the steam generaton nodal model are presented in this section. All caladations involumg pesformanie pasametess were mack for the nosiunal $100 \%$ load case; infonmation ob taund fiom computa output "Pesformance study of sodicum deated Steam Gerresatos".

Node Descenetrons - (all semesent termperature, exceptions moted) 48 - stearn in the sepasation chum (enthoepy)

49- drum metal uppe portion

so- mrxed (separated sfeed) water in the drum (enthulay)

si- drum metal, lower postion

$15^{-}$- water within seasculatiox pumps.

133-142 - sodum in the superheater tube bandle 143.152 - pressuse tabe woll - supenketer bundle 153-162 - stean annulus - superkeate bandle 163-172 - Baysoset tube assembly - supe, hecter bundle 173-182 - Aiser tube stem - Superhecter bundle 183-185 - sodum arkist segron - supeshouter 18\%-188 - sodum en at region - supesho ater 189-197 - steam inlet and outept negrom enclueling additional heat exchange above sodium bevel.

198-203 - Sodum enset and out let segions - evaposatio 204-212 - steam/wates inlet and outht segrons includeng additional teat exchange above sockum bevel

213-218 - 50dum pipung be tween superticater and ev aposath

$229-243$ - Sodurn in the evaposator tube bunctle 244-258 - pressure tube wall - evaposator bundle $259-273$ - stean/wates ann ulas - evapesater bundle (entroling)

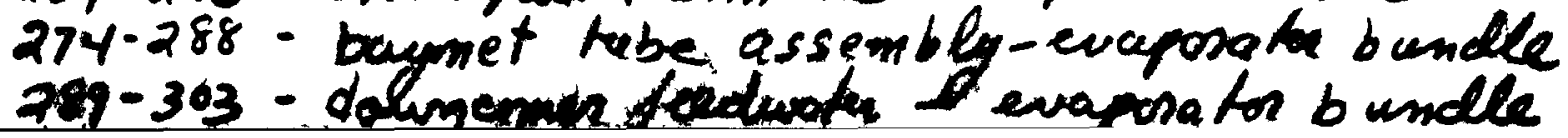


COMBustion ENGINEERING. INC.

WINDSOR, CONN.

Cont. No

Made BY

Date.

DNG. No.

Crk'o $\mathrm{Br}$

Date

57-72-Tempentive us enthalpy curve fit connecting nodes 386-400 with node 259-273, se specturely.

72 - saturation temperature for node 362 which cossespends to steam enthalpy node 48.

73 - Temperature vo enthalpy anne fit connectury nowt 363 with subcooted water node so.

74 - Secondary sodium enter temperature

75- - Feed water enthalpy

76 - secondary sodium flow nate per module

71 - secondary sodium flow nates per supeshroten tube

T8- secondary sodium flow nate per evapos a tor tube

19- steam flow sate pes superheated module

so- steam flow rate per super beater tube

81 - steam How nate pe loop

82- feed water How sate per loop

83 - secuculation flow sate pes evaporator module

St - recescuration flow sate pes exoposatos tube

85 - recuentation flow sate loop

86- saturation vape enthalpy

87- saturated liquid enthalpy

81 - saturated enthalpies: $1 / h_{\text {sg }}$

89- saturated enthalpies: hF/hig

Other nodes and flow equation may be used to effect particular transients or to obtain particular

- punted output.

$-1$ 
COMBUSTION ENGINEERING, INC.

WINDSOR. CONN.

CONT. No

Made Br_Date

DWG. No.

Chк'd Br

Dan

309-309-Pupung form evaposator to sepasation drum fleid nodes ase enthalfy.

310-313 - puping form sepasation chum to secuculation pump.

333-338-pepung form sepesation chum to superhectec

339-344-puing form secusculation pump to evaposotor

356 - saturated vapen enthaley for hum node if

355 - saturated hqued enthaby for hum node so

361 - enthaly consespondeng to node 303

362 - temperature corresponden to mode 48

363 - temperature conesponding to node 50

$36 x$ - second any sodum inist temperative

$365^{\circ}$ - feeduata en thalpy

366 - separated water in drum

367- separated stears in drum

368 - steam qualety (computed)

389- unity node - needed for cepos equation format

380-400 - steam/arta temperateres conesponding to enthaly nodes 305, 307, 309, 205, 206, 207, 255-973 sespeckinely

Zlow equotiones Desegmations

47. - Flow per loop of separated water in dium 50- enthulpy is Tamperitare curve fit connecting node 361
with pock 303.

51-56- saturation temperature for nodes $380-385$ which conespand to enthalyy nocles 305,307,309, 205, 206, 207, nespecturely 
COMBUSTION ENGINEERING. INC.

WINDSOR, CONN.

CONT. No

Made BY

Dare DWG. No. Chr' Br DATE

Location

The deferential nodes are manipulated into the following standard format.

$$
\dot{F}_{i}=y_{i} F_{i}+q_{j} \dot{\omega}_{a} F_{i}+\sum_{j}\left(c_{i j} F_{j}+c_{i j} \dot{\omega}_{b} F_{j}\right)
$$

2 - mode andes consideration

$y_{6}, c_{12}$ - self connector, including flow equation dependersee

1 - all nodes to which nodi $l$ is connected

$C_{i j}$, $C_{i j}$ - connector between nodes $c$ and $d$.

Algebraic nodes, non-deffenential connector between nodes

$$
F_{e}=c_{r c} \dot{\omega} F_{e}+\sum_{j}\left(c_{i j} F_{j}+c_{i j} \dot{\omega} F_{y}\right)
$$

How equations are each defined by 10 constants, $\left(\sigma_{1}, \ldots \epsilon_{0}\right)$ 1) If $\varepsilon_{1}<0$, it must be an integer since $t$ refers to a variable $z=F_{\mid b_{1} 1}$, and

$$
\dot{\omega}=6 z+\epsilon_{3} z^{2}+\frac{\epsilon_{4}}{z}+\frac{\epsilon_{5}}{z^{2}}+\epsilon_{6}+\epsilon_{7} z^{2}+\epsilon_{8} z^{4}+\epsilon_{4} z^{5}+\epsilon_{10} z^{6}
$$

2) If $\epsilon_{1} \geqslant 0$, it must also be an integer since $t$ refers to a variable $z=F_{e} \quad\left(z=0, f, e_{1}=0\right)$. In addition

a) If $\epsilon_{10}=0$

$$
\omega=H+R\left(C_{t}+\epsilon_{t}+\epsilon_{5} \exp \left(\epsilon_{6} t+\epsilon_{7} t^{2}\right) ; t^{*}=t+\epsilon_{9}\right.
$$

b) If $C_{0}>0$

$$
\begin{aligned}
& \omega=\left\{\begin{array}{l}
H+\epsilon_{10} \quad t_{s} \leqslant 0, t_{m} \leqslant 0 \\
H+R\left(t_{m}^{*}\right)+\epsilon_{2}+\epsilon_{s} \exp \left(\epsilon_{6} t+\epsilon_{7} t^{2}\right), t_{m}>0
\end{array}\right. \\
& t_{m}=t-\left(t_{0}+\theta_{s}\right) \text { and } t_{m}=z_{m}+\epsilon_{q}
\end{aligned}
$$

where

$$
H=\left\{\begin{array}{lll}
0 & \epsilon_{1}=0 \\
z & \varepsilon_{1}>0
\end{array} ; R(t)= \begin{cases}0 & t \leqslant 0 \\
e_{3} t+\epsilon_{4} t^{2} & t \geqslant 0\end{cases}\right.
$$


COMBUSTION ENGINEERING

NUCLEAR POWER DEPARTMENT

Supenteater

I. Mass Heat Inansfes Peguen

As described below the transient model reset is the "Outlet temperature model" where the nodal point is chanactenged by the properties at the outlet. of the finite element which the node represents. Due to the steepness of the steam temperature profile a strict adherence to this model well yield a lase heat flex. Consequently at is assumed that the heat transfer es based on the average fled temperature and fled capacity is based on the outlet temperature. Energy balances

$$
\begin{aligned}
& -(U A)_{1}\left[T_{N V}-T_{P T}\right]+\left(w C_{P}\right)_{N a} T_{N a}=\left(w c_{P}\right)_{N a} T_{N a}+\left(p V C_{P}\right)_{N a} \frac{d T_{N a}}{d t} \\
& (U A)_{1}\left[T_{A V}-T_{P T}\right]-(U A)_{2}\left[T_{P_{F}}-T_{A v}\right]=\left\langle(\rho \vee C)_{\rho T} \frac{d T_{P T}}{d t}\right.
\end{aligned}
$$

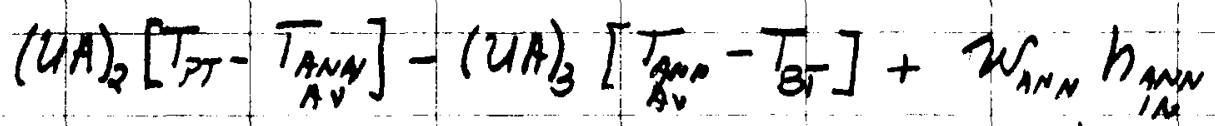

$$
\begin{aligned}
& =w_{A N} h_{A N N}+\frac{d}{d t}(\rho \vee v)_{A N N} \\
& (U A)_{3}\left[T_{A N N}-T_{B T}\right]-(U A)_{Y}\left[T_{B T}-T_{A V}\right]=(\rho \vee C)_{B T} \frac{d T_{B T}}{d t} \\
& \left(U A_{A}\left[T_{B T}-T_{R V}\right]+w_{R} h_{R}=W_{R} h_{R}+\frac{d}{d t}(p v U)_{R}\right.
\end{aligned}
$$

Fo the steam in the annuli and rises the Following assumptions are made:

$\frac{d \rho}{d t}=0 \quad$ (implicit, since conlonuty has not) 
COMBUSTION ENGINEERING NUCLEAR POWER DEPARTMENT

$$
\begin{aligned}
& d h=C_{\rho} d T \\
& \frac{d p}{d t} \approx 0 \Rightarrow \frac{d}{d t}(p u)=\frac{d}{d t}(\rho h-p)=\frac{d}{d t}(\rho h)^{t}=\rho C_{\rho} \frac{d T}{d t}
\end{aligned}
$$

and for all fluid node the "average" value is one half the sum of the inlet and pullet value.

$$
T_{n v}=D_{2}\left(T_{N}+T\right)
$$

It should be noted that Tin is the value associated with the serous mode. The sescelts of these assumptions" are substituted into the energy palaces. The equations are then se assanged into stand and for nat.

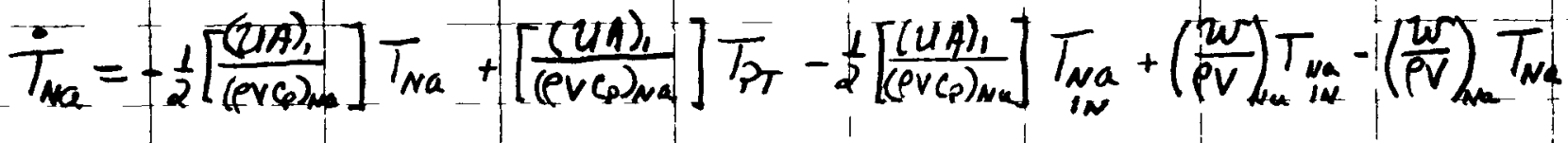

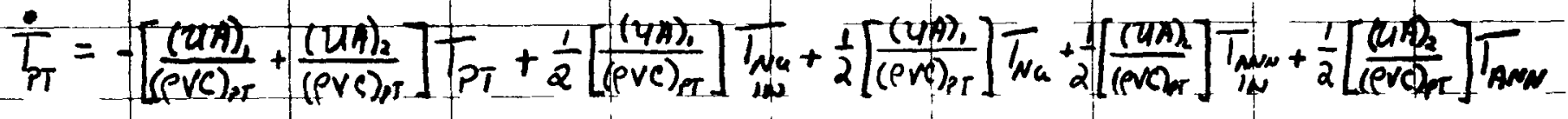

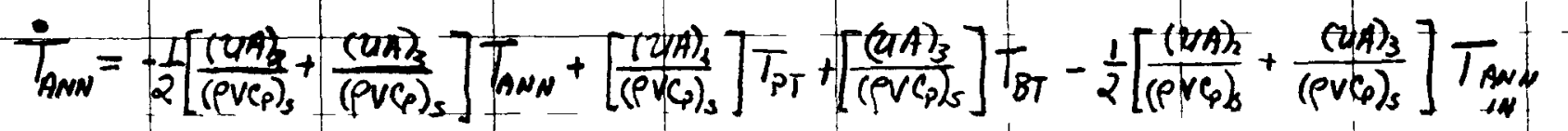

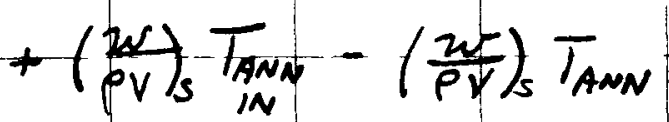

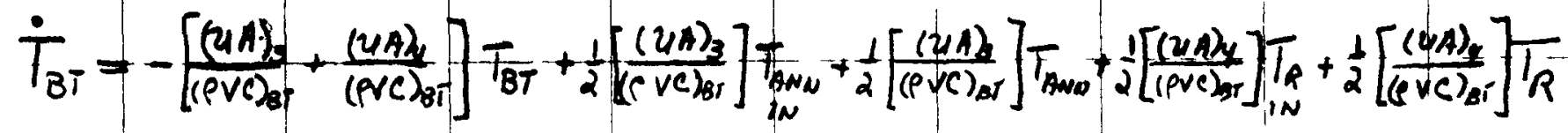

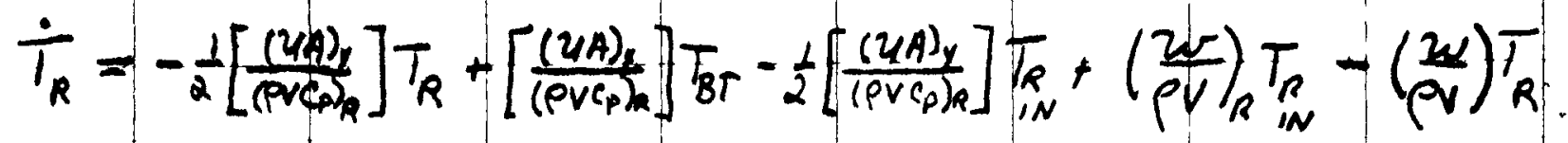


COMBUSTION ENGINEERING NUCI EAR POWER DEPARTMENT

Design parameters and axil variations of the properties of the suposheater working fluids were obtained fin the computer output "Pespomance Studies for Sodium Bleated Steam Generator". A program wo wsilfen for the GE Time Sharing Compute, which takes all the above data and calculates the coefficients for the equations governing the transient.

Ip put data:

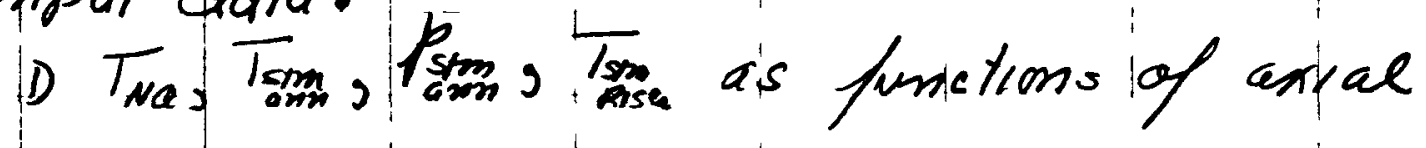
position.

2) steam and sodium flow sates ip tube, sodium Film coefficient (twa), riser stein film colfucient $\left(h_{R}\right)$; annular steam flem coeffurent (hs) as a function of axial position.

3) properties for sodium, pesessure lube and bayonet tube materials, and steam in the bayonet tube insulation gap. In addition, $\vec{C}_{0}=\Delta h / \Delta r$ fop each superheated sing movement is input.

4) Tube geometry

$d_{1}, d_{2}=$ inner bayonet tube ID, OD

$d_{3}, d_{4}=$ outer baymet tube ID, OD

$d_{i j}, d_{6}=$ pesessure tube ID, OD

$P=$ pitch

$L_{T}=$ beat transfer Jersth of tubes.

The following parameters are computed:

1 Parameters that do mot vary with axial position. 
COMBUSTION ENGINEERING

MIICI EAR POWER DEPARTMENT

This category includes the properties and parameters for the sodium, the pressure tube, and the bayonet tube assembly. The variation of properties and parameters of the steam in the risen is slight and may be neglected. This may not be done for the annular steam.

a) Volumes and Capautances

$$
\begin{aligned}
& V_{N a}=\left(\frac{\sqrt{3}}{2} P^{2}-\frac{\pi}{4} d_{b}^{2}\right) \Delta L ; \quad C_{N a}=\rho_{N a} V_{N a} C_{P} P_{N a} \\
& V_{P T}=\frac{\pi}{4}\left(d_{G}^{2}-d_{s}^{2}\right) \Delta L ; \quad C_{P T}=\rho_{P T} V_{P T}\left(C_{P}\right)_{P T} \\
& V_{B T}=\frac{\pi}{4}\left[\left(d_{4}^{2}-d_{3}^{2}\right)+\left(d_{2}^{2}-d_{1}^{2}\right)\right] \Delta L ; \quad C_{B T}=\rho_{B T} V_{B T}\left(C_{P}\right)_{B T}
\end{aligned}
$$

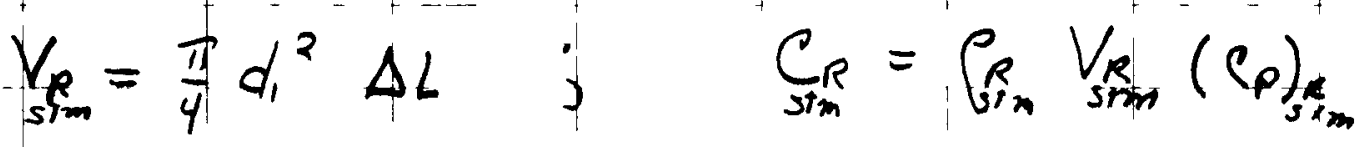

$$
\begin{aligned}
& V_{\text {wm }}=\frac{\pi}{4}\left(d_{s}^{2}-d_{y}^{2}\right) \Delta L
\end{aligned}
$$

where $\Delta L=$ length of each nodal increment in the CEROS model.

b) Thermal Resistances

$$
\begin{aligned}
& R_{N a}=\frac{1}{\pi d_{b} \Delta L h_{N a}} ; R_{P T_{1}}=\frac{\ln \left(d_{b} / \delta\right)}{2 \pi k_{P T} \Delta L} \\
& \text { and }\left(U_{A}\right)_{1}=\left(R_{N_{a}}+R_{P T_{1}}\right)^{-1}
\end{aligned}
$$


COMBUSTION ENGINEERING NIICLEAR POWER DEPARTMENT

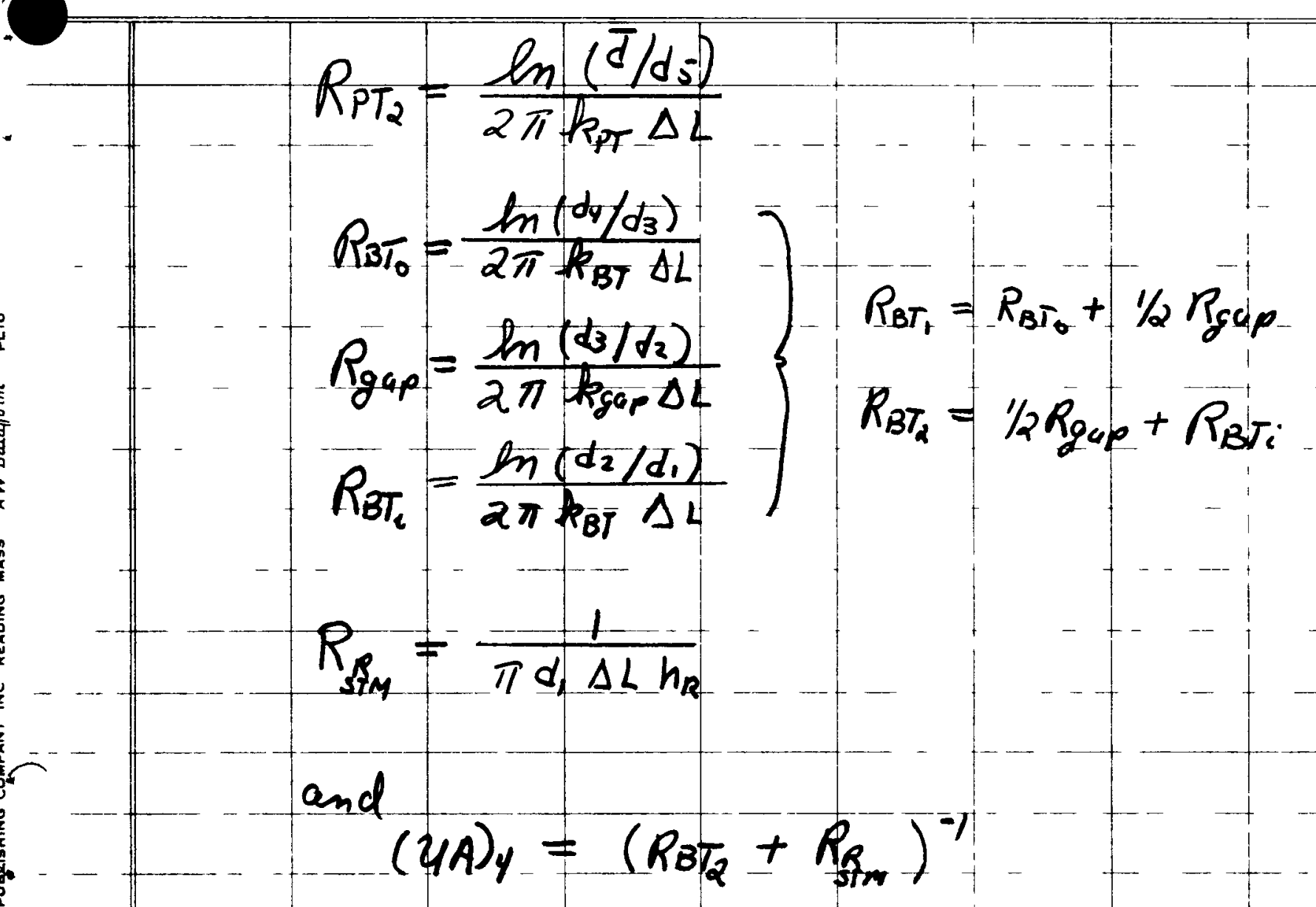

2) Parameters that vary with axial position are then computed. Since the properties of the annular steam vary, the thermal capartances and resistances also vary. Thus, node by node computations must be made.

The model employed is the "Outlet Temperature model" wherein the node is characterized by the properties at the outlet of the finite element the node represents. For a set of nodes at a given axial position, the sodium and riser steam conditions are obtained at the given axial position, but the associated an rutan steam conditions exist a nodal 
COMBUSTION ENGINEERING NIJCIEAR POWER DEPARTMENT

increment away. Consequently the associated pressure tube and bayonet tube assembly average tempenatines are "diagonal" arresages. (see figure)

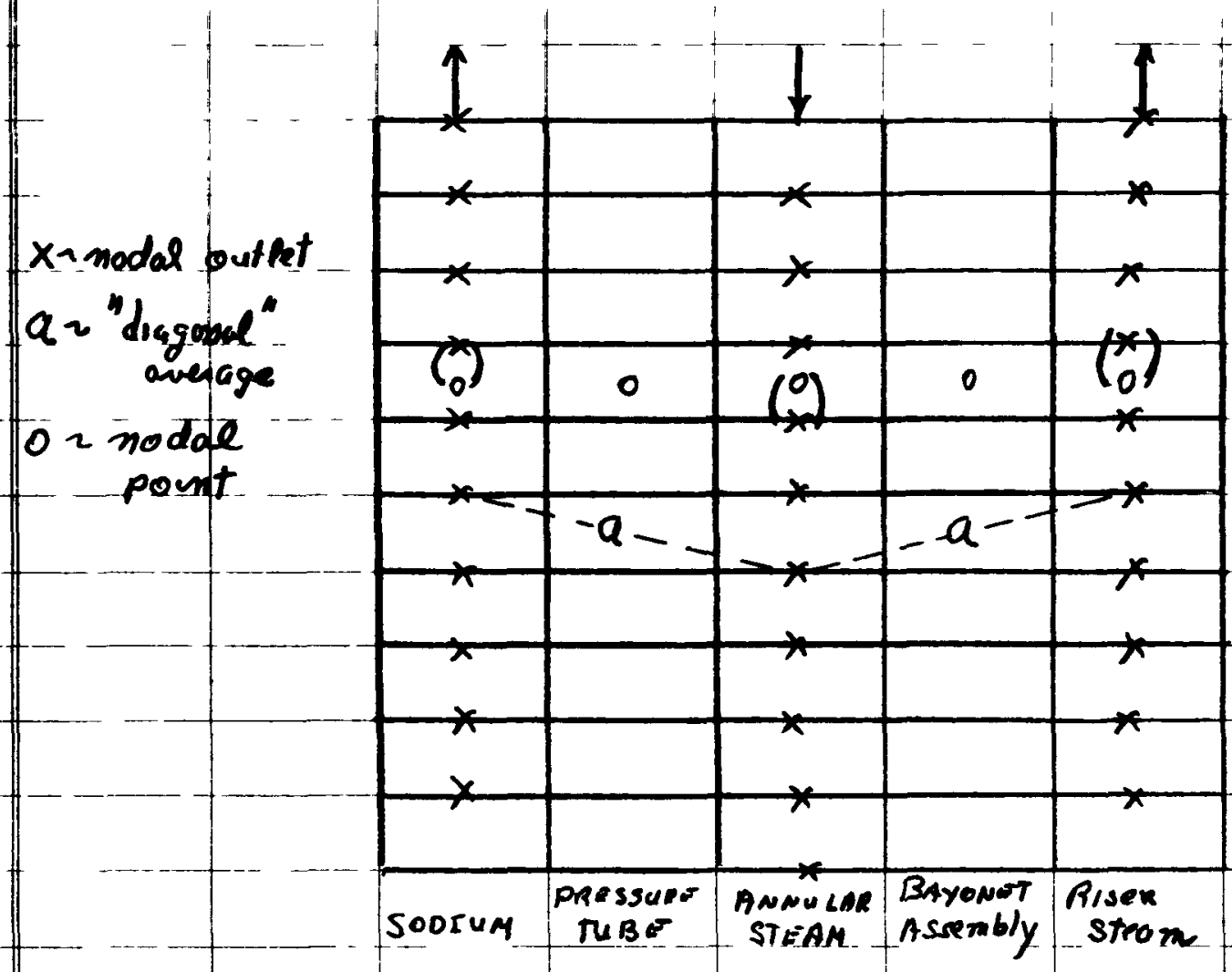

The coefficients of the governing differential equations were cobivated and a steady state temperature distribution obtained. The heat flux from the sodium to the annular steam was calculated from the output.

$$
\frac{d q}{d t}=U_{N A S M}\left(T_{N G}-T_{S I M}\right)
$$

(- J his was then compared to the output of the sung program. The heat sher distribution for the ceros model was consistently and conscolenably below 
COMBUSTION ENGINEERING NIICLEAR POWER DEPARTMENT

that of the Sung code model. The heat transfer colfucients in the two models were the same; the differences in heat fluxes wee due to the differences in $\left(T_{w a}-T_{s t m}\right)$.

The not cause of this dispart is the strict adherence to the "Du let Temperature Model" in the CEROS model. A flue node is represented by the conditions at the outlet of the finite element. which the node represents. Thus, for Avo feuds flowing counter to each o then the temperature between them would be a deference in the element outlet tempenatopes; this us indurated in the accompanying diagram. The difference in the average element temperature which is mere

- representative of the actual schuation is also indicated on the diagram. The templesatupe

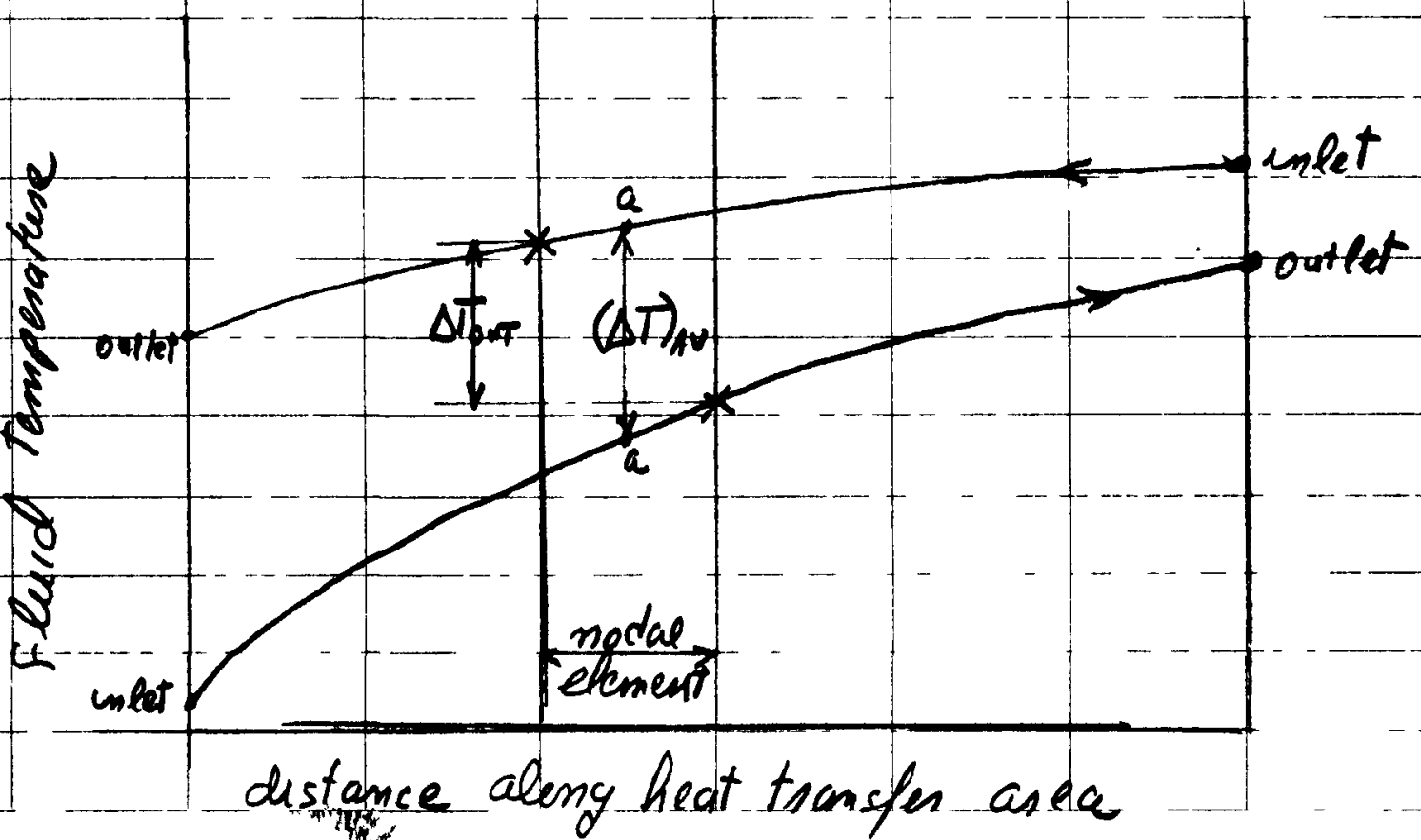

distance along heat transfer as ea

, 
COMBUSTION ENGINEERING NUCLEAR POWER DEPARTMENT

effect we heat capacity is bequeied

$$
\bar{C}_{\bar{p}}=\left(\frac{d h}{d T}\right)_{\text {sir inciomente }}
$$

This effectwe value is presented out as est in the scigeng code. The CPSH fo each output line furs associated with the end of each interment of the size code model, and an extropolaticu of this assay to $x=0$ was used for the initial point. This assay eras input to the time shaseng compute program.

Fo the inert and outlet of each element of the CERT model a value of Chon is obtained from interpolation of the input array. These wo values are then averaged to obtain an accepted value of Cram to be associated with the node; this supersedes the steam table value. the thermal capacity of each annular steam node es then calculated.

$$
C_{s}=\frac{1}{\int_{\operatorname{sim}} V_{\text {sim }} C^{P_{s I m}}}
$$

The film coefficient for the annular steam is

$$
\begin{aligned}
& h_{j}=\frac{k_{s \mathrm{~m}}}{D_{c}}\left[0.023 \mathrm{Rg}^{0.8} P_{r_{s}}^{0.4}\right] \\
& R_{e_{s}}=-\frac{W_{s}}{A_{\text {show }}} \frac{P_{e}}{U_{s / m}} \\
& \bar{P}_{r_{s}}=\left(\frac{\mu p_{p}}{k}\right)_{s} \\
& D_{e}=d_{s}-d_{y}
\end{aligned}
$$


COMBUSTION ENGINEERING

NUCLEAR POWER DEPARTMENT

These coefficients differed sigmpicantly with those printed out for the suing Code. The source of this deference is that the time shone mg computer has only the Keenan 5 Keys steam Tables transport properties $(\mu, k)$, and the sym g program used the ASME steam tables transport properties; these two sourness clusagpe anscolesably un the range of assent inter pst. The $\$ S M E$ tables are considered to most up -to. date.

In order to connect this difference the firn coffuciente form the suing code point out was accepted. An andy representing hs as a function of axial position was input to the the sharing computer program. The bs for each output line was associated with the end of the sizing code model increment, and an extrapolation of this assay to $x=0$ was used for the initial point.

Fo the inlet and outlet of each element of the CERDS model a value of $h s$ is ob tamed. from interpolation of the isp ut ass y. These two values are then averaged to obtain an accepted value of hi to be a sracrated with the node. This procedure supersedes the meed to obtain $\mu, k$ and and the calculation sequence for hs. The associated thermal resistances and conductanas.

$$
R_{s_{1}}=\frac{1}{\pi d_{s} \Delta L h_{s}} ; \quad R_{s_{2}}=\frac{1}{\pi d_{L} \Delta L h_{s}}
$$


COMBUSTION ENGINEERING NUCLEAR POWER DEPARTMENT

and

$$
(U A)_{2}=\left(R_{P T_{2}}+R_{S_{1}}\right)^{-1} ;(U A)_{3}=\left(R_{S_{2}}+R_{B T_{1}}\right)^{-1}
$$

The associated average temperatures for the pressure tube and bayonet tube assembly are then calculated.

$$
\begin{aligned}
& T_{P T}=\frac{(U A)_{1} T_{T_{U}}+(U A)_{2} T_{S}}{(U A)_{1}+(U A)_{2}} \\
& T_{B T}=\frac{(U A)_{3} T_{S}+(U A)_{4} T_{B}}{(U A)_{3}+(U A)_{Y}}
\end{aligned}
$$

Since the $v$ blues of $T_{1} a, T_{S}, T_{R}$ were interpolated at the outlet of the nodal element, TPT, TBT are the "diagonal" avenglges. Elise 5 temperature values ares not necessary for the CERDS calculations so they have not been jewised to reflect average temperifurs, They have been calculated and punted out in informatemal purposes only

Anally the coefficients of the governing deferential equations as e calculated.

$$
\begin{aligned}
& C_{1}=-\frac{C_{2}}{2} ; C_{2}=\frac{(U A)_{1}}{C_{\text {Na }}} ; C_{3}=\frac{1}{\rho_{\text {Na }} V_{\text {Na }}} \\
& C_{4}=2\left(C_{5}+C_{6}\right) ; C_{5}=\frac{1}{2} \frac{(U A)_{1}}{C_{P_{T}}} ; C_{6}-\frac{1}{2} \frac{(U A)_{2}}{C_{P T}} \\
& C_{7}=\frac{1}{2}\left(C_{8}+C_{9}\right) ; C_{8}=\frac{(U A)_{2}}{C_{5}} ; C_{9}=\frac{(U A)_{3}}{C_{5}} ; \\
& C_{10}=\frac{1.0}{\rho_{5} V_{\text {ST M }}}
\end{aligned}
$$




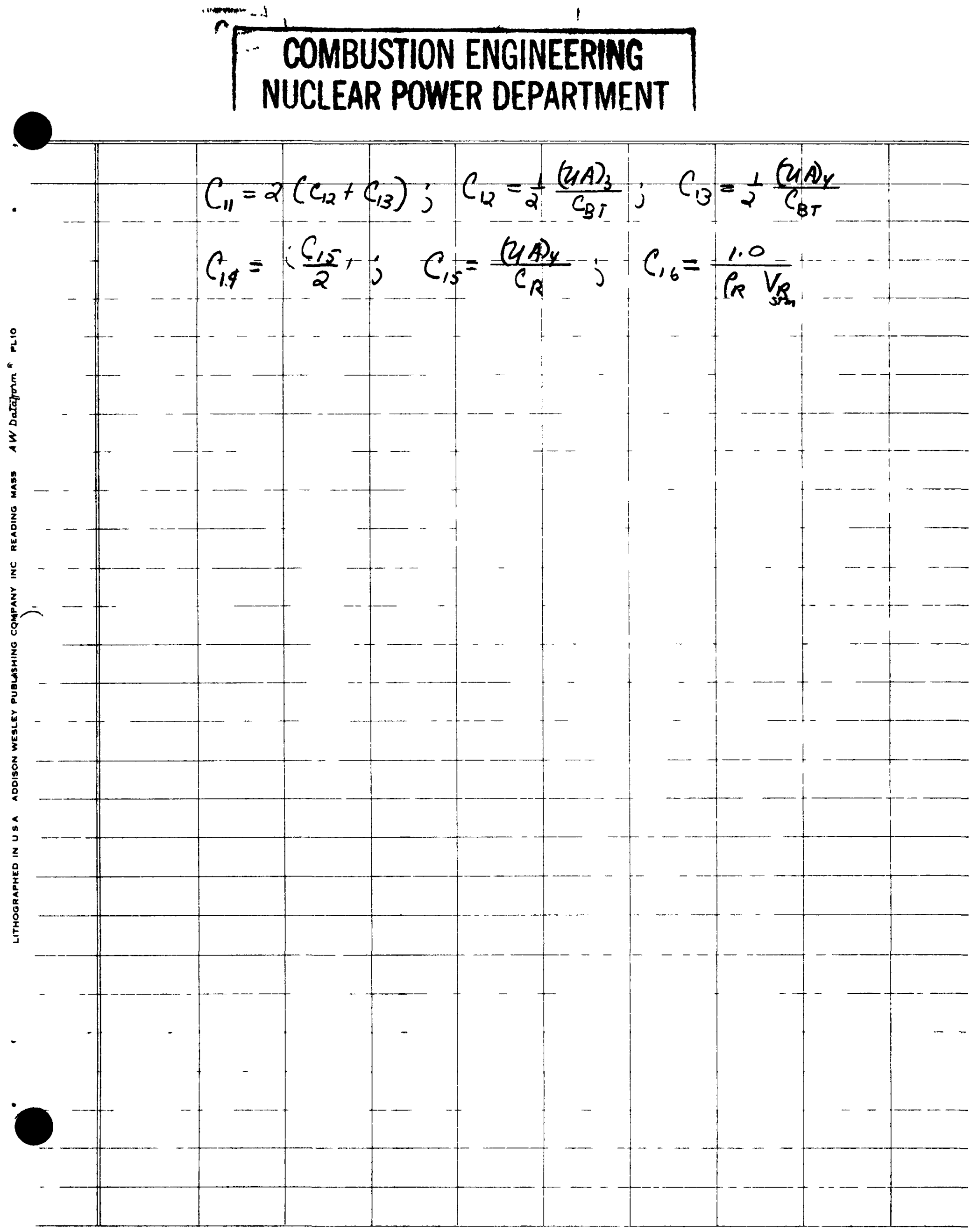


100 DIMENSION XTAB(29), YTAB(29),ZTAB(29), TTAB(29),PTAB(29)

101 DIMENSIEN HTAB (29),CPB(29)

110 NTAB $=293$ NPT $=3$; IERR $=0$

120 DATA XTAB/0.0.1.099.2.199.3.298.4.397.5.496.6.596.7.695.8.794. $12189 \cdot 894 \cdot 10 \cdot 993 \cdot 12.092 \cdot 13 \cdot 191 \cdot 14 \cdot 291 \cdot 15 \cdot 390 \cdot 16 \cdot 489 \cdot 17 \cdot 589 \cdot 18 \cdot 688$. $122819 \cdot 787 \cdot 20 \cdot 886,21 \cdot 986 \cdot 23 \cdot 085,24 \cdot 184.25 \cdot 283 \cdot 26 \cdot 383 \cdot 27 \cdot 482 \cdot 28 \cdot 581$, $123829.681 \cdot 30.78 /$

130 DATA YTAB/866.02.872.21.878.23.884.05.889.70.895.10.900.21, $131: 905 \cdot 14 \cdot 909 \cdot 79 \cdot 914 \cdot 21: 918 \cdot 36,922 \cdot 29,925 \cdot 96 \cdot 929 \cdot 42 \cdot 932 \cdot 66$. $1326935 \cdot 68 \cdot 938 \cdot 50,941 \cdot 13 \cdot 943 \cdot 57 \cdot 945 \cdot 85 \cdot 947 \cdot 96 \cdot 949 \cdot 93 \cdot 951 \cdot 75$. $1338953.44 .955 .02 .956 .47 .957 .81 .959 .06 .960 .21 /$

140 DATA ZTAB/903.60,904.28,904.94.905.58,906.21,906.81.907.38. $141 \& 907.93 .908 \cdot 44,908 \cdot 93.909 \cdot 38,909 \cdot 80,910 \cdot 19 \cdot 910 \cdot 55 \cdot 910 \cdot 88$. $1428911 \cdot 17.911 \cdot 44.911 \cdot 67.911 \cdot 88.912 \cdot 07.912 \cdot 22.912 .36 .912 .47$. $1438912.57 .912 .57 .912 .57 .912 .57 .912 \cdot 57.912 .57 /$

150 DATA TTAB/674.28.678.85,684.78,691 .38,699.38,708.87.718.12, $151.728 \cdot 62 \cdot 739 \cdot 05 \cdot 750 \cdot 41 \cdot 761 \cdot 36 \cdot 772 \cdot 83 \cdot 783 \cdot 87 \cdot 794 \cdot 89 \cdot 805 \cdot 63$. $1528816 \cdot 08 \cdot 826 \cdot 20 \cdot 835 \cdot 85 \cdot 845 \cdot 10,853 \cdot 91 \cdot 862 \cdot 08 \cdot 870 \cdot 05 \cdot 877 \cdot 40$, $1538884 \cdot 22 \cdot 890 \cdot 74 \cdot 896 \cdot 76 \cdot 902 \cdot 34 \cdot 907 \cdot 78 \cdot 912 \cdot 771$

155 DATA CPB/5.4.4.576,3.426.2.977.2.388,1.919,1.896,1.586.1.506.1.315. $15681 \cdot 278 \cdot 1 \cdot 157 \cdot 1 \cdot 123 \cdot 1 \cdot 058 \cdot 1 \cdot 016 \cdot 0 \cdot 9749 \cdot 0 \cdot 9391 \cdot 0.9151 .0 .8897$. $15780.8677 .0 \cdot 8677 \cdot 0 \cdot 8284.0 \cdot 8284 \cdot 0 \cdot 8284 \cdot 0 \cdot 7979 \cdot 0 \cdot 7979 \cdot 0 \cdot 7979$. $15840.7596,0.7596 /$

160 DATA PTAB/2606.07.2604.64.2603.12.2601.49.2599.77. $16122597.96 \cdot 2596 \cdot 05 \cdot 2594 \cdot 04.2591 \cdot 95.2589 \cdot 76,2587 \cdot 50.2585 \cdot 15.2582 \cdot 73$. $16242580 \cdot 23 \cdot 2577 \cdot 66 \cdot 2575 \cdot 02 \cdot 2572 \cdot 32 \cdot 2569 \cdot 56 \cdot 2566 \cdot 75 \cdot 2563 \cdot 88 \cdot 2560 \cdot 96$. $16382557.99 \cdot 2554 \cdot 98 \cdot 2551 \cdot 93.2548 \cdot 84.2545 \cdot 71 \cdot 2542 \cdot 55 \cdot 2539 \cdot 36 \cdot 2529 \cdot 75 /$

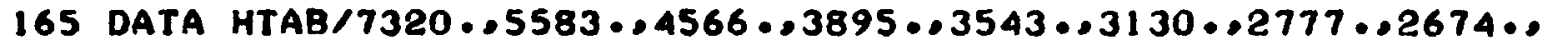
$16682445 \ldots 2346 \cdot .2184 \cdot .2128 \ldots .2019 . .1975 \ldots 1913 \ldots 1869 \ldots 1828 \ldots 1792 \ldots$ $167 \& 1767 \ldots 1741 \ldots 1720 \ldots 1716 \ldots 1682 \ldots 1679 \ldots 1677 \ldots 1651 \ldots 1650 \ldots 1649 \ldots 1616 ., 1$ $170 \quad D 1=0.6363 \quad D 2=0.7163 \quad D 3=0.8363 \quad D 4=0.9163 \quad D 5=1.1163 \quad 06=1.5$

$175 P=2.03 \quad X L T=30.78$

$180 W N A=29020.1$ WS $=2648.52$

190 CPNA $=0.301683$ XKNA=39.03 RHONA $=52.33$ XMUNA $=0.603$ HNA $=7780$. 195 CPR $=0.653$ XKR=0.05053 $R H Q R=3.667$ \& XMUR $=0.07313 \quad H R=1212$. 200 CPT $=0.1553$ XKPT $=15.93$ RHOPT $=480$. 205 CBT $=0.1553 \quad X K B T=15.93 \quad R H D B T=480$.

210 XKG $=0.12$

$220 N P=103 \quad D X=3.0779$

250 RNA $=3.8197 /(D 6 * D X * H N A)$

$255 D 8=S Q R T((D 5 * * 2+D 6 * * 2) / 2.0)$

256 RPT $1=0.159155 * A L O G(D 6 / D B) /(D X * X K P T)$

257 RPT2 $=0.159155 * A L O G(D B / D 5) /(D X * X K P T)$

260 RBT I $=0.159155 * A L G G(D 4 / D 3) /(D X * X K B T)$

$261 R G A P=0.159155 * A L Q G(D 3 / D Q) /(D X * X K G)$

262 RBTO=0.159155*ALOG (D2/DI)/(DX*XKBT)

$263 R B T I=R B T I+0.5 * R G A P I \quad R B T 2=0.5 * R G A P+R B T O$

270 RSTM $=3.8197 /(01 * D X * H R)$

$280 U A 1=0.000277777 /(R N A+R P T 1)$ ) UAA $=0.000277777 /(R B T 2+R S T M)$

$300 A 1=(0.866025 * P * * 2-0.785398 * D 6 * * 2) / 144.3 \quad V 1=A 1 * D X$ 
GOLMO3

$301 A 2=0.785398 *(06 * * 2-05 * 2) / 144.3 V 2=A 2 * D X$

$302 A 3=0.785398 *(D 5 * * 2-D 4 * * 2) / 144 * 3 \quad V 3=A 3 * D X$

$303 A 4=0.785398 *(D 4 * * 2+D 2 * 2-D 3 * * 2-D 1 * 2) / 144 \cdot 3 \quad V 4=A 4 * D X$

$304 A 5=0.785398 *(D 1 * * 2) / 144 \cdot 3$ V $5=A 5 * D X$

$305 \mathrm{DE}=(D 5-D 4) / 12$.

310 CANA $=R H O N A * V 1 * C P N A$

$311 C A R=R H O R * V 5 * C P R$

312 CAPT $=R H D P T * V 2 * C P T$

$313 \mathrm{CABT}=\mathrm{RHOBT} * \mathrm{~V} 4 * \mathrm{CBT}$

$320 \mathrm{C2}=U A 1 / C A N A 3 \quad C 1=C 2 / 2.03 C 3=1.0 /(R H \theta N A * V I)$

325 C5 $=0.5 * U A 1 / C A P T$

330 CI $3=0.5 * U A A / C A B T$

335 C15 $=U A 4 / C A R: C 14=C 15 / 2.03$ C16 $=1.0 /$ (RHBR*VS)

350 PRINT, "VOLUMES AND CAPACITIES"

351 PRINT,VI,CANA,VZ,CAPT, VA,CABT, V5,CAR,V3

352 PRINT 200

353 200 FORMAT (/)

360 PRINT,"THERMAL RESISTANCES ANO CONDUCTANCES"

361 PRINT -RNA,RPTI " " "UAI

362 PRINT,RPT2

363 PRINT คRBT I คRGAP, RBTE

364 PRINT .RBTI

365 PRINT.RBT2.RSTM." ".UA4

370 PRINT 300

371300 FORMAT $(1 / 1 / 1)$

400 DQ $100 \quad I=1$ INP

$405 X I=I 3 \quad X 1=(X I-1.0) * D \times 3 \quad X 2=X I * D X$

410 TNA =TNT $1(X), N T A B, X T A B, Y T A B, N P T$, IERR)

$420 T R=T N T I(X)$, NTAB $, X T A B, Z T A B, N H T, I E R R)$

$430 T S=T N T 1(X 2, N T A B, X T A B, T T A B, N P T, I E R R)$

440 PS=TNT I (X2, NTAB,XTAB,PTAB, NPT , IERR)

$447 \mathrm{CPI}=\mathrm{TNT} I(X I, N T A B, X T A B, C P B, N P T \cdot I E R R)$

$448 C P 2=T N T 1(X 2, N T A B, X T A B, C P B, N P T, I E R R)$

449 CPS $=(C P 1+C P 2) / 2 \cdot 0$

450 XMUS =STMNU (PS , TS) \& XKS =STMEK(PS,TS)

451 RHGS $=S U P D(P S, T S$ ) 1 PRS $=X M U S * C P S / X K S$

455 RES $=W S * D E /(A 3 * X M U S)$

$460 \mathrm{HSI}=\mathrm{TNT} 1(X 1, N T A B, X T A B, H T A B, N P T, I E R R)$

$461 \mathrm{HS2}=T N T 1(X 2, N T A B, X T A B, H T A B, N P T, 1 E R R)$

$462 H S=0.5 *(H S 1+H S 2)$

$465 R S 1=3.8197 /(D 5 * D X * H S), R S 2=3.8197 /(D 4 * D X * H S)$

470 UA2 $=0.000277777 /(R P T 2+R S 1)$ I UA3 $=0.000277777 /(R S 2+R B T 1)$

$480 C 6=0.5 * U A 2 / C A P T ; C 4 * 2 \cdot 0 *(C 5+C 6)$

485 CAS $=R H O S * V 3 * C P S$

$486 C 8=U A 2 / C A S \& C 9=U A 3 / C A S 3 C 7=0.5 *(C 8+C 9) \& C 10=1 \cdot 0 /(R H O S * V 3)$

$490 \mathrm{C} 12=0.5 * \mathrm{UA3} / \mathrm{CABT}, \mathrm{C} 11=2.0 *(\mathrm{C} 12+\mathrm{C} 13)$

$500 T P T=(U A T * T N A+U A Q * T S)((U A I+U A Q), T B T=(U A 3 * T S+U A 4 * T R)(U A 3+U A 4)$

510 PRINT, "TEMPERATURE DISTRIBUTION"

511 PRINT , TNA,TPI,TS,TBT,TR

512 PRINT 200 
520 PRINT, "STEAM PROPERTIES"

521 PRINT ,PS, XMUS,XKS,CPS,RHES ,PRS,CAS

522 PRINT 200

530 PRINT, "THERMAL CONDUCTANCES--STEAM"

531 PRINT,$H S \cdot \infty$

- UAz, Ua3

532 PRINT 200

540 PRINT: "COEFFICIENTS"

541 PRINT,CI $, \mathrm{C2}, \mathrm{C3}$

542 PRINT.C4.C5.C6

543 PRINT,C7,C8,C9,CIO

544 PRINT.CI1.C12.C13

545 PRINT,C14,C15,C16

S46 PRINT 400

547400 FORMAT $(/ / 1)$

600100 CONT INUE

650 STOPS ENO 
VOLUMZS AMD CAPACITIES
3.6271224E-02
5.7828243E-01
$1.6863619 E-02$
$1 \cdot 2546532 E+00$
$4.1686314 E-03$
$3 \cdot 1014618 E-01$
$6 \cdot 7904106 E-03$
$1.6185283 E-02$
$6.8223735 E-03$
THERMAL RESISTANCES AND CONDUCTAMCES
$1.0634177 E-04$
$5.5093606 E-04$
$4-10766775-04$
$5 \cdot 3717348 \varepsilon-01$
2.9720538E-04
$3.3681468 E-02$
$3 \cdot 3769581 E-02$
$6.6768524 E-02$
$3 \cdot 8531824 E-04$
I.6099597E-03
$7 \cdot 8513456 E-03$

TEMPERATURE DISTRIBUTIEN

8.6602000E+02

$9.0360000 E+02$

STEAM PROPERTIES

$2.6018254 E+03$

$6 \cdot 7048413 E+00$
$7 \cdot 9403857 E+08$

$6 \cdot 9000414 E+02$

$5 \cdot 33132035-02$

$4.5122550 E+00$

$4-9688207 E-02$ 1.9236948E-01

$3.7167041 E-01$

5-2715229E-01

$1.48116795-01$

$4.2569060 E-02$

I. $2657492 E-02$

$4.0159940 E+01$

$1.3201820 E-02$

$4.8509165 \varepsilon-01$
9.3865100E-01

2.1 407249E-01
$4 \cdot 2054472 E+00$

$2 \cdot 1861301 E+01$

$5.1718624 E-02$

$7.9455402 E+02$

$8 \cdot 1889880 E-03$$$
2.18613012+01
$$

$8.0815480 E+02$

$7 \cdot 1444817 E+02$

B -8289999E+02

$9.0545338 E+02$

8.2022218E+02

$7.944817 E+08$

STEAM PROPERTIES

$2.5968261 E+03$

$5.9290938 E+00$

$5 \cdot 4499137 E-02$

2.8892239E +00

$4.5860374 E-02$

$9.8345157 E-02$

THERMAL CENDUCTAMCES---STCAM

$$
3 \cdot 4563881 \subset+03
$$

$3 \cdot 18309425-01$

COEFFICIENTS

$4.6932550 \mathrm{E}-01$

$6.8184809 E-01$

$1.6597753 E+00$

5. 1 600340E-02

2.4254582E-01
$9.3865100[-01$

2.1 407249E-01

$3.2366558 E+00$

$1.3148678 E-02$

$4.8509165 E-01$
5.2715229E-01

1 -2685155E-01

$8.2894804 E-02$

$1.26574925-02$

$4.0159940 E+01$
$8 \cdot 1523025 E-03$

$2 \cdot 4312474 E+00$

$2 \cdot 4721578 E+01$ 
TEMPRATURE DISTRIBUTION

$9 \cdot 3265858 E+02$

$9 \cdot 1087985 E+02$

STEAM PROPERTIES

$2.5701190 E+03$

$4.2377926 E+00$

$6.0296931 \Sigma-02$

$1.5214189 E+00$

THERMAL CONDUCTANCES-- STEAM

$1.8559303 E+03$

CoEfFICIENTS

$4.6932550 E-01$

$6.2064701 E-01$

$4 \cdot 4615250 E+00$

$5.1342143 E-02$

2.4254582E-01
$9.38651005-01$

$2 \cdot 1407249 E-01$

$1 \cdot 30135795-02$

$4.8509165 E-01$
$8 \cdot 6344676 E+00$

$8 \cdot 3394992 E+02$

$8 \cdot 7188133 E+02$

$3 \cdot 8343754 E-02$

2.7971994E-02

$2 \cdot 4152328 I-01$

5 -2715229E-01

$9.6251010 E-02$

2.8858235E-01

$1 \cdot 2657492 E-02$

$4.0159940 E+01$

$8 \cdot 5888464 E+02$

9.4061711E+02

9-1162702E+02

?.1573631E+02

STEAM PREPERTIES

$2.5621356 E+03$

$4.0446371 E+00$

$6.1506674 E-02$

$1 \cdot 4470060 E+00$

THERMAL CENDUCTANCES---STEAM

$1 \cdot 7633191 E+03$

\section{CoEfFICIENTS}

$4.6932550 \mathrm{r}-01$

6.1552009L-01

$4.9392898 E+00$

$5 \cdot 13131775-02$

2. $4254582 \varepsilon-01$
$9 \cdot 3865100 E-01$

2.1 $107249 E-01$

$9 \cdot 55099565+00$

$1.2999096 E-02$

$4.8509165 E-01$
$3 \cdot 7916113 E-02$

$2 \cdot 4614269 E-02$

$2 \cdot 3509078 E-01$

$5 \cdot 2715229 E-01$

$9 \cdot 3687553 E-02$

$3 \cdot 2758397 \varepsilon-01$

$1.26574925-02$

$4.0159940 E+01$
$8 \cdot 0722237 E-03$

$9 \cdot 6749391 E-01$
$3 \cdot 4587949 E+01$
$8 \cdot 8490471 E+02$

$8 \cdot 9201447 E-01$

$8.0632401 E-03$

$3 \cdot 6239729 E+01$

TEMPERATURE DISTRIBUTION

$9.4713532 E+02 \quad 9.27022708+02$

$9 \cdot 1216473 E+02$

STEAM PROPERTIES

2.5537659E+03

$3.8965544 \mathrm{C}+00$

$6.2540291 E-02$

$1 \cdot 40443712+00$

THERMAL CONOUCTAMCES-A-STCAM

$1.7024461 \mathrm{E}+03$

Cotr ICIENTS

$4.6932550 E-01$

$6 \cdot 12011185-01$

$5.3032807 E+00$

S.1292461E-02

2.4854582E-01
$9.3865100 E-01$

2. $1407249 E-01$

$1.0848627 E+01$

$1.2988738 E-08$

$4.8509165 E-01$
$8 \cdot 8018910 E+02$

$8 \cdot 9597041 E+02$

3.7705201E-02

2.2509192E-02

2.3068831E-01

B $.0568150 E-03$

5.2715229E-01

9.1933098E-02

$3.5793444 E-01$

1.2657492E-02 .

$4.0159940 \mathrm{E} \bullet 01$ 
TEMPERATURE DISTRIBUTIEN

$\begin{array}{llll}9.5244098 E+02 & 9.3620390 E+02 & 8.9790757 E+02 & 9.0511706 E+02 \\ 9.1251117 E+02 & & \end{array}$

STEAM PREPERTIES

2.5450824E+03

$6.3399927 E-02$

3.7615499E-02

$8 \cdot 1315000 E-01$

$3.7816577 E+00$

I.3705488E+00

2.0979173E-02

THERMAL CENDUETANCES-O-STEAM

$1 \cdot 6689438 \varepsilon+03$

$2 \cdot 27753535-01$

$8 \cdot 05240005-03$

\section{Cogrf ICIENTS}

$4.6932550 \mathrm{E}-01$

$6.0967206 E-01$

$9.3865100[-01$

$2 \cdot 1407249 E-01$

$5.27152295-01$

$9 \cdot 0763538 E-02$

$5.6200005 E+00$

$1.08561735+01$

S.1278286E-02

$1.8981621 E-02$

3 .8382828E-01

2.4254582E-01

$4.8509165 E-01$

1.2657492E-02

$3 \cdot 8759869 E+01$

$4.0159940 E+01$

$9 \cdot 1276566 E+02$

$9 \cdot 1266904 E+02$

$9.5674593 E+08$

$9 \cdot 4374459 E+02$

$9 \cdot 1256999 E+02$

STEAM PROPERTIES

2.5297617E+03

$6.4180788 E-02$

3.7567820E-02

l.9541188E-02

$7 \cdot 7874130 E-01$

$3.6780893 E+00$

$1 \cdot 32915635+00$

THERMAL CEMDUCTAMCES-O-STEAM

$1.6324250 E+03$

$2 \cdot 2544268 E-01$

$8 \cdot 0488460 z-03$

CEEFFICIENTS

4.6932550E-01

$9.38651005-01$

5.2715229E-01

$6.0783023 E-01$

2.1407849E-01

$5.9743431 \mathrm{x}+00$

$1 \cdot 1536795 E+01$

S.1266767t-08

$1.2975891 \mathrm{E}-02$

8.9842625E-02

$4.1189133 E-01$

1. $26574925-02$

$3.9851277 E+01$

2.4RS4S8er-01

$4.05091655-01$

$4.0159940 \mathrm{C} \uparrow 01$ 
COMBUSTION ENGINEERING

NUCLEAR POWER DEPARTMENT

$$
\begin{aligned}
& \text { Summary } \\
& \dot{T}_{133}=-(0.469326) T_{133}-(0.469326) T_{134}+(0.938651) T_{143} \\
& +(0.527152) k \dot{v}_{\mathrm{Ma}} T_{134}-(0.527152) \dot{\omega}_{\mathrm{ma}} T_{133} \\
& \dot{T}_{134}=-(0.169326) T_{134}-(0.469326) T_{135}+(0938651) T_{144} \\
& +(0.527152) \dot{\omega}_{N a} T_{135}-(0.527152) \omega_{\text {wat }} T_{134} \\
& \dot{T}_{135}=-(0.469326) T_{135}-(0.469376) T_{136}+(0.938651) T_{763}= \\
& +(0.527152) \dot{\omega}_{\mathrm{ma}} T_{136}-(0.577152) \omega_{\mathrm{wa}} T_{135} \\
& \dot{T}_{136}=-(0.469336) T_{136}-(0.469326) T_{137}+(0.938651) T_{146} \\
& +(0.527153) \dot{\omega}_{\mathrm{Na}} T_{137}-(0.52715 ?) \dot{\omega}_{\mathrm{ma}} T_{136} \\
& \dot{T}_{137}=-(0.469326) T_{137}-(0.469326) T_{38}+(0.938651) T_{147} \\
& +(0.527152) \dot{\omega}_{214} T_{138}-(0.527152) \omega_{14} T_{137} \\
& \dot{T}_{138}=-(0.469326) T_{138}-(0.469326) T_{135}+(0.938651) T_{148} \\
& +(0.527152) \operatorname{cis}_{14} T_{138}-(0.527152) \omega_{219} T_{138} \\
& \dot{T}_{128}=-(0.469326) T_{139}-(0.469326) T_{142}+(0.938651) T_{149} \\
& +(0.527152) \dot{c}_{\text {va }} T_{100}-(0.527153) \omega_{\text {na }} T_{339} \\
& \dot{T}_{140}=-(0.469326) T_{140}-(0.469326) T_{y_{1}}+(0.938651) T_{150}
\end{aligned}
$$

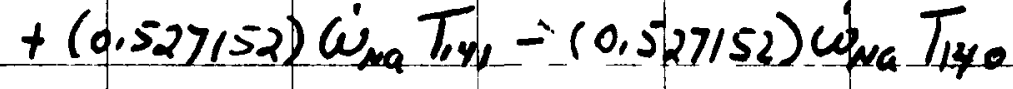

$$
\begin{aligned}
& \dot{T}_{141^{\prime}}=-(0.469326) T_{141}-(0.469326) T_{142}+(0.938661) T_{151} \\
& +(0.527152) \dot{v}_{\mathrm{Na}} T_{142}-(0.527152) T_{141} \\
& \dot{T}_{142}=-(0.469326) T_{142}-(0.469326) T_{188}+(0.938651) T_{152} \\
& +(0.527152) \dot{c}_{\mathrm{va}} T_{18 \mathrm{a}}-(0.527152) \dot{w}_{\mathrm{Na}} T_{142} \\
& \dot{\omega}_{\text {NA }}=\text { sodium Flow per tube }=\dot{\omega}_{77}
\end{aligned}
$$


COMBUSTION ENGINEERING NUCLEAR POWER DEPARTMENT

$$
\begin{aligned}
& \left.\dot{T}_{143}=-6.724379\right) T_{143}+(0.214072) T_{133}+(0.214012) T_{134} \\
& +(0.148147) T_{153}+(0.188117) T_{192} \\
& \dot{T}_{144}=-(0.681848) T_{144}+(0.214072) T_{134}+(0.214072) T_{135} \\
& +(0.126852) T_{153}+(0.186852) T_{154} \\
& \dot{T}_{145}=-(0.656272) T_{145}+(0.214072) T_{135}+(0.214072) T_{136} \\
& +(0.114064) T_{154}+(0.114064) T_{155} \\
& \dot{T}_{146}=-(0.639981) T_{146}+(0.2146 .72) T_{136}+(0.214072) T_{137} \\
& +(0.105918) T_{155}+(0.105918) T_{156} \\
& \bar{T}_{147}=-(0.628741) T_{147}+(0.214072) T_{137}+(0.214072) T_{138} \\
& +(0.100298) T_{66}+(0.160298) T_{1527} \\
& \bar{T}_{148}=-(0.620647) T_{148}+(0.214072) T_{138}+(0.21407 p) T_{138} \\
& +(0.0962510) T_{157}+(0.0962570) T_{158} \\
& \dot{T}_{149}=-(0.615520) T_{1199}+(0.214072) T_{139}+(0.214072) T_{180} \\
& +(0.0936876) T_{158}+(0.0936876) T_{159} \\
& \dot{T}_{150}=-(0.612011) T_{100}+(0.214072) T_{140}+(0.214 .072) T_{141} \\
& +(0.0919331) T_{159}+(0.0919331) T_{60} \\
& \dot{T}_{151}=-(0.609672) T_{151}+(0.214072) T_{141}+(0.214072) T_{142} \\
& +(0.0907635) \pi_{160}+(0.0907635) T_{161} \\
& \dot{T}_{152}=-(0.607830) T_{152}+(0.214072) T_{142}+(0.214072) T_{188} \\
& +(0.0898426) T_{161}+(0.08988426) T_{162}
\end{aligned}
$$




\section{COMBUSTION ENGINEERING NUCLEAR POWER DEPARTMENT}

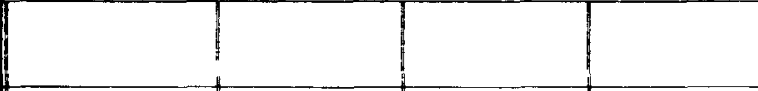

$\bar{T}_{153}=-(.987317) T_{133}-(.987317) T_{192}+(1.93207) T_{143}+(.0425691) T_{113}$ $+(221.86 / 3) \dot{\omega}_{3} T_{192}-(21.86 / 3) \dot{\omega}_{3} T_{1 / 3}$

$\dot{T}_{154}=-(1.65978) T_{104}-(1.65578) T_{153}+(3.23666) T_{14 y}+(.08 \$ 8948) T_{661}$

$+(24.72 / 6) \omega_{5} t_{503}-(24.72 / 6) \psi_{4} T_{16} T_{164}$

$\bar{T}_{155}=-(2.46634) T_{155}-(2.46634) T_{154}+(4.79654) T_{145}+(.136142) T_{1655}$ $+(27.605 s) \dot{\omega}_{s} T_{s y}-(27.6055) \dot{k i s}_{s} T_{5 s}$

$\bar{T}_{156}=-(3.20880) T_{156}-(3.20880) T_{155}+(6.22744) T_{146}+(6.189 \$ 533) T_{166}$ $t(30.300) \omega_{s} T_{155}-(30.3000) \omega_{3} T_{106}$

$\dot{T}_{157}=-(3.92351) T_{157}=(3.923511) T_{156}+(7.60277) T_{147}+1.244$ \$49 $) T_{167}$

t $(32.6138) \dot{\omega}_{s} T_{1-6}-(32.6138) \dot{s}_{s} T_{15} z$

$\dot{T}_{158}=-(6.46 / 53) T_{158}-(4.46633) T_{157}+(8.63447) T_{148}+(.0288582) T_{168}$

$+(34.5879) \omega_{5} T_{107}-(345879) \cos _{3} T_{158}$

$\dot{T}_{1,59}=-(4.93929) T_{159}=(4.93929) T_{108}+(9,55100) T_{149}+(63727549) T_{169}$

$+(36.2397) \dot{\omega}_{s} T_{158}-(36 \cdot 2397) \omega_{s} T_{i s 9}$

$\dot{T}_{160}=-(5.30328) T_{160}-(5.30328) T_{154}+(10.2486) T_{150}+(.357934) T_{120}$

$+(37.6170) \dot{c}_{s} T_{154}-(37.6170) \dot{\omega}_{5} T_{160}$

$\dot{T}_{161}=-(5.62000) T_{161}-(5.62000) T_{160}+(10.8562) T_{151}+(.383828) T_{1721}$

$+(38.7599) \dot{\omega}_{5} T_{100}-(38.7599) \dot{\omega}_{3} T_{161}$

$\dot{T}_{162}=-\left(5.974344 T_{162}-(5.97434) T_{161}+(11.5368) T_{152}+(.411891) T_{1,72}\right.$

$+(39.8513) \omega_{s} T_{161}-(39,8513) \omega_{s} T_{162}$

$\dot{U}_{s}=$ stean flow per tubs $=\dot{c}_{\psi_{0}}$ 
COMBUSTION ENGINEERING NUCLEAR POWER DEPARTMENT

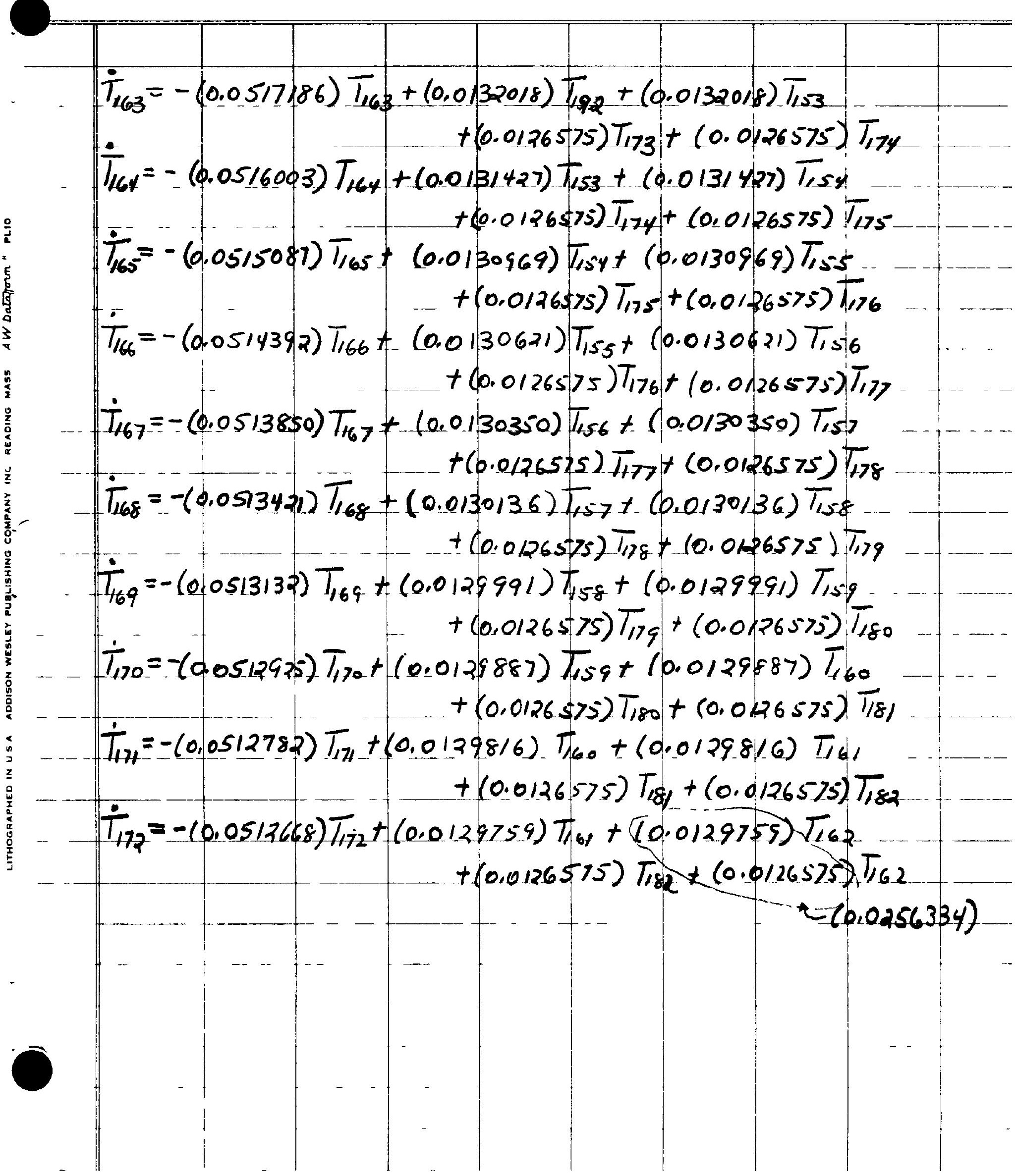


COMBUSTION ENGINEERING NUCLEAR POWER DEPARTMENT

$$
\begin{aligned}
& \dot{T}_{173}=-(0.242546) T_{173}-(0.242546) T_{174}+(0.485092) T_{163} \\
& +(40.1599) \dot{\omega}_{5} T_{174}-(40.1599) \dot{\omega}_{5} T_{173} \\
& \dot{T}_{174}=-(0.242546) T_{174}-(0.247546) T_{175}+(0.485092) T_{164} . \\
& +(40.1559) \dot{\omega}_{3} T_{175}-(40.1599) \dot{\omega}_{5} T_{1.74} \\
& \dot{T}_{175}=-(0.242546) T_{175}-(0.247546) T_{176}+(0.485097) T_{165} \\
& +(40,1559) \mathrm{w}_{3} T_{176}-(40,1599) \omega_{1} T_{175} \\
& \dot{T}_{176}=-(0.242546) T_{176}-(0.242546) T_{177}+(0.485092) T_{166} \\
& +(40,1559) \dot{\omega}_{s} T_{77}-(10,1599) \dot{\omega}_{3} T_{17 T_{6}} \\
& \dot{T}_{177}=-(0.242546) T_{177}-(0.242546) T_{178} \pm(0.485092) T_{167} \\
& +(40.1599) \dot{\omega}_{s} T_{18}-(40.1599) \dot{\omega}_{s} T_{17} \\
& \dot{T}_{178}=-(0.242546) T_{178}-(0.242546) T_{179}+(0.485092) T_{168} \\
& +(40.1599) \omega_{s} T_{179}-(40.1559) \omega_{s} T_{128} \\
& \dot{T}_{179}=-(0.242549) T_{179}-(0.242546) T_{180}+(0.4850927) T_{169} \\
& +(40.1559) \omega_{1} T_{180}-(40.1559) \dot{c}_{3} T_{17} \\
& \dot{T}_{180}=-(0.242546) T_{80}-(0.247546) T_{181}+(0.48509) T_{170} \\
& +(40,1599) \text { is } T_{181}-(40,1599) \text { is } T_{118} \\
& \dot{T}_{181}=-(0.342546) T_{181}-(0.242546) T_{182}+(0.485092) T_{111} \\
& +(40.1599) \text { us } T_{152}-(40.1595) \omega_{3} T_{18} \\
& \dot{T}_{182}=-(0.242546) T_{182}-(0.242546) T_{162}+(0.485092) T_{172} \\
& +(40.1599) c_{5} T_{162}-(40.1599) E_{5} T_{182} \\
& \dot{\omega}_{s}=\text { steam flow per robe }=\omega_{80}
\end{aligned}
$$


COMBUSTION ENGINEERING

$\not$

NUCLEAR POWER DFPARTMFNT

III Sodium In lat and Outlet Regions.

Energy balances for inlet and outlet plenums: The regions as e assumed to be bounded by achabote walls.

$$
\left(w C_{p}\right)_{N a} T_{N_{a}}=\left(w C_{p}\right)_{u_{a}} T_{N a}+\left(\rho v C_{p}\right)_{N a} \frac{d \bar{G}_{a}}{d t}
$$

In standard format

$$
\dot{T_{N a}}=-\left(\frac{w}{\rho V}\right)_{N a} T_{N G}-\left(\frac{w}{\rho V}\right)_{N G} \bar{T}_{N a}
$$

Energy balances for inlet and outlet nuzzles:

$$
\begin{aligned}
& -(U A)\left[T_{N o z}-T_{N a}\right]=(\rho \vee C)_{N o z} \frac{d T_{\text {No z }}}{d t} \\
& -(U A)\left[T_{\text {No q }}=T_{N a}\right]+\left(w C_{p}\right)_{N_{a}} T_{N a}=\left(w C_{\rho}\right)_{N a} T_{N a}+\left(\rho V C_{p}\right)_{N a} \frac{d T_{N a}}{d t}
\end{aligned}
$$

In standard format

$$
\begin{aligned}
& \dot{T}_{N 0 Z}=-\left[\frac{(Z A)}{(\rho K C)_{N 0 Z}}\right] T_{N O Z}+\left[\frac{(U A)}{(\rho V C)_{N O Z}}\right] T_{N G} \\
& \dot{T}_{N a}=-\left[\frac{(U A)}{(\rho v G)_{N a}}\right] T_{N a}+\left[\frac{(U A)}{(\rho V C)_{W a}}\right] T_{N O Z}+\left(\frac{w}{\rho V}\right)_{N a} T_{N a}-\left(\frac{w}{\rho V}\right)_{N_{a}} T_{N a}
\end{aligned}
$$


COMBUSTION ENGINEERING NUCLEAR POWER DEPARTMENT

Sodium Inlet Region.

$W_{\text {Na }}=4.353 \times 10^{6} \mathrm{lbm} / \mathrm{hs}=1209 \mathrm{lbm} / \mathrm{sec}$ (Design)

Properties are evaluated at temperature for full fo ad

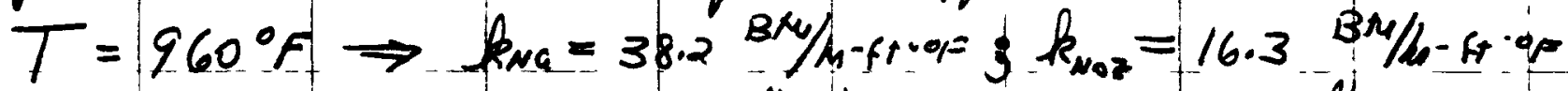

$$
\begin{aligned}
& \rho_{N G}=51.7 \mathrm{l} \mathrm{lm} / \mathrm{st} \mathrm{F}^{2} \quad ; \rho_{\text {Not }}=478 \mathrm{ldm} / \mathrm{ft}^{3}
\end{aligned}
$$

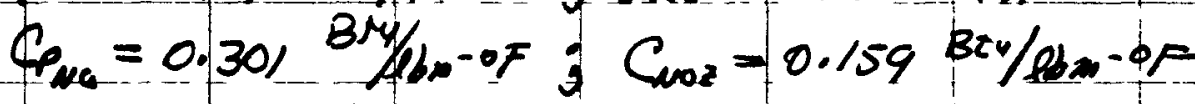

$$
\begin{aligned}
& \mu_{N a}=0.559 \mathrm{ldm} / \mathrm{fr} \cdot \mathrm{mm}
\end{aligned}
$$

$$
\begin{aligned}
& { }^{12} \epsilon_{\text {Na }}=\frac{w_{\text {Na }}}{A}=\frac{4.353 \times 10^{6}}{\frac{\pi}{4}(1678 / 12)^{2}}=2.803 \times 10^{6}-\frac{16 \mathrm{~m}}{h_{-5 / 2}} \\
& V_{N_{a}}=\frac{G_{N a}}{P_{N a}}=\frac{2.803 \times 106 / 3600}{51.7}=15.06 \mathrm{Fr} / \mathrm{sec} \\
& R_{R_{\text {wa }}}=\frac{G_{\text {Na }} D_{l}}{\mu_{\text {va }}}=\frac{\left(2.803 \times 10^{6}\right)\left(\frac{16^{7 / 8}}{12}\right)}{.554}=7.051 \times 10^{6} \\
& P_{e}=R_{e} \frac{\mu C_{e}}{k}=\left(7.051 \times 10^{6}\right) \frac{.559(.30)}{38.2}=31060 \\
& h_{M G}=\frac{k_{N a}}{D_{i}}\left[5.0+0005 P_{e}^{.0}\right]=\frac{38.2}{1618 / 12}\left[5.0+.025(3,060)^{.0}\right]
\end{aligned}
$$

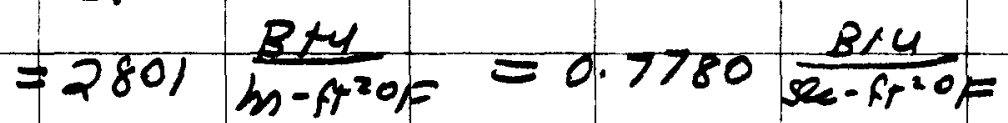

Entrance effects on the heat transfer coefficient we neglected.

2) The average diameter for the nozzle is computed at the thickest section. 


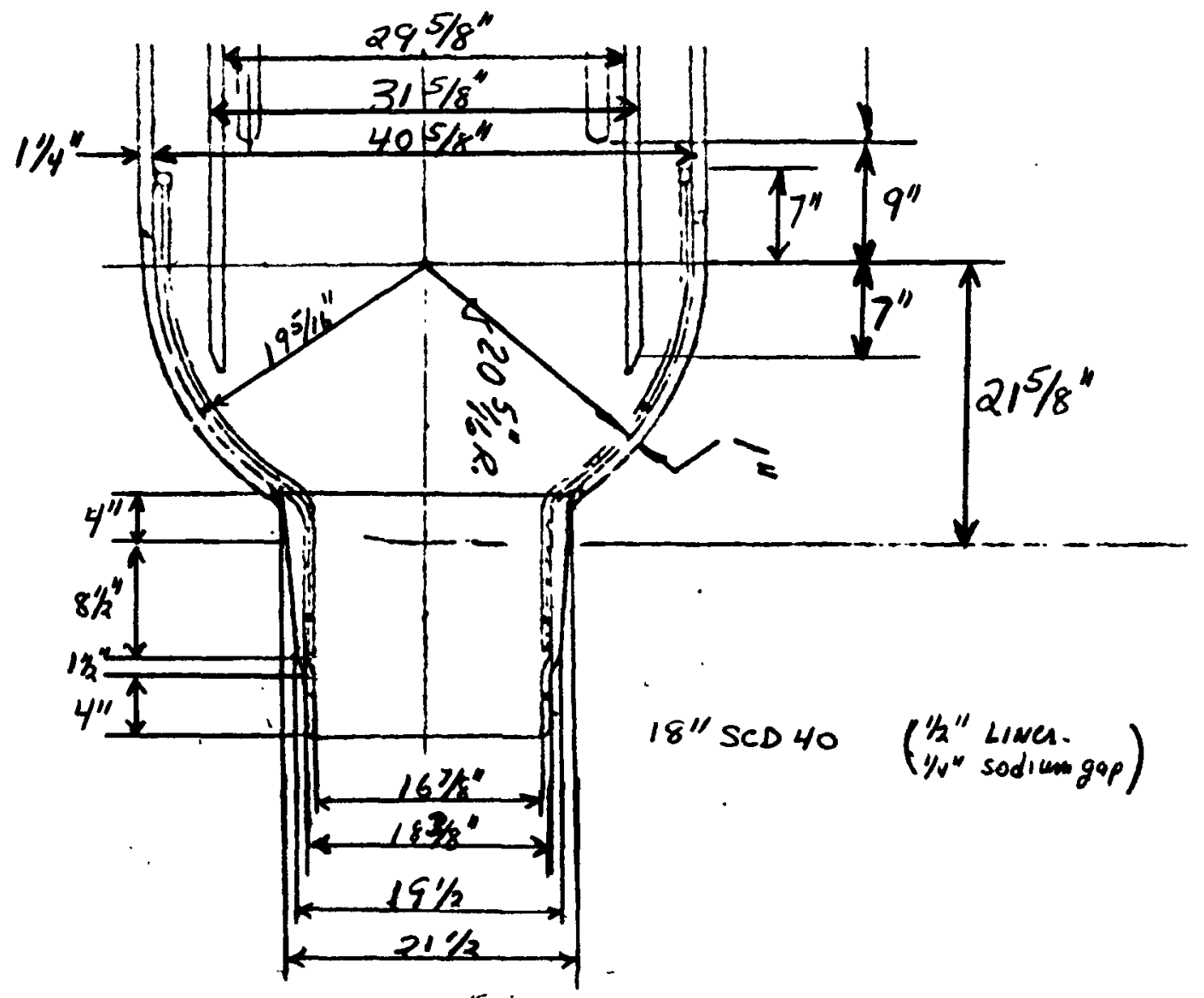

SODTUM INLET PLENUMY

$$
\begin{aligned}
\mathcal{V}_{N a} & =\left\{\frac{\pi}{4}(405 / 8)^{2}(9)+\frac{2 \pi}{3}(20 \% \%)^{3}\right\}-\left\{\pi(305 / 8)(1)(16)+\frac{\pi(3)}{6}\left(3(16 / 8)^{2}+3^{2}\right)\right\} \\
& =26300 \mathrm{~m}^{3}=15.2 \mathrm{ft}
\end{aligned}
$$

Sodium Inuer Norzle

$$
\begin{aligned}
& V_{N a}=\frac{\pi}{4}(167 / 8)^{2}(18)=4030 \mathrm{~m}^{3}=2.33 \mathrm{ft}
\end{aligned}
$$

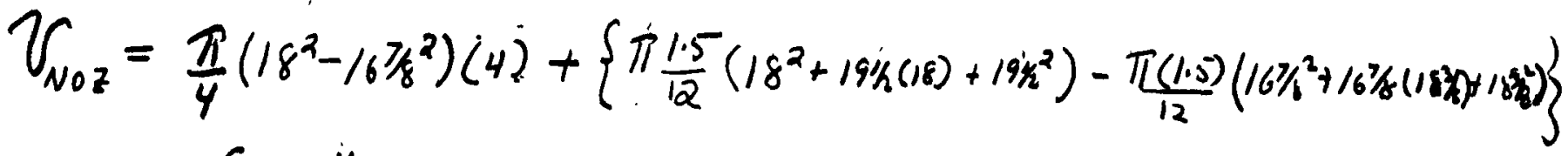

$$
\begin{aligned}
& +\left\{\frac{\pi 2^{3} / 2}{12}\left(19 \%^{2}+(14 x)(21 \%)+21 k^{2}\right)-\frac{\pi}{4}(18 \%)^{2}(12 \%)\right\} \\
& =986 \mathrm{~m}^{3}=0.570 \mathrm{ft}^{3}
\end{aligned}
$$


COMBUSTION ENGINEERING NUCLEAR POWER DEPARTMENT

$$
\bar{D}=\left(\frac{D_{1}^{2}+D_{0}^{2}}{2}\right)^{1 / 2}=\left(\frac{18^{3 / 2}+212^{2}}{2}\right)^{1 / 2}=20.0^{\prime \prime}
$$

Assume, for the entire length of the nozzle, that there is a $1 / 2$ "thermal lime $\left(21 / 14-1 M_{0}\right)$ and a 1/4 stagnant sodium gap between the flown sedum and the noble. In addition the nesistarre of the thickest section of the nozzle will chanactergle the nozzle for its entice length.:

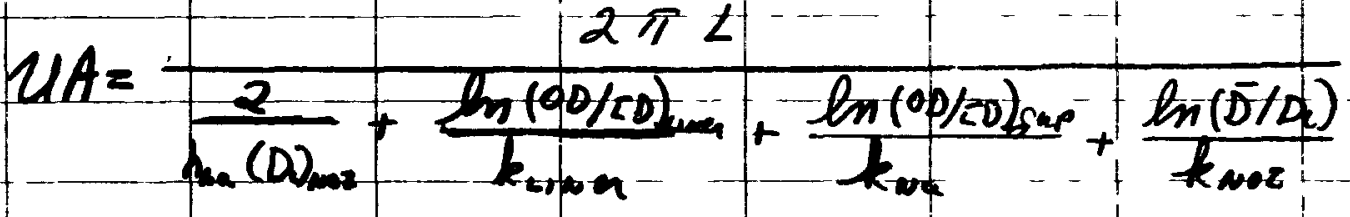

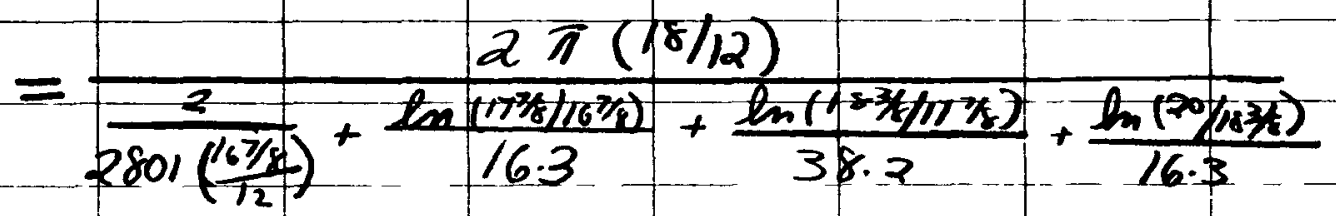

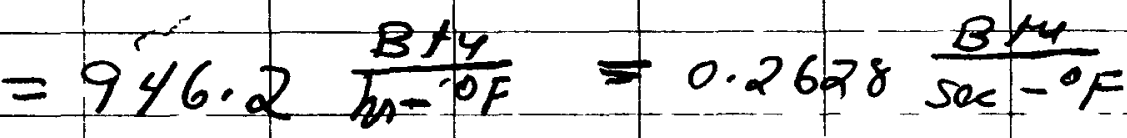

Volumes

$$
\begin{aligned}
& \left(v_{N_{a}}\right)_{N O P}=2.33 \mathrm{ft} \\
& \left(Z_{\text {metro }}\right)_{\text {N.7 }}=0.570 \mathrm{~kg} \\
& \left(v_{\text {vas }}\right)_{\text {plenum }}=15.2 \mathrm{ft}^{3}
\end{aligned}
$$

Computations are sham on the figure. 
COMBUSTION ENGINEERING

NUCLEAR POWER DEPARTMENT

Coefficients

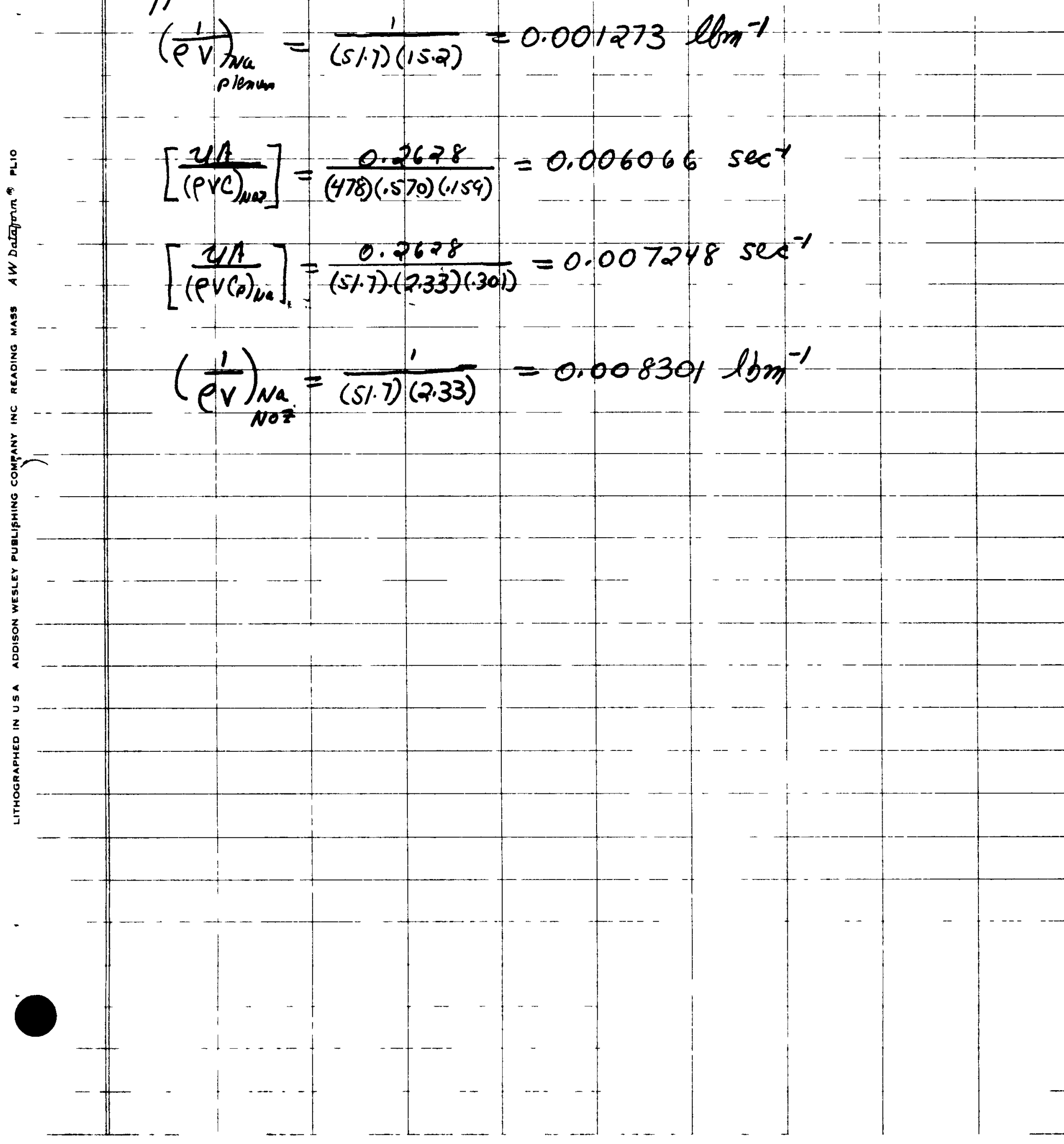


COMBUSTION ENGINEERING

NUCLEAR POWER NFPARTMANT

Soszyer Outlet Region

$$
w_{N a}=4.353 \times 10^{6} \mathrm{ebm} / \mathrm{h}=1209 \mathrm{lbm} / \mathrm{sec}
$$

(Design)

Properties are evaluated at tempenatise for full load

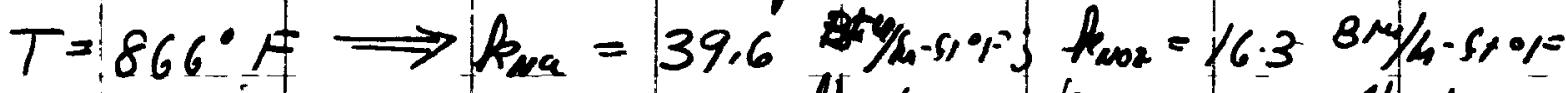

$$
\begin{aligned}
& \rho_{\text {Na }}=52.5 \mathrm{lbm} / \mathrm{sp}^{3} ; \rho_{\text {No }}=478 \mathrm{lbm} / \mathrm{spr}^{3}
\end{aligned}
$$

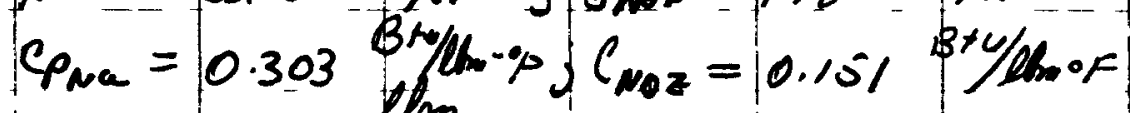

$$
\begin{aligned}
& \psi_{\mu a}=0.605 \frac{t h m}{\frac{t h}{4-m}}
\end{aligned}
$$

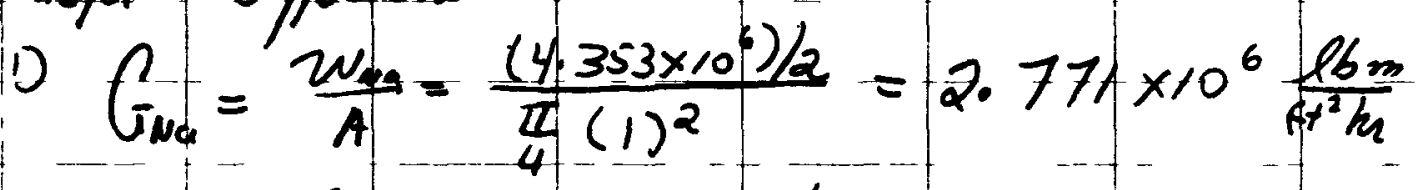

$$
\begin{aligned}
& V_{\text {Na }}=\frac{G_{\text {Ma }}}{P_{\text {Me }}}=\frac{2.771 \times 10 \% / 3600}{52.5}=14.67 \mathrm{Ft} / \mathrm{Aec} \\
& R_{l}=\frac{C_{D}}{\mu_{N a}}=\frac{\left(2.771 \times 10^{6}\right)(1)}{.605}=4.581 \times 10^{6} \\
& P_{e}=\operatorname{Re}\left(\frac{4 C_{b}}{h}\right)_{N_{2}}=\left(4.581 \times 10^{6}\right) \frac{.605(303)}{39.6}=21204 \\
& h_{N v}=\frac{k_{\text {Na }}}{D}\left[5+.025 \mathrm{Pe}^{.8}\right]=\frac{39.6}{(1)}\left[57.025(21204)^{18}\right]
\end{aligned}
$$

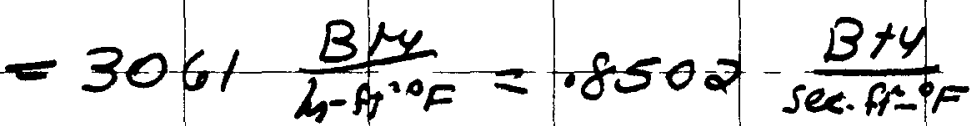

Entrance effects on the heat transfer coeffurent ore neglected.

2) The average diameter for the nuzzle es computed at the thelest section. 
$=$

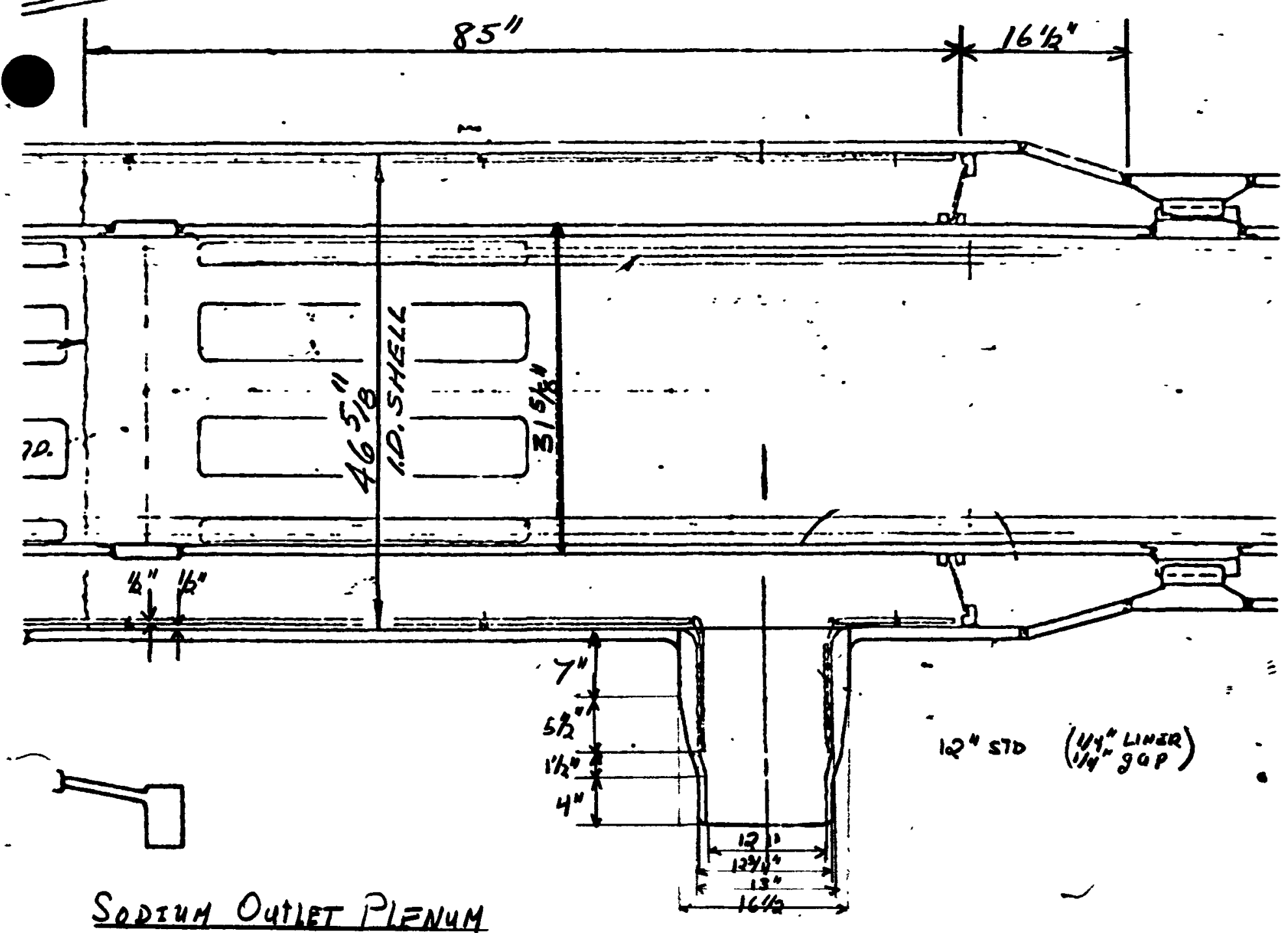

Sodium Outlet Plenum

$$
V_{N a}=\frac{\pi}{4}\left(465 / 8^{2}-315 / 8^{2}\right) 85=78400 \mathrm{~m}^{3}=45.3 \mathrm{ft}
$$

Sodium Outlier Nozzle

$$
\begin{aligned}
& V_{N a}=\frac{\pi}{4}(12)^{2}(18)=2040 \mathrm{~m}^{3}=1.18 \mathrm{ft}^{3} \\
& \left.V_{N 0 Z}=\frac{\pi}{4}\left(12^{3} y^{2}-12^{2}\right)(4)+\frac{\pi(1.5)}{12}\left\{(13)^{2}+13 / 4\left(12^{2} / 4\right)+13^{3} / 4^{2}\right)-\left(13^{2}+13(12)+12^{2}\right)\right\} \\
& +\left\{\frac{\pi(5 / 2)}{12}\left(16^{\prime 2} 2^{2}+16 \%\left(13^{2} / 4\right)+13^{3} 4^{2}\right)-\frac{\pi}{4}(13)^{2}\left(5^{\prime} / 2\right)\right\}+\frac{\pi}{4}\left(16 \%^{2}-13^{2}\right)(7) \\
& =910 \mathrm{~m}^{3}=0.526 \mathrm{ft}^{3}
\end{aligned}
$$


COMBUSTION ENGINEERING NUCLEAR POWER DEPARTMENT

$$
\bar{D}=\left(\frac{D_{\alpha}^{2}+D_{\alpha}^{2}}{2}\right)^{1 / 2}=\left(\frac{\left(3^{2}+16^{1 / 2}{ }^{2}\right.}{2}\right)^{1 / 2}=14.85 .10
$$

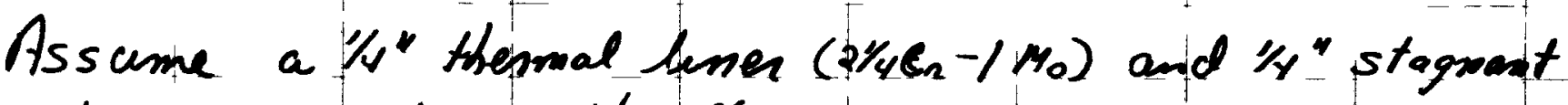
sodium gap between the Hewing solver and the niggle for the entire length of the outlet nozzle. In addition, the resistance of the thickest section of the nog le characterizes the nozzle for its entire length.

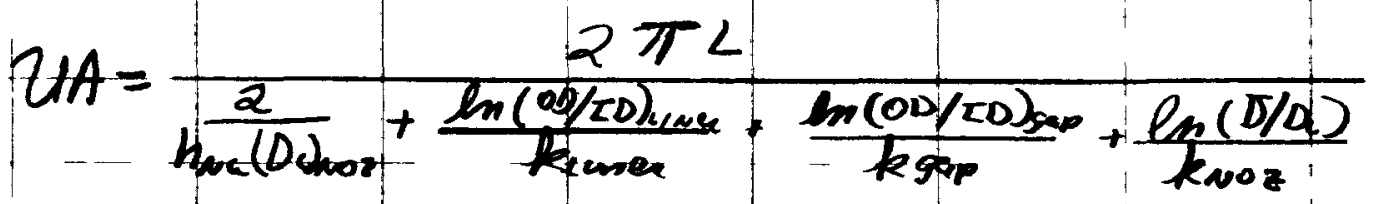

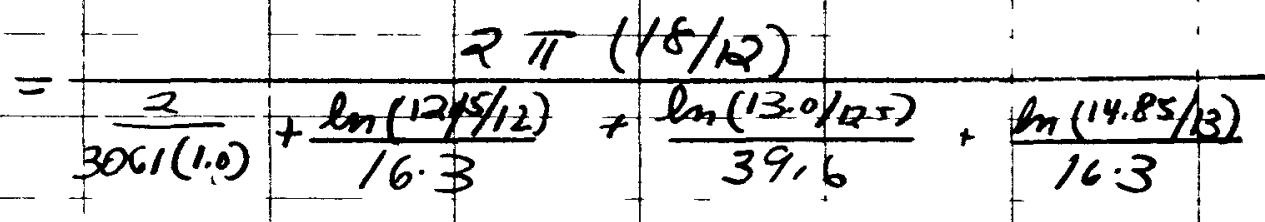

$$
\begin{aligned}
& =766.2 \frac{B A 4}{\ln \phi F}=0.2128 \frac{B A 4}{\mathrm{sec}^{\circ} \mathrm{F}}
\end{aligned}
$$

Volumes

$$
\begin{aligned}
& \left(v_{N O}\right)_{N O Z}=1.18 \mathrm{ft}^{3} \\
& \left(V_{\text {metal }}\right)_{\text {No }}=0.526 f^{3}
\end{aligned}
$$

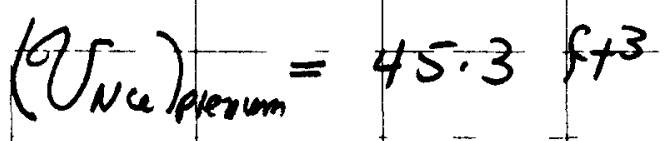


COMBUSTION ENGINEERING NIIII FAR PNWFR NFPARTMFNT

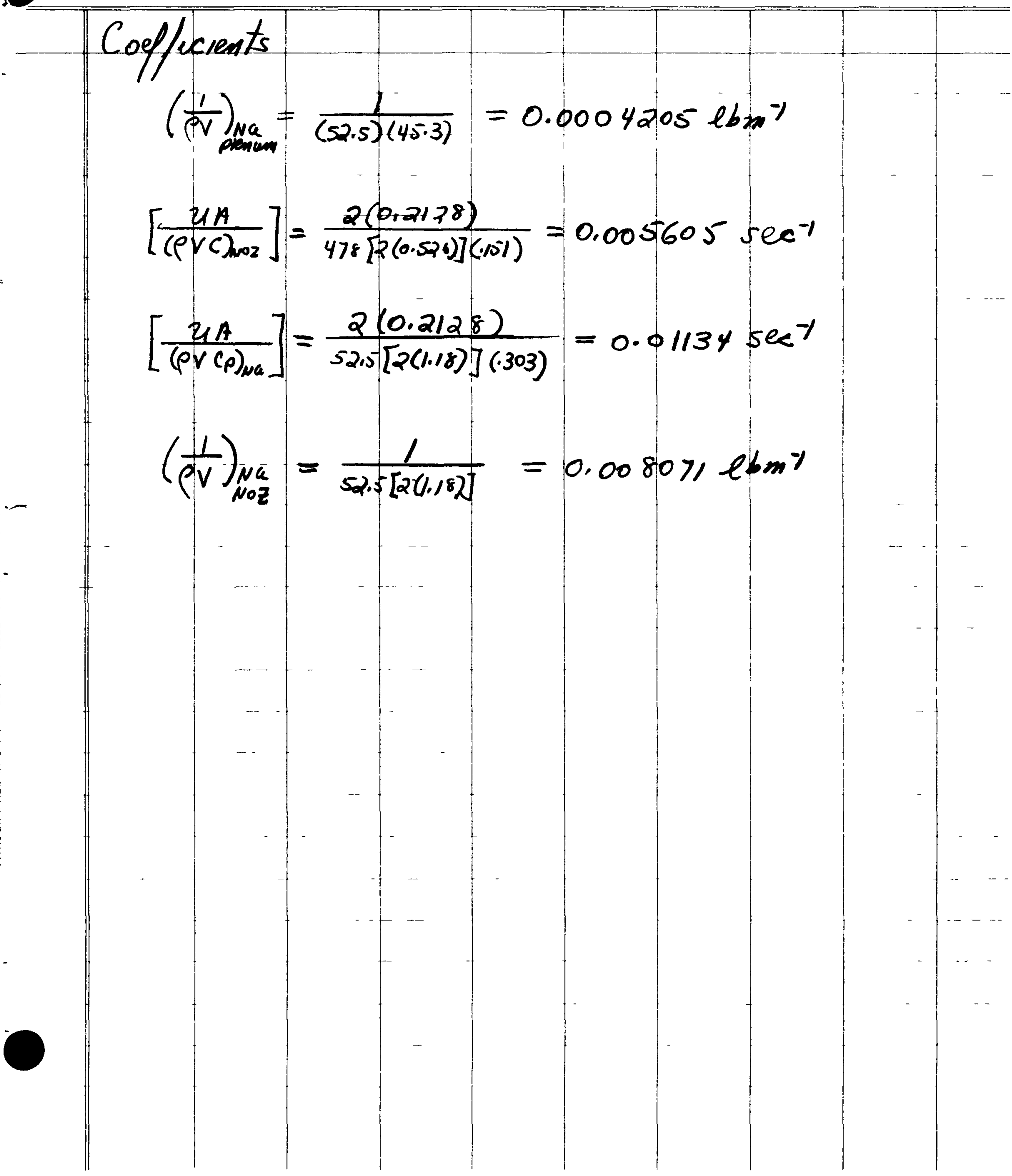


COMBUSTION ENGINEERING NUCLEAR POWER DEPARTMENT

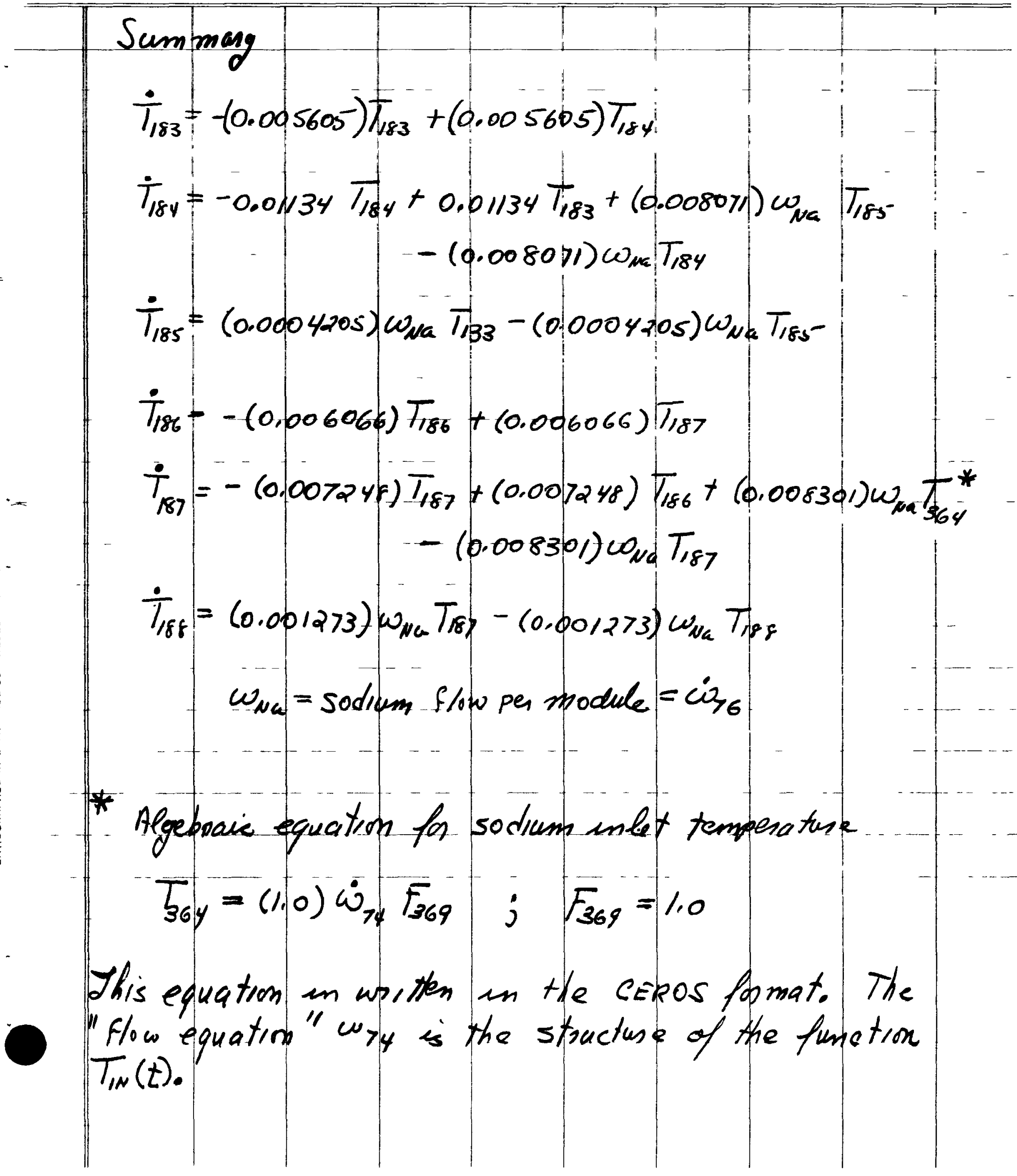


COMBUSTION ENGINEERING

本 NUCLEAR POWER DEPARTMENT

III Steam Inlet and Outlet pogroms

Energy balances for the additional heat exchange between the inlet and outlet ste an on the regin above the sodium level: The pressure tube wall is assumed to be an adiabatic boundary.

$$
\begin{aligned}
& -(U A)_{3}\left[T_{A N N}-T_{B T}\right]+w_{A N N} h_{A N N}=w_{A N N} h_{A N N}+\frac{d}{d t}(\rho v U)_{A N N} \\
& (U A)_{3}^{\prime}\left[T_{A N N}-T_{B T}\right]-(U A)_{4}^{\prime}\left[T_{B T}-T_{R}\right]=(\rho v C)_{B T} \frac{d T_{B T}}{d t} \\
& (U A)_{T}^{\prime}\left[T_{B T}-T_{R}\right]+w_{R} h_{R}=w_{R} h_{R}+\frac{d}{d t}(\rho v U)_{R}
\end{aligned}
$$

Recalling the assumptions made in I. Mam peat Tolunsfer Region, and searsangeng into the standard format

$$
\begin{aligned}
& \dot{T}_{A N N}=-\left[\frac{(U A)_{3}^{\prime}}{(\rho V C)_{A}}\right] T_{A N N}+\left[\frac{(U A)_{3}^{\prime}}{(\rho V G)_{A}}\right] T_{B T}+\left(\frac{w}{\rho V}\right)_{A N N} T_{A N N}-\left(\frac{w}{\rho V}\right)_{A N N} T_{P_{N N}} \\
& \dot{T}_{B T}=-\left[\frac{(U A)_{3}^{\prime}}{\left(\rho V C_{B T}\right.}+\frac{(U A)_{Y}^{\prime}}{(\rho V C)_{B-T}}\right] T_{B T}+\left[\frac{(U A)_{3}^{\prime}}{(\rho V C)_{B T}}\right] T_{A N N}+\left[\frac{(U A)^{\prime}}{(\rho V S)_{B F}}\right] T_{R} \\
& \dot{\bar{T}}_{R}=-\left[\frac{(w A)_{V}^{\prime}}{(\rho V G)_{R}}\right] T_{R}+\left[\frac{(U A)_{V}^{\prime}}{(\rho V G)_{R}}\right] \frac{1}{T_{B T}}+\left(\frac{w}{\rho V}\right)_{R} T_{R}-\left(\frac{w}{\rho V}\right)_{R} T_{R}
\end{aligned}
$$

Energy balances for the inlet and outlet plenums: The regions are assumed to be bounded by adiabatic walls.

$$
u_{G_{m}} h_{s / m}=w_{s m} h_{s m}+\frac{d}{d t}(p \vee u)_{s / m}
$$


COMBUSTION ENGINEERING NUCLEAR POWER DEPARTMENT

Recalling the assumptions made above concerning ste an enthalpy and internal energy, and then peassanging the equations in to stand and format.

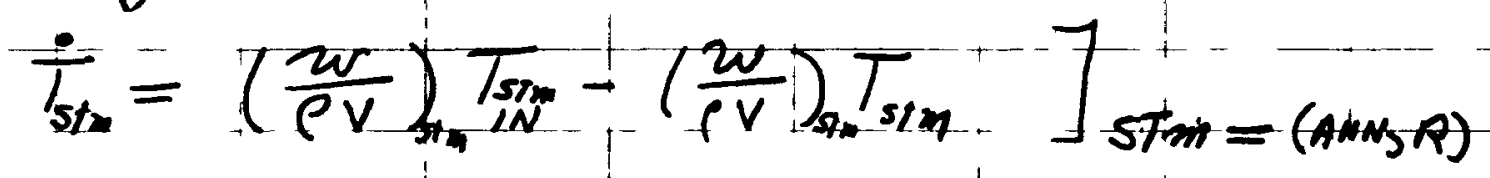

Energy balances for the in tet and outlet nozzles:

$$
\begin{aligned}
& \left.-(U A)\left[T_{\text {No }}-T_{\text {som }}\right]=(P V C)_{N O Z} \frac{d T_{\text {WOw }}}{d t}\right]
\end{aligned}
$$

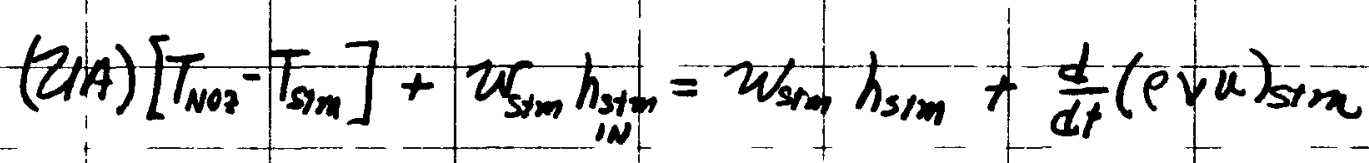

Applying the same assumptions as above, and reasiangung the equations into stand and format

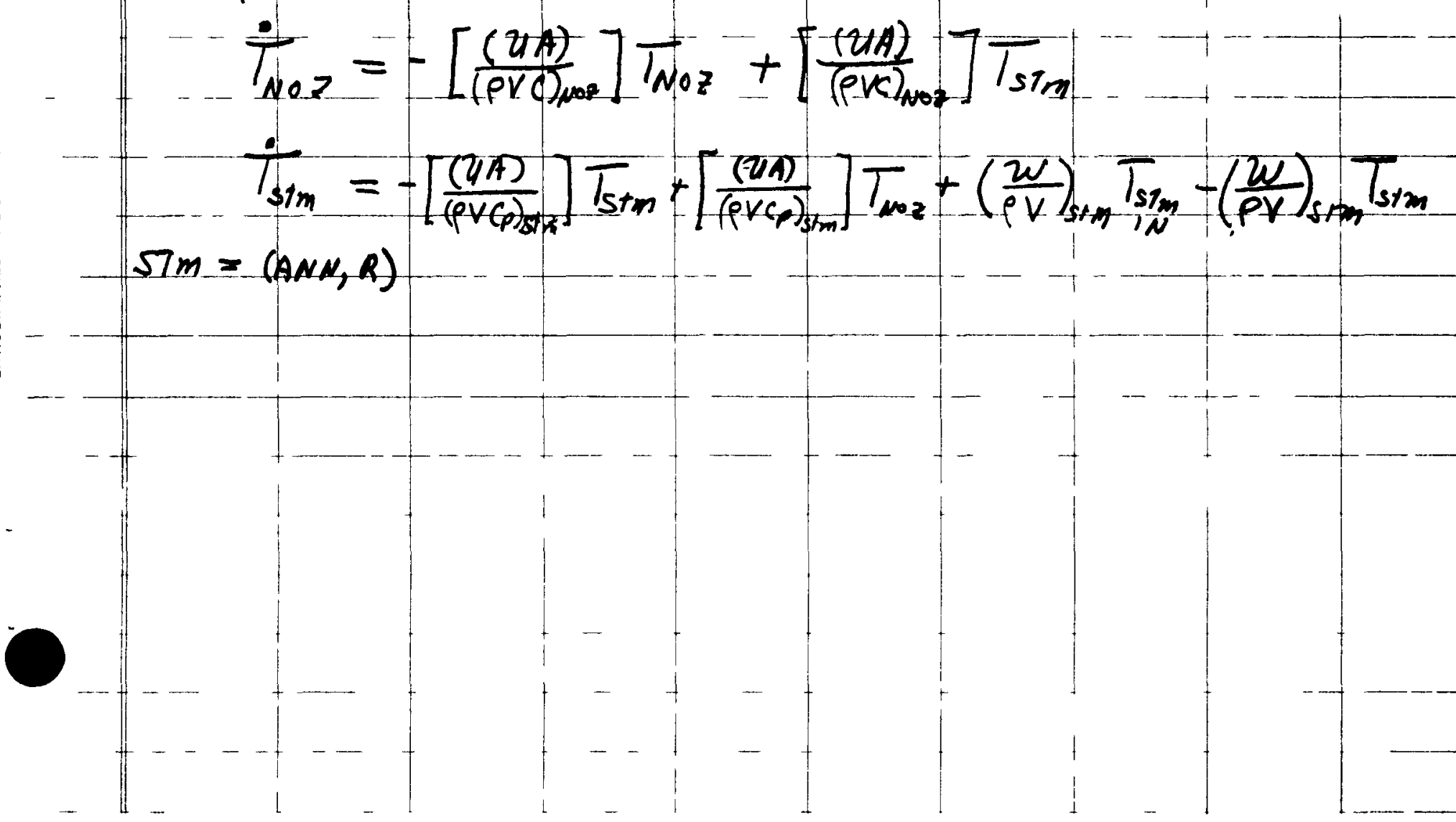


COMBUSTION ENGINEERING NUCLEAR POWER DEPARTMENT

SEEAM INLET Region

$$
w_{s}=397278 \mathrm{lbm} / \mathrm{hr}=110.355 \mathrm{lbm} / \mathrm{kec}(\text { design })
$$

Properties are evaluated at pressure and temperature for fall load e

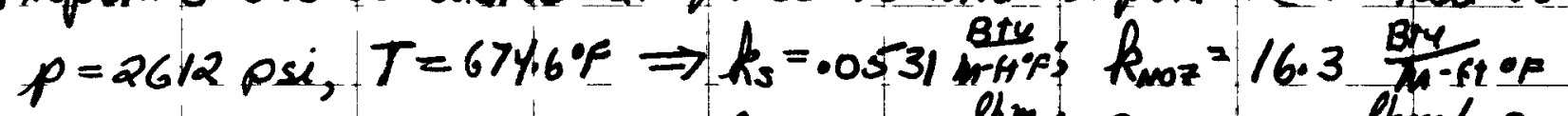

$$
\begin{aligned}
& \rho_{s}=8.325 \frac{\mathrm{lbm}}{\mathrm{H}^{3}} ; \rho_{\mathrm{NO} z}=481 \mathrm{lbm} / \mathrm{st}^{3}
\end{aligned}
$$

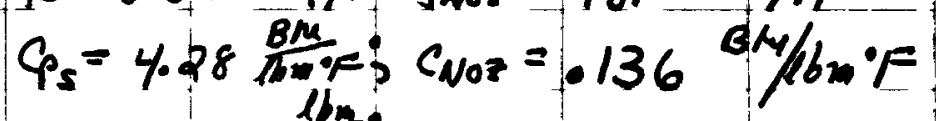

$$
\begin{aligned}
& \mu_{s}=.052610 \text { of }
\end{aligned}
$$

Heat Transfer coeffuents

10

$$
\begin{aligned}
& G_{s}=\frac{W_{s}}{A}=\frac{397278}{\frac{\pi}{4}(113 / 8 / 12)^{2}}-5.629 \times 10^{5} \frac{\mathrm{lbm}}{\mathrm{ft}^{2}-\mathrm{m}} \\
& V_{s}=\frac{C_{s}}{\rho_{s}}=\frac{5.629 \times 105 / 3600}{8.325}=18.78 \mathrm{Ft} / \mathrm{sec} \\
& R_{e_{s}}=\frac{C_{3} D}{\mu_{0}}=\frac{\left(5.629 \times 10^{5}\right)\left(\frac{113 / 4}{12}\right)}{10526}=1.014 \times 10^{7} \\
& P_{r_{3}}=\frac{\mu_{s} b_{3}}{t_{s}}=\frac{0.0526(428)}{.0531}=4.24 \\
& h_{s}=\frac{k_{s}}{D}\left[.023 R_{e s}^{.8} P_{r_{s}}^{14}\right]=\frac{.0531}{113 / 1 / 12}\left[.023\left(1.014 \times 10^{-1.8}(4.24)^{17}\right]\right. \\
& =924.7 \frac{B+4}{m-4 t^{2}{ }^{\circ} \mathrm{F}}-0.2569 \frac{\mathrm{BAY}}{\mathrm{Secst}^{2} \mathrm{OF}}
\end{aligned}
$$

2) The average diameter for the snuggle is computed at the thickest section.

$$
\bar{D}=\left(\frac{a_{0}^{2}+D_{0}^{2}}{2}\right)^{1 / 2}=\left(\frac{113 / 8^{2}+21^{2}}{2}\right)^{1 / 2}=16.89^{\prime \prime}
$$




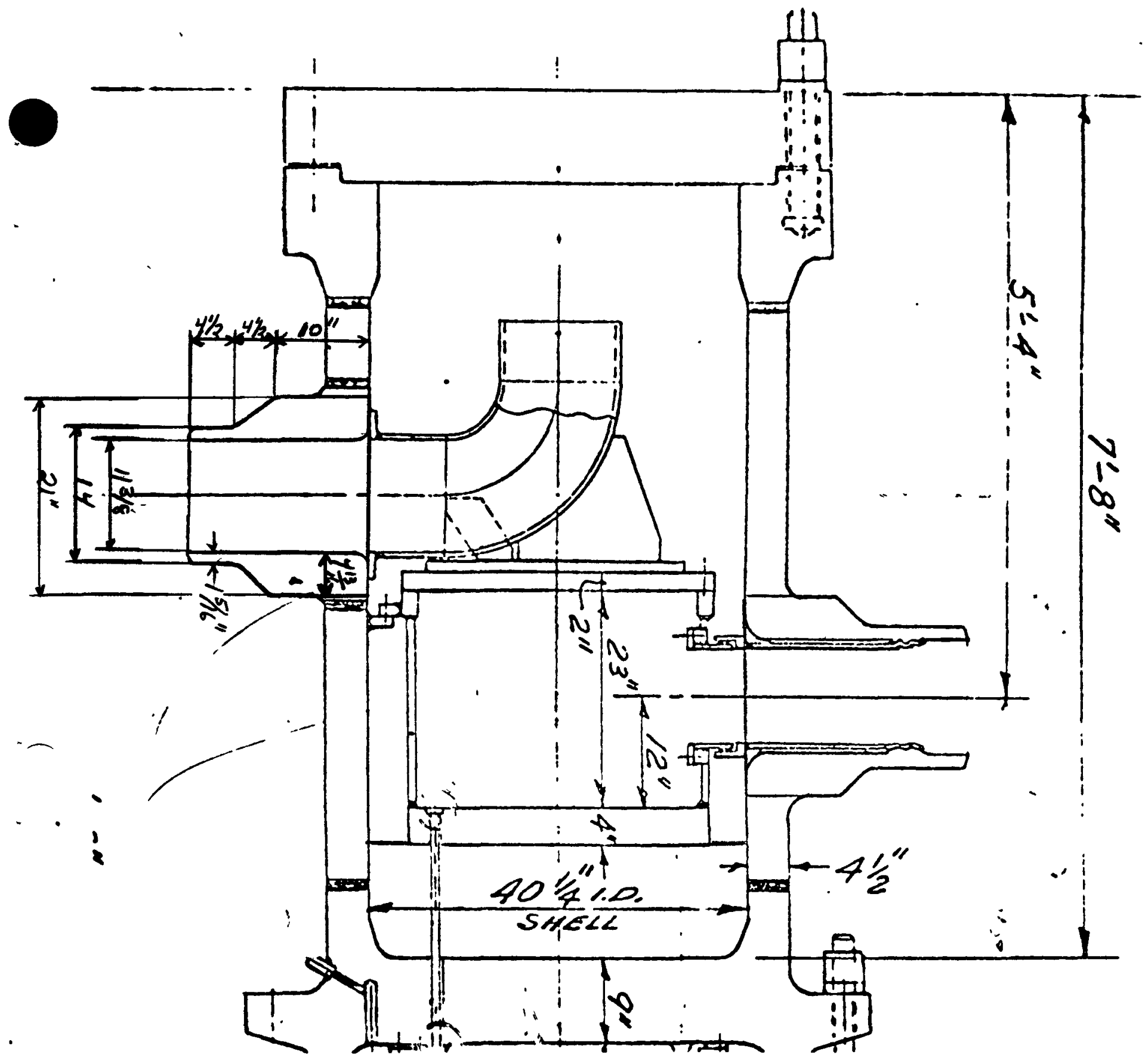

Saturated STEAM TabeT NozrlFe

$$
\begin{aligned}
& V_{\text {stm }}=\frac{\pi}{4}(11 / \%)^{2}(19)=1930 \mathrm{~m}^{3}=1.12 \mathrm{ft} 3 \\
& V_{N O Z}=\frac{\pi}{4}\left(14^{2}-11^{2} /^{2}\right)(4 / 2)+\left\{\pi \frac{4 / 2}{12}\left(21^{2}+21(14)+.14^{2}\right)-\frac{\pi}{4}\left(11^{3 / 3}\right)^{2}(4 / 2)\right\} \\
& +\frac{\pi}{4}\left(21^{2}-113 \mathrm{k}^{2}\right)(10)=3320 \mathrm{~m}^{3}=1.92 \mathrm{ft}
\end{aligned}
$$




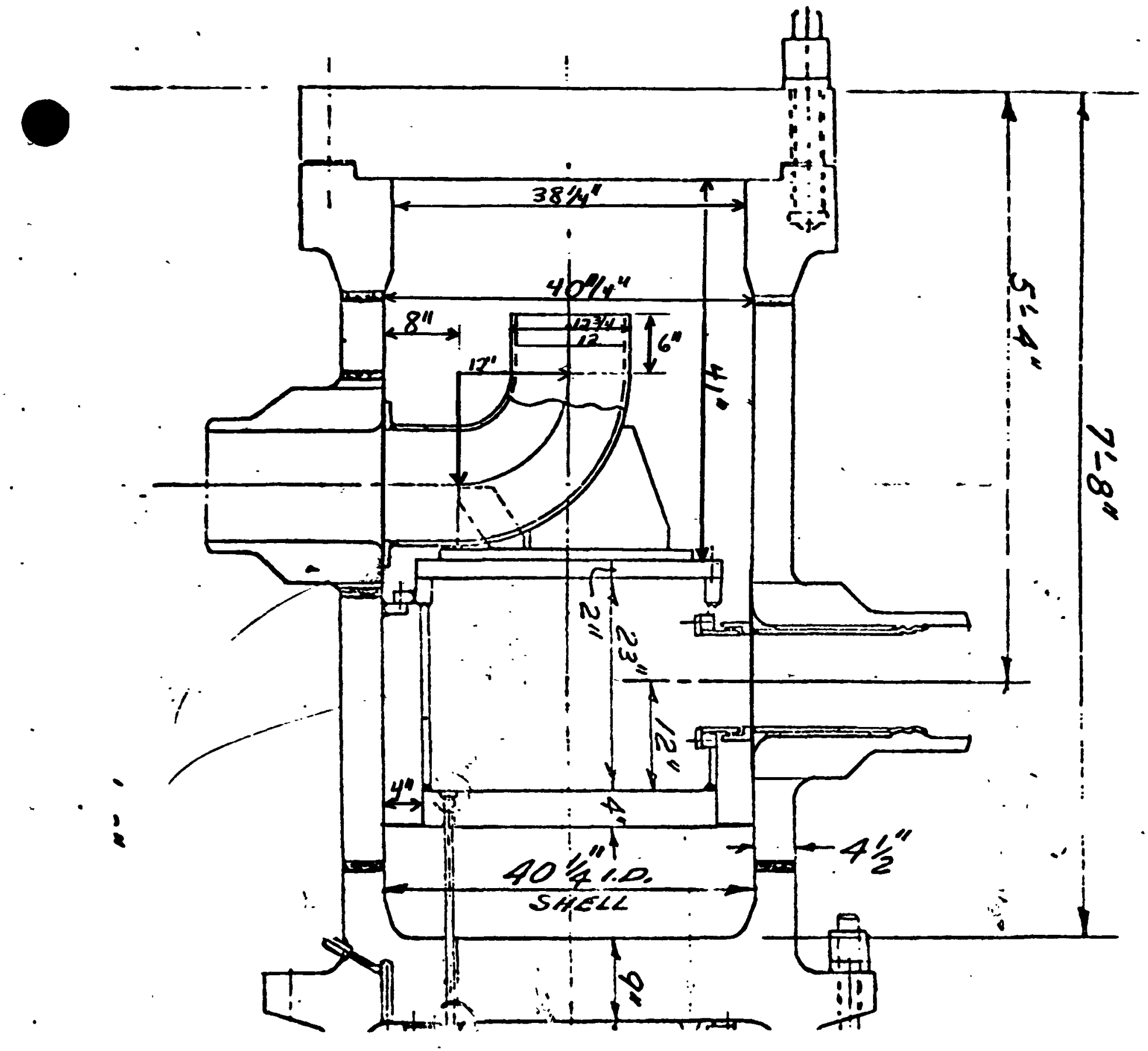

SIEAM INLET PlENUN

$$
\begin{aligned}
& V_{s+m}=\frac{\pi}{4}(40 \%)^{2} 41+\frac{\pi}{4}\left(401^{2}-32 \%^{2}\right)(29)-\frac{\pi}{4}\left(123 \%^{2}-12^{2}\right)\left(6+\frac{\pi}{2}(12)+8\right) \\
& \text { - \{estumate of addeltrumal }\} \text {. } \\
& =64900-\{\text { estumate }\} \\
& =64400 \mathrm{~ms}^{3}=37.3 \mathrm{ft}^{3}
\end{aligned}
$$


COMBUSTION ENGINEERING

NUCLEAR POWER DEPARTMENT

The thermal usistance of the thuchast section of the nozzle is assumed to chanactenze the nozzle for its entire length!. In addition entrance affects on the steam heat transfer coefficient are neglected.

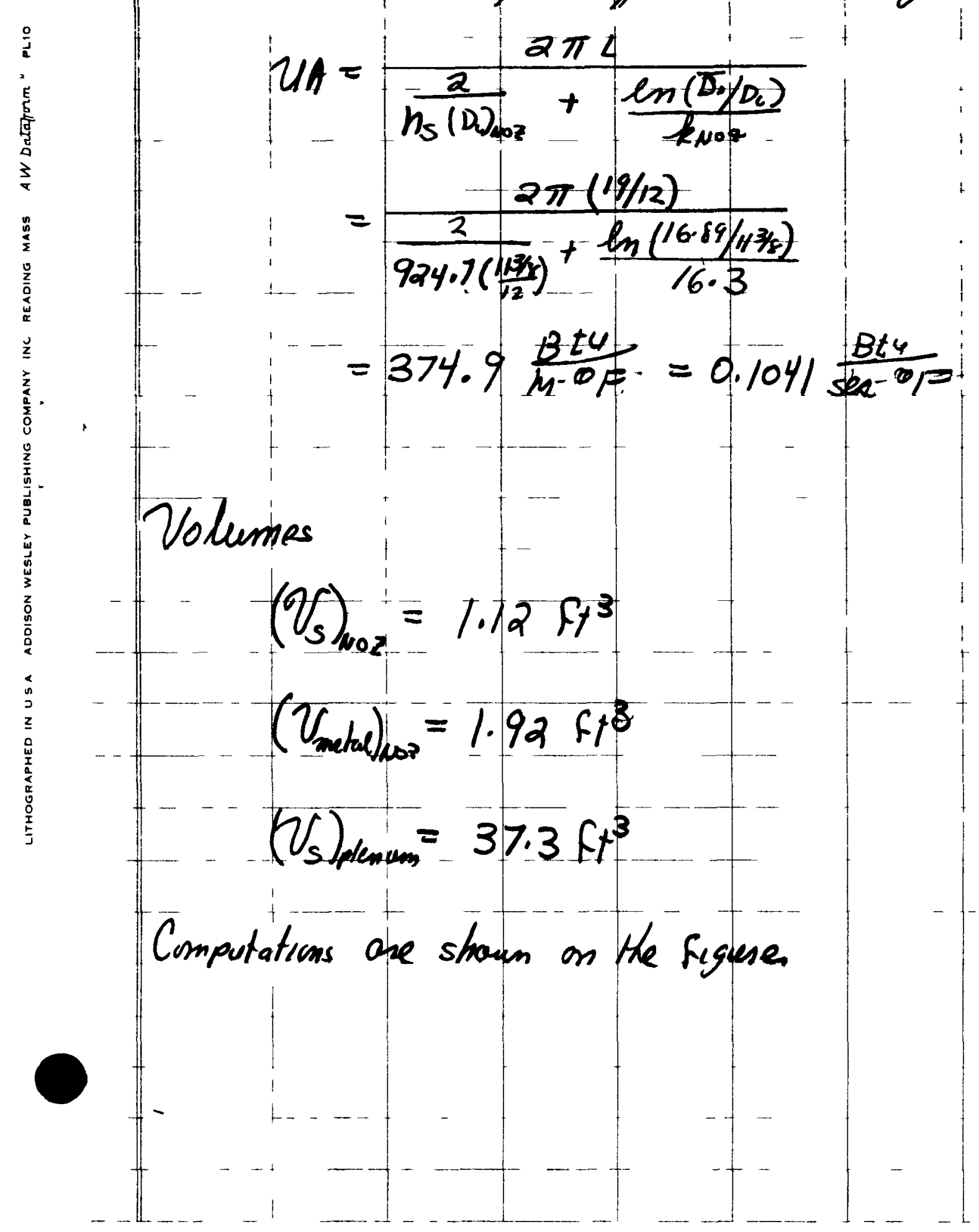


COMBUSTION ENGINEERING NUCLEAR POWER DEPARTMENT

Coefueients

$$
\begin{aligned}
& \left(\frac{1}{\mathrm{eV}}\right)_{\text {stamen }}=\frac{1}{(8.325)(37.3)}=0.003220 \mathrm{ebmon} \\
& {\left[\frac{41}{\left(p^{2} 4\right)_{102}}\right]=\frac{0.1041}{(481)(1.92)(1.136)}=0.0008288 \mathrm{sec}^{-1}} \\
& {\left[\frac{u_{A}}{(\rho v)_{s}}\right]=\frac{0.1041}{(8.325) 112(4.28)}=0.002609 \mathrm{sec}^{-1}} \\
& \left(\frac{1}{\rho v}\right)_{s n_{n}}=\frac{1}{(8.3235)(1.12)}=0.1073 \mathrm{lem}-1
\end{aligned}
$$


COMBUSTION ENGINEERIIIG

NUCLEAR POWER DEPARTMENT

Stean Outlet Regrow

$$
W_{s}=397278 \mathrm{lom} / \mathrm{ks}_{s}=110.355 \mathrm{jm} / \mathrm{sec}(\mathrm{dps} / \mathrm{gx}) \text {. }
$$

Propestres are qualvated at pressuseand tamperature in futel load,

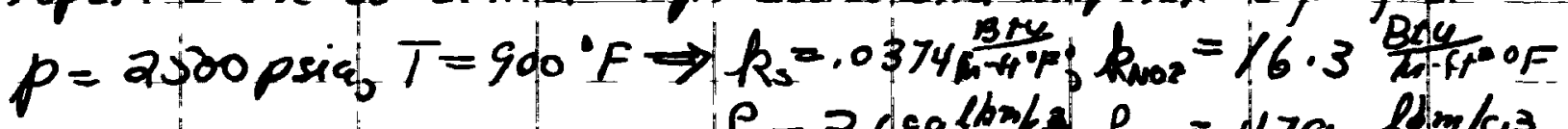

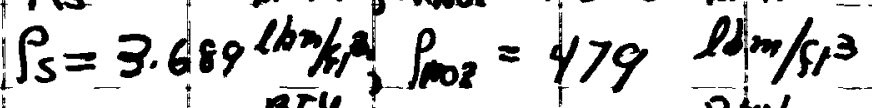

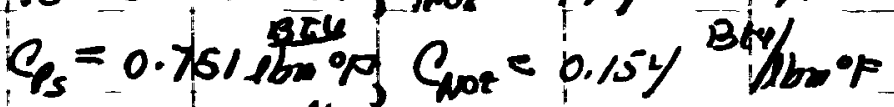
$\mu_{s}=.0635 \frac{160}{6 t-m}$

Theat Transfe coeffuient

$$
\begin{aligned}
& \text { iD } G=\frac{W}{A}=\frac{397278}{\frac{\pi}{4}(1 / 12)^{2}}-7.284 \times 10^{5}-\frac{\operatorname{mm}}{m-\omega^{2}} \\
& V_{s}=\frac{G_{s}}{\beta_{s}}=\frac{7.261 \times 10^{5} / 3500}{3.689}=54.85 \mathrm{kt} / \mathrm{sec}
\end{aligned}
$$

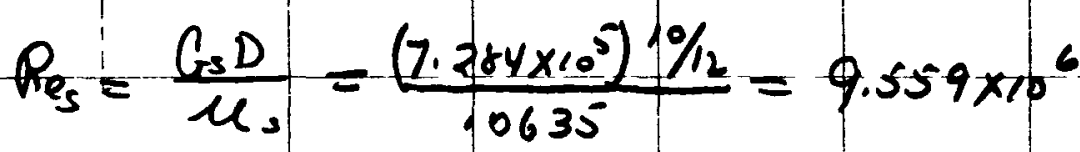

$$
\begin{aligned}
& P_{r_{s}}=\frac{\mu_{s} p_{s}}{k_{s}}=\frac{.0635(.751)}{1.374}=1.27
\end{aligned}
$$

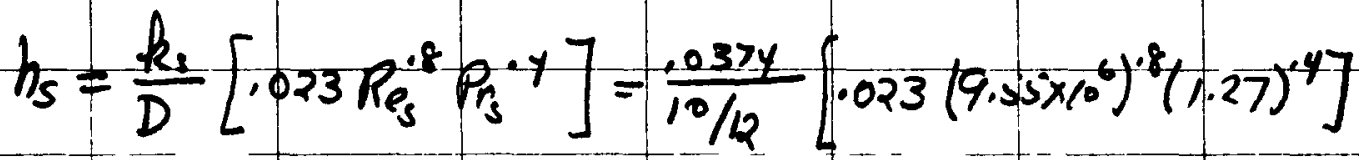

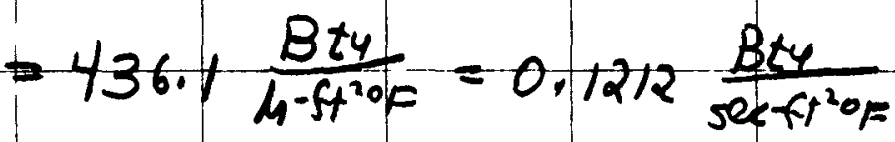

Entramce effects on the heat inansfer coefferents ase negected.

2) The averase diameter for the nogle is compulied at the thushest section. 


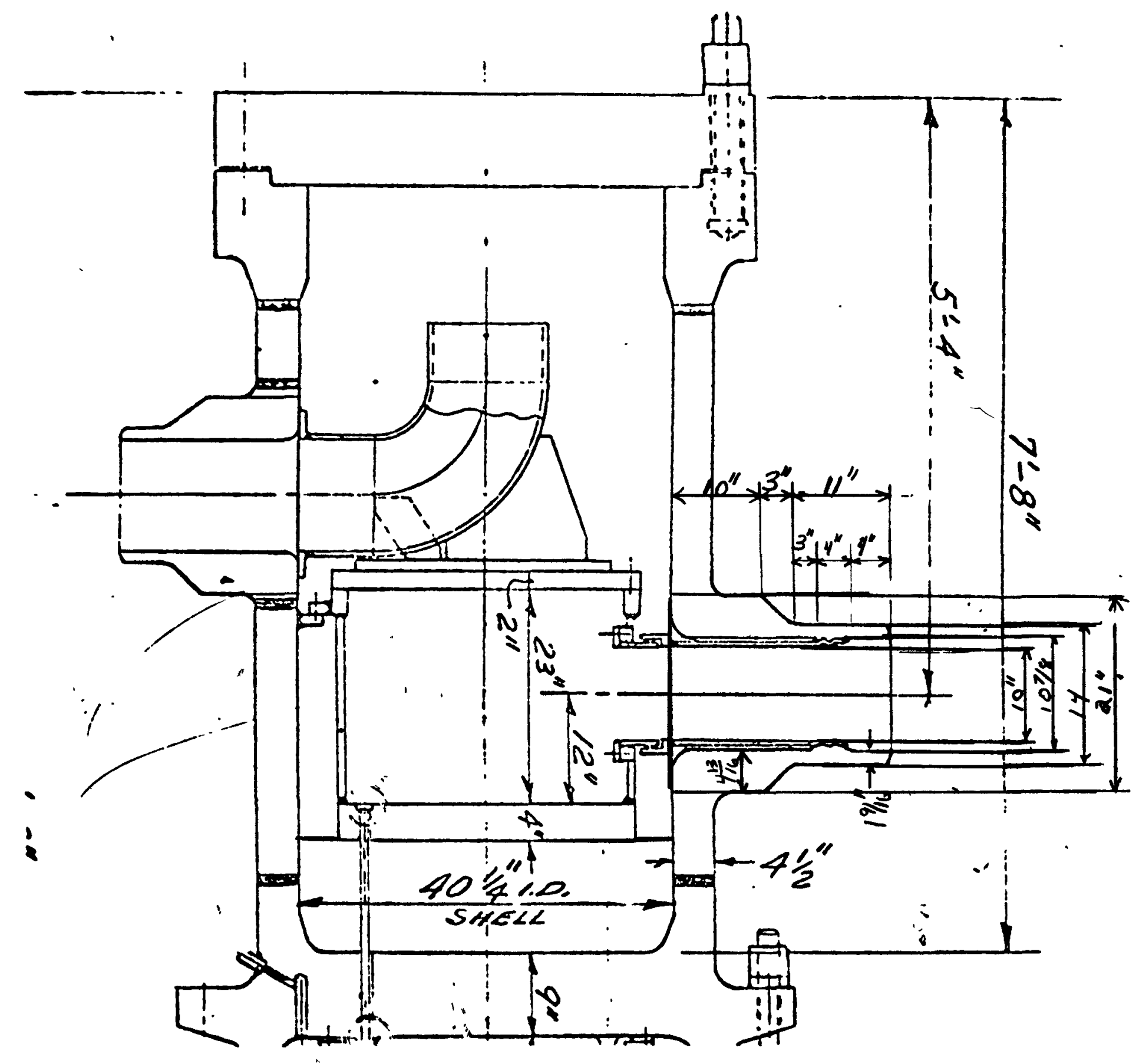

STEAM OUTLET NOZZLIE

$$
\begin{aligned}
V_{\text {STM }}= & \frac{\pi}{4}(10)^{2}\left(20+\frac{\pi}{4}(107 / 8)^{2}(4)=1940 \mathrm{en}^{3}=1.12 \mathrm{ft}^{2}\right. \\
V_{\text {NO2 }}= & \frac{\pi}{4}\left(21^{2}-10 \mathrm{z}^{2}\right)(10)+\left\{\pi \frac{3}{12}\left(21^{2}+21(14)+1.4^{2}\right)-\frac{\pi(3)}{4}(107 / 8)^{2}\right\} \\
& +\frac{\pi}{4}\left(14^{2}-10^{7} / \mathrm{z}^{2}\right)(11)=3660 \mathrm{~m}^{3}=2.12 \mathrm{ft} \mathrm{t}^{3}
\end{aligned}
$$

\section{COMBUSTION ENGINEERING . NUCLEAR POWER DEPARTMENT}




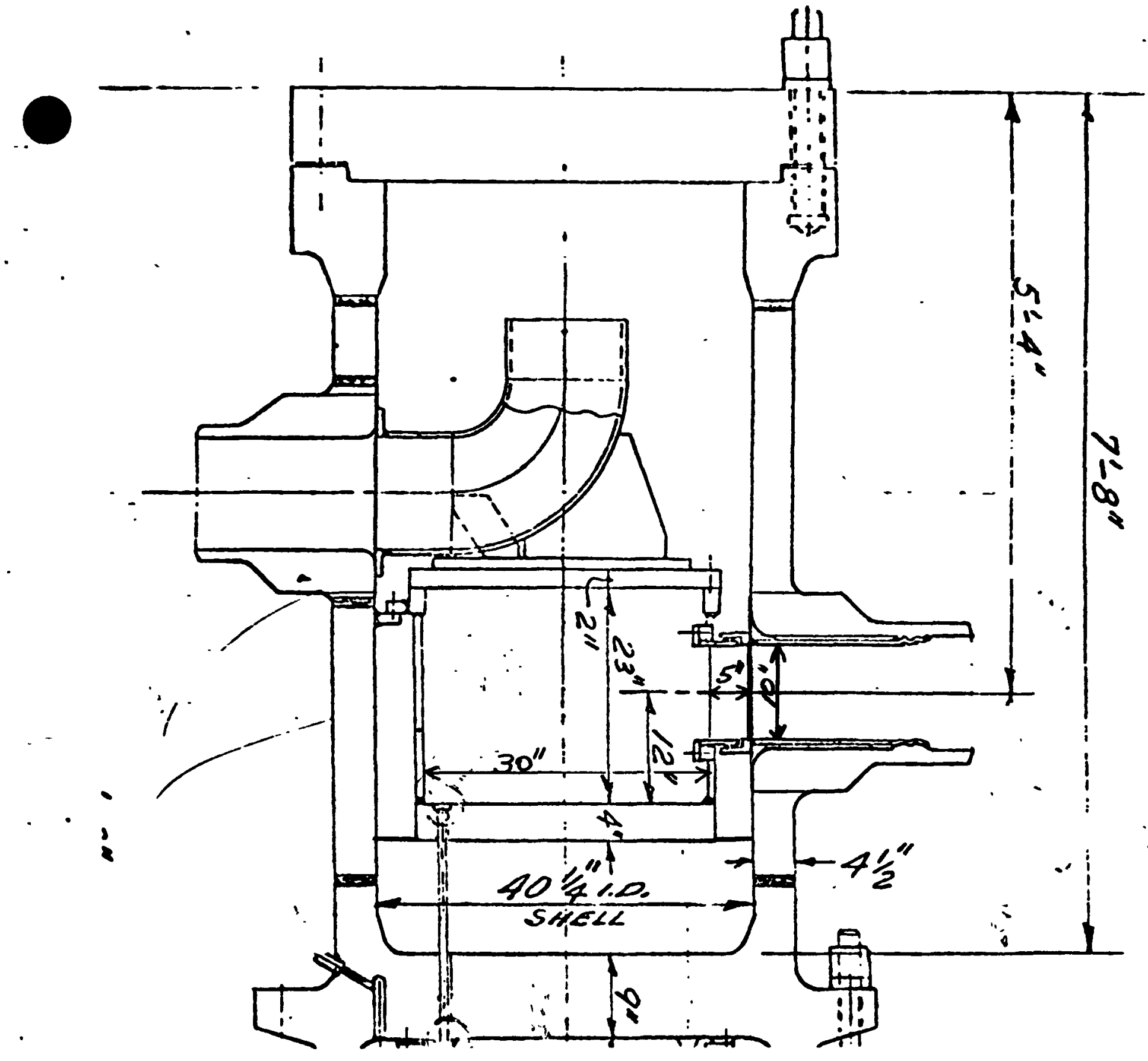

STEAM OUTLET PLENiMM

$$
\begin{gathered}
V_{s T m}=\frac{\pi}{4}(30)^{2}(23)+\frac{\pi}{4}(10)^{2}(5)=16700 \mathrm{~m}^{3}=9.64 \mathrm{ft}^{3} \\
\text { COMBUSTION ENGINEERING } \\
\text { NUCLEAR POWER DEPARTMENT }
\end{gathered}
$$


COMBUSTION ENGINEERING NUCLEAR POWER DEPARTMENT

$$
\bar{D}=\left(\frac{D_{L}^{2}+D_{0}^{2}}{2}\right)^{1 / 2}=\left(\frac{101 / 8{ }^{2}+21^{2}}{2}\right)^{1 / 2}=16.72^{4}
$$

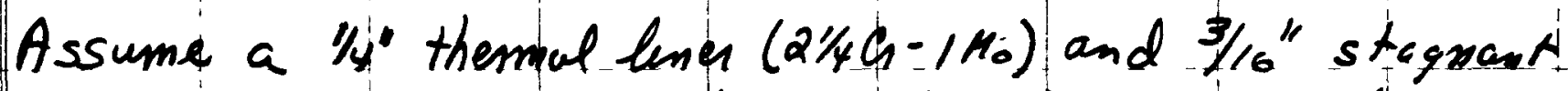
supenkatid steam gap between the flowing supuhioted steam and the nozzle for the entire length of the outlet nozzle. In addition, the resistance of the thickest section of the on yak characterizes the muggle for it entire length.

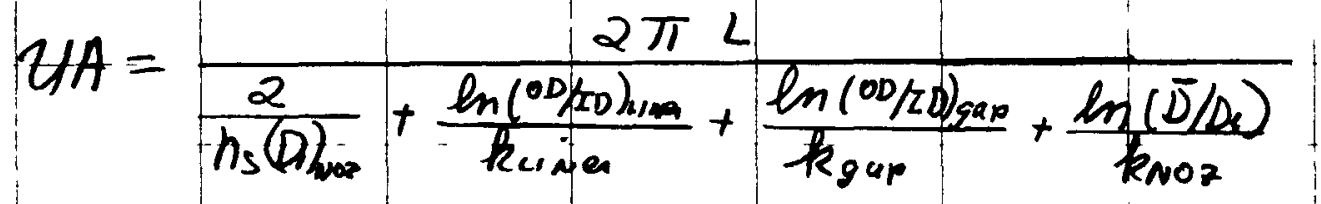

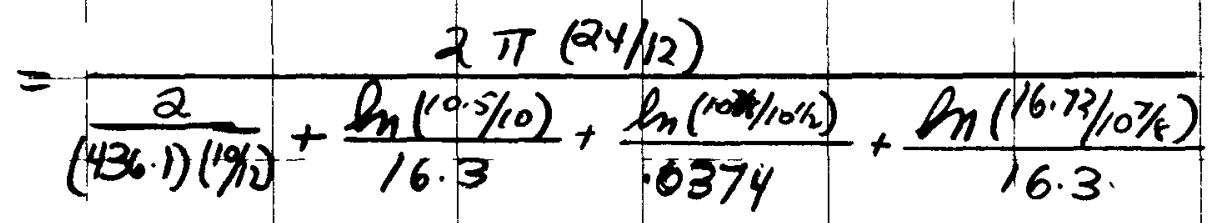

$$
\begin{aligned}
& =12.91 \frac{B+4}{m-0 \%}=0.003587 \frac{B t 4}{\sec -0 / 7} \\
& \left(V_{s}\right)_{N 02}=1.12 \mathrm{Fi}^{3} \\
& \left(V_{\text {metal }}\right)_{\text {NO }}=2.12 \mathrm{ft} \\
& \left(V_{s}\right)_{\text {plenum }}=9.64 \mathrm{ft}^{3}
\end{aligned}
$$

Computations ore shown on the figurer. 
COMBUSTION ENGINEERING

NUCLEAR POWER DEPARTMENT

Coefurents

$$
\begin{aligned}
& \left(\frac{1}{\rho v}\right)^{-1 / \operatorname{mon}}=\frac{1}{3.689)(9.64)}=0.02812 \mathrm{etm}^{-1}
\end{aligned}
$$

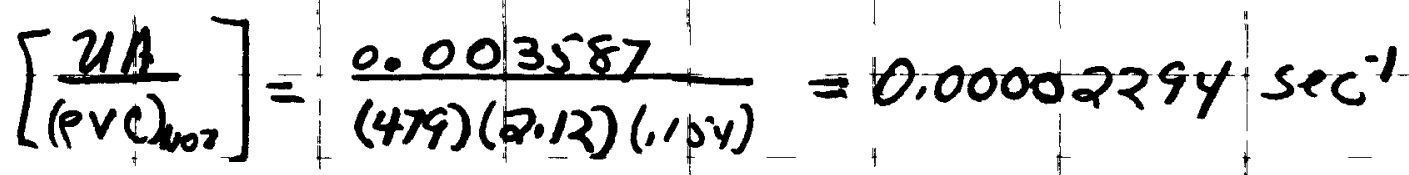

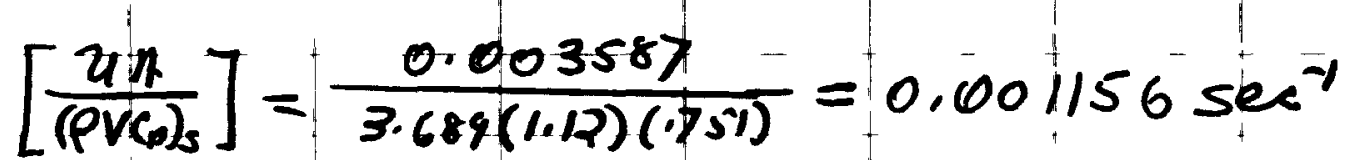

$$
\begin{aligned}
& \left(\frac{1}{\rho V}\right)_{s m 2}=\frac{1}{(3689)(11 / 2)}=0.2420 \mathrm{lbm}^{-1}
\end{aligned}
$$


COMBUSTION ENGINEERING

NUCLEAR POWER DEPARTMENT

Additional bleat Exchange Regin

$$
W_{s}=2648.52 \mathrm{lbm} / \mathrm{m} / \mathrm{tube}=0.7357 \mathrm{lbm} / \mathrm{sec} / \mathrm{table} \text { (desires) }
$$

Properties are evaluated at pressure and temperature for fall load.

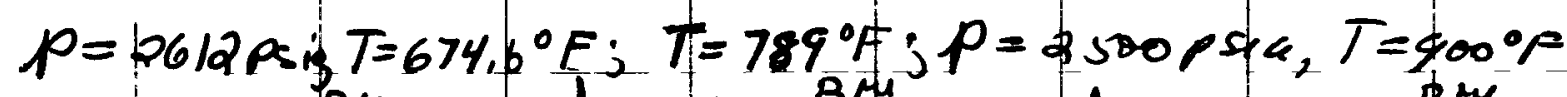

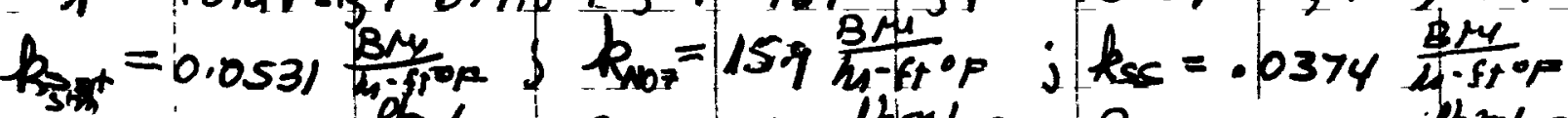

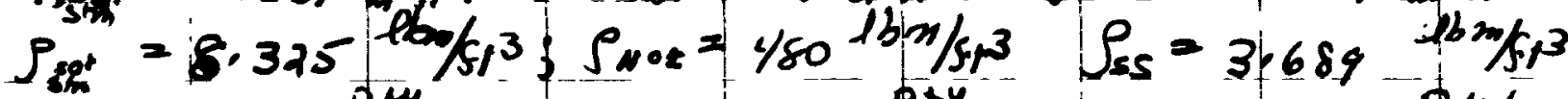

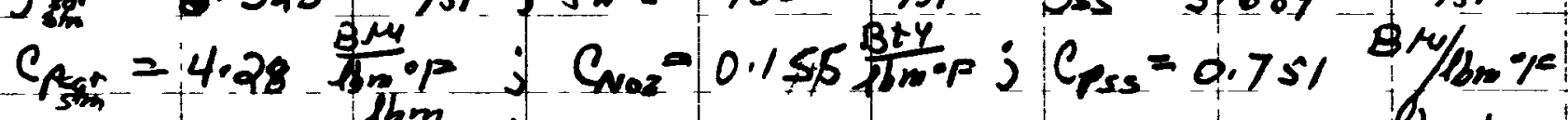

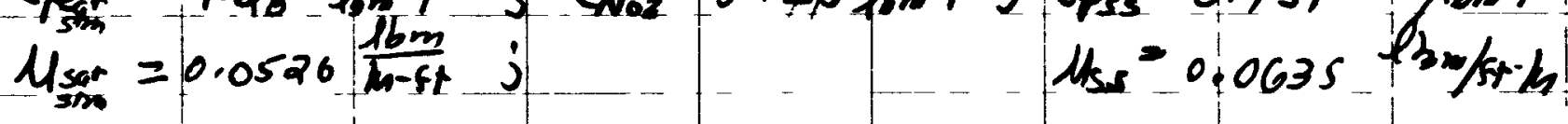

Heat Transfer Coefficients - Thermal Bostanses

1) For $12^{\prime \prime}(19 \%)$ of the odshtional heat transfer length the inlet saturated stan flows obliquely about the bayonet lube assembly (typical heat exchange shells cole flow patten). 7\% the semang 53 " the saturated steam Haws in the annuli defined by the pressure tabes and baymet tube assembles. In pup poses of characterizing the heat transfer the latten How pattern is a assumed for the entire length.

$$
\begin{aligned}
& G_{s}=\frac{W_{s}}{A_{s}}=\frac{2648.52}{\frac{\pi}{4}\left(1116^{2}-.916^{2}\right) / 1 / 4}=1.195 \times 10^{6} \frac{16 \mathrm{~m}}{h_{1}-57^{2}} \\
& V_{s}=\frac{G_{s}}{\rho_{s}}=\frac{1.195 \times 10^{6} / 3600}{8.325}=39.87 \mathrm{ft} / \mathrm{sec} \\
& R_{e_{s}}=\frac{G D_{0}}{\mu}=\frac{(1.195 \times 109)\left(\frac{1.116-916}{12}\right)}{.0526}=3.786 \times 10^{5} \\
& P_{r_{s}}=\frac{0.0526(4.23)}{.0531}=4.24
\end{aligned}
$$




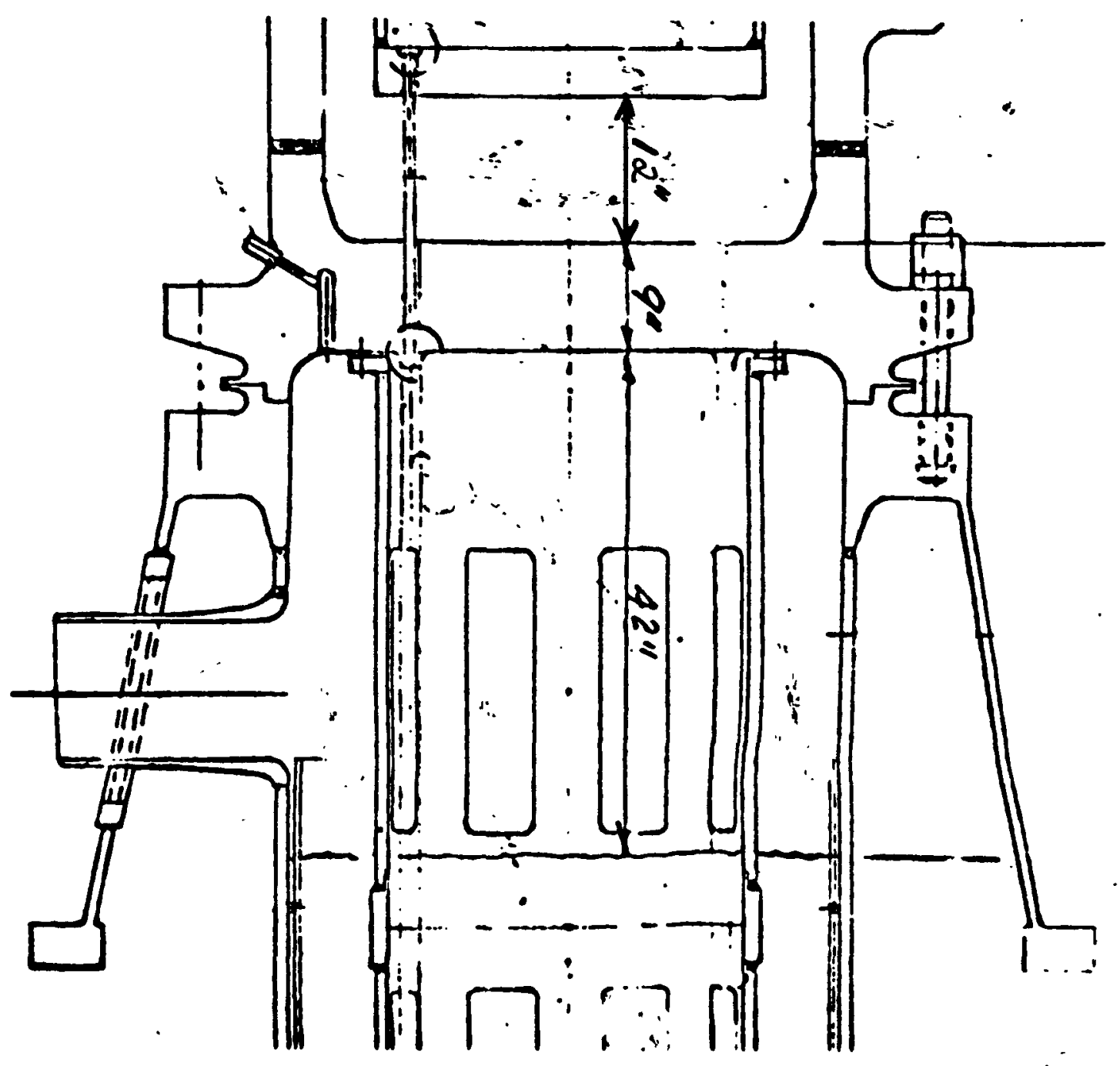

ADDETION HEaT EXchange LENGTH

$$
\begin{aligned}
& L=12+9+42=63 " \\
& d_{1}=0.636^{\prime \prime}, \quad d_{3}=0.836^{\prime \prime} \quad d_{5}=1.116^{\prime \prime} \\
& d_{2}=0.716^{\prime \prime}, \quad d_{4}=0.916^{\prime \prime} \quad d_{6}=1.50^{\prime \prime}
\end{aligned}
$$

COMBUSTION ENGINEERING NUCLEAR POWER DEPARTMENT 
COMBUSTION ENGINEERING

NISI FAR POWER DFPARTMFNT

$$
\begin{aligned}
& h_{s}=\frac{k_{s}}{D_{e}}\left[.023 Q_{e_{s}}^{.8} P_{s}^{4}\right]=\frac{.0531}{.2 / 12}\left[.023\left(3.786 \times 10^{5}\right)^{-5}(4.27)^{-4}\right]
\end{aligned}
$$

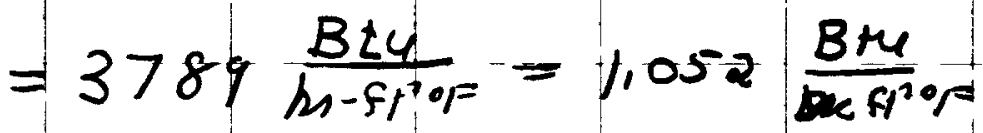

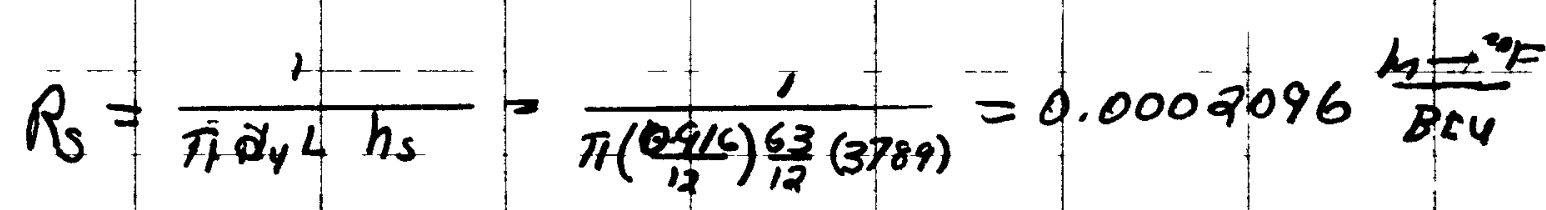

2) Outer Buymet Tube Resistance

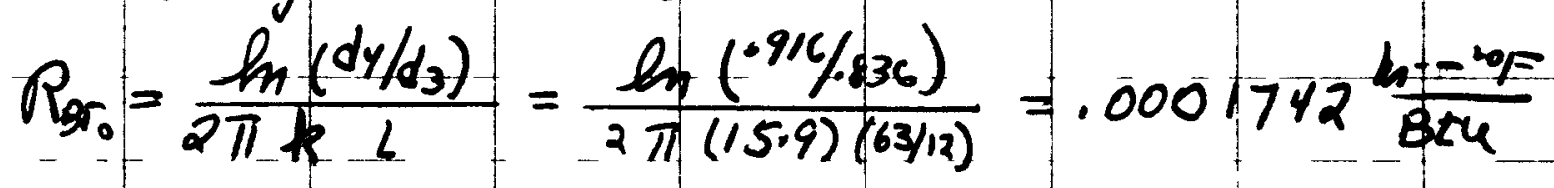

3) Insulation Gap Resistance

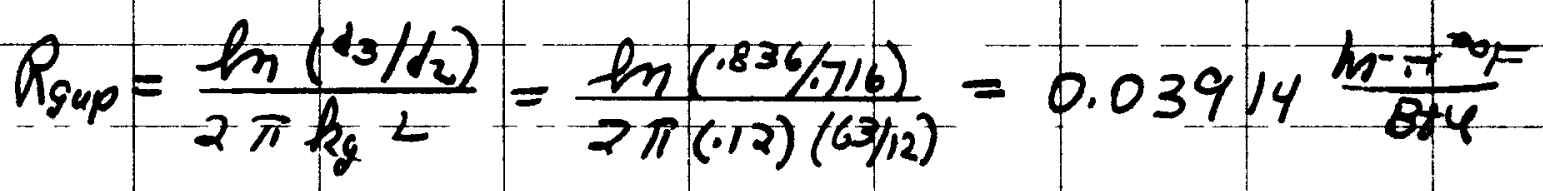

4) In on Bayonet Tube Resistance

$$
R_{B T_{i}}=\frac{\ln \left(d_{2} / d_{1}\right)}{2 \pi k L}=\frac{\ln (716 / .636)}{2 \pi(15.9) 62 / 12}=0.0002259 \frac{\pi T_{1} \cdot F_{1}}{B E 4}
$$

5) Superheated steam

$$
\begin{aligned}
& G_{s}=\frac{W_{s}}{A_{s}}=\frac{2648.52}{\frac{\pi}{4}(.636 / 12)^{2}}=1.200 \times 10^{6} \frac{\mathrm{lbm}}{\mathrm{m}-f \mathrm{f}^{2}} \\
& H_{S}=\frac{C_{S}}{\rho_{S}}=\frac{.200 \times 106 / 3600}{3.689}=90.40 \mathrm{Ft} / \mathrm{sec} \\
& R_{e_{f}}=\frac{C_{5} D}{t_{s}}=\frac{\left(1.200 \times 10^{6}\right)\left(\frac{.636}{12}\right)}{.0335}-1.002 \times 10^{6} \\
& P_{R_{S}}=\frac{\mu_{s} C_{s}}{k_{s}}=\frac{0.635(0.751)}{.0374}=1.27
\end{aligned}
$$


COMBUSTION ENGINEERING NUCLEAR POWER DEPARTMENT

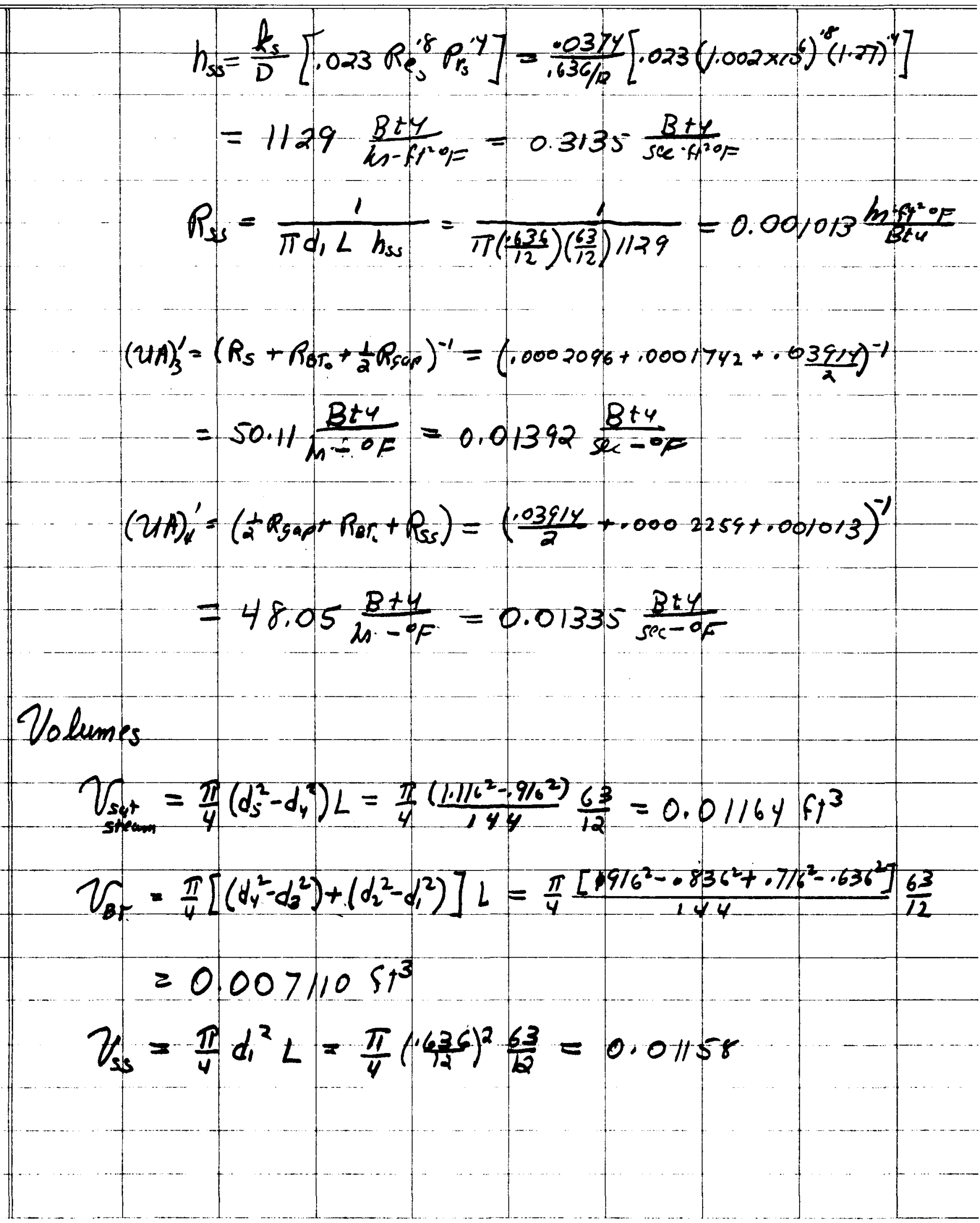


COMBUSTION ENGINEERING

NUCLEAR POWER DEPARTMENT

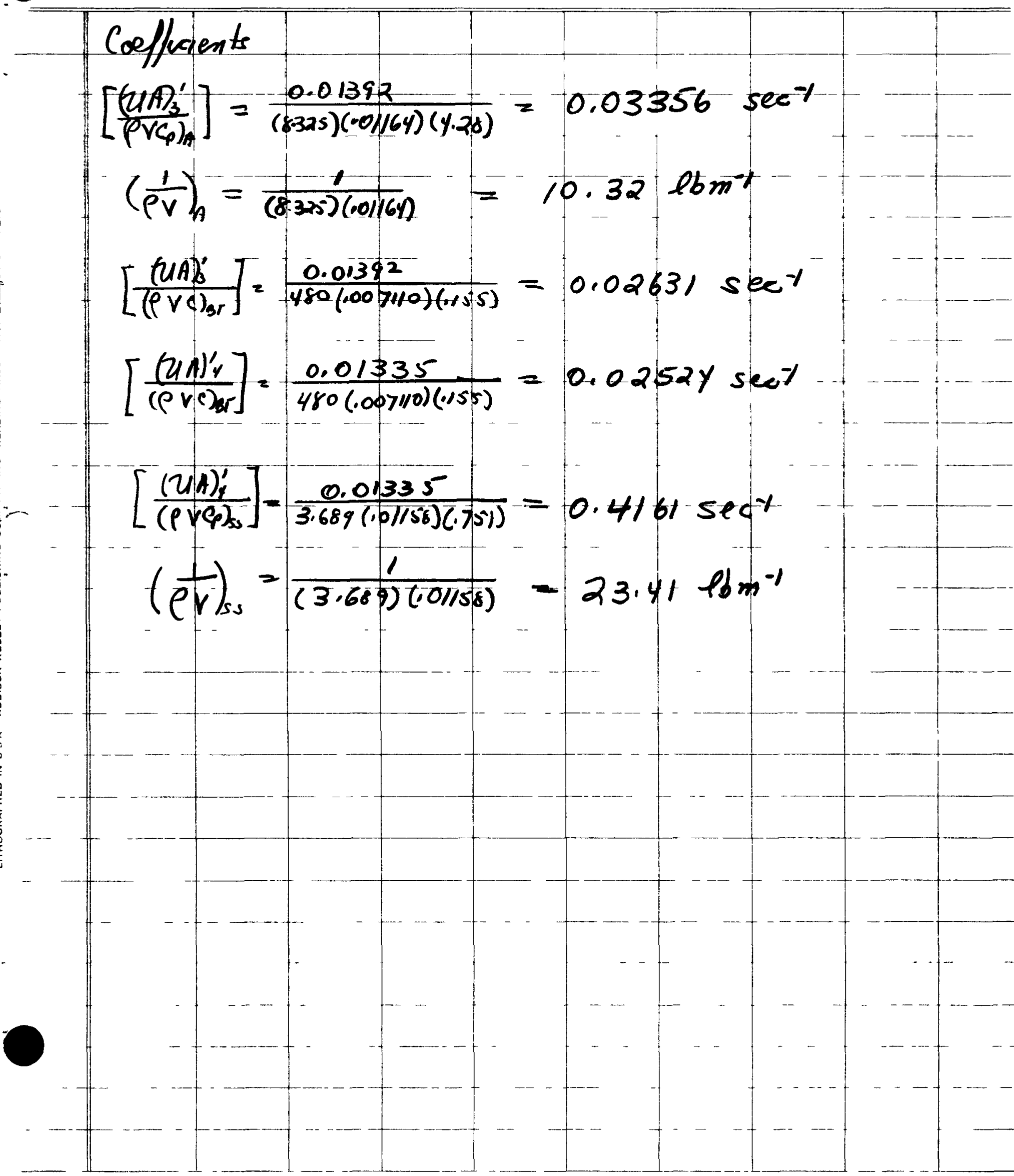


COMBUSTION ENGINEERING NUCLEAR POWER DEPARTMENT

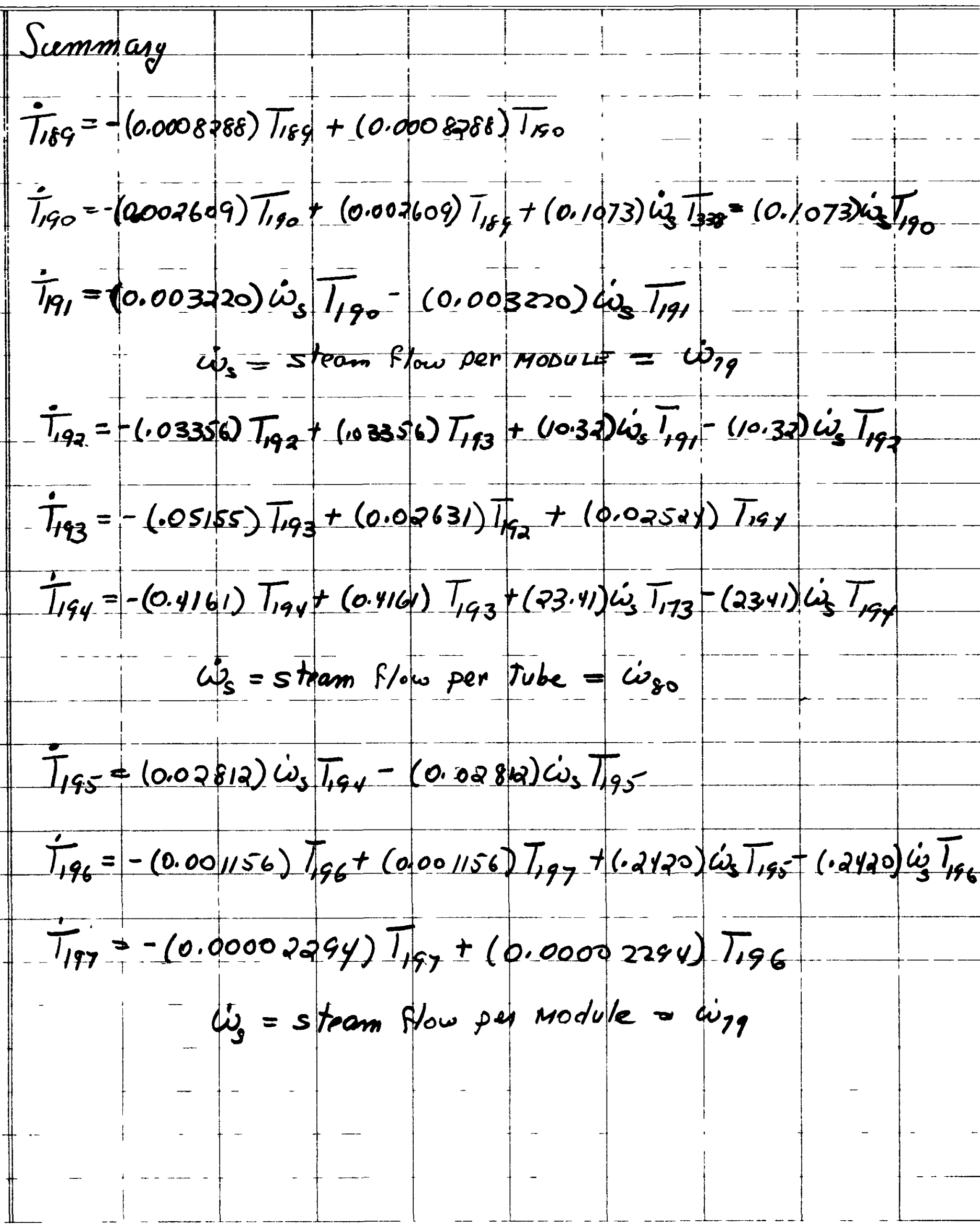


COMBUSTION ENGINEERING NUCLEAR POWER DEPARTMENT

Evaporator.

I Main Heat Tams fer Regin

Energy balances:

$$
\begin{aligned}
& -(u A)_{1}\left[T_{N a}-T_{P T}\right]+\left(w C_{P}\right)_{w a} T_{N a}=\left(w C_{p}\right) T_{N a}+(p \vee C)_{N a} \frac{d T_{N a}}{d t} \\
& \left(U A A_{1}\left[F_{N a}-T_{P T}\right]-(U A)_{2}\left[T_{P T}-T_{\text {AN }}\right]=(\rho \vee C)_{P T} \frac{d T_{P T}}{d t}\right. \\
& (U A)_{2}\left[T_{T_{T}}-T_{A \text { iN }}\right]-(U A)_{3}\left[T_{\text {ANN }}-T_{B T}\right]+w_{\text {ANN }} h_{A N N} \\
& =w_{A N M} h_{A N N}+\frac{d}{d t}(\rho v u)_{A N N} \\
& (U A)_{3}\left[T_{\text {AnN }}-T_{B T}\right]-(U A)_{y}\left[T_{B T}-T_{D C}\right]=(\rho V C)_{B T} \frac{d T_{B T}}{d t} \\
& (U A)_{4}\left[T_{B T}-T_{D C}\right]+\left(w C_{P}\right)_{D C} T_{D C}=\left(w C_{P}\right)_{D C} T_{D C}+\left(\rho v C_{P}\right)_{D C} \frac{d T_{D C}}{d t}
\end{aligned}
$$

The water in the downcomer has already been treated as an mampresible thud. Thus cannot be done in the annulus dive to the two phase flow it the fast pot en of the flow channel. The following assumptions are made for the annular flow:

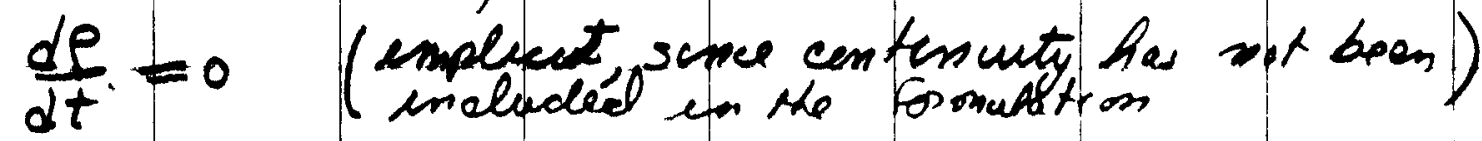

$$
\begin{aligned}
& \frac{d p}{d t}=0 \Rightarrow \frac{d(\rho \omega)}{d t}=\frac{d}{d t}(\rho h-p)=\frac{d(\rho h)}{d t}
\end{aligned}
$$

The results of these assumptions are substituted into the energy bal lances. the equations are then seassanged. 
COMBUSTION ENGINEERING

NUCLEAR POWER DEPARTMENT

In standard format

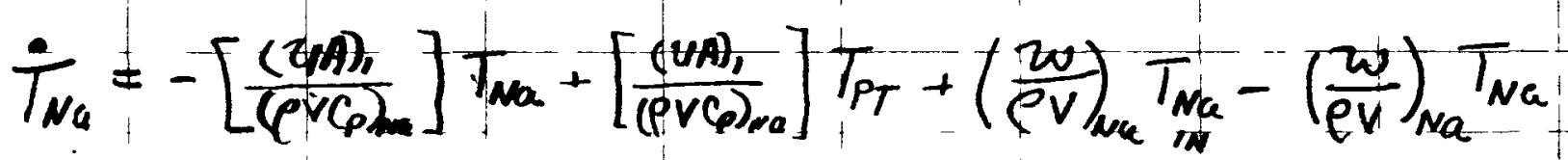

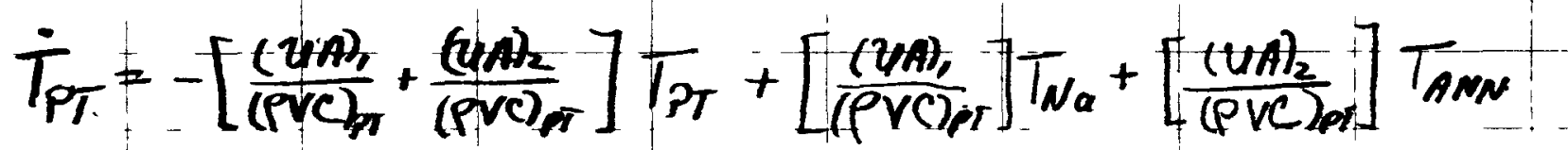

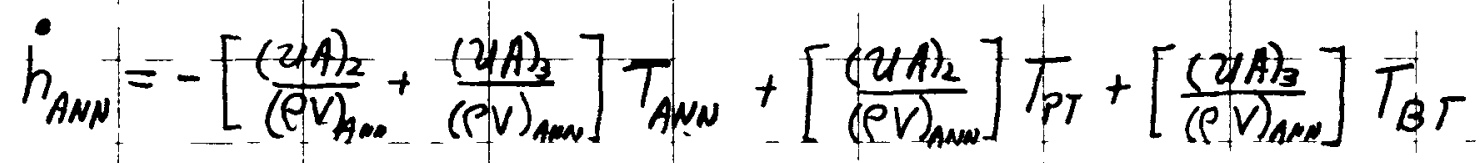

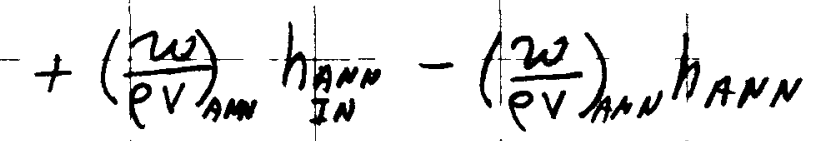

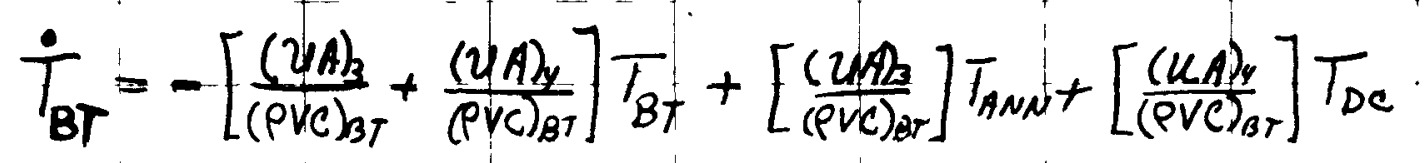

$$
\begin{aligned}
& \dot{T}_{D C}=-\left[\frac{(U A)_{U}}{\left(\rho V C_{D C}\right)_{D C}}\right] T_{D C}+\left[\frac{(U A)_{Y}}{\left(\rho V C C_{D C}\right.}\right] T_{B r}+\left(\frac{w}{\rho V}\right)_{D C} T_{D C}-\left(\frac{w}{\rho V}\right)_{D C} T_{D C}
\end{aligned}
$$

In addition, a curve fit of $T_{\text {ANN }}$ is h avN at a given pressure connects each how node with a corresponding TAN mode.

Fo the axial nods which is the inlet to the annulus the term in the energy balance for inlet enthalpy becomes

$$
\left(\frac{w}{P V}\right)_{D W N} h_{n N N} \rightarrow\left(\frac{w C P}{P V}\right)_{A N N} T_{D C T} .
$$


COMBUSTION ENGINEERING NUCLEAR POWER DEPARTMENT

Design parameter and axial distributions of pressure and temperature, for the evaporator writing ifherds revere obtained from the computer output "Performance :Studits for Sodium, Heated Strap Greats". "A computer program! was written for the CE time Shan ing computer, punch takes all the above dat ce and computes the coefficemis for the transient equations.

Input data

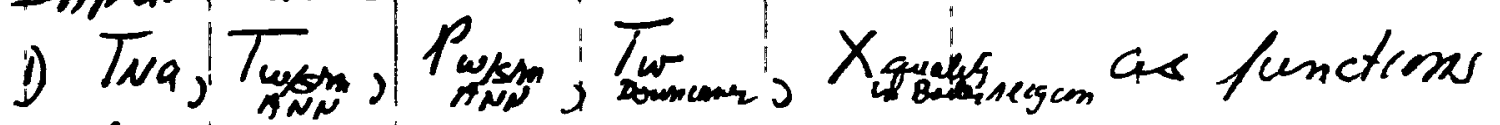
of axial opsition.

2) Tube geometry: $d_{1}, d_{2}$ vine, bayonet hike $2 D_{1}, 0 D$ $d_{3}, d_{y}$ L outer buy met tube $I D, D D$ $d_{5,}, d_{c}{ }^{2}$ oppessune tube ID, OD: $P_{2}$ rube pitch, LT tube heal trompe length

3) properties for soduem, pressure tale, bayonet tubes, water in downomess, and water in the bayonet tube insulation gap.

4) water and sodium flows per tabes, sodium film coepleient (ha), downcomer water film coefficient (haw).

The following pasametos are computed:

1) fixed quantities

a) Volumes and thermal capacitance

$$
\begin{aligned}
& V_{N a}=\left(\frac{\sqrt{3}}{2} P^{2}-\frac{\pi}{4} c_{b}^{2}\right) \Delta L \\
& C_{N a}=\rho_{N a} V_{N a} C_{M a}
\end{aligned}
$$


COMBUSTION ENGINEERING NUCLEAR POWER DEPARTMENT

whee $\Delta L=$ length of each nodal increment.

$$
\begin{aligned}
& V_{P_{T}}=\frac{\pi}{4}\left(d_{s}^{2}-d_{y}^{2}\right) \Delta L \\
& C_{P T}=\rho_{P T} V_{P T}\left(C_{P}\right)_{P T} \\
& V_{B T}=\frac{\pi}{4}\left[\left(d_{y}^{2}-d_{3}^{2}\right)+\left(d_{2}^{2}-d_{1}^{2}\right)\right] \Delta L \\
& C_{B T}=\rho_{B T} V_{B T}\left(C_{P}\right)_{B T} \\
& V_{w}=\frac{\pi}{4} d_{1}^{2} \Delta L \\
& C_{w}=\rho_{w} V_{w}\left(C_{P}\right)_{w} \\
& V_{S T M / w}=\frac{\pi}{4}\left(d_{s}^{2}-d_{y}^{2}\right) \Delta L
\end{aligned}
$$

The properties of the wake in the douncomess do not wary signefuently so they may be considered constant. The properties for the fluid in the annuli must be computed node by node due to the two distinct reed segues that exist.

b) The thermal resistance.

$$
\begin{aligned}
& R_{N a}=\frac{1}{\pi d_{b} \Delta L h_{N a}} \\
& R_{P T_{1}}=\frac{\ln \left(d_{G} / \bar{d}\right)}{2 \pi k_{P T} \Delta L} ; \quad J=\left(\frac{d_{s}^{2}+d_{c}^{2}}{2}\right)^{1 / 2}
\end{aligned}
$$


COMBUSTION ENGINEERING NUCLEAR POWER DEPARTMENT

$$
\begin{aligned}
& (U A)=\frac{1.0}{R_{N a}+R_{P i_{1}}} \\
& R_{P T_{2}}=\frac{\ln \left(d / d_{s}\right)}{2 \pi k_{P T} \Delta L} \\
& R_{B T_{0}}=\frac{\ln \left(d_{4} / d_{3}\right)}{2 \pi k_{B T} \Delta L} \\
& R_{\text {gap }}=\frac{\ln \left(d_{3} k_{\alpha}\right)}{2 \pi k_{\text {goo }} \Delta L} \\
& R_{B T_{C}}=\frac{\ln \left(d_{z} / d_{1}\right)}{2 \pi k_{B T} \Delta L} \quad \int R_{B T_{2}}=\frac{1}{2} R_{g a p}+P_{B T_{T}} \\
& R_{\omega}=\frac{1.2}{\pi \cdot d_{1} \Delta L h_{w}} \\
& (U A)_{4}=\frac{1.0}{R_{B T_{2}}+R_{w}}
\end{aligned}
$$

2) Quantities that ing with axial position are then emoted. Since the properties of the annular Fund vary, the thermal capacitance and resistames also vang. Thus node by node computations one performed.

The transient model used is the "outlet Temperature model wheres the nelda pant is chasactenged by the properties at the out lest y' the element. Fo ce set of nodes at a given axial position, the sodium and downcomer water conditions are obtained at the given axial position, but the 
COMBUSTION ENGINEERING

NUCLEAR POWER DEPARTMENT

associated annular wates/steam is a nodal invement away. Conseriently, the associated pressure tube and bayonet tube assembly average tempartuses, are "diagonal" average: (see figure).

$x$ - nodal out bt

a 2 "diagonal" average

to 2 modal point
for tubes

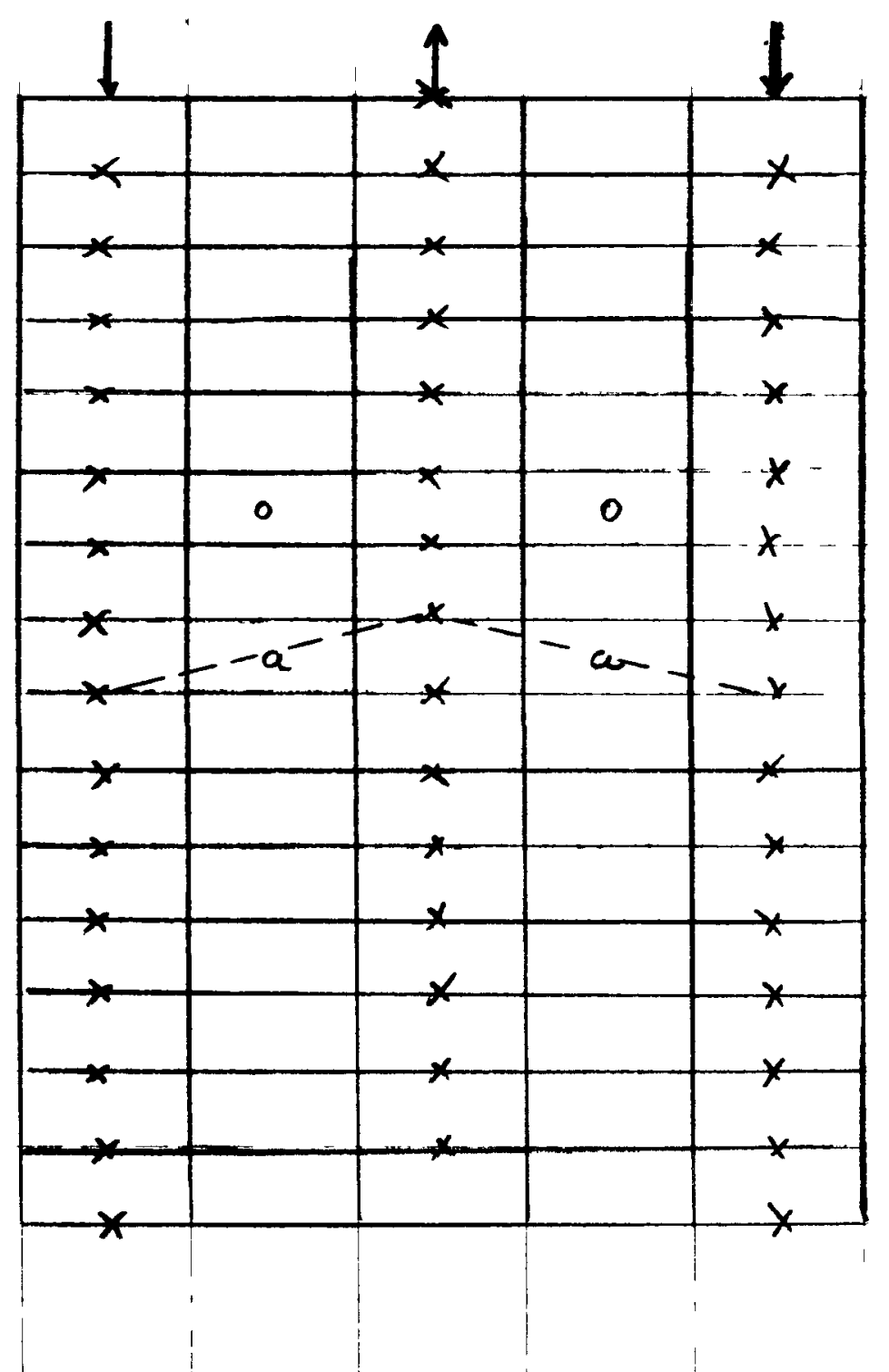

For each radial set Ti', Pan, TAN Twa, Tue obtained by interpolation of the input data.

If the outlet of the annular fluid mode is in the two phase zoe, the quality of the mixture les also obtained by interpolation of the input data. 
COMBUSTION ENGINEERING NISI FAR POWER DFPARTMFNT

The GE Mark II Steam Tables (curve fits to Koran. "keys) are used to obtain density and enthalpy Is the saturated hued and saturated vapor. The average for the mixture

$$
\begin{aligned}
& \bar{\rho}=\frac{\rho_{f} \rho_{g}}{(1-x) \rho_{g}+x \rho_{5}} \\
& \bar{H}=(1-x) H_{F}+x H_{g}
\end{aligned}
$$

The thermal capacity of the node

$$
C_{\text {ANN }}=\frac{1}{\bar{\rho} V_{\text {ANN }}}
$$

The hat transf coeffrent is calculated form the Levy correlation. This requites thou " the coal temperature.

$$
h=\frac{p^{4 / 3}}{495}\left(T_{w}-T_{s_{0}}\right)^{2}=\frac{p^{4 / 3}}{495} \Delta T^{2}
$$

From a steady state energy balance across the pressure tube

$$
\frac{T_{\text {wall }}-T_{\text {ANN }}}{R}=\frac{T_{N a}-T_{\text {ANN }}}{R_{T}}
$$

noting that

$$
\begin{aligned}
& R=\left(\frac{1}{\pi_{s}-\Delta_{2}}\right) / h \\
& R_{\text {TOT }}=R_{\text {NC }}+R_{P T_{1}}+R_{P T_{2}}+R
\end{aligned}
$$


COMBUSTION ENGINEERING

NUCLEAR POWER DEPARTMENT

These equations are combined and a cubiciequation for in is obtamed.

$$
h^{3}+\left(2 \frac{z_{1}}{z_{2}}\right) h^{2}+\left(\frac{z_{1}}{z_{2}}\right)^{2} h-z_{4}\left(\frac{z_{1} z_{3}}{z_{2}}\right)^{2}=0
$$

where

$$
\begin{aligned}
& z_{1}=\frac{=1}{\pi d_{5} \Delta L} \\
& Z_{*}=R_{N a}+R_{p t}+R_{p-i} \\
& z_{3}=T_{N a}-T_{\text {man }} \\
& Z_{4}=P^{4 / 3} / 495
\end{aligned}
$$

A special subroutine un as upitten to obtain the appropriate not of this poly rial. The associated thermal resistance

$$
R_{\text {SN }}=\frac{1}{\pi d_{5} \Delta L h}
$$

Fo the film coeffucent of the mixture on the outer wall of the out a buyout tube, the quantity used en the seguing compute n program eras adopted.

$$
h_{B_{2}}=4056 \frac{13+4}{\left.m-t^{2}-0\right)^{2}}
$$

so

$$
\operatorname{RANN}_{Q}=\frac{1.0}{\pi d_{4} \Delta L h_{B 2}}
$$

If the outlet of the annular thud node is in the single phase crater region, then the 
COMBUSTION ENGINEERING

NUCLEAR POWER DEPARTMENT

density, enthalpy, viscosity, specific hat, and thermal conductivity of the water are obtained from the GE Mark II storm tables. The this mol capacitance of the mode is calculated.

$$
C_{\text {BN N }}=\frac{1,0}{P_{\text {NW N }} V_{\text {NW }}}
$$

The film coefficient

$$
h=\frac{k}{D e}\left[.023 P_{e} \cdot \gamma p_{r} \cdot 4\right]
$$

whee: $R_{e}=\frac{W_{d_{0}}}{A_{\text {flow }}} \frac{D_{e}}{\mu_{\text {pun }}}$

$$
\begin{aligned}
& P_{r}=\left(\frac{\mu\left(C_{p}\right.}{K_{p}}\right)_{w} \\
& D_{e}=d_{s}-d_{y}
\end{aligned}
$$

and the associated thermal resistances

$$
R_{\text {ANN }}=\frac{1.0}{\pi d_{S} \Delta L h} ;, \quad R_{A N N}=\frac{1 . d}{\pi d_{y} \Delta L, h}
$$

In ether region the remaining. calculations se the same. The overall conduction rs

$$
(U A)_{2}=\frac{1.0}{\left(R_{P T_{2}}+R_{A N N}\right)}, \quad(U A)_{3}=\frac{1.0}{\left(R_{A N N}+R_{B T_{1}}\right)}
$$

Ot he associated. "diagonal" average temperature for the pressure tube and the bayonet tube assembly is then calculated. 
COMBUSTION ENGINEERING NUCLEAR POWER DEPARTMENT

$$
\begin{aligned}
& T_{P T}=\frac{(U A)_{1} T_{N A}+(U A)_{2} T_{A N N}}{(U A)_{1}+(U A)_{2}} \\
& T_{B T}=\frac{(U A)_{3} T_{A N N}+(U A)_{4} T_{w}}{(U A)_{3}+(U A)_{4}}
\end{aligned}
$$

Finally the coefficients of the governing defferintial. equations are calculated.

$$
\begin{aligned}
& C_{1}=\frac{(U A)}{C_{N a}} \quad ; \quad C_{2}=\frac{1}{\rho_{N a} V_{\text {Na }}} \\
& C_{3}=C_{4}+C_{5} ; \quad C_{4}=\frac{(U A)_{1}}{C_{P T}} ; C_{5}=\frac{(U A)_{2}}{C_{P T}} \\
& C_{6}=C_{7}+C_{8} ; \quad C_{7}=\frac{(U A)_{2}}{C_{\text {ANN }}} ; \quad C_{8}=\frac{(U A)_{3}}{C_{\text {ON }}} ; C_{9}=\frac{1.0}{\rho V_{\text {ANN }}} \\
& C_{10}=C_{11}+C_{12} ; \quad C_{11}=\frac{(U A)_{3}}{C_{B i}} ; \quad C_{12}=\frac{(U A)_{Y}}{C_{B T}} \\
& C_{13}=\frac{(U A)_{y}}{C_{w}} ; \quad C_{14}=\frac{110}{\rho_{w} V_{w}}
\end{aligned}
$$




\section{DIFENSION XTAB(37),YTAB(37),ZTAB(37).TTAB(37),PTAB(37),XTB1 613$).$} $10180 T A B(13)$

110 NTAB $=373$ NTBI $=133$ NPT $=3$ s IERR $=0$

120 DATA XTAB/0.0.0.51658, 1.0570.1 .6254.2.2245.2.8580.3.5328. $12144 \cdot 2518 \cdot 5 \cdot 0210 \cdot 5 \cdot 8481 \cdot 6 \cdot 7425 \cdot 7 \cdot 7161 \cdot 8 \cdot 7842,9 \cdot 7842,10 \cdot 7842 \cdot 11 \cdot 7842$. $122812 \cdot 7842 \cdot 13 \cdot 7842 \cdot 14 \cdot 7842 \cdot 15 \cdot 7842 \cdot 16 \cdot 7842,17 \cdot 7842 \cdot 18 \cdot 7842$. $123419 \cdot 7842 \cdot 20 \cdot 7842 \cdot 21 \cdot 7842 \cdot 22 \cdot 7842 \cdot 23 \cdot 7842 \cdot 24 \cdot 7842 \cdot 25 \cdot 7842,26 \cdot 7842$. $124427 \cdot 7842 \cdot 28 \cdot 7842 \cdot 29 \cdot 7842 \cdot 30 \cdot 7842 \cdot 31 \cdot 7842 \cdot 32 \cdot 451$

130 DATA YTAB/866.02,857.78.849.56,841 .34.833.11.824.89,816.62. $1314808 \cdot 35 \cdot 800 \cdot 07 \cdot 791 \cdot 79 \cdot 783 \cdot 49 \cdot 775 \cdot 17 \cdot 766 \cdot 84 \cdot 760 \cdot 43,754 \cdot 37 \cdot 748 \cdot 64$. $1328743 \cdot 21 \cdot 738 \cdot 05 \cdot 733 \cdot 14 \cdot 728 \cdot 47 \cdot 724 \cdot 00 \cdot 719 \cdot 74 \cdot 715 \cdot 65 \cdot 711 \cdot 74 \cdot 707 \cdot 98$. $1336704 \cdot 37 \cdot 700 \cdot 90 \cdot 697 \cdot 55 \cdot 694 \cdot 33 \cdot 691 \cdot 22 \cdot 688 \cdot 21 \cdot 685 \cdot 30 \cdot 682 \cdot 49 \cdot 679 \cdot 77$. $1348677.13 .674 .57 .672 .92 /$

140 DATA ZTAB/634.49.634.55.634.63.634.70.634.78.634.86,634.95. $1418635 \cdot 04 \cdot 635 \cdot 14.635 \cdot 25 \cdot 635 \cdot 36 \cdot 635 \cdot 49 \cdot 635 \cdot 62 \cdot 635 \cdot 75 \cdot 635 \cdot 86 \cdot 635 \cdot 97$. $1424636 \cdot 08 \cdot 636 \cdot 18 \cdot 636 \cdot 27 \cdot 636 \cdot 36 \cdot 636 \cdot 44 \cdot 636 \cdot 51 \cdot 636 \cdot 58 \cdot 636 \cdot 65 \cdot 636 \cdot 71$. $1438636 \cdot 76 \cdot 636 \cdot 81 \cdot 636 \cdot 85 \cdot 636 \cdot 89 \cdot 636 \cdot 92 \cdot 636 \cdot 95 \cdot 636 \cdot 97 \cdot 636 \cdot 99 \cdot 637 \cdot 00$. $1444637.01 .637 .02 .637 .02 /$

150 DATA TTAB/676.46.676.47.676.49.676.50.676.51.676.53.676.54. $1518676.56 \cdot 676 \cdot 58 \cdot 676 \cdot 60 \cdot 676 \cdot 62 \cdot 676 \cdot 64.676 \cdot 66 \cdot 674 \cdot 86.673 .03$. $1528671 \cdot 17.669 \cdot 31.667 \cdot 44.665 \cdot 60 \cdot 663 \cdot 73.661 \cdot 96.660 \cdot 19.658 \cdot 44.656 \cdot 72$. $1534655 \cdot 03 \cdot 653 \cdot 36.651 \cdot 72 \cdot 650 \cdot 09 \cdot 648 \cdot 49 \cdot 646 \cdot 91 \cdot 645 \cdot 35 \cdot 643 \cdot 82 \cdot 642 \cdot 32$, $1544640.84 .639 \cdot 39 \cdot 637 \cdot 95 \cdot 637.01 /$

160 DATA PTAB/2644.92.2645.15.2645.39.2645.63.2645.89.2646.18. $16182646 \cdot 48 \cdot 2646 \cdot 72 \cdot 2647 \cdot 02 \cdot 2647 \cdot 35 \cdot 2647 \cdot 70 \cdot 2648 \cdot 07 \cdot 2648 \cdot 47.2648 \cdot 81$. $16282649.16 .2649 \cdot 51.2649 .86 .2650 \cdot 21.2650 \cdot 57.2650 \cdot 93.2651 \cdot 28 \cdot 2651.64$. $16382652 \cdot 00 \cdot 2652 \cdot 37.2652 \cdot 73.2653 \cdot 10.2653 \cdot 46 \cdot 2653 \cdot 83.2654 \cdot 20.2654 \cdot 57$, $16442654 \cdot 94.2655 .31 .2655 \cdot 69 \cdot 2656.06 .2656 \cdot 43.2656 \cdot 81 \cdot 2657.06 /$ 170 DATA XTB1/0.0.0.51658.1.0570.1 .6254.2.2245.2.8580.3.5328. $171 \% 4 \cdot 2518,5 \cdot 0210,5 \cdot 8481,6 \cdot 7425,7 \cdot 7161 \cdot 8 \cdot 7842 /$

180 DATA QTAB/0.285714.0.261905.0.238095,0.214286.0.190476. $18180 \cdot 166667 \cdot 0 \cdot 142857 \cdot 0 \cdot 107143,0 \cdot 095238 \cdot 0 \cdot 071428 \cdot 0 \cdot 047619$. $18220.023809 .0 .0 /$

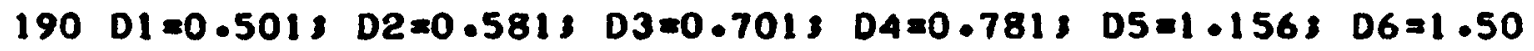

$195 \mathrm{P}=2.03 \mathrm{XLT}=32.453 \quad \mathrm{XLB}=8.784$

200 WNA $=4353000 \cdot 1380.1 W W=3 \cdot 5 * 397278 \cdot 1380$.

210 CPT $=0.1423$ XKPT $=15.73$ RHOPT $=482$.

220 CBT $=0.1433 \quad X K B T=15.63 \quad R H E B T=482$.

230 CPNA $=0.305083$ XKNA=41 .53 RHDNA=53.83 XMUNA=0.723 HNA=5701.

$240 \mathrm{CPW}=1.663 \mathrm{XKW}=0.2833 \mathrm{RH} W \mathrm{~W}=40.53$ XMUW $=0.1933 \mathrm{HW}=6855$.

$250 \times K G=0.64$

$260 N P=151 \quad D X=2.163$

270 RNA $=3.8197 /(D 6 * D X * H N A)$

$280 \mathrm{DB}=\mathrm{SORT}((\mathrm{D}) * 2+D 6 * 2) / 2.0)$

285 RPT $1=0.159155 * A L O G(D 6 / D B) /(D X * X K P T)$

$286 R P T 2=0.159155 * A L O G(D B / D 5) /(D X * X K P T)$

290 RBTO $=0.159155 * A L O G(D 4 / D 3) /(D X * X K B T)$

$291 R G A P=0.159155 * A L O G(D 3 / D 2) /(D X * X K G)$

292 RBT I $=0.159155 * A L O G(D 2 / D 1) /(D X * X K B T)$

300 RBT I $=R B T 0+0.5 * R G A P \&$ RBT $2=0.5 * R G A P+R B T I$ 
GrD

$02 / 13 / 73$

$310 R W=3.8197 /(D 1 * D X * H W)$

320 UAI $=0.000277777 /$ (RNA +RPTI ) S UAA $=0.000277777 /(R B T 2+R W)$

$330 \mathrm{HB2}=4056$

$331 \quad 21=3 \cdot 8197 /(D 5 * D X) \& \quad Z 2=R N A+R P T 1+R P T 2$

$350 \mathrm{Al}=(0.866025 * P * 2-0.785398 * D 6 * 2) / 144.3 \quad \mathrm{~V} 1=A 1 * D X$

355 A2 $=0-785398 *(D 6 * 2-D 5 * 2) / 144 \cdot 1$ V2 $=A 2 * D X$

$360 A 3=0.785398 *(D 5 * * 2-D A * * 2) / 144 \cdot 3 \quad V 3=A 3 * D X$

$365 A 4=0.785398 *(D 4 * 2 * D 2 * * 2-D 3 * * 2-D I * 2) / 144 \cdot 3 \quad V 4=A 4 * D X$

370 AS $=0.785398 *(D 1 * * 2) / 144.3$ V $=A 5 * D X$

$380 \mathrm{DE}=(\mathrm{DS}-\mathrm{D} 4) / 12$.

390 CANA $=R H G N A * V I * C P N A$

$395 \mathrm{CAW}=\mathrm{RHOH} * \mathrm{~V} 5 * \mathrm{CPW}$

400 CAPT $=R H E P T * V 2 * C P T$

$\triangle 05 \mathrm{CABT}=\mathrm{RHOBT} * \mathrm{~V} 4 * \mathrm{CBT}$

$410 \mathrm{Cl}=U A 1 / C A N A 3 \mathrm{C} 2=1 \cdot 0 /(R H O N A * V 1)$

420 C4=UAI/CAPT

430 C12 $=U A 4 / C A B T$

440 C13 $=U A 4 / C A H S C 14=1 \cdot 0 /$ (RHOW*VS)

450 PRINT, "VOLUNES AND CAPACITIES"

451 PRINT ,VI ,CANA,V2 ,CAPT ,V4,CABT , V5,CAH •V3

455 PRINT 200

456200 FORMAT (/)

460 PRINT "THERmAL RESISTANCES AND CONDUCTANCES"

461 PRINT, RNA, RPTI,"

Q UA1

465 PRINT \& RPT2

470 PRINT •RBTE,RGAP •RBTI

475 PRINT,RBTI

480 PRINT,RBT2,RW,"

490 PRINT 300

491300 FERMAT $(/ / 1 / /)$

500 DO $100 \quad 1=1$, NP

$510 \times 1=13 \quad X 1=X 1 * D \times 3 \quad \times 2=(X 1-1 \cdot 0) * D X$

$520 T$ TNA $=T N T 1(X 1, N T A B, X T A B, Y T A B, N P T, I E R R)$

$525 T H=T N T 1(X), N T A B, X T A B, Z T A B, N P T, I E R R)$

$530 T A=T N T 1(X 2, N T A B, X T A B, T T A B, N P T, I E R R)$

535 PA=TNT I (X2,NTAB, XTAB,PTAB, NPT, IERR)

540 IF $(X 2-X L B) 40,50,50$

550 10 QUAL =TNT 1 (X2,NTB1 XTB1 , QTAB,NPT , IERR)

560 DENF $=S A L D(P A) \&$ DENG $=S A T D(P A) \&$ RHE $=D E N F * D E N G /((1,-Q U A L) * D E N G+$ 56 1 \&QUAL $\# D E N F$ )

565 CANN=RHO\#V3

570 HLIQ=SALH $(P A) \&$ HVAP $=S A T H(P A) \&$ ENTH=(1 -QUAL) *HLIQ+QUAL*HVAP

$580 \quad Z 3=T N A-T A 3 \quad Z 4=(P A * * 1 \cdot 33333) / 495$.

$590 \mathrm{CALL}$ BOIL(Z1,22,23,Z4,HF)

$600 \mathrm{RAL}=3.8197 /(\mathrm{DS} * \mathrm{DX} * \mathrm{HF}$ ) \& $\mathrm{RA} 2=3.8197 /(\mathrm{D} 4 * \mathrm{DX} * H B 2$ )

$610 \mathrm{GO} T \mathrm{~TB} 75$

62050 RHO =WATDPT $(P A, T A) \&$ CANN=RHO*V3

630 ENTH=WATH(PA,TA)

640 XMU $=W A T N U(T A) \& C P=W A T C P(T A) \& \quad X K=W A T E K(T A) \&$ PR $=X M U * C P / X K$

$650 R E=W W * D E /(A 3 * X M U)$ 
ErD

$02 / 13 / 73$

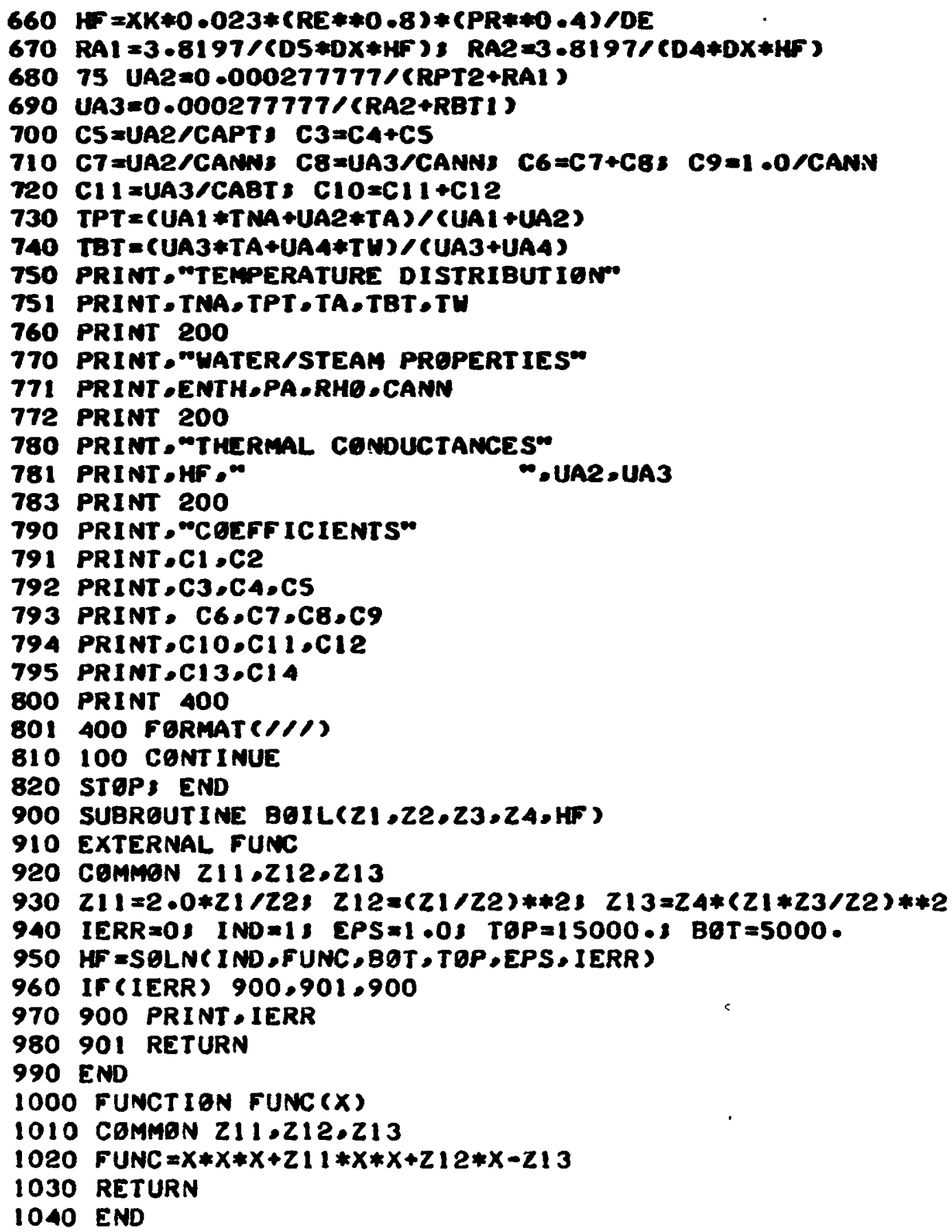


VOLUMES AND CAPACITIES
$2 \cdot 5489671 E-02$
$4 \cdot 1836971 E-01$
$1.07787985-02$
$7 \cdot 3774404 E-01$
$2.4198689[-03$
$1.6679188 E-01$
$2.9611423 E-03$
$1.9907759 E-01$
$8.5692873 E-03$
THERMAL RESISTANCES AND CENDUCTANCES
2.0650494E-04
$5.31810925-04$
$3 \cdot 7623057 E-01$
$6.8906281 E-04$
$2 \cdot 1586400 \Sigma-02 \quad 6 \cdot 9875536 E-04$
5.0972197E-04
$1.1302922 E-02$
$1.1491955 E-02$
$5 \cdot 1419465 E-04$
$2 \cdot 3136226 E-02$

TEMPERATURE DISTRIBUTION
B.3393433E+02
$7 \cdot 5909934 \varepsilon \backsim 02$
$6 \cdot 7646000 E+02$
$6 \cdot 5574304 E+02$
$6.34771492+02$

MATER/STEAM PRGPERTIES

$8 \cdot 4231775 E+02$

$2 \cdot 6449200 E+03$

$|\cdot 8285841 E+0|$

$1.5669662 E-01$

THERMAL CONDUCTANCES

I.2099915E+04

$3 \cdot 4069976 E-01$

$2 \cdot 3420553 E-02$

COEFFICIENTS

8.9927774E-01

9.7178736E-01

$2 \cdot 3237279 E+00$

$2.7913097 E-01$

$1 \cdot 1621713 E-01$
$7 \cdot 2921148 E-01$

$5.09974405-01$

$2 \cdot 1742636 E+00$

$1 \cdot 4041782 E-01$

$8 \cdot 3384572 E+00$
$4.6181296 E-01$

$1.4946431 E-01$

$1.3871314 E-01$

$6 \cdot 3817585 E+00$

TEMPERATURE DISTRIBUTIGN

8.0752571E+02 7.4595827E+02

$6 \cdot 7650900 E+02$

$6 \cdot 5590584 E+02$

$6.3504948 E+02$

WATER/STEAM PRBPERTIES

$8.1214240 E+02 \quad 2.6458630 E+03$

$2.14719835+01$

$\mid \cdot 8399959 E-01$

THLRMAL CONDUCTAMCES

I.06es30sL 404

$3.3353204 t-01$

$2 \cdot 3420553 E-02$

\section{CotrFicichts}

$8.9987774[-01$

$9.6207163 E-01$

$1.9399640 E+00$

$2.7913097 \mathrm{E}-01$

$1 \cdot 16217135-01$
$7.89211485-01$

5.0997440E-01

$1.8126781 \mathrm{t}+00$

$1.4041782 E-01$

$8 \cdot 3384572 E+00$
$4.5209723 E-01$

$1 \cdot 2728589 E-01$

$1 \cdot 3871314 E-01$
$5 \cdot 4347947 E+00$ 
TEMPERATURE DISTRIBUT IEN

$7.8577349 E+02$

$6.3532977 E+02$

MATER/STEAM PROPERTIES

$7.8356899 \Sigma+02 \quad 2.6467499 E+03$

THERMAL GENDUCTANCES

$9 \cdot 3342590 E+03$

\section{COEFFICIENTS}

$8.9927774 E-01$
$9 \cdot 5152871 E-01$
$1.5848212 E+00$
$2 \cdot 7913097 E-01$
$1 \cdot 1621713 E-01$

5.0997440E-01

$1.4785209 E+00$

$1 \cdot 40417825-01$

$8 \cdot 3384572 E+00$
$7 \cdot 2981148 E-01$

$6 \cdot 7656199 E+02$

$6 \cdot 5607178 E+02$

2.5710924E+01

$2 \cdot 20324295-01$

$3 \cdot 2575406 E-01$

$2 \cdot 3420553 E-02$

$4.4155431 E-01$

$1.0630037 E-01$

$1 \cdot 3871314 E-01$

$4.5387641 E+00$

$6 \cdot 7661450 E+02$

$6 \cdot 56234795402$

$7 \cdot 6782576 E+02$

$7 \cdot 2609218 \varepsilon+02$

$6 \cdot 3560462 E+02$

MATER/STEAM PROPERTIES

$7.6719107 E+02 \quad 2.6476015 E+03$

2•8997521E•0!

$2 \cdot 4848809 E-01$

THERMAL CONDUCTANCES

$8 \cdot 2017517 \varepsilon+03$

$3 \cdot 17344118-01$

$2 \cdot 3420553 E-02$

CogrFicients

8.9927774E-01 7.2921148E-01

9.4012916E-01 5.0997440E-01

$1.3713521 E+00 \quad 1.2770999 E+00$

2.7913097E-01 1.4041782E-01

$1.1621713 E-01$

$8 \cdot 3384572 E+00$

$4.3015476 E-01$

9.425221 $4 E-02$

$1.3871314 E-01$

$4.0243377 E+00$

$6.7665763 E+02$

$6 \cdot 5638508 E+02$

7.541 8859E+02

$7 \cdot 1921886 E+02$

$6 \cdot 3586339 E+02$

WATER/STEAM PROPERTIES

$7.5060365 E+02 \quad 2.6484208 E+03$

THERMAL CONDUCTANCES

$7.2906113[+03$

$3.0912365 E-01$

$2 \cdot 3420553 E-02$

COEFFICIENTS

8.9927774E-01

9.2898646E-0!

$7 \cdot 2921148 E-01$

$1 \cdot 1651713 E+00$

2.7913097L-01

$1-16217132-01$

5.0997440E-O1

1.08311 025 +00

I - 4041782 [ -01

B - $3384578[+00$
$4.1901206 E-01$

8.2061142E-08

I. 387131 a $[-01$
$3 \cdot 5038089 \varepsilon+00$ 
TEMPERATURE DISTRIBUTION

$\begin{array}{llll}7.4218890 E+02 & 7 \cdot 1502344 E+02 & 6.7297317 E+02 & 6.5456091 E+02 \\ 6.3610017 E+02\end{array} \quad$.

UATER/STEAM PREPERTIES

7.3574105E+02 2.6491708E+03 3.4980706E+01 2.9975972E-01

THERMAL CONDUCTANCES

$3 \cdot 3662839 E+03$

$2 \cdot 4305374 E-01 \quad 2 \cdot 3197155 E-02$

CeEFFICIENTS

8.9927774E-01 7.2921148E-01

8.3942977E-01 5.0997440E-01

$8.8821438 E-01 \quad 8 \cdot 1082855 E-01$

2.7779159E-01 $1.3907844 E-01$

$1 \cdot 1621713 E-01 \quad 8 \cdot 3384572 E+00$

$3 \cdot 29455385-01$

$7 \cdot 7385831 E-02 \quad 3 \cdot 3360053 E+00$

$1 \cdot 3871314 E-01$

TEMPERATURE DISTRIBUTION

$7.3144621 E+02$

$7 \cdot 0700649 E+08$

$6 \cdot 3630212 E+02$

$6 \cdot 6894836 E+02$

$6 \cdot 52639792+02$

WATER/STEAM PREPERTIES

$7.2698895 E+02 \quad 2.6499278[+03$

$3 \cdot 5680295 E \bullet 01$

$3.05754692-01$

THERMAL CENDUCTANCES

$3.3161418 E+03$

$2 \cdot 4160316 E-01 \quad 2 \cdot 3177497 E-02$

\section{COEPFICIENTS}

$$
\begin{aligned}
& 8 \cdot 9927774 E-01 \\
& 8 \cdot 3746354 E-01 \\
& 8 \cdot 6599050 E-01 \\
& 2 \cdot 7767373 E-01 \\
& 1 \cdot 1621713 E-01
\end{aligned}
$$

$7 \cdot 2921148 E-01$

$5.0997440 E-01$

$7 \cdot 9018627 \varepsilon-01$

$1 \cdot 3896058 \mathrm{E}-01$

$8 \cdot 3384572 E+00$

$$
\begin{aligned}
& 3 \cdot 2748914 E-01 \\
& 7 \cdot 5804222 E-02 \\
& 1 \cdot 3871314 E-01
\end{aligned} \quad 3 \cdot 2705958 E+00
$$

TEMPERATURE DISTRIBUTION

$7.2175945 E+02 \quad 6.9961565 E+02$

$6 \cdot 6493623 E+02$

$6 \cdot 5071385 E+02$

$6 \cdot 36477642+02$

WATER/sTEAM PROPCRTIES

7.1868003R+08 Q.4506905E+03

$3.6334065[+01$

$3.1135704[-01$

THERMAL CONDUCTANCES

$3.2696284[+03$

2.4023385E-01

$2 \cdot 3158753[-02$

\section{COEFFICIENTS}

$$
\begin{array}{ll}
8.9927774 E-01 & 7.2921148 E-01 \\
8.3560746 E-01 & 5.0997440 E-01 \\
8.4595037 E-01 & 7.7157031 E-01 \\
2.7756135 E-01 & 1.3884820 E-01 \\
1.1621713 E-01 & 8.3384572 E+00
\end{array}
$$

$3 \cdot 2563306 E-01$

$7.4380052 E-02$

$1 \cdot 3871314 E-01$

$3 \cdot 2117468 E+00$ 
TEMPERATURE DISTRIBUTIGN

$7.1296076 E+02$

$6.3662780 E+02$

MATER/STEAN PROPERTIES

$7.1079535 E+02 \quad 2.6514659 E+03$

THERMAL CONDUCTAMCES

$3.2875784 E+03$

CEEFFICIENTS

8.992777AE-01

$8.3390220 E-01$

8 -2821664E-01

8.7745713E-01

$1.1621713 E-01$

$7.2921148 E-01$

5.0997440E-01

T.5509641E-01

1 . 3874398E-01

$8 \cdot 3384572[+00$
$6.6103996 E+02$

$6 \cdot-4883523 E+02$

$3.6932339 \varepsilon+01$

$3 \cdot 1648382 E-01$

2.3897580E-01

2.3141370E-02

$3 \cdot 83987795-01$

$7.3120231 E-02$

$1.3871314 E-01$

$3 \cdot 1597192 E+00$

TEMPERATURE DISTRIBUTION

7.0491689E+02

$6.8646030 \Sigma+02$

$6.5726234 E+02$

$6.4700521 E+02$

$6.3675294 E+02$

WATER/STEAM PROPERTIES

$7.0346392 E+02 \quad 2.6522516[+03$

$3 \cdot 7481884 E+01$

$3.211930 A E-01$

THERMAL CONDUCTANCES

$3 \cdot 1895876 E+03$

$2 \cdot 3782237 E-01$

$2 \cdot 3125295 E-02$

COEFFICIENTS

$8.9927774 E-01$

$8 \cdot 323387$ AE -01

$8 \cdot 1243250 E-01$

$2.7736075 E-01$

$1 \cdot 1621713 E-01$
$7 \cdot 2921148 E-01$

5.0997440E-01

$7 \cdot 4043438 E-01$

$1.38647605-01$

$8 \cdot 3384572 E+00$
$3 \cdot 22364335-01$

$7 \cdot 1998119 E-02$

$1 \cdot 3871314 E-01$

$3 \cdot 1133925 E+00$

TEMPERATURE DISTRIBUTIEN

$6.9752110 E+02$

$6 \cdot 8056297 E+02$

$6 \cdot 3685036 E+02$

WATER/STEAM PROPERTIES

$6.9660304 E+02 \quad 2.6530483 E+03$

$3 \cdot 7986780 E+01$

$3 \cdot 2551963 E-01$

THERMAL CONDUCTANCES

$3.1553586 \pm+03$

$2 \cdot 3676917 E-01$

$2.31104995-02$

CoEPr ICIENTS

8.9927774E-01

$8.3091114 E-01$

7 -2921 148E-01

$7.9835330 \mathrm{E}-01$

2.7727804E-01

1 - 1621713E-01

5.0997440E-01

$7 \cdot 2735758 E-01$

$1.3855890 \mathrm{E}-01$

$8 \cdot 3384572 E+00$

$3.2093675 E-01$

7.09957ISE-02

$1 \cdot 3871314 E-01$
$3.0720113 E+00$ 
TEMPERATURE DISTRIBUTION
$6.9069578 E+02$
$6 \cdot 7504585 E+02$
$6 \cdot 5007578 E+02$
$6 \cdot 4349487 E+02$
$6.3692516 E+02$

WATER/STEAM PRGPERTIES

$$
6.9012553 E+02 \quad 2.6538333 E+03
$$

$3 \cdot 8455349 E+01$

$3 \cdot 29534945-01$

THERMAL COMDUCTANCES

$$
3 \cdot 1242877 E+03
$$

$2 \cdot 3580147 E-01$

$2 \cdot 3096805 E-02$

COEFTICIENTS

$$
\begin{array}{ll}
8 \cdot 9927774 E-01 & 7 \cdot 2921148 E-01 \\
8 \cdot 2959944 E-01 & 5.0997440 E-01 \\
7 \cdot 8564742 E-01 & 7.1555833 E-01 \\
2.7718994 E-01 & 1.3847679 E-01 \\
1.1621713 E-01 & 8.3384572 \varepsilon+00
\end{array}
$$

$3.1962504 E-01$

7.0089092E-02

$1.3871314 E-01$

$3.0345796 E+00$

TEMPERATURE DISTRIBUTION
$6 \cdot 8434808 E+02$
$6.6985397 E+02$
$6.3697670 E+02$
$6 \cdot 4664057 E+02$
$6 \cdot 4180319 E+02$

WATER/STEAM PROPERTIES

$$
6.8399948 E+02 \quad 2.6546336 E+03
$$

$3 \cdot 8891439 E+01$

$3 \cdot 3327191 E-01$

THERMAL COMDUCTAMCES

$3.0960724 E+03$

e.3491289E-01 2.3084145E-02

COEFF ICIENTS

8.992777AE-01

$7 \cdot 2921148 E-01$

$8 \cdot 2839499 \varepsilon-01$

5.0997440E-01

$7.7413376 E-01$

$7.0486856 E-01$

$2 \cdot 7711404 E-01$

$1.3840089 E-01$

$1 \cdot 1621713 E-01$

$8 \cdot 3384572 E+00$

$3 \cdot 1842059 E-01$

$6.9265199 E-02$

$1.3871314 E-01$

$3 \cdot 0005529 E+00$

TEMPERATURE DISTRIBUTIEN

$6.7844581 E+02$

$6 \cdot 3700498 E+02$

$6.6497079 E+02$

$6 \cdot 4331447 E+02$

$6 \cdot 4015536 E+02$

WATER/STEAM PROPERTIES

$6 \cdot 7820548 E+02$

$2 \cdot 6554361 E+03$

THERMAL CONDUCTAMCES

$3.0704701 E+03$

\section{CocrFICIENTS}

8.998777AK-01

$8.87290965-01$

$7.6367698 E-01$

2.7704403E-01

$1.1621713 E-01$

$7.8921148[-01$

5.0997440E-01

6.9516256E-01

$1.3833089 E-01$

$8 \cdot 33845725+00$
$3.17316565-01$

$6.8514423 E-02$

$1 \cdot 3871314 E-01$
$2 \cdot 9695314 E+00$ 
TEMPERATURE DISTRIBUTION

$6.7293223 E+02 \quad 6.60369246+02$

$6 \cdot 3702002 E+02$

WATER/STEAM PRGPERTIES

$6.7274919 E+02 \quad 2.6562442 E+03$

THERMAL CENDUCTANCES

$3 \cdot 0473477 E+03$

CoEFF ICIENTS

8.9927774E-01

8.2628463E-01

$7 \cdot 5420046 E-01$

$2 \cdot 7697986 E-01$

$1 \cdot 1621713 E-01$

$7.2921148 E-01$

$5.0997440 E-01$

$6.86368995-01$

$1.38266725-01$

$8 \cdot 3384572 E+00$
$6.4011444 E+08$

$6 \cdot 3856474 E+08$

$3 \cdot 9674970 \varepsilon+01$

$3 \cdot 3998621 E-01$

$2 \cdot 3335599 E-01$

$2.3061766 E-02$

$3.1631023 E-01$

$6 \cdot 7831473 E-02$

1.387131AE-01

$2 \cdot 9412957 E+00$

PRgGRAM STgP AT 820 


\section{COMBUSTION ENGINEERING NUCLEAR POWER DEPARTMENT}

Summany

$\dot{\zeta}_{229}=-(.899278) T_{209}+(.899278) T_{244}+(.729211) \dot{\omega}_{N_{0}} T_{200}-(.729211) \dot{\omega}_{\text {ma }} T_{224}$

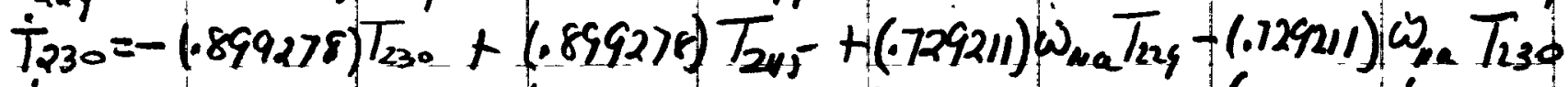

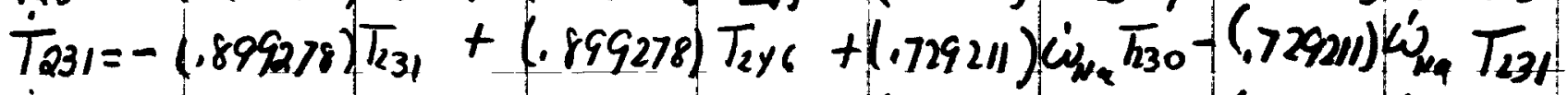

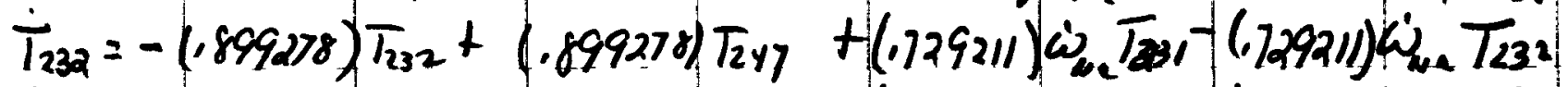

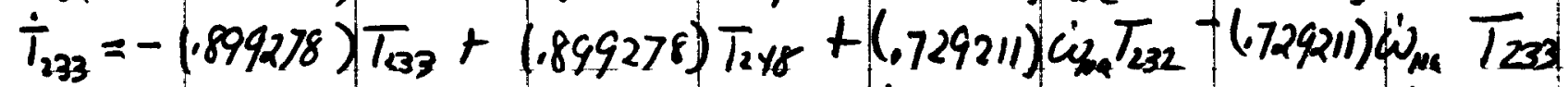

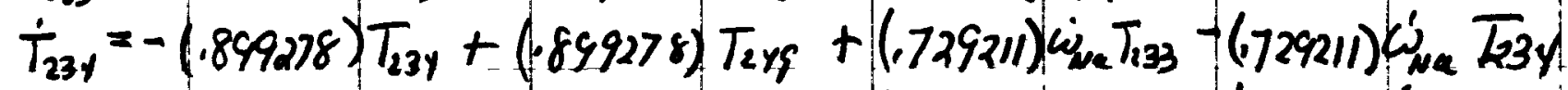

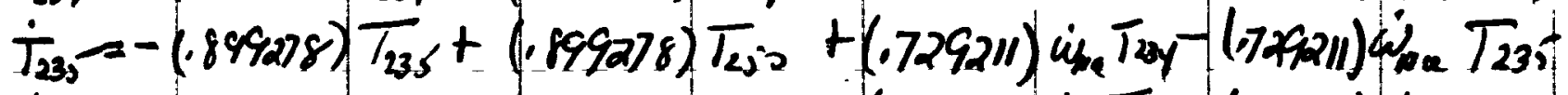

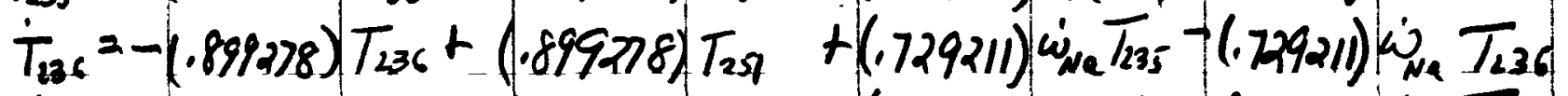

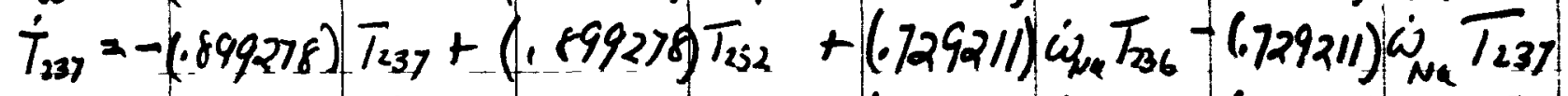

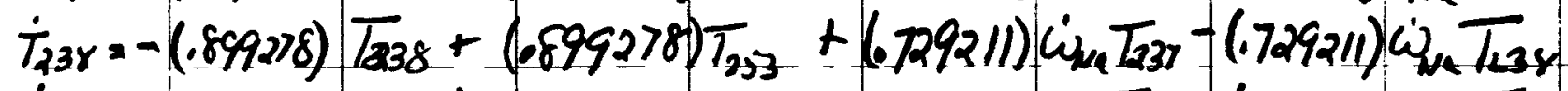

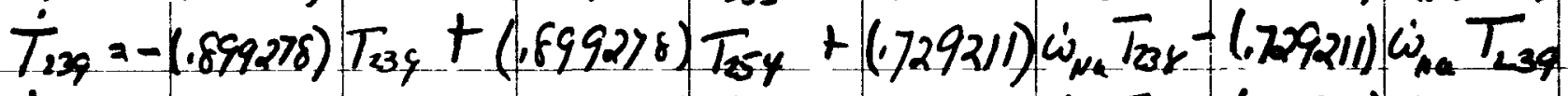

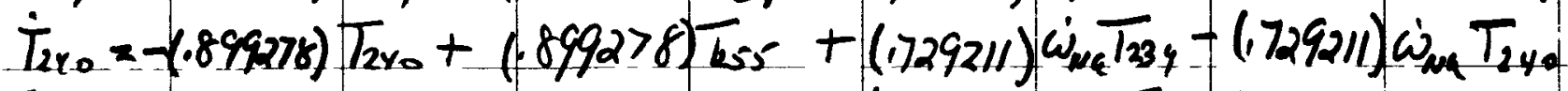

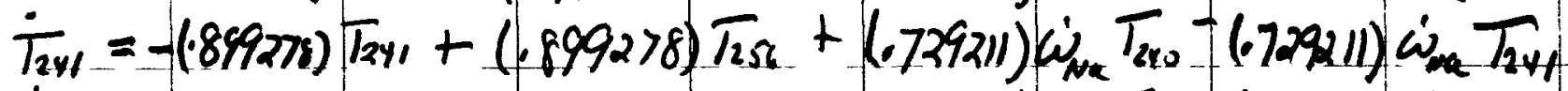

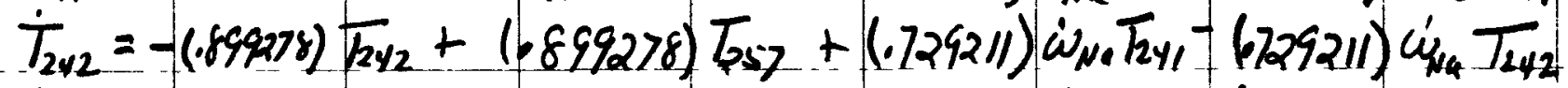

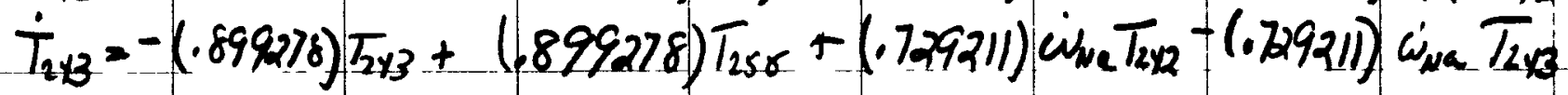

$\dot{T}_{244}=-(.901787) T_{24 y}+(.509974) T_{229}+(.461813) T_{386}$ $\bar{T}_{245}=-(.962072) T_{245}+(.50997 y) T_{230}+(.458097) T_{1387}$ $T_{246}=-(.985529) T_{246}+(.509974) T_{331}+(4481051) T_{138}$

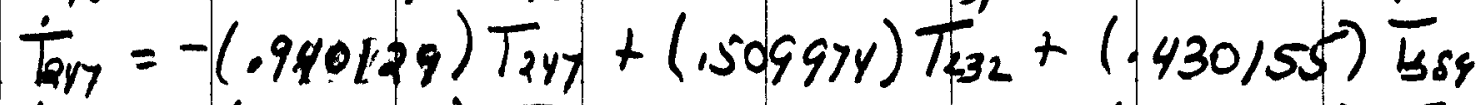
$T_{2 y z}=-(.928906) T_{12 y 8}+(.509948) T_{233}+(.419012) T_{390}$ $T_{249}=-(.839430) T_{2 y 9}+(.509974) T_{237}+(.329455) T_{391}$

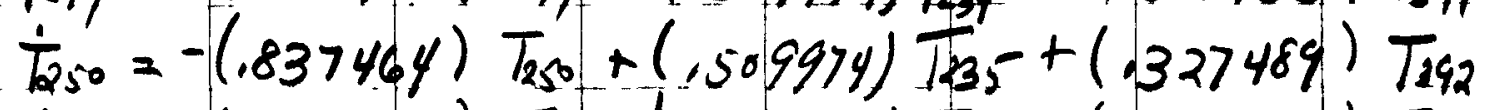
$T_{251}=-(.835697) T_{591}+(.509971) T_{336}+(.325633) T_{393}$ 
COMBUSTION ENGINEERING NUCLEAR POWER DEPARTMENT

$$
\begin{aligned}
& T_{252}=-(.033902) T_{252}+(.509974) T_{237}+(.323928) T_{344} \\
& T_{253}=-(.832338) T_{253}+(.509514) T_{35}+(.322364) T_{395} \\
& T_{25 y}=-(.8309 y 1) T_{25 y}+(.509974) T_{259}+(.320 .937) T_{396} \\
& \dot{T}_{205}=-(.829599) T_{255}+(1509974) T_{\text {Tern }}+(.319625) T_{394} \\
& \dot{T}_{256}=-(.828395) T_{256}+(.069974) T_{241}+(.318420) T_{358} \\
& \dot{T}_{257}=-1(.827291) T_{25}+(.509974) T_{242}+(.317317) T_{359} \\
& \dot{T}_{258}=-(.826285) T_{55}+(.509974) T_{148}+(.316310) T_{400} \\
& h_{759}=-\left(2.323 T_{3}\right) T_{386}+(2.17436) T_{244}+(.149464) T_{274} \\
& +(6.38176) \dot{\omega}_{n} h_{200}-(6.38 / 76) \dot{\omega}_{n} h_{259} \\
& \dot{h}_{260}=-(1.93996) T_{387}+(1.81268) T_{245}+(.127286) T_{755} \\
& +(5.34379) \dot{s}_{n} h_{261}=(5.34379) \cos h_{26} \\
& \bar{h}_{261}=-(1.58482) \bar{T}_{388}+(1.47852) \bar{h}_{246}+(.106300) T_{276} \\
& +(4,53376) \dot{\omega}_{r} h_{262}-(4.53876) \omega_{r} h_{261} \\
& h_{262}=-(1.37135) T_{364}+(1.27710) T_{47}+(0992522) T_{277} \\
& +(7.02934) \dot{\omega}_{n} h_{263}-(7.02434) \dot{\omega}_{n} h_{262} \\
& \bar{h}_{263}=-(1.16517) T_{390}+(1.08311) T_{246}+(.0820611) T_{278} \\
& r(3.5038) \dot{\omega}_{n} h_{26 y}-(3.50381) \dot{\omega}_{n} h_{263} \\
& h_{264}=-(.888244) T_{341}+(.810829) T_{249}+(.0773858) T_{279} \\
& +(3.33601) \omega_{n} h_{265}-(3.33601) \dot{\omega}_{n} h_{26 y} \\
& h_{265}^{\prime}=-(.865991) T_{392}+(.790186) T_{250}+(10758042) T_{280} \\
& +(3.27060) \dot{w}_{n} h_{26 s}-(3.27060) \dot{w}_{n} h_{26,} \\
& \dot{h}_{266}=-(.845950) T_{283}+(.771570) T_{251}+(.0743801) T_{281} \\
& +(3.21175) \omega_{n} h_{267}-(3.21175) \dot{c}_{n} h_{266} \\
& h_{267}=-(.828217) T_{36 y}+(.755096) \bar{F}_{252}+(.0731202) \bar{T}_{222} \\
& +(3.15972) \dot{\omega}_{n} h_{268}-(3.15972) \dot{\omega}_{n} h_{267}
\end{aligned}
$$


COMBUSTION ENGINEERING NUCLEAR POWER DEPARTMENT

$$
\begin{aligned}
& \dot{h}_{268}=-(.812433) T_{398}+(.740434) T_{253}+(.0719981) T_{2 \times 3} \\
& +(3.11339) \dot{c o n}_{n} h_{269}-(3.1 / 339) \dot{\omega}_{n} h_{26} \\
& \dot{h}_{269}=-(.798353) T_{5916}+(.727358) T_{254}+(.0709951) T_{284} \\
& +(30072 \phi) \dot{\omega}_{r} h_{270}-(307201) \omega_{r} h_{269} \\
& h_{270}=-(.785647) T_{317}+(.715559) T_{255}+(.0700891) T_{245} \\
& +(3.03458) \omega_{r} h_{271}-(3.03458) \omega_{r} h_{2}>0 \\
& \dot{h}_{271}=-(.774134) T_{398}+(.764869) T_{256}+(.0692652) T_{2,46} \\
& +(3,00055) \dot{\omega}_{n} h_{272}-(3,00055) \dot{w}_{n} h_{271} \\
& h_{272}=-(.763677) T_{399}+(.695 / 63) T_{257}+(.0685 / 44) T_{257} \\
& \pm(2.96953) \dot{\omega}_{r} h_{273}-(2.9695 \beta) \dot{\omega}_{r} h_{272} \\
& h_{273}=-(.754200) T_{400}+(.686369) T_{258}+(.06783 / 5) T_{128} \\
& +(2.94 / 30) \ddot{\omega}_{n} h_{36 t}-(2.94 / 30) w_{n} h_{2273} \\
& \dot{\omega}_{r}=\text { Total water flow per Fuse }=\bar{\omega}_{\text {gl }} \\
& T_{274}=-(.279 / 31) T_{274}+(.140418) T_{386}+(.138713) T_{289} \\
& \dot{T}_{775}=-(.279131) T_{275}+(.140418) T_{377}+(.138713) T_{280} \\
& \dot{\bar{T}}_{276}=-(279131) T_{216}+(.140418) T_{388}+(.138713) T_{241} \\
& \dot{T}_{277}=-(.279131) T_{277}+(.1404 / 8) T_{359}+(.1387 / 3) T_{292} \\
& \dot{T}_{278}=-(.279 / 31) T_{278}+(.1409 / 8) T_{390}+(.1387 / 3) T_{293} \\
& \dot{J}_{279}=-(.277791) T_{779}+(.139078) T_{391}+(.138713) T_{274} \\
& \dot{T}_{280}=-(.277674) T_{280}+(.1389 .61) T_{392}+(.1387 .3) T_{295} \\
& t_{180}=-(.277561) T_{281}+(.138848) T_{393}+(.138713) T_{296} \\
& \left.\dot{\tau}_{82}=-(.277457) T_{282}+(.138744) T_{284}+1.138713\right) T_{297} \\
& \dot{T}_{233}=-(.277361) T_{253}+(.138748) T_{395}+(.138713) T_{258} \\
& T_{284}=-(.277272) T_{284}+(.138559) T_{396}+(-B 8713) T_{299} \\
& T_{285}=-(.277190) T_{285}+(.138477) T_{397}+(.138713) T_{300} \\
& \dot{T}_{286}=-(.277114) T_{286}+(.138401) T_{348}+(.138713) T_{301}
\end{aligned}
$$




\section{COMBUSTION ENGINEERING NUCLEAR POWER DEPARTMFNT}

$\dot{T}_{267}=-(.277044) T_{287}+(.138331) T_{399}+(.1387 / 3) T_{392}$ $T_{286}=-(.276980) T_{288}+(.138266) T_{400}+(.1387 / 3) T_{303}$

$\dot{T}_{289}=-(.116217) T_{28}+(.116217) \bar{t}_{274}+(8.33846) \dot{\omega}_{r} T_{209}-(8.33846) \dot{q}_{1} T_{289}$ $T_{240}=-(.116217) T_{240}+(.116217) T_{275}+(6.33846) \omega_{r} T_{249}-(8.33846) \omega_{n} T_{k 80}$ $T_{29}=-(.116217) \bar{T}_{1291}+(.1 / 6217) \bar{T}_{2} 76+(8.3384 c) \omega_{n} T_{190}-(8.33846) \omega_{n} T_{291}$ $\dot{T}_{252}=-(1 / / 6217) T_{292}+(1 / / 6217) T_{277}+(8.33840) \dot{\omega}_{n} T_{241}-(8.33816) \dot{\omega}_{n} T_{122}$ $\bar{T}_{293}=-(1.116217) T_{293}+(.116217) T_{278}+(8.338 \times 6) \dot{\omega}_{r} T_{242}-(8.33846) \dot{\omega}_{n} T_{293}$

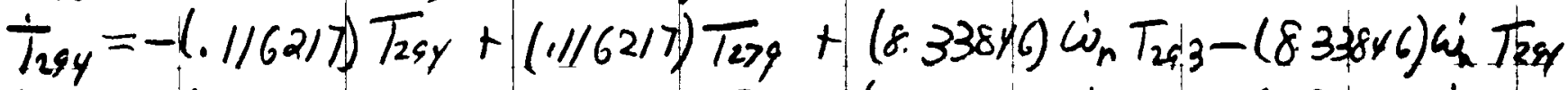

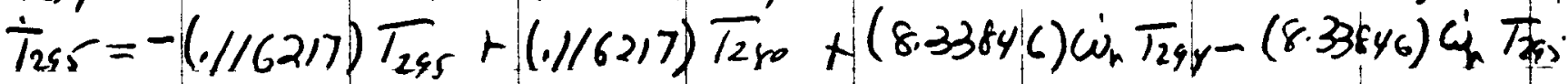
$T_{296}=-(1 / 16217) T_{29 c}+(11 / 6217) T_{281}+(8.33846) \dot{c}_{h} T_{295}-(8.33846) \dot{c}_{h} T_{296}$ $t_{297}=-(.1 / 6217) T_{247}+(.116217) T_{282}+\left(8.33840 \omega_{n} T_{296}(833546) \omega_{n} T_{37}\right.$ $\bar{h}_{28}=-(.116217) T_{298}+(.116217) T_{213}+(8.33846) \omega_{r} T_{297}-\left(8338400 \omega_{n}^{\prime} T_{9 r}\right.$ $\dot{T}_{299}=-(.1 / 6217) T_{299}+(.1 / 6217) T_{284}+(8.33846) \omega_{n} T_{295}-(833646) \omega_{n} T_{154}$ $\bar{T}_{1300}=-(.116217) T_{300}+(.1 / 6277) T_{285}+(8.33646) \dot{\omega}_{n} T_{299}-(8,33016) \omega_{n} T_{300}$ $T_{301}=-(.1 / 627) T_{301}+(.1 / 62 / 7) T_{286}+(8.33846) i_{n} T_{300}-(8.33846) c_{n}^{\prime} T_{30}$ $\dot{T}_{302}=-(1 / 6217) T_{302}+(.116217) T_{657}+(8.33846)$ in $_{301} T_{301}-(8.33846) \omega_{k} T_{302}$ $T_{303}=-(.1 / 6217) T_{1303}+(.116217) T_{288}+(8.33846) \dot{\omega}_{n} T_{302}=(8.33846) \dot{\omega}_{n} T_{303}$

$$
\dot{\omega}_{p}=\text { total water flow pes tube }=\dot{\omega}_{\delta y}
$$


COMBUSTION ENGINEERING NUCLEAR POWER DEPARTMENT

The last element of the downcomer represents temperature and is connected to the fist annular node which represents enthalpy. An auxclloy node is associated with the last downcomer node which is the enthalpy corresponding to the douncemen temperature. These two pods ane connected by a flow equation"; this equation is an algebraic equation whose constants ore spercaluged to an enthalpytemperature cause fit at a given picssake.

$$
\begin{aligned}
& \dot{\omega}=\epsilon_{2} z+\epsilon_{3} z^{2}+\frac{\epsilon_{4}}{z}+\frac{\epsilon_{5}}{z^{2}} \\
& +\epsilon_{6}+\epsilon_{7} z^{3}+\epsilon_{8} z^{4}+\epsilon_{9} z^{5}+\epsilon_{10} z^{6} \\
& k=e_{1}<0.0 \quad \Longrightarrow \quad z=F_{|k|}=\text { modal value }
\end{aligned}
$$

the value $C_{1}$ indicates which node temperature $\left(F_{i k 1}\right)$ is to be used.

The selected pressure is 2645 which is the pressure of the steam/water mixture at the exit of the main heat transfer region of the evaporator and very nearly the messure in the ovum. The effect of the higher pressure in the douncemer tubes of the evaporator will be very small since the properties of compressed water are a weak function of pressure.

the values of enthalpy-tempartine were obtained from the GE Mask II steam tables (curve fits to gleeman and keys tables). GE Mack II program POLFRT was then used to obtain the coefficients for a 
COMBUSTION ENGINEERING NUCLEAR POWER DEPARTMENT

polynomial curve fit.

$$
\begin{gathered}
h=-(7371.36)+(38.792) T-\left(6.50377 \times 10^{-2}\right) T^{2} \\
+\left(3.75985 \times 10^{-5}\right) T^{3}
\end{gathered}
$$

valid for $T \leqslant$ TS.

Consequently

$$
\begin{aligned}
& \epsilon_{1}=38.792 \\
& \epsilon_{3}=-6.50377 \times 10^{-2} \\
& \epsilon_{y}=0 \\
& \epsilon_{5}=0 \\
& \epsilon_{6}=-7371.36 \\
& \epsilon_{7}=3.75985 \times 10^{-5} \\
& \epsilon_{8}=0 \\
& \epsilon_{8}=0 \\
& \epsilon_{10}=0 .
\end{aligned}
$$

In CEROS format the h node is equated to the product of the flow equation with the unity node.

$$
h_{361}=(1.0) \omega_{50} F_{369} ; \epsilon_{1}=-303 .
$$

If downemen boding were to occur this curve fit must be revised for that particular potion of the transient. 
COMBUSTION ENGINEERING NUCLEAR POWER DEPARTMENT

the modes representing the temperature of the withes or steasifwator multure in the a annuli are connected to the consespondng enthalpy modes. by a "Flow equation". This equation is an algebras. equation whose constants are specialized to ce temperature tenthuppy curve fit at a ger en pressure.

$$
\begin{aligned}
& \dot{\omega}==e_{2} Z+\epsilon_{3} \mid z^{2}+\frac{\epsilon_{4}}{z}+\frac{\epsilon_{5}}{z^{2}} \\
&+\epsilon_{0}+\epsilon_{7} z^{3}+\epsilon_{8} z^{4}+\epsilon_{9} z^{5}+e_{10} z^{6} \\
& k=\epsilon_{1}<0.0 \Rightarrow z=F_{|k|} \mid=\text { nodal value }
\end{aligned}
$$

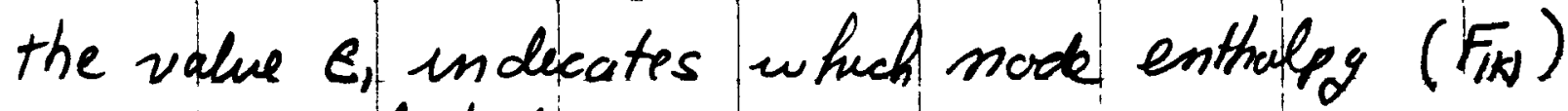
is to be selected.

The selected pressure is 2645 psia which is: the pressure of the steam/ water mixture at the exit of the main heat transfer region. All temperature -enthalpy conespondance is at the pressure This causes some enacauacres for the water in the ecorsomigh regin which is af chafes press ene. This effect is small since properties of compressed. water one a very weak function of pressure.

The values of temperature - enthalpy were ob tamed from the GE Mask II steam tables (curve fits to Keenan 5 keas tables). GE MARK II program POLFIT was then used to obtain the coeffuerents for a polynomial curve fit. 
COMBUSTION ENGINEERING NUCLEAR POWER DEPARTMENT

$$
\begin{aligned}
T= & (-1083.24)+(4.9272) h+\left(-3.50727 \times 10^{-3}\right) h^{2} \\
& +\left(-7.16029 \times 10^{-7}\right) h^{3}+\left(1.05166 \times 10^{-9}\right) h^{4}
\end{aligned}
$$

Consequently for all curve fits

$$
\begin{aligned}
& \epsilon_{2}=4.9272 \\
& \epsilon_{3}=-3.50727 \times 10^{-3} \\
& \epsilon_{4}=0 \\
& \varepsilon_{5}=0 \\
& \epsilon_{6}=-1083.24 \\
& \epsilon_{7}=-7.16029 \times 10^{-7} \\
& \epsilon_{8}=1.05166 \times 10^{-9} \\
& \epsilon_{9}=0 \\
& \epsilon_{10}=0
\end{aligned}
$$

In the CEROS format the Trade is equated to the pos duct of the posteculas flow equation with the unity NoDe $\left(\dot{F}_{369}\right)$. 
COMBUSTION ENGINEERING NUCLEAR POWER DEPARTMENT

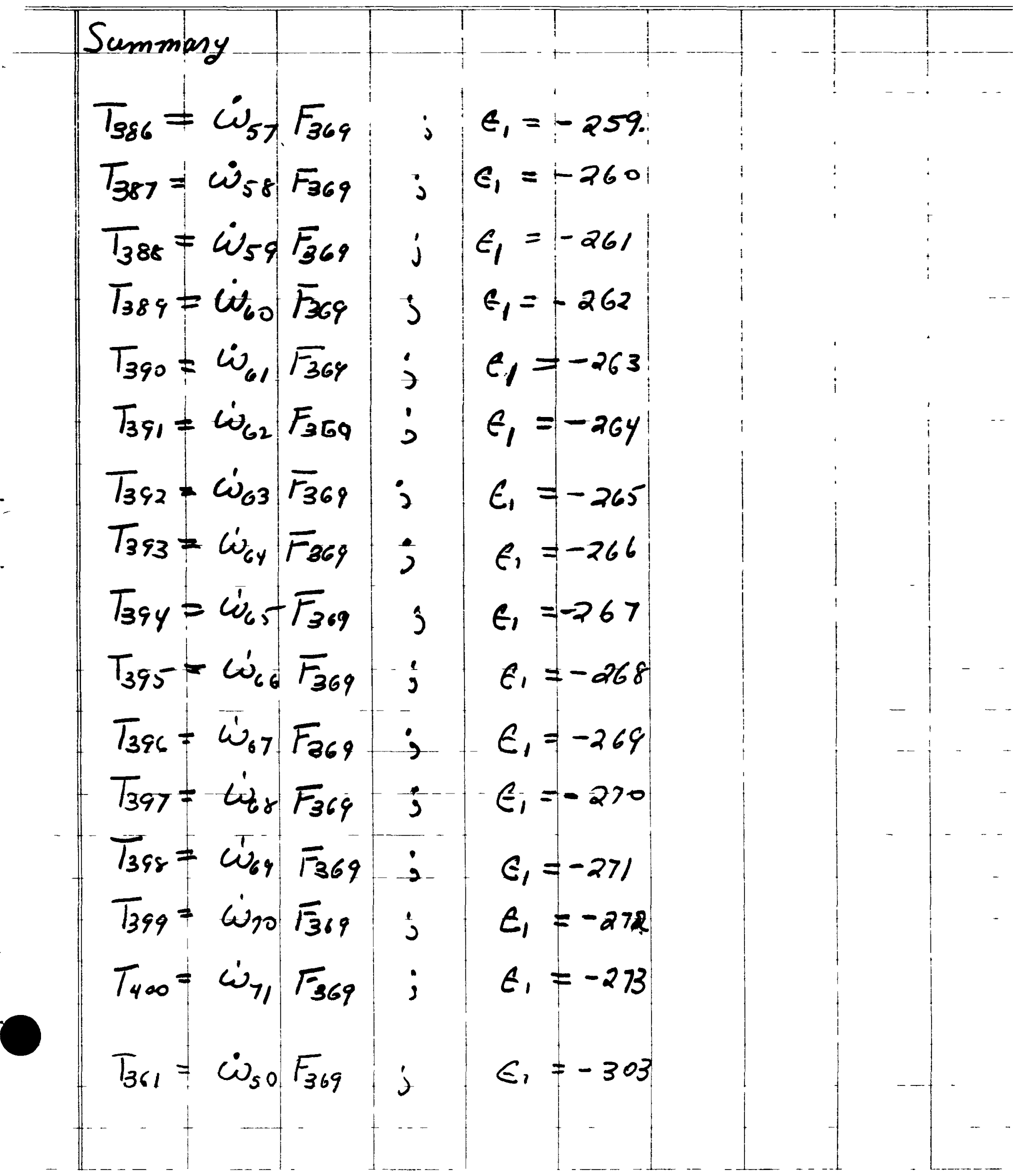


COMBUSTION ENGINEERING

NUCLEAR POWER DEPARTMENT

II Sodium In let and Outlet Pogroms.

Energy balances for the inlet and outlet plenums: The regions ape assumed to be, bounded by adiabatic walks.

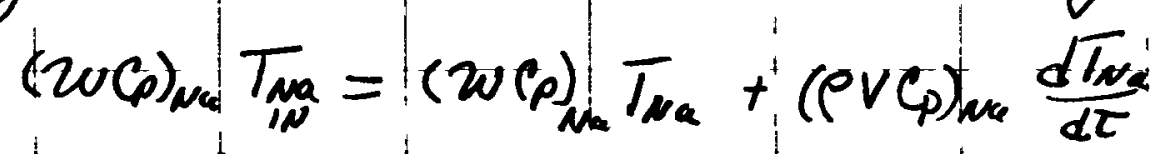

In standard format

$$
\dot{T}_{N G}=\left(\frac{w}{\rho v}\right)_{N a} T_{N G}-\left(\frac{w}{\rho v}\right)_{N a} T_{N d}
$$

Energy balances for the inlet and outlet nozzles:

$$
\begin{aligned}
& -(U A)\left[T_{\text {No }}-T_{\text {Na }}\right]=(\rho V C)_{\text {NOE }}\left|\frac{d T_{\text {wo }} \mid}{d t}\right|
\end{aligned}
$$

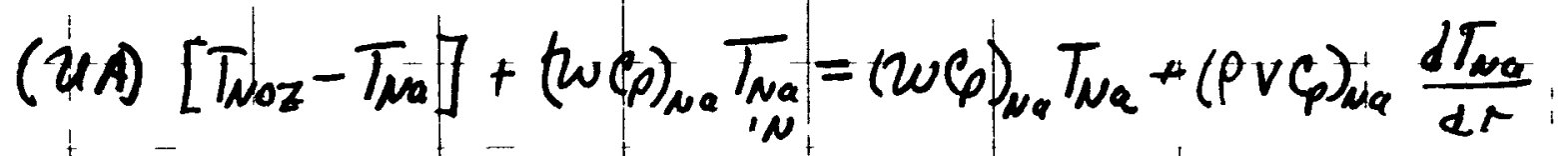

$\bar{I}_{n}$ stand and format

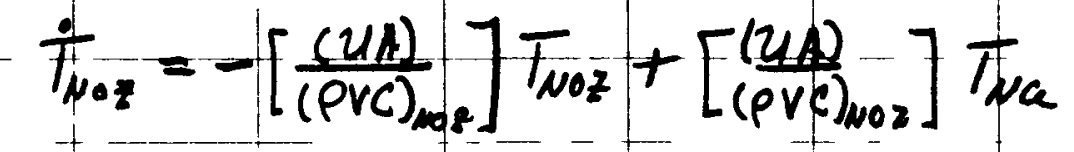

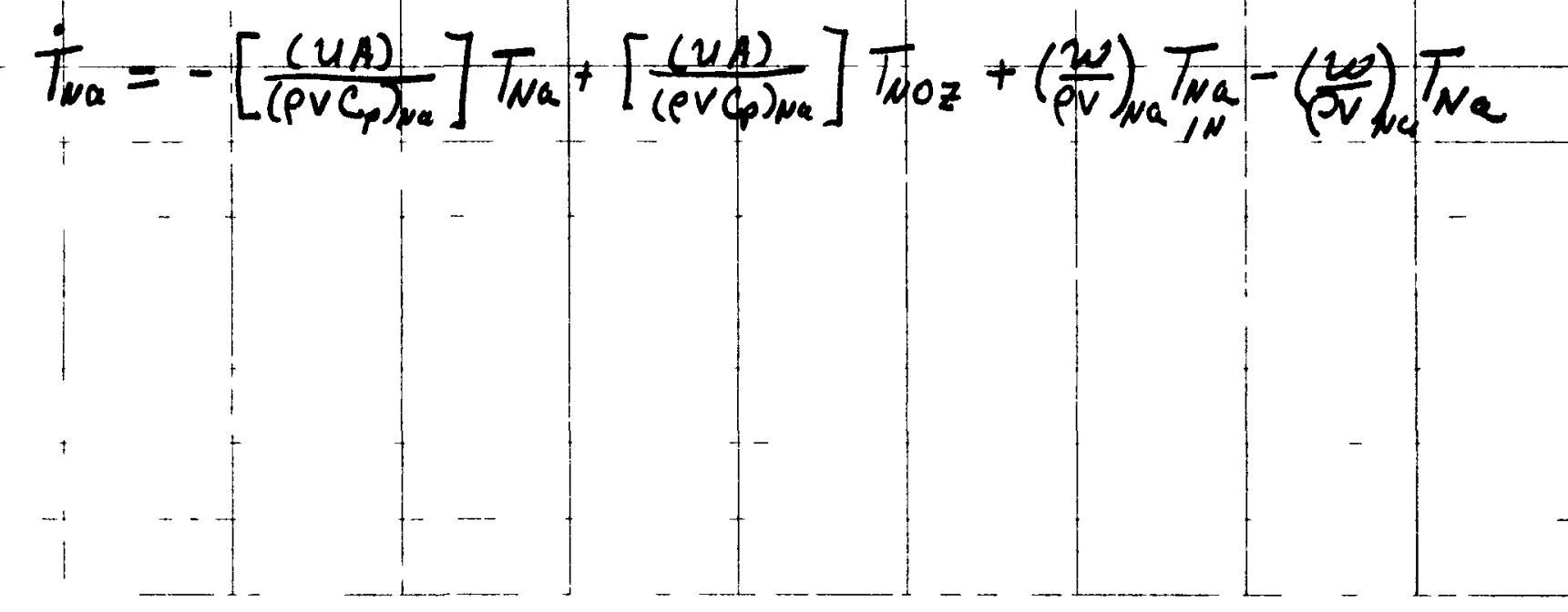


COMBUSTION ENGINEERING NUCLEAR POWER DEPARTMENT

Sodium In let Regin

$$
W_{\text {Na }}=4.353 \times 10^{6} \mathrm{lbm} / \mathrm{h}=1209 \mathrm{lbm} / \mathrm{sec} \quad(\text { Design })+
$$

Properties are evaluated at temperature for full load

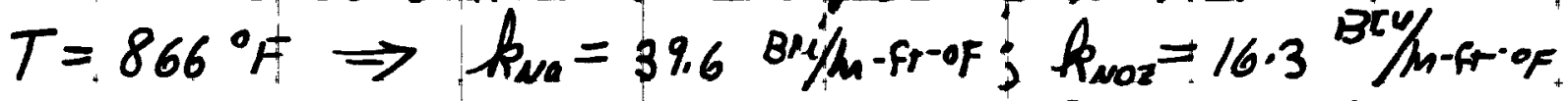

$$
\begin{aligned}
& \rho_{\mathrm{Na}}=5.2 .5 \mathrm{lbm} / \mathrm{fs}^{3} ; \rho_{\text {ez }}=478 \mathrm{lbm} / \mathrm{kg}, 3
\end{aligned}
$$

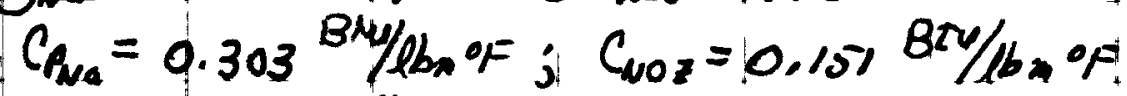

$$
\begin{aligned}
& \mu_{N a}=0.605 \mathrm{pbm} / \mathrm{sr}-\mathrm{hr} \text {. }
\end{aligned}
$$

Heat transfer coefficient

$$
\begin{aligned}
& \text { 1) } G_{N a}=\frac{w_{N a}}{A}=\frac{\left(4.353 \times 10^{6}\right) / 2}{\frac{\pi}{4}(1)^{2}}=2.771 \times 10^{6} \frac{\mathrm{lbm}}{\mathrm{A}^{2} \mathrm{~m}} \\
& V_{N u}=\frac{G_{N a}}{S_{N e}}=\frac{(2.771 \times 109 / 3600}{52.5}=14.67 \mathrm{Fr} / \mathrm{sec} \\
& P_{e}=\frac{G D}{\mu}=\frac{\left(2.771 \times 10^{9}\right)(1)}{.605}=4.581 \times 10^{6} \\
& P_{e}=P_{e} \frac{\mu c_{e}}{k}=\left(4.581 \times 10^{6}\right)^{-605(.303)} \frac{39.6}{31204} \\
& h_{N a}=\frac{k_{N a}}{D}\left[51.025 P_{e}^{.8}\right]=\frac{39.6}{(1)}\left[5.0+.025(21204)^{.8}\right]
\end{aligned}
$$

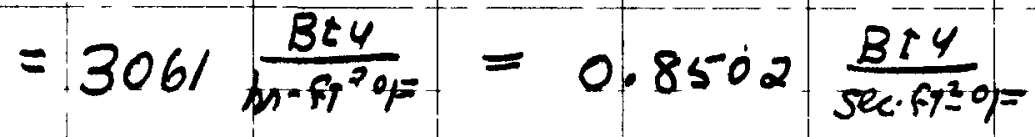

Entrance affects on the heat transfer coefficient are neglected.

p) The average diameter for the nozzle is computed at the thickest section. 


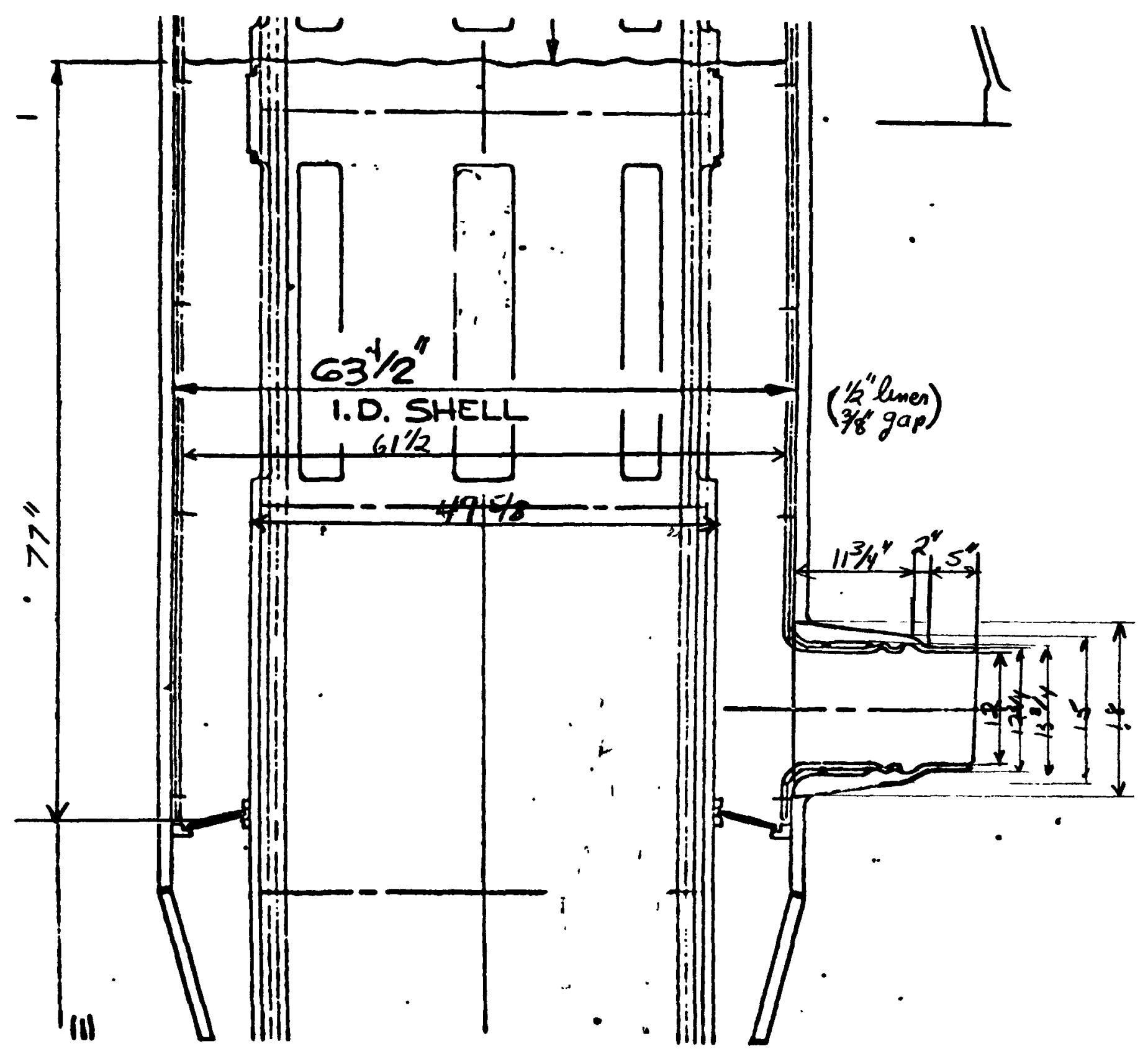

SODIUM InLET PLENUM

$$
V_{N G}=\frac{\pi}{4}\left(631^{\prime} 2^{2}-49^{\prime} \dot{3} / \mathrm{s}^{2}\right)(77)=94900 \mathrm{mn}^{3}=54.9 \mathrm{ft}^{3}
$$

SODIUM InLET NOZzLE

$$
\begin{aligned}
& V_{N G}=\frac{\pi}{4}(12)^{2}\left(18^{3} / 4\right)=2120 \mathrm{~m}^{3}=1.23 \mathrm{ft}^{3} \\
& V_{\text {NO }}=\frac{\pi}{4}\left(12^{3} y^{2}-1^{2}\right)(5)+\frac{\pi(2)}{12}\left\{\left(15^{2}+15\left(L^{2} / 1\right)+123 y^{2}\right)-\left(\left.133^{2}\right|^{2}+\left(13^{2} / 1\right) 12+12^{2}\right)\right\} \\
& +\left\{\frac{\pi\left(11^{3 / 1}\right)}{12}\left(18^{2}+18(13)+15^{2}\right)-\frac{\pi}{4}\left(13^{3 / 4}\right)^{2} \cdot(113 / 4)\right\} \\
& =890 \mathrm{~ms}^{3}=0.515 \mathrm{ft}^{3}
\end{aligned}
$$


COMBUSTION ENGINEERING NUCLEAR POWER DEPARTMENT

$\quad-\bar{D}=\left(\frac{D^{2}+D_{0}^{2}}{2}\right)^{1 / 2}=\left(\frac{133^{2}-18^{2}}{2}\right)^{1 / 2}=16.02^{12}$

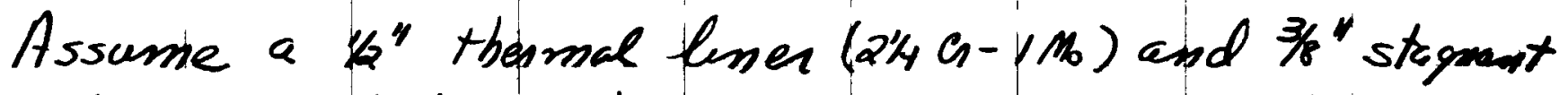
sodium gap between the Flown g sodium and the nozzle for the entire length of the inlet niggle. In addition, the resistance for the thickest section of the nozzle is assumed to chasacteszed the maze for its entire length.

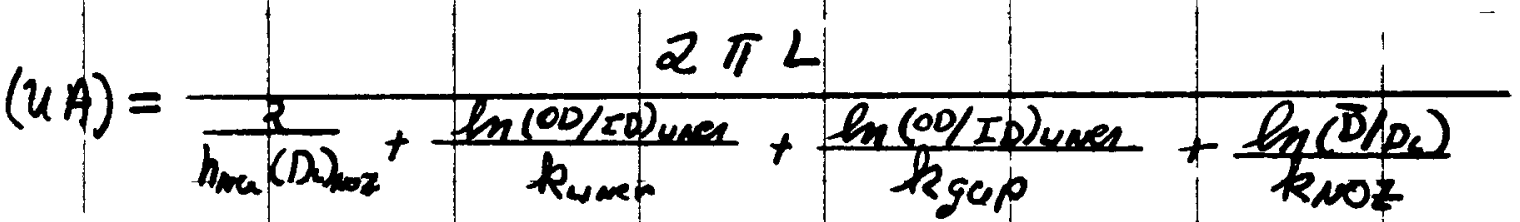

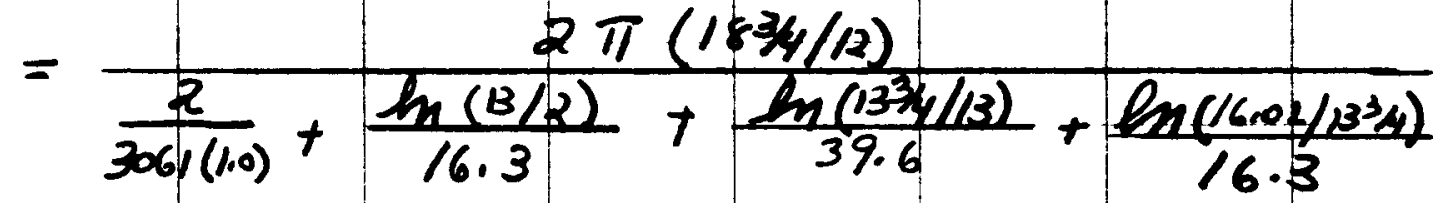

$$
\begin{aligned}
& =6003 \frac{B 24}{m \circ F}=0.1667 \frac{B L u}{\sec ^{\circ} \mathrm{F}}
\end{aligned}
$$

Volumes

$$
\begin{aligned}
& \left(v_{N_{a}}\right)_{10 z}=1.23 \mathrm{ft}^{3} \\
& \left(P_{\text {meth }}\right)_{\text {wot }}=0.515 \mathrm{Ft}^{3} \\
& \text { (in plenum }=54.9 \mathrm{Ft}^{3}
\end{aligned}
$$


COMBUSTION ENGINEERING

NUCLEAR POWER DEPARTMENT

Coeffuents

$$
\begin{aligned}
& \left(\frac{1}{\rho V}\right)_{\text {Demam }}=\frac{1}{(52.5) 54.9}=0.0003470 \mathrm{ebm}^{-1} \\
& {\left[\frac{4 A}{(\rho V C)_{00}}\right]=\frac{2(0.1667)}{478[2(0.5150)](1011)}=0.004485 \mathrm{sec}^{-1}}
\end{aligned}
$$

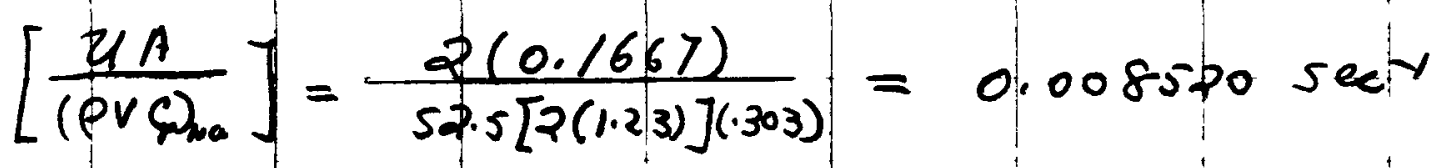

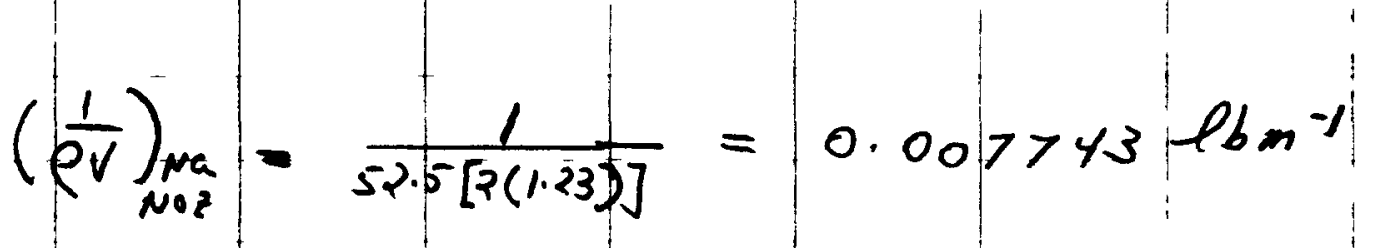


COMBUSTION ENGINEERING NUCLEAR POWER DEPARTMENT

Sodium Outlet Region

$w_{\text {Na }}=4.353 \times 10^{6} \mathrm{ebm} / \mathrm{h}=1209 \mathrm{ebm} / \mathrm{sec}$ (Design)

Properties are evaluated at temperature for full load

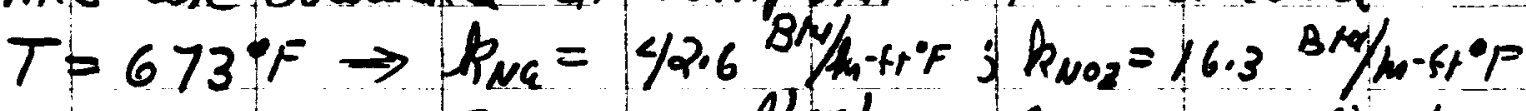

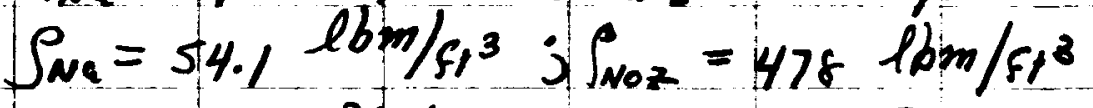

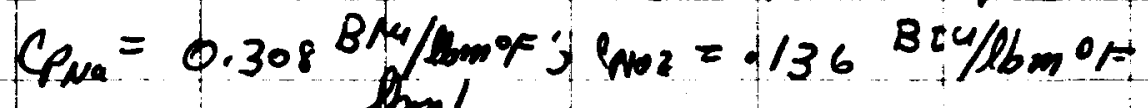

$$
\begin{aligned}
& \mu_{w 4}=0.736 \mathrm{pm} / \mathrm{fs} \mathrm{he}_{1}
\end{aligned}
$$

Heat Transfer coefperent

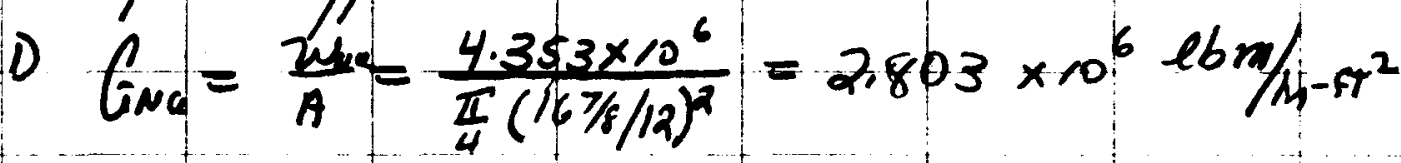

$$
\begin{aligned}
& V_{N a}=\frac{G_{m a}}{\rho_{w a}}=\frac{2803 \times 10^{6} / 3600}{54.1}=14.39 \mathrm{st} / \mathrm{sec} \\
& R_{e}=\frac{G D}{\mu}=\frac{\left(2.803 \times 10^{6}\right)\left(\frac{167 / 8}{12}\right)}{.736}=5.355 \times 10^{6} \\
& P_{e}=\operatorname{Re}_{e} \frac{4 C_{p}}{k}=\left(5.355 \times 10^{6}\right) \cdot \frac{.736(.308)}{42.6}=28500 \\
& h_{\mu_{4}}=\frac{\hbar_{m_{1}}}{D}\left[5.0+.025 P_{e}^{.8}\right]=\frac{42.6}{167 / 12}\left[5+.025(28500)^{8}\right] \\
& =2925 \frac{B \times 4}{h n f^{2} t^{2} F}=0.8126 \frac{B t 4}{\mathrm{sec}-f^{2}}=0 \%
\end{aligned}
$$

Entrance affects on the heat transfer coepferent we neglected.

2) The average diameter for the nozzle es computed at the thickest section. 


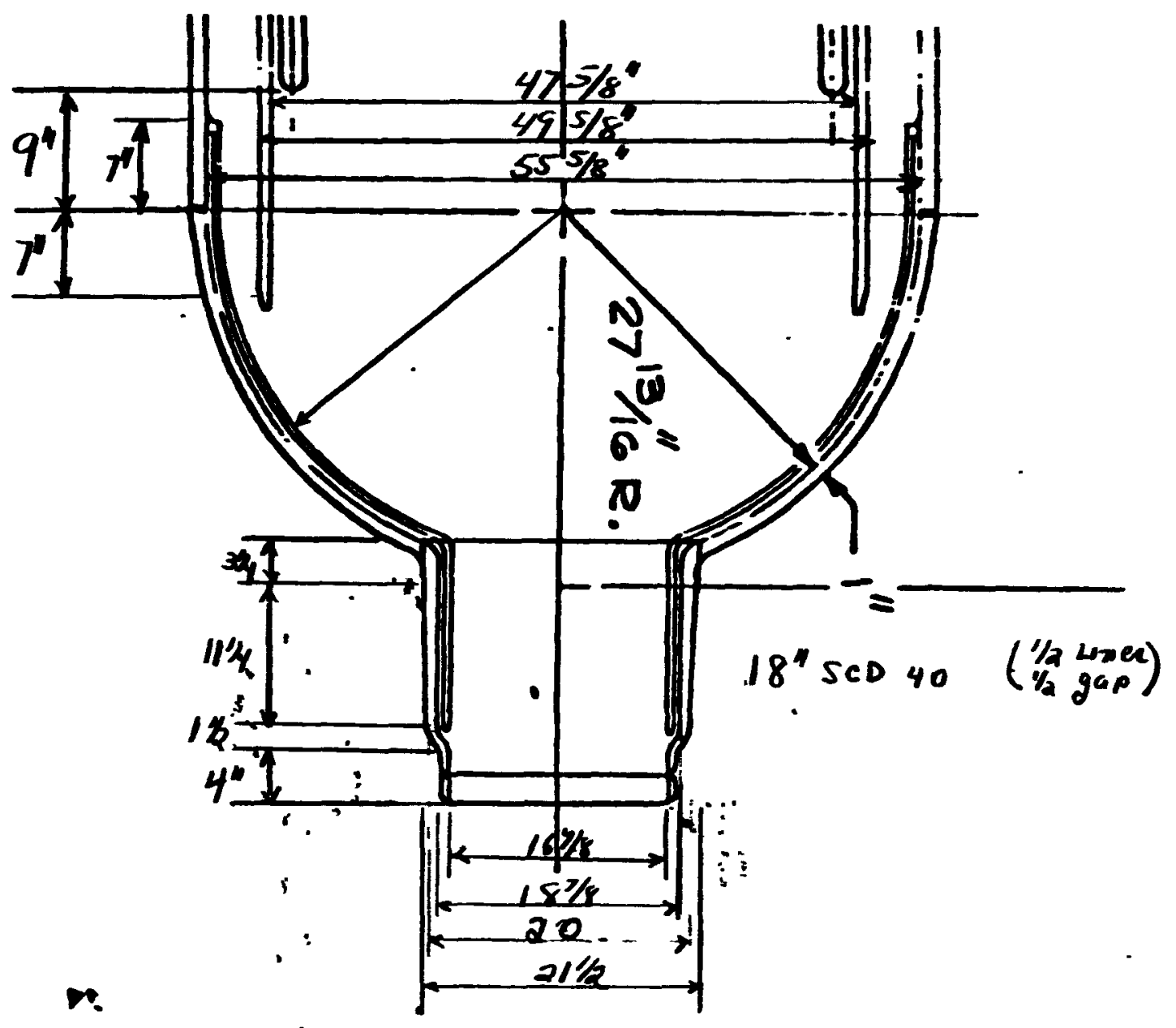

Sodrum Outket Plenum

$$
\begin{aligned}
V_{N a} & =\left\{\frac{\pi}{4}(555 / 8)^{2}(9)+\frac{2 \pi}{3}(2713 / 16)^{3}\right\}-\left\{\pi(485 / 6)(1)(16)+\frac{\pi(3)}{6}\left(3(16 \% / /)^{2}+2 / 4^{2}\right)\right\} \\
& =63100 \mathrm{~m}^{3}=36.5 \mathrm{ft}
\end{aligned}
$$

SoDzUM OUTLET NOzZLE

$$
\begin{aligned}
& V_{N a}=\frac{\pi}{4} \cdot(167 / 8)^{2}(18)=4030 \mathrm{~mm}^{3}=2.33 \mathrm{ft}^{3} \\
& V_{N 07}=\frac{\pi}{4}\left(18^{2}-16^{7 / 8}\right)(4)+\frac{\pi(1.0)}{12}\left\{\left(18^{2}+18(20)+20^{2}\right)-\left(167 / 8^{2}+16 \frac{1}{8}(187 / 8)+1678^{2}\right)\right\} \\
& \left.+\left\{\frac{\pi 14 / 4}{12}\left(21 \%^{2}+212(20)+20^{2}\right)-\frac{\pi}{4}(18 \%)\right)^{2}(14 / 2)\right\} \\
& =1020 \mathrm{~m}^{3}=0.590 \mathrm{Ft}^{3}
\end{aligned}
$$


COMBUSTION ENGINEERING

NUCLEAR POWER DEPARTMENT

$$
\bar{D}=\left(\frac{D_{c}^{2}+\bar{D}_{0}^{2}}{2}\right)^{1 / 2}=\left(\frac{18 / 8^{2}+21 / 2}{2}\right)^{1 / 2}=20.23 "
$$

Assume a $K^{\prime}$ " thenmul limen $\left(2 \% G-1 M_{0}\right)$ and $K^{\prime \prime}$ stagrant sodiom gap between the flowng sodiom and the wozzte Fon the entuse length of the outhet worate. In adolition, the sesistance for the thuckest secturn of the nosile is assumed to chasactenge the nigz/e for its entine kength.

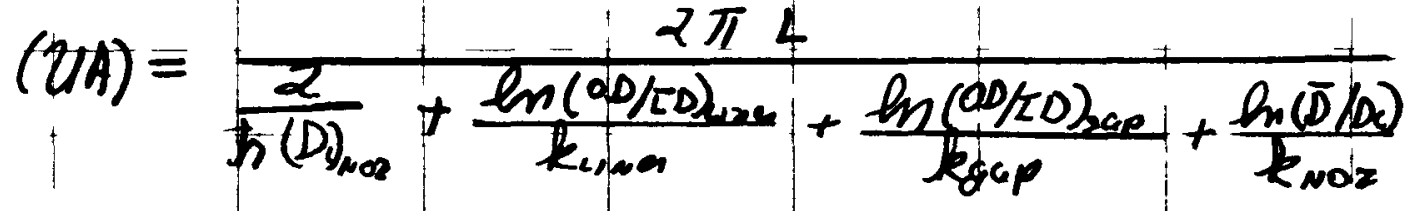

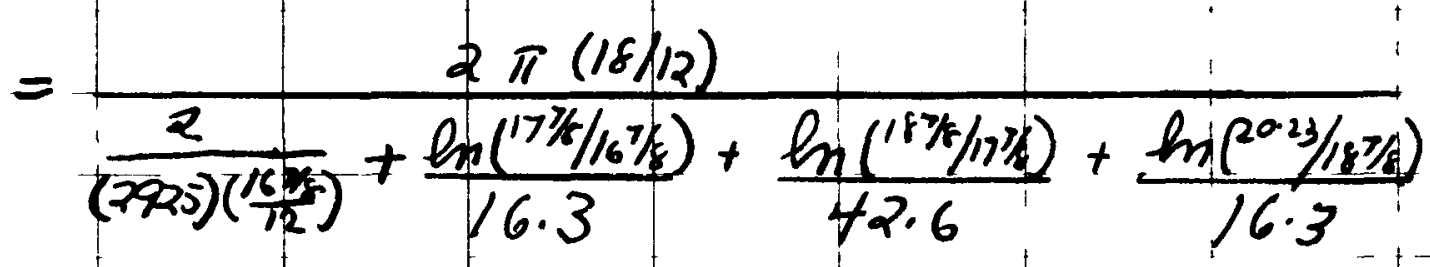

$$
\begin{aligned}
& =987,0 \frac{B+4}{m-0 F}=0.2742 \frac{B+4}{\sec -10 \%} . \\
& \left(\nabla_{N a}\right)_{\text {NOL }}=2.33 \mathrm{Ft}^{3} \\
& \text { - (VActal })_{\text {Moz }}=0.590 \mathrm{ft}^{3} \\
& \left(V_{\text {Na }}\right)_{\text {plevum }}=36.5 \mathrm{Ft}^{3}
\end{aligned}
$$

Computations ase shoum on the figure. 
COMBUSTION ENGINEERING

NUCLEAR POWER DEPARTMENT

$$
\begin{aligned}
& \text { Coefficients. } \\
& \left(\frac{4}{\rho v}\right)_{\text {plerer }}=\frac{1}{(54.1)(36 \cdot 5)}=0.0005064 \mathrm{lbm}^{-1} \\
& {\left[\frac{v_{A}}{(\rho \vee C)_{\operatorname{Lag}}}\right]=\frac{0.2742}{(478)(.590)(.136)}=0.007149 \mathrm{sec}^{-1}} \\
& {\left[\frac{U A}{(P V C)_{10}}\right]=\frac{0.2742}{(54 \cdot 1)(2.33)(308)}=0.007063 \mathrm{sec}^{-1}} \\
& \left(\frac{1}{\rho V}\right)_{\substack{N a \\
N o z}}=\frac{1}{(54.1)(2.33)}=0.007933 \mathrm{ebm}^{-1}
\end{aligned}
$$


COMBUSTION ENGINEERING

NII,LEAR POWER DEPARTMENT

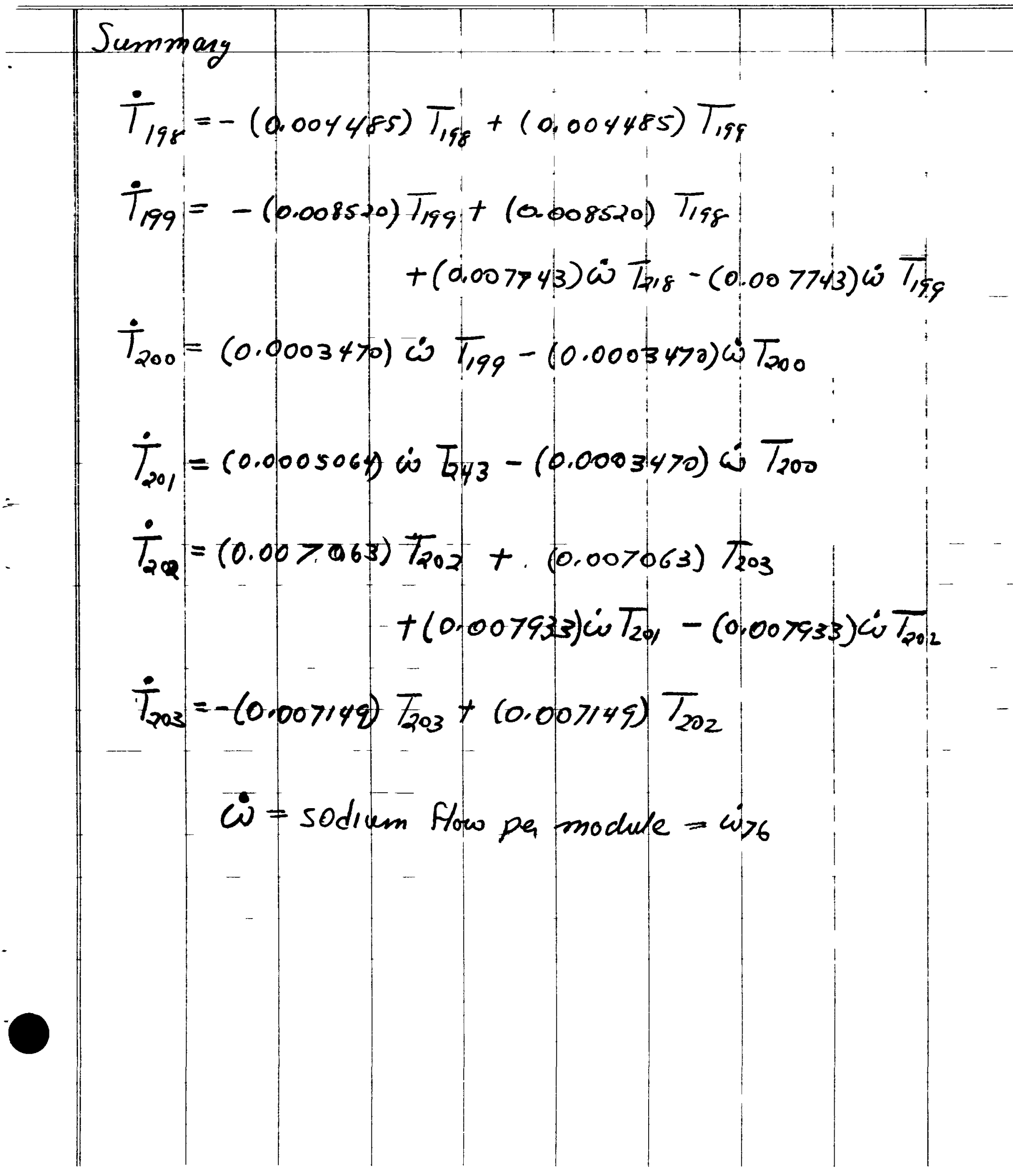


COMBUSTION ENGINEERING NUCLEAR POWER DEPARTMENT

III Mater/stear InLET Aw o OutLet Regime

Energy balances for the additional heat exchange between the inlet water and outlet water/stomimintine in the region above the soduem level:

The pressure tube wall is assumed to be an:adrabatic boundary.

$$
\begin{aligned}
& -(U A)_{3}^{\prime}\left[T_{\text {MiN }}-T_{B T}\right]+w_{\text {ANN }} h_{\text {ANN }}=w_{\text {hmo }} h_{\text {ARd }}+\frac{d}{d t}(\rho v U)_{\text {Ain }} \\
& (U A)_{3}^{\prime}\left[T_{A \operatorname{Nin}} T_{B T}\right]-(U A)_{4}^{\prime}\left[T_{B T}-T_{D C}\right]=\left(q v C_{B T} \frac{d T_{B T}}{d t}\right.
\end{aligned}
$$

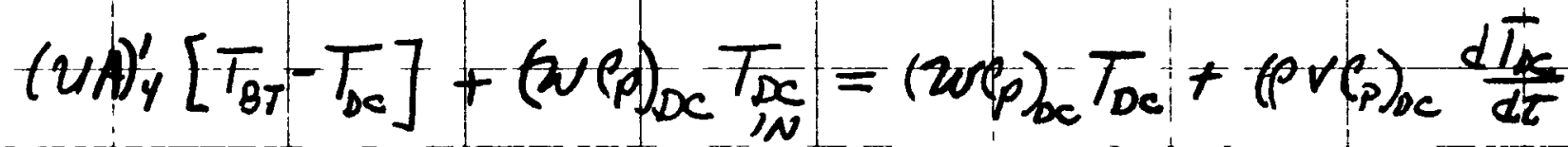

Recalling the assumptions made in I. Mam bleat Transfer Region, and reassanging into standard format

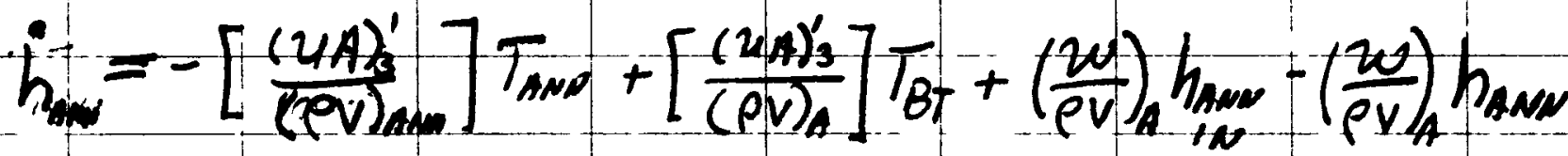

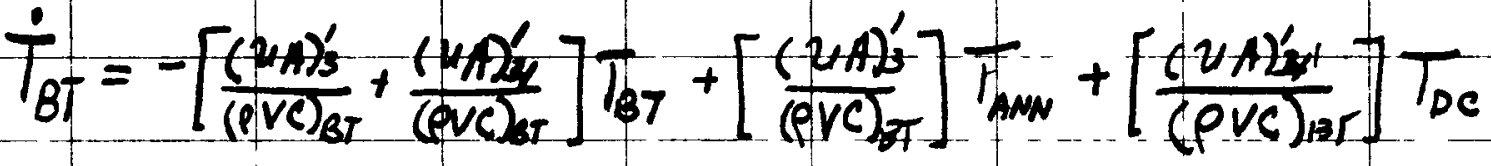

$$
\begin{aligned}
& \dot{T}_{D C}=-\left[\frac{(U A)_{y}^{\prime}}{(\rho V C)_{p C}}\right] T_{D C}+\left[\frac{(U A)^{\prime}}{\left(\rho V C_{P}\right)_{D C}}\right] T_{B T}+\left(\frac{w}{\rho V}\right)_{D C} \frac{1}{T_{C C}}-\left(\frac{w}{\rho V}\right)_{D C} T_{D C}
\end{aligned}
$$

In addition, a curve fit of Two us han n at a given pressure connects the hama node with the corresponding T TN node. 
COMBUSTION ENGINEERING

NUCLEAR POWER DEPARTMENT

Energy balancer for the inlet and outlet plenums: The regions are assumed to be bounded by adiabatic walks.

$$
\begin{aligned}
& \left(W C_{\rho}\right)_{w} T_{T_{N}}=\left(\omega C_{p}\right)_{a} T_{\omega}+\left(p \vee C_{p}\right)_{\omega} \frac{d T_{\omega}}{d t}
\end{aligned}
$$

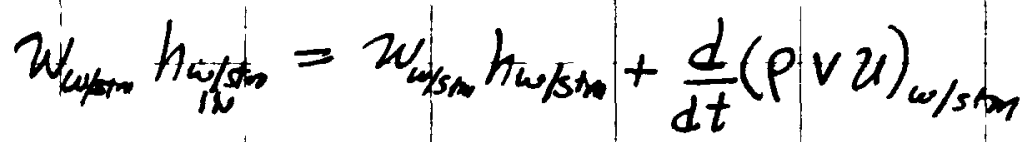

Noting the assumptions made above concerning the water/ steam enthalpy and internal energy, and then

seassanging the equations into standard format.

$$
\begin{aligned}
& \dot{T}_{\omega}=\left(\frac{w}{\rho v}\right)_{\omega} T_{\omega}-\left(\frac{20}{\rho v}\right)_{\omega} T_{\omega} \\
& h_{w / s m}=\left(\frac{w}{\rho v}\right)_{w / s m m} h_{w / s m}-\left(\frac{w}{\rho v}\right)_{w / s m m} h_{w / s t m}
\end{aligned}
$$

The temperature corresponding to hw/gm is obtain ied from a curve fit Tux om us huston for a given prosscuse.

Energy balance for the inset nozzle

$$
\begin{aligned}
& -(U A)\left[T_{N 0 Z}-T_{\omega}\right]=(P \vee C)_{N o z} \frac{d T_{00 Z}}{d t}
\end{aligned}
$$

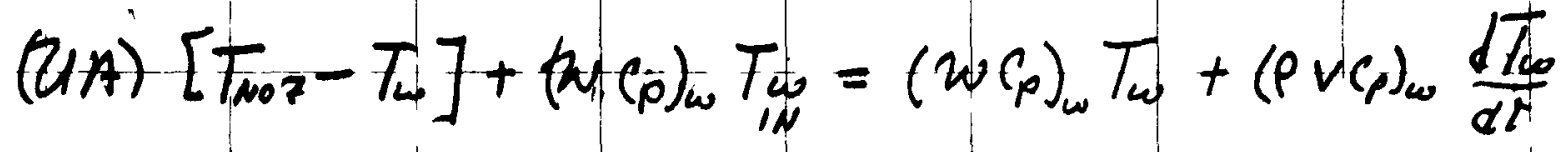

en standard format

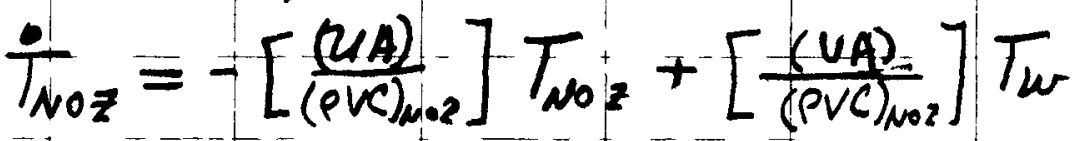

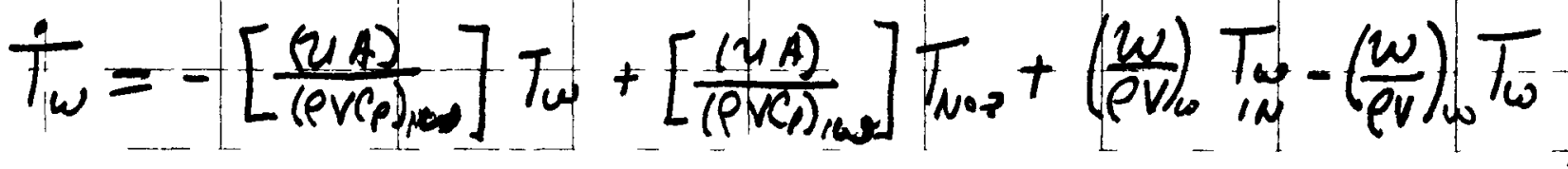


COMBUSTION ENGINEERING

NUCLEAR POWER DEPARTMENT

and the energy balance for the outlet nozzle

$$
\begin{aligned}
& \left.-(U A)\left[T_{\text {wow }}-T_{\text {uxtom }}\right]=(\rho) C\right)_{\text {oz }} \frac{d T_{\text {dor }}}{d t}
\end{aligned}
$$

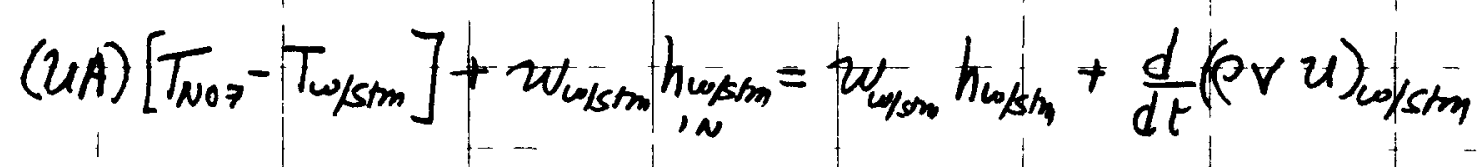

Applying the same ass umptrons is above, and seanangung the equations into standard format

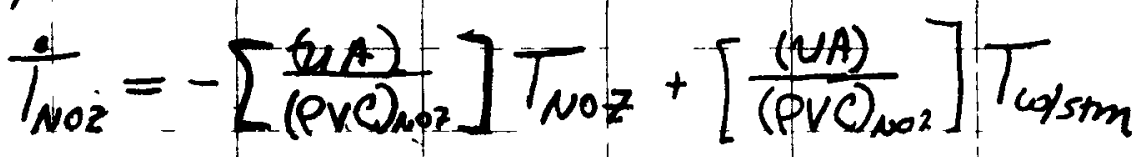

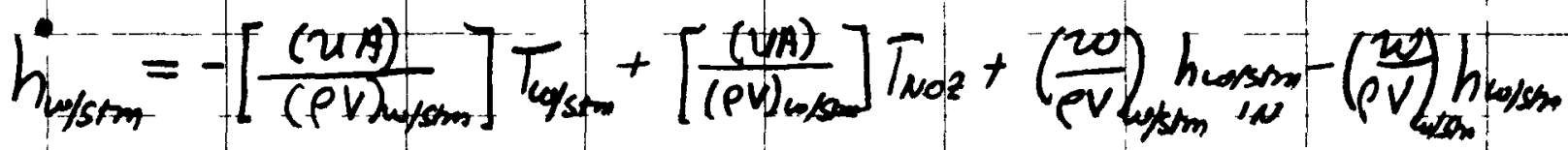

Twoston and hw/stm are connected by a tempuatupeenthalpy arrive fit at a given pressure 
COMBUSTION ENGINEERING

NUCLEAR POWER DEPARTMENT

WATER INLET REG EON

$w_{s}=1,390,473 \mathrm{lbm} / \mathrm{m}=386.2425 \mathrm{lbm} / \mathrm{sec}$ (design)

Properties are evaluated at pressure and tembesoture for full load.

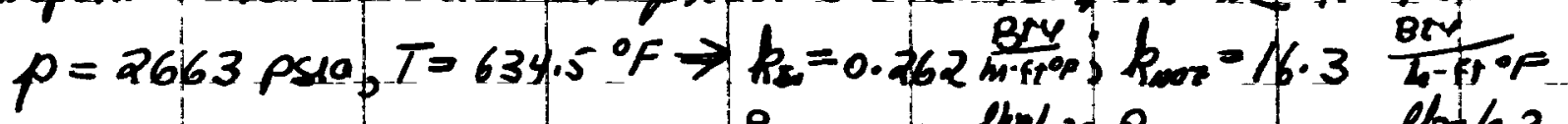

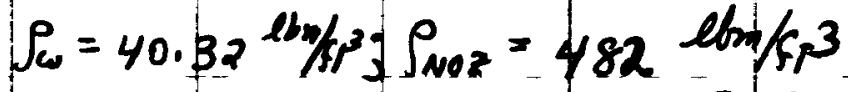

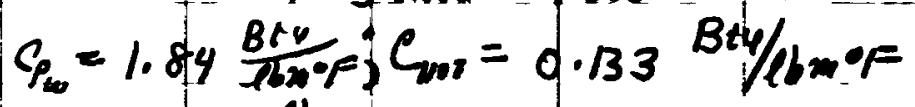

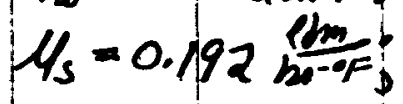

Pleat Transfer coefficient

$$
\begin{aligned}
& { }^{1} G_{\omega}=\frac{W}{A}=\frac{1390473}{\frac{\pi}{4}\left(4^{2} 3 / 1 / 2\right)^{2}}=2.014 \times 10^{6} \frac{\mathrm{lbm}}{\mathrm{hm}-\mathrm{ft} \mathrm{t}^{2}} \\
& V_{w}=\frac{G_{\omega}}{\rho_{\omega}}=\frac{2.014 \times 10^{6} / 3600}{40.32}=13.88 \mathrm{~F} / \mathrm{sec} \\
& R_{\varepsilon_{\omega}}=\frac{G_{\omega} D_{c}}{\mu_{\omega}}=\frac{\left(2.014 \times 10^{6}\right)\left(\frac{\mu_{1} \mu_{1}}{12}\right)}{.192}=9.836 \times 10^{6} \\
& P_{r_{w}}=\frac{u_{\omega} C_{w}}{k_{\omega}}=\frac{.192(1.84)}{.262}=1.35 \\
& h_{\omega}=\frac{k_{w 1}}{D}\left[.023 R_{e_{s}}^{.8} P_{n^{3}} \cdot 4\right]=\frac{262}{114 / 12}\left[.023\left(9.1836 \times 10^{6}\right)^{-8}(1.35)^{14}\right]
\end{aligned}
$$

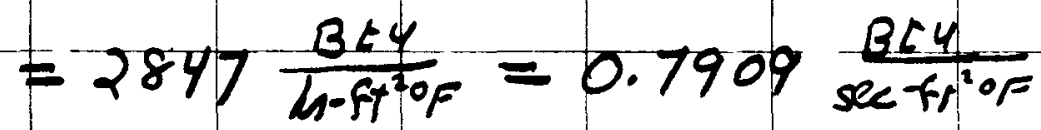

Entrance affects on the heat transfer coefficient ape neglected.

2) The average clumeta for the nozzle is computed at the thusest section. 


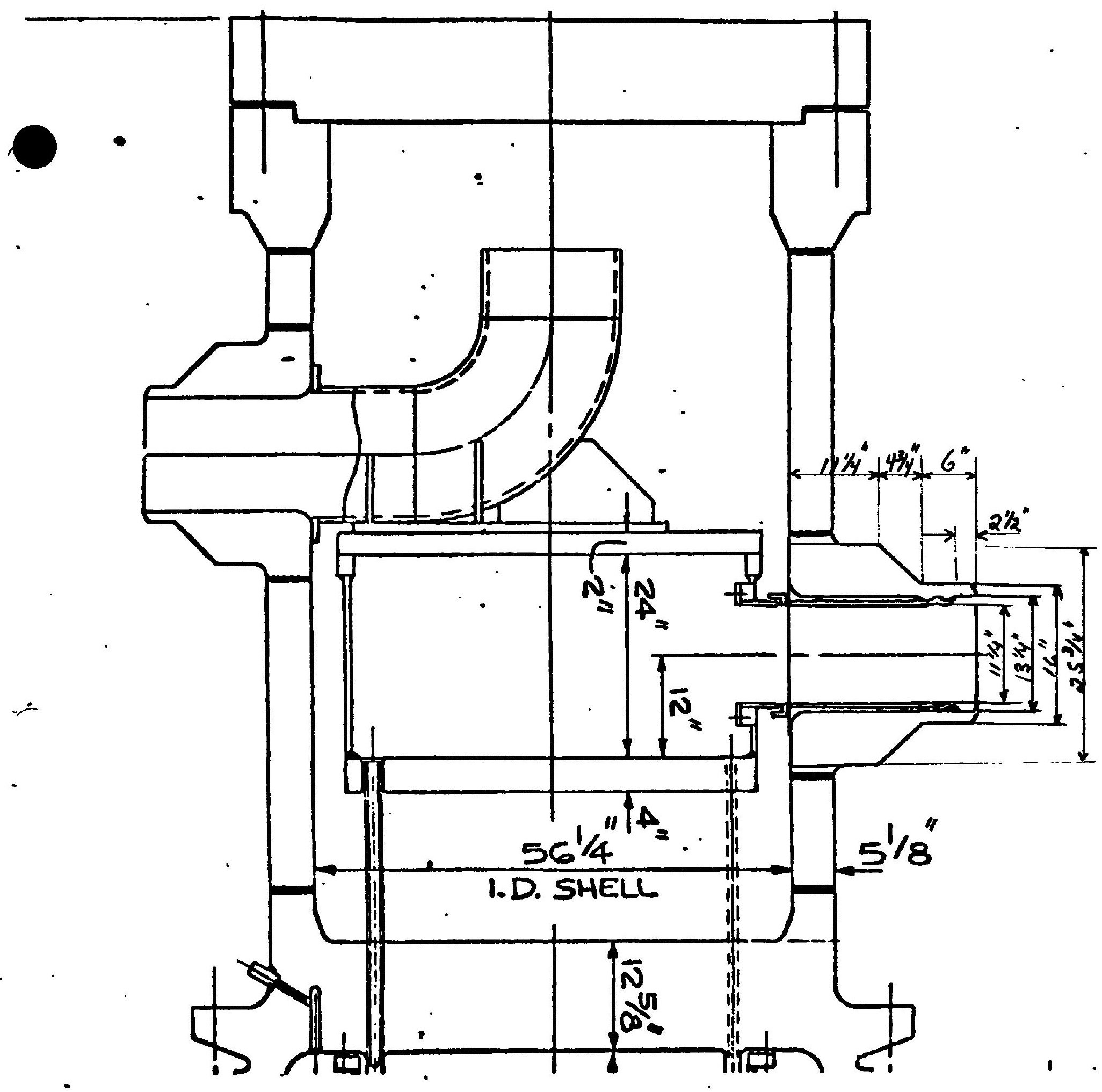

RECTRC. TNLET NOzzLi:

$$
V_{\mathrm{H}_{2} \mathrm{O}}=\frac{\pi}{4}(11 / 4)^{2}(19 /)+\frac{\pi}{4}\left(13^{1 / 4}\right)^{2}\left(2^{1 / 2}\right)=2280 \mathrm{~m}^{3}=1.32 \mathrm{ft}^{3}
$$$$
V_{\text {NOZ }}=\frac{\pi}{4}\left(255 y^{2}-13^{1 / 4^{2}}\right)\left(11^{1 / 4}\right)+\left\{\pi \frac{4^{2} / 4}{12}\left(25^{3} / 4^{2}+253 / 4(16)+10^{2}\right)-\frac{\pi}{4}\left(13^{2} / 4\right)^{2} 4^{3} / 4\right\}
$$$$
+\frac{\pi}{4}\left(16^{2}-134^{2}\right)(6)=5690 \mathrm{~m}^{3}=3.29 \mathrm{Ft}^{3}
$$ 


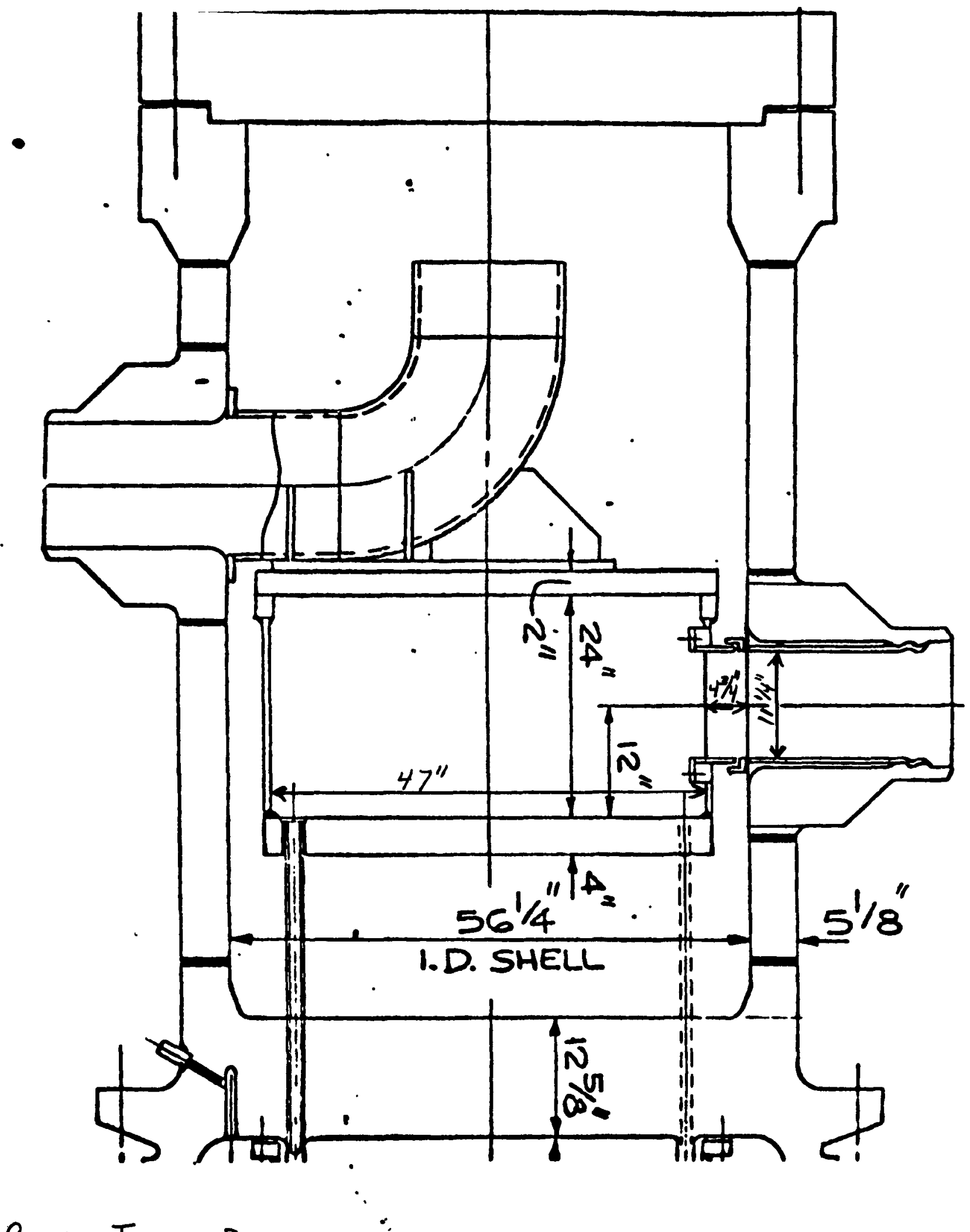

REGERC. InLET PLENUM

$$
V_{H_{20}}=\frac{\pi}{4}(47)^{2} 24+\frac{\pi}{4}\left(11^{\prime} / 4\right)^{2}\left(4^{3} / 4\right)=42100 \mathrm{~m}^{3}=24.4 \mathrm{Fr}^{3}
$$


COMBUSTION ENGINEERING NIICI EAR POWIER NCPARTMFNT

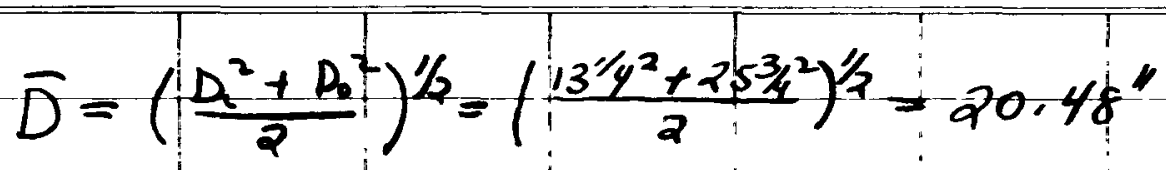

Assume a "al" thermal lemen (Q"1/G-1M) and a "Q" stegrant water gap bekween the Howny wates and the nosizle fos the enturetength of the inket vokzle. In addition, the sesstande of the thichest section of the nogzte is assumed to chasacterge the nogzle for its entse Pength.

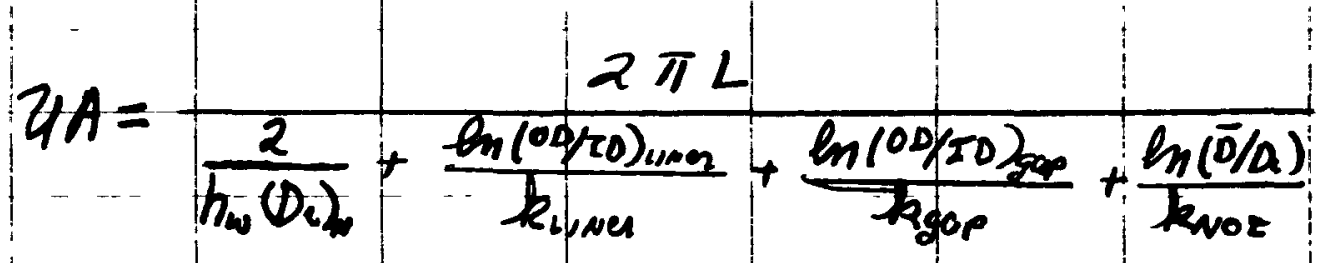

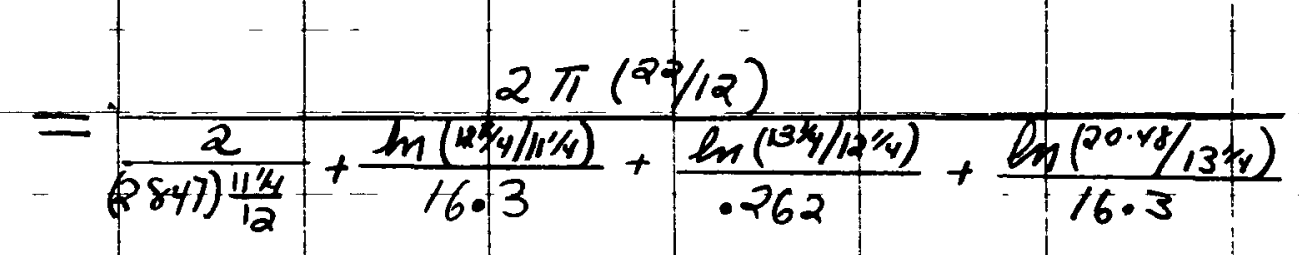

$$
\begin{aligned}
& =34.68 \frac{B+4}{h .0 \%}=0.009632 \frac{B L 4}{56.0} \\
& \text { Volumes } \\
& \left(V_{\omega}\right)_{\text {No2 }}=7.32 \mathrm{ft}^{3} \\
& \left(v_{\text {mpetal }}\right)_{\text {hoz }}=3.29 \mathrm{ft}^{3} \\
& \left(V_{w}\right)_{\text {plexum }}=24 \cdot 4 \mathrm{si}^{3}
\end{aligned}
$$


COMBUSTION ENGINEERING

NUCLEAR POWER DEPARTMENT

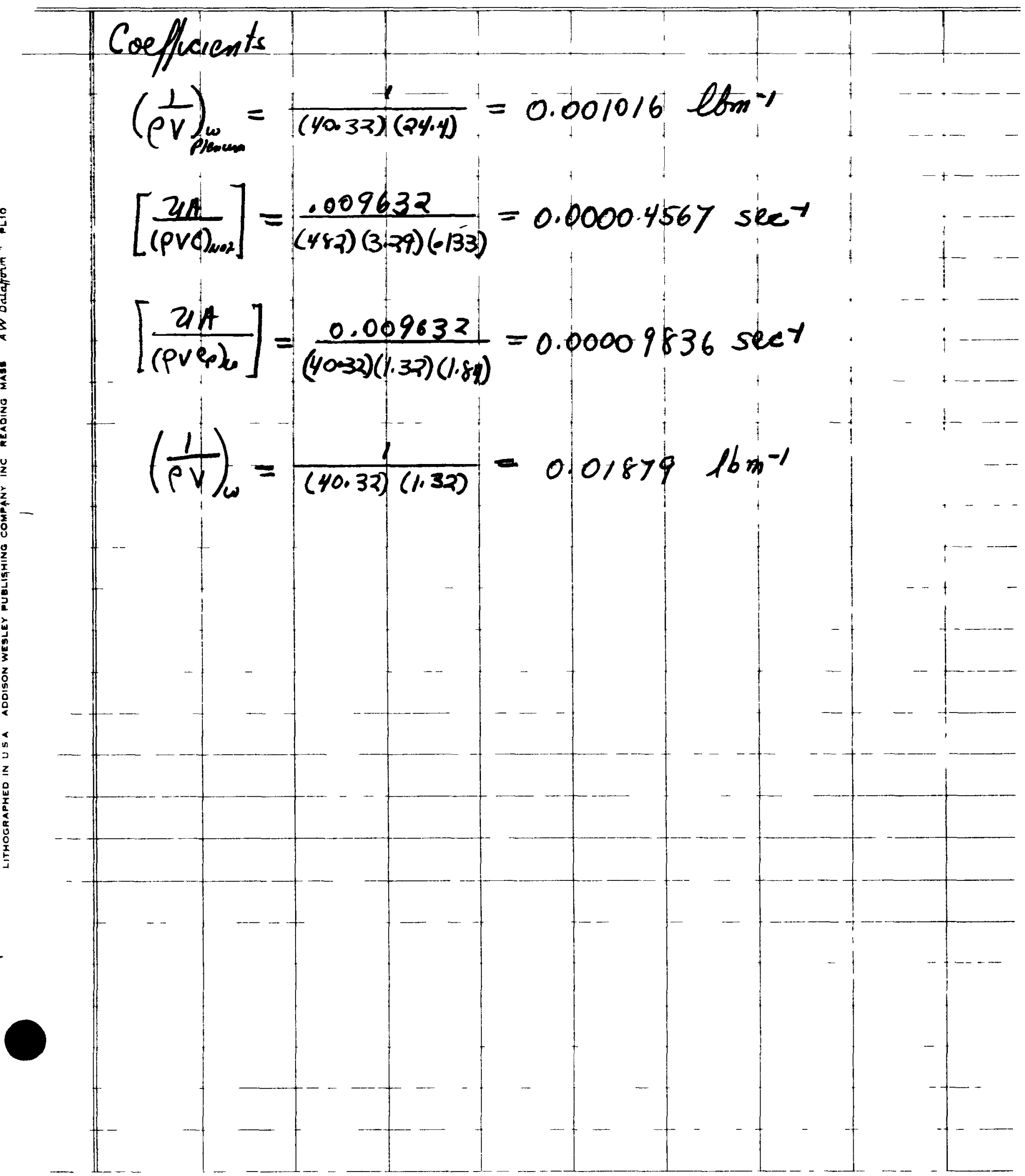


COMBUSTION ENGINEERING NUCLEAR POWER DEPARTMENT

STEAM/WATER QUTLET REgIoN

$$
W_{s}=390473 \mathrm{lbm} / \mathrm{m}=386.2425 \mathrm{lbm} / \mathrm{sec} \quad(\text { design })
$$

properties are evaluated at pressure and temperature for full load,

$$
\begin{aligned}
& P_{\text {sat }}=2645 \text { psia } \Rightarrow \quad T_{\text {ar }}=676.5^{\circ} \mathrm{F}
\end{aligned}
$$

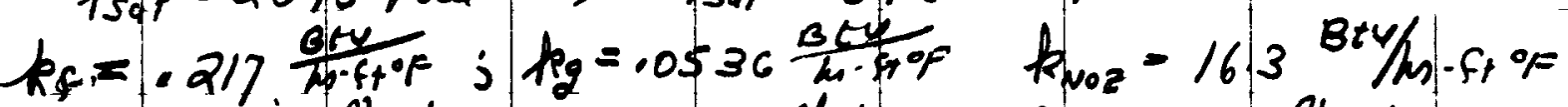

$$
\begin{aligned}
& \rho_{F}=33.62 \rho \mathrm{lm} / \mathrm{st}^{3} ; \rho_{g}=8.545 \mathrm{~lm} / \mathrm{st}^{3} ; \quad \rho_{\text {No }}=481 \mathrm{lbm} / \mathrm{st} 3
\end{aligned}
$$

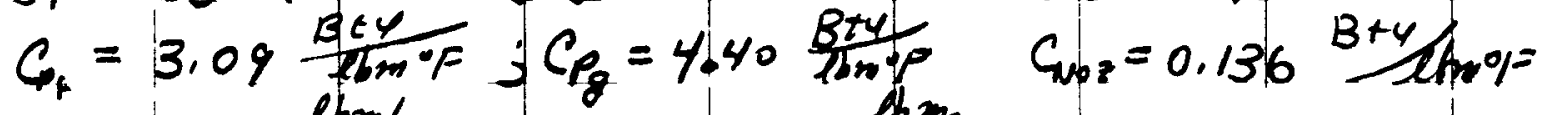

$$
\begin{aligned}
& \mu_{f}=1.178 \mathrm{lmm} / \mathrm{stm} ; \mu_{g}=0.0527 \frac{25}{s+m_{2}}
\end{aligned}
$$

Pleat Trances coefficient

1) The steam/water mixture flows in the nozzle generally under adiabatic conditions. The heat transfer coefficient, under these conditions, pepresents the potential to transfer heat if temperatures changed. Since boiling. is not occurring in the nozzle under design conditions, this heat transfer potential is assumed to be characterized by annular flow pattern, and the coefficient computed assuming the liquid phase Slows alone.

This computation may be very inaceusctes but its effects on the overall heat trons fer coefficient between the fluid and the nozzle will be small since the nozzle resistance is the dormant component.

$$
G_{L}=\frac{w}{A}(1-x)=\frac{1390473}{\frac{\pi}{4}(134 / 1 / 2)^{2}}(1-.286)=1.037 \times 10^{6} \frac{\mathrm{dbm}}{\mathrm{s}+\mathrm{b}^{2} \mathrm{~m}}
$$




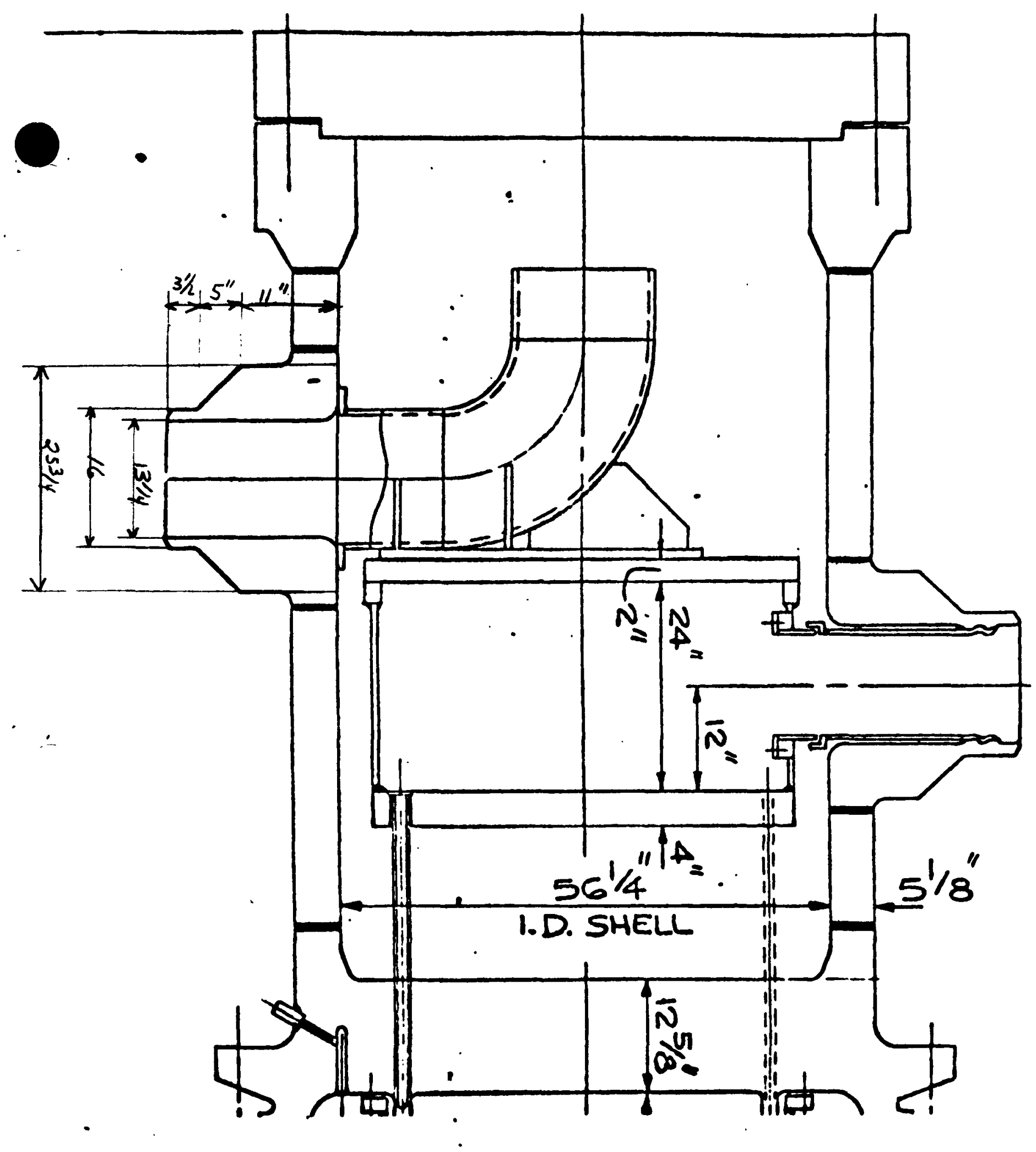

Saturated STEAM/Water Outhet Nozzle

$$
\begin{aligned}
& V_{\mathrm{sm} / \mathrm{m}_{10}}=\frac{\pi}{4}\left(13 \mu_{1}\right)^{2}(19 / 2)=2690 \mathrm{~m}^{3}=1.56 \mathrm{ft}{ }^{2} \\
& \left.V_{N O Z}=\frac{\pi}{4}\left(25^{3} 4^{2}-13^{1} 4^{2}\right)(11)+\left\{\frac{\pi(5)}{12}\left(25^{3} / 4^{2}+65^{3} 4\right)(16)+16^{2}\right)+7(13 / 4)^{2} 5\right\} \\
& +\frac{\pi}{4}\left(166^{2}-13^{2} 4^{2}\right) 3 \%=5490 \mathrm{~m}^{3}=.3 .17 \mathrm{ft}^{3}
\end{aligned}
$$




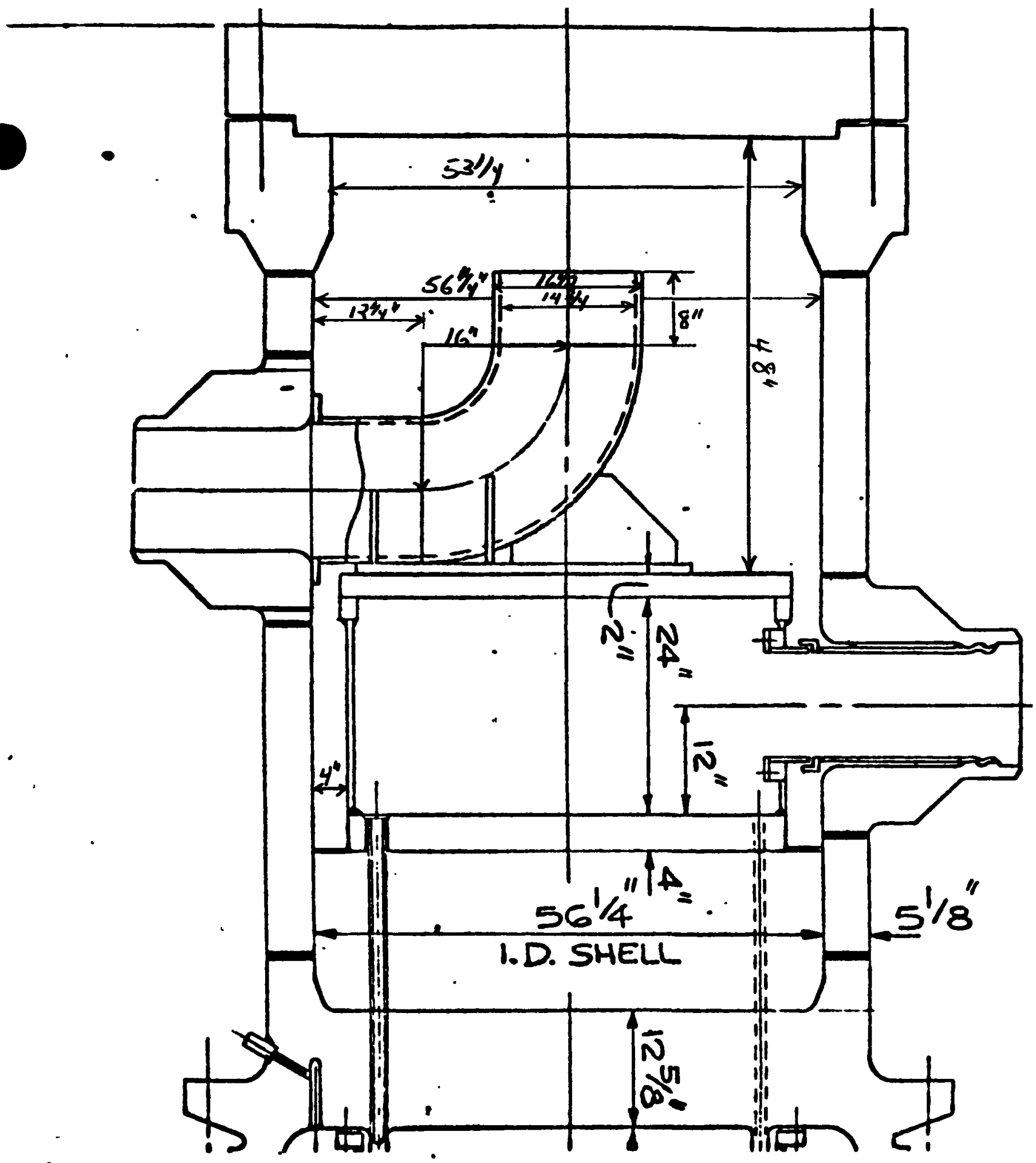

Saturated steam/wateb Outuet Plenum

$$
\begin{aligned}
& q_{5 \mathrm{~m} / \mathrm{H}_{20}}=\frac{\pi}{4}(56 / 4)^{2} 48+\frac{\pi}{4}\left(56 / 4^{2}-48 / 4^{2}\right)(30)=\left\{\frac{\pi}{4}\left(16 \%^{2}-14^{3} \%^{2}\right)\left(8+\frac{\pi}{2}(16)+12 / 4\right)\right\} \\
& \text { - }-\left\{\begin{array}{l}
\text { Estrmate of additional } \\
\text { elems in Phrum }
\end{array}\right. \\
& =135000 \mathrm{~m}^{3}=78.2 \mathrm{ft}^{3}
\end{aligned}
$$


COMBUSTION ENGINEERING

NUCLEAR POWER DEPARTMENT

$$
\begin{aligned}
& R_{e_{2}}=\mid \frac{G_{2} D}{\mu_{2}}=\frac{\left(1.037 \times 10^{6}\right)\left(\frac{13 \%}{12}\right)}{.178}=6.432 \times 10^{6} \\
& P_{r_{L}}=\frac{\mu_{L} P_{r_{L}}}{k_{L}}=\frac{.178(3,09)}{.217}=2.53 \\
& h_{2}=\frac{k_{2}}{D}\left[.023 R_{e^{2}}^{.8} \mid P_{r_{2}}^{.4}\right]=\frac{.217}{1314 / 12}\left[.023\left(6.432 \times 10^{6}\right)^{18}(2.53)_{1}^{14}\right] \\
& =1833 \mid \frac{B t y}{h-f^{20} \mathrm{~F} F}=0.5090 \frac{B+4}{\mathrm{sec}-t^{20} \mathrm{~F}}
\end{aligned}
$$

2) The average diameter for the nozzle is computed at the rhechest section.

$$
\bar{D}=\left(\frac{D^{2}+D^{2}}{2}\right)^{1 / 2}=\left(\frac{13^{1 / t^{2}+253 / y^{2}}}{2}\right)^{1 / 2}=20,48^{\prime \prime}
$$

The thermal resistance of the thickest section of the nozzle es assumed to charactery the nozzle for ts entire length.

$$
\begin{aligned}
& U A=\frac{2 \pi}{h_{L} D_{C}+\frac{\ln \left(\bar{D} / D_{C}\right)}{k_{N O Z}}} \\
& =\frac{2 \pi(19.5 / 12)}{\frac{2}{1833\left(\frac{13.202}{12}\right)}+\frac{\ln \left(20.48 /\left(3 y_{1}\right)\right.}{16.3}} \\
& =368.6 \frac{B t 4}{h-B / F}=0.1024 \frac{B t 4}{\sec 0 / F}
\end{aligned}
$$


COMBUSTION ENGINEERING

NIICLEAR POWER DEPARTMENT

$$
\begin{aligned}
& \text { Volumes } \\
& \left(v_{\omega}\right)_{\text {tot }}=1.56 \mathrm{ft}^{3} \\
& (2 \mathrm{stat})_{0 \mathrm{O}}=3.17 \mathrm{Ft}^{3} \\
& \left(v_{w}\right)_{\text {menus }}=78.2 \mathrm{Fr}^{3}
\end{aligned}
$$

Computations are shown on the figures.

Average Density of stoam/water mixture

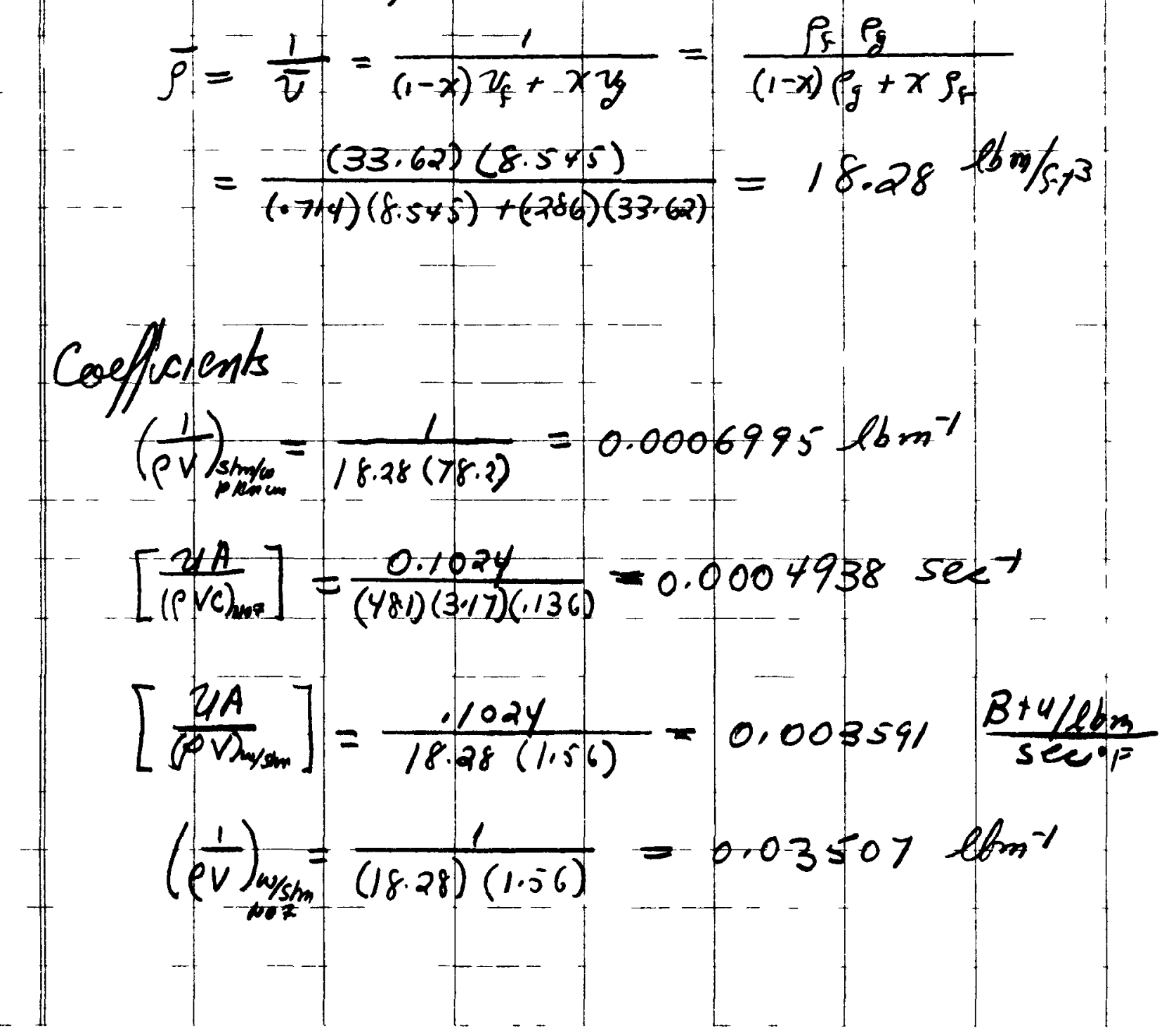


COMBUSTION ENGINEERING

NUCLEAR POWER DEPARTMENT

AdDitional Heat Exchange REgion:

$$
w_{s}=3659.14 \frac{\text { limb }}{\text { tube }}=1.016 \frac{\text { leminsed }}{\text { tube }} \text { (design). }
$$

Properties are evaluated at pressure and temperature for full load.

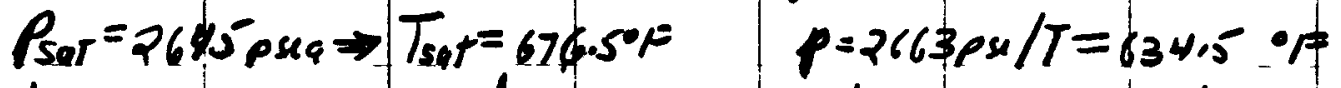

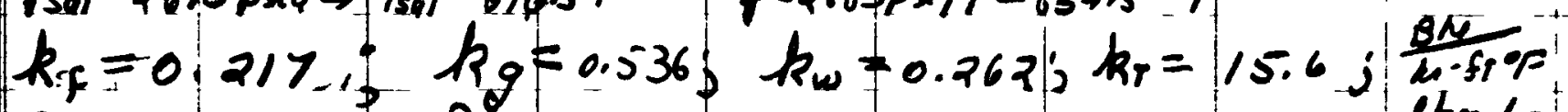

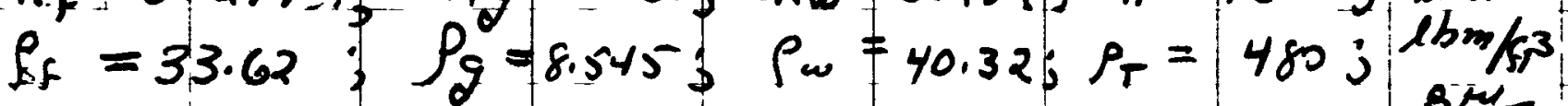

$$
\begin{aligned}
& C_{P_{f}}=3.09 ; \quad C_{g}=4.40 ; \quad C_{P_{w}}-1.84 ; C_{T}=0.138: \frac{8 \mathrm{j}_{\mathrm{T}}}{\mathrm{lbm}} \\
& \mu_{f}=0.178 ; \mu_{g}=0.0527, \mu_{10}=0.192
\end{aligned}
$$

Beat Transfer Caefeccents - Thermal Resistances

1) 7 . 1 $7^{\prime \prime}(24 \%)$ of the additional heat transf length the outlet steam wat en mixture flows obliquely. about the bayonet tube assembly. (Appeal hat exchanges shellscole flow pattern). Fo the remaining $54{ }^{3} / 8$ " the muxhere flows in the annuli defined by the pussune tubes and the bayonet tube assemblers. Fo purposes of calculating a representalim heat transfer coefficient the latter bow pattern is assumed for the en tie length. In accuracies due to this assumption or assumption made in the actual caloutatum will have little effect since the them ul resistance of the bayonet tube assembly insulates gur is dominant.

The steam/water mixture is being cooled by the inlet water; consequently condensation is occurng. A bower limit to either boiling or condensing heat transfer coefficients would be calculated of it is assumed 


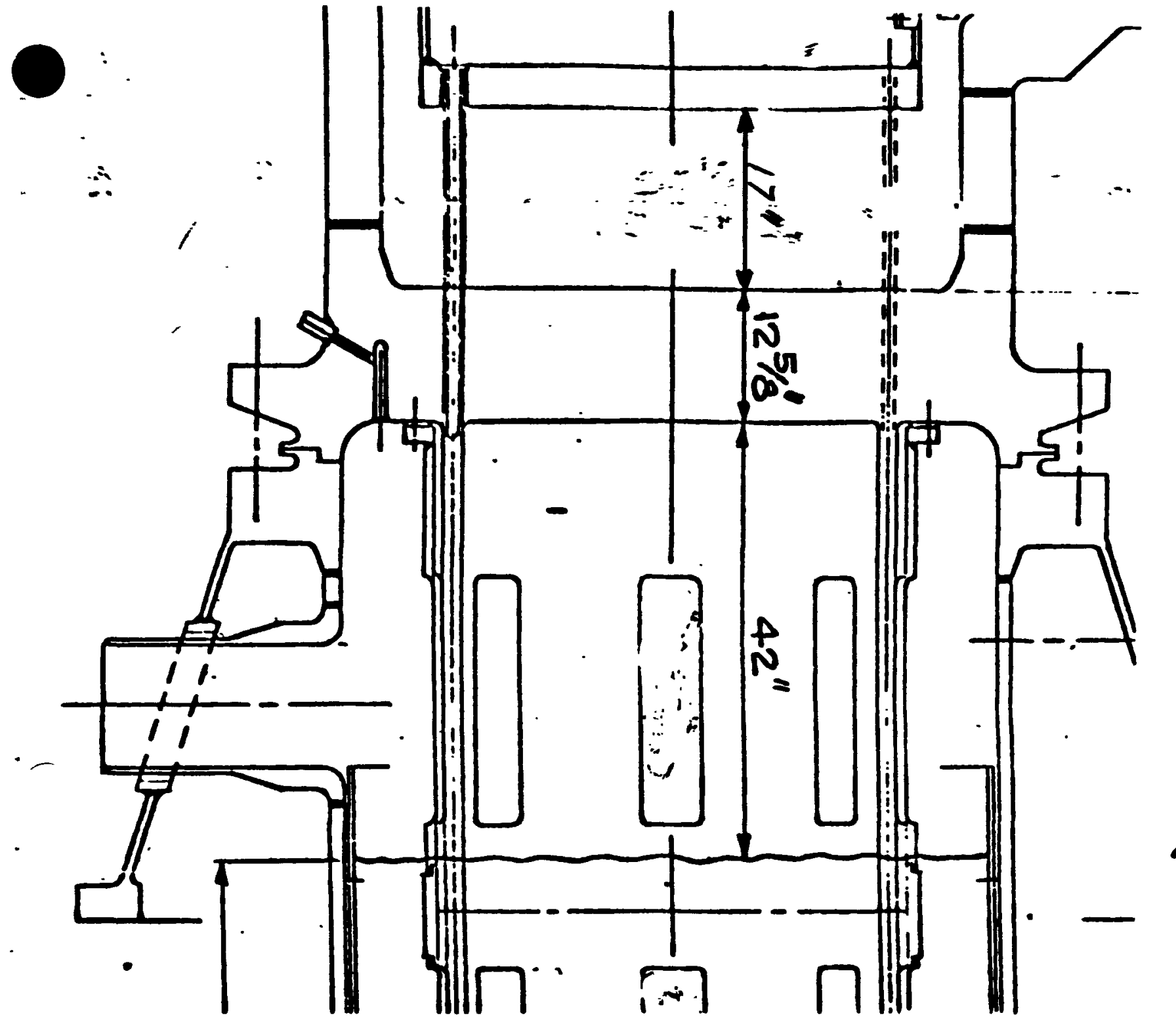

ADDTTEONAL HEAT EXGHange length

$$
\begin{aligned}
& L=17+125 / 8+42=.715 / 8^{\prime \prime} \\
& d_{1}=0.501^{\prime \prime} ; \quad d_{3}=0.701^{\prime \prime} ; \quad d_{5}=1.156^{\prime \prime} \\
& d_{2}=0.581^{\prime \prime} ; \quad d_{4}=0.781^{\prime \prime} ; \quad d_{6}=1.500^{\circ}
\end{aligned}
$$


COMBUSTION ENGINEERING NUCI EAR POWER DEPARTMENT

that the lequed alone flowed.

$$
\begin{aligned}
& G_{L}=\frac{W_{L}}{A}(1-x)=\frac{36-59.14}{\frac{\pi}{4} \frac{\left(1.156^{2}-.761^{2}\right)}{144}}(1-.286)=6.595 \times 0_{9}^{5}
\end{aligned}
$$

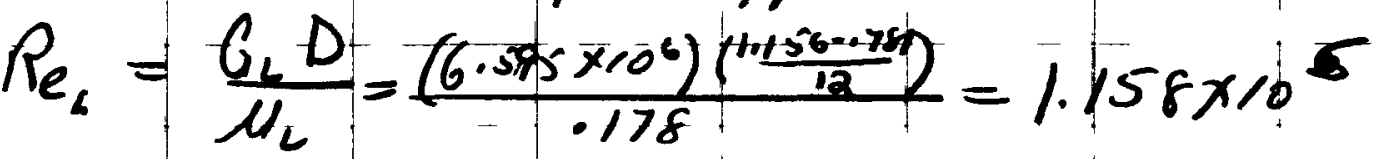

$$
\begin{aligned}
& P_{r_{L}}=\frac{\mu_{L} C_{P_{L}}}{k_{L}}=\frac{-178(3.09)}{.217}=2.53
\end{aligned}
$$

$$
h_{L}=\frac{k_{L}}{D_{e}}\left[.023 R_{e}^{\cdot 8} P_{r_{L}}^{\cdot 4}\right]=\frac{.217}{.375 / 12}\left[.023\left(1.158 \times 10^{5}\right)^{-8}(2.57)^{-4}\right]
$$

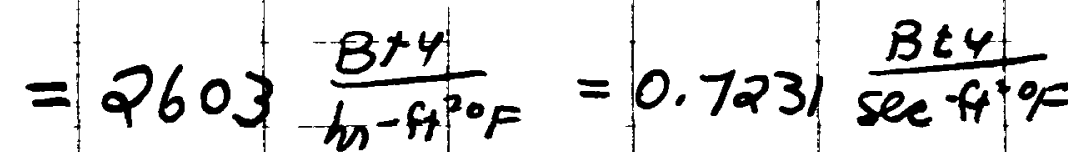

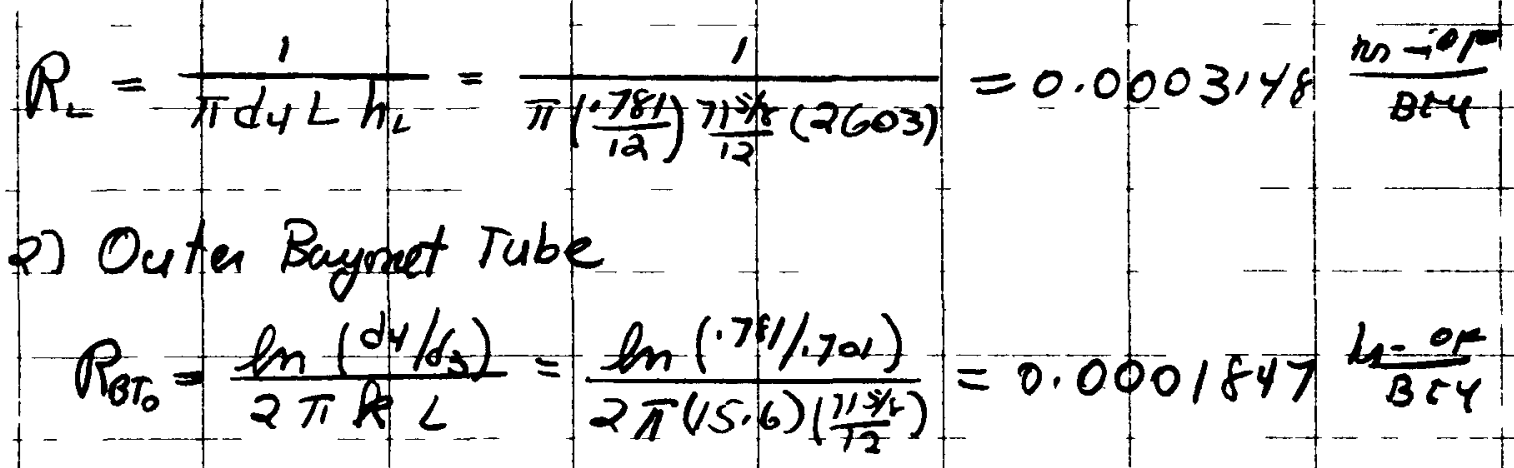

3) Insulation Gap Resistance

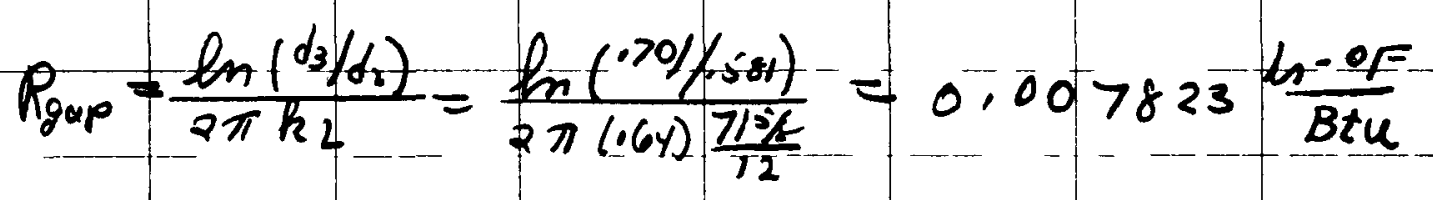

4) Inter Buysonet tube

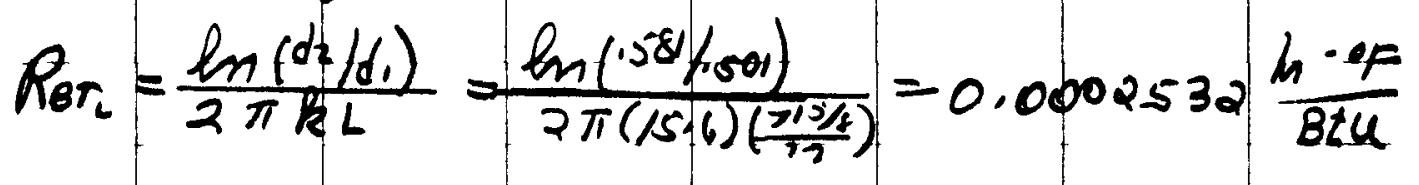

5) Water

$$
G_{\omega}=\frac{w_{2}}{A}=\frac{3659.14}{\frac{\pi}{4}(1501 / 12)^{2}}=2.673 \times 10^{6} \frac{t 6 m}{\mathrm{~F}^{2} \mathrm{~m}}
$$


COMBUSTION ENGINEERING NUCLEAR POWER DEPARTMENT

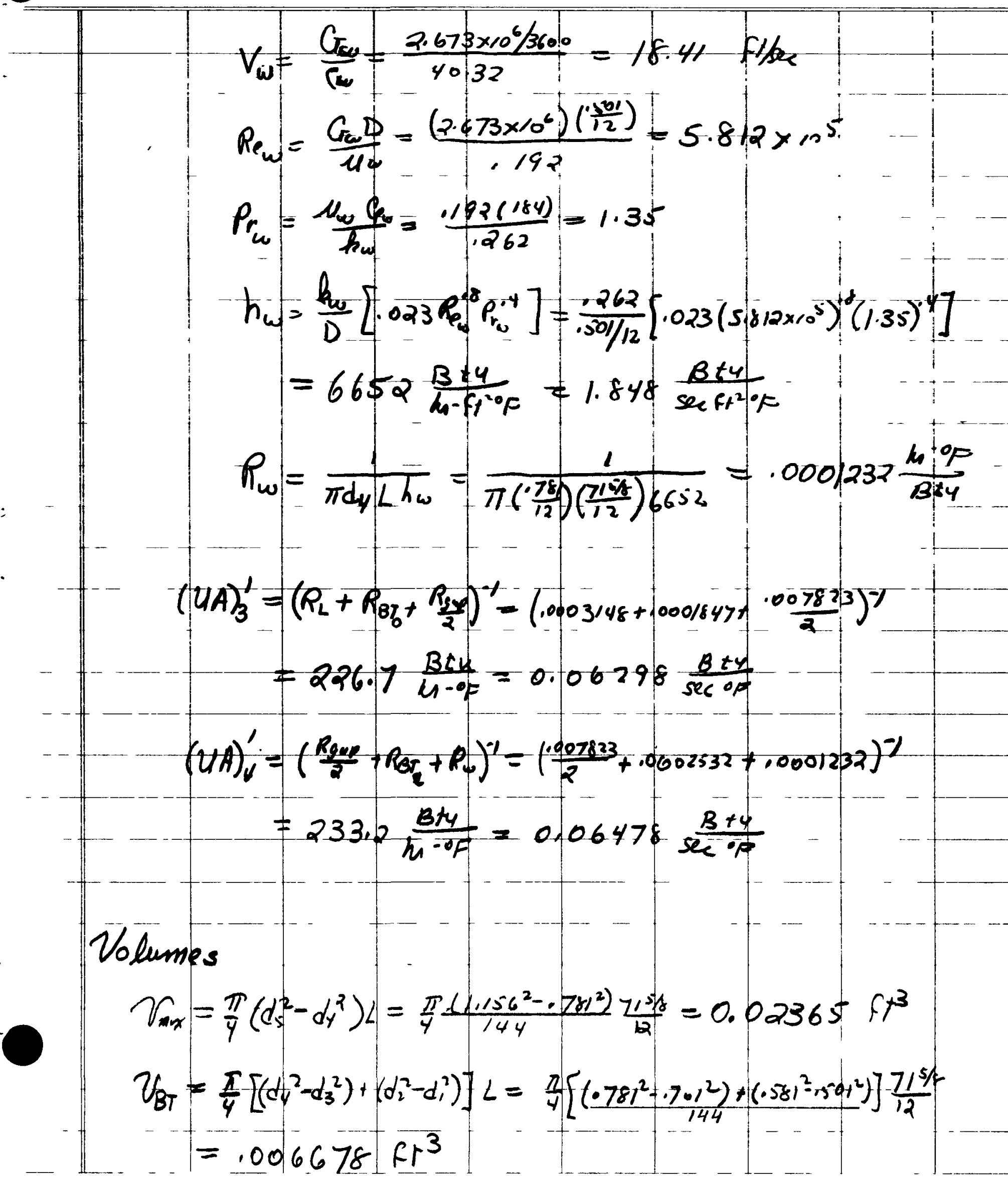


COMBUSTION ENGINEERING

NUCLEAR POWER DEPARTMENT

$V_{\omega}=\frac{\pi}{4} \mathrm{~d}^{2} L=\frac{\pi}{4} \frac{(501)^{2}}{1 v 4} \frac{7 / 4}{12}=0.008171 \mathrm{ft}^{3}$

Average density for praxkure

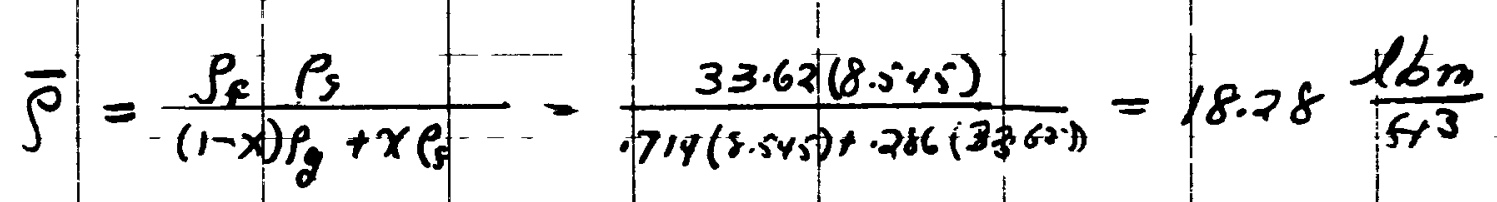

Coefficients

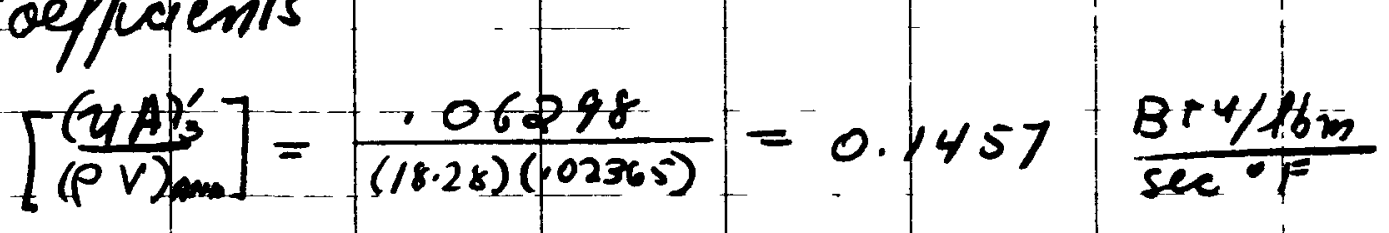

$$
\begin{aligned}
& \left(\frac{1}{\rho v}\right)_{\text {no }}=\frac{1}{(18.28)(.02365)}=2.313 \mathrm{Apm}^{-1} \\
& {\left[\frac{\left(\overline{u A T_{3}}\right.}{\left(\mathrm{PVC}_{31}\right.}\right]=\frac{.06298}{480(1006678) \cdot 138}=0.1424 \mathrm{sec}^{-1}} \\
& {\left[\frac{(u A)_{8}^{\prime}}{(P V C)_{B r}}\right]=\frac{0.06478}{480(10066)(1038)}=0.1464 \mathrm{sec}^{-1}} \\
& {\left[\frac{(4 A)_{1}^{\prime}}{\left(\rho \vee(0)_{w}\right.}\right]=\frac{.06478}{(40.32)(.008171)(1.84)}=0.1069 \mathrm{sect}} \\
& \left(\frac{T}{\rho V}\right)_{\omega}=\frac{1}{(40.32)(.008171)}=3.035 \mathrm{elm}^{-1}
\end{aligned}
$$


COMBUSTION ENGINEERING NIICI FAR POWFR DFPARTMENT

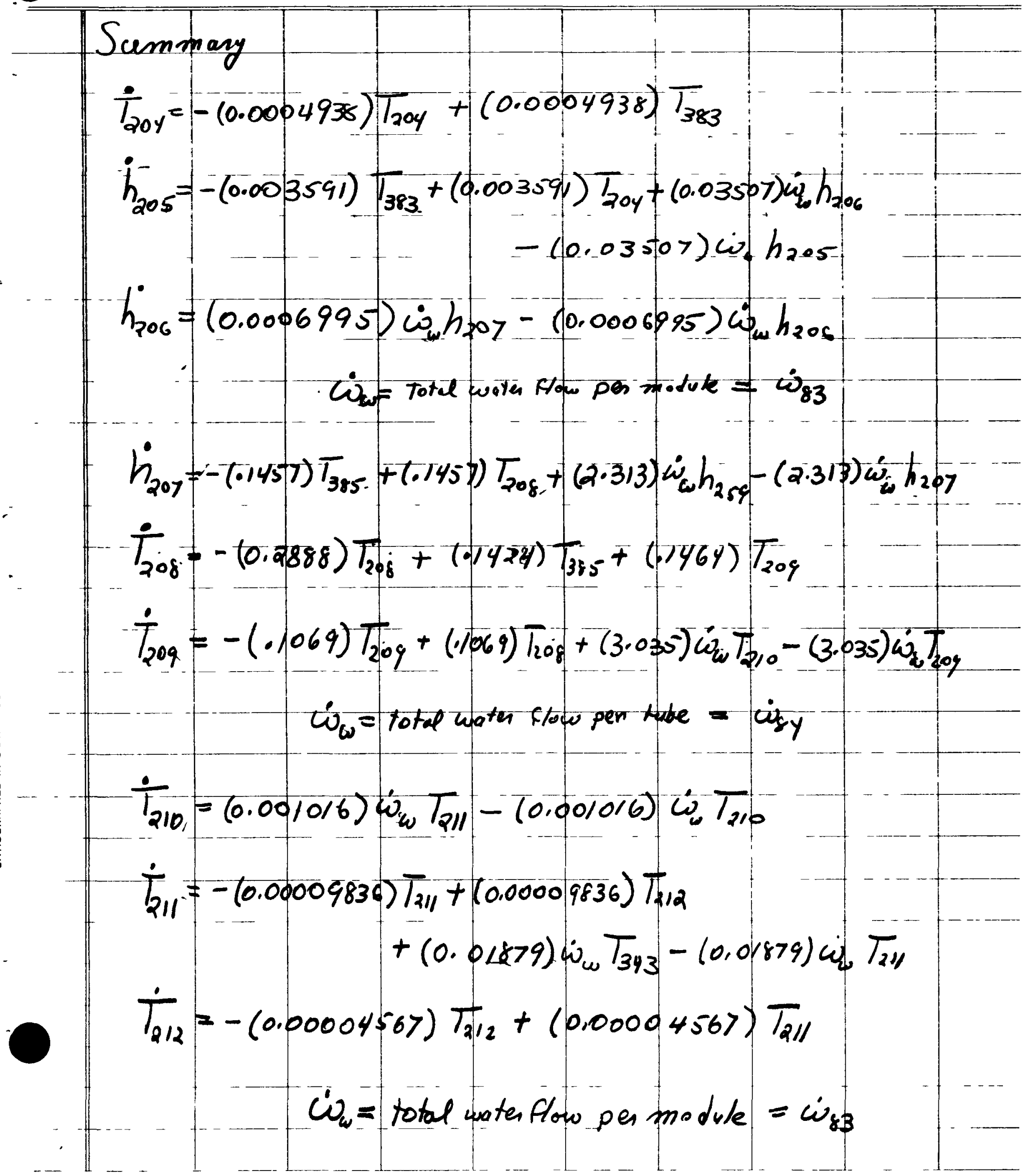


COMBUSTION ENGINEERING

NUCLEAR POWER DEPARTMENT

The nodes representing the temperature of the steam limewater mature in the last annuli node and the evaporator outlet negro are connected to the corresponding enthalpy nodes by "flow equations". These equations can be used as apopopiate curve fits, lo. a polynomial in $h$ os a function of time.

In general

$$
k=\epsilon_{1} ; z=F_{(k)}=\text { nodal value }
$$

1) $k<0$

$$
\begin{aligned}
\dot{\omega}=\epsilon_{2} z & +\epsilon_{3} z^{2}+\frac{e_{4}}{z}+\frac{\epsilon_{5}}{z^{7}} \\
& +\epsilon_{0}+\epsilon_{7} z^{3}+\epsilon_{8} z^{4}+\epsilon_{9} z^{5}+\epsilon_{0} z^{6}
\end{aligned}
$$

2) $k \geqslant 0$

a) $\epsilon_{10}=0$

$$
H=\left\{\begin{array}{ll}
0 & k=0 \\
z & k>0
\end{array} ; R=\left\{\begin{array}{c}
0, t \leqslant 0 \\
\epsilon_{3} t+\epsilon_{4} t^{2}, \tau \geqslant 0
\end{array}\right.\right.
$$

b)

$$
\left\{\begin{aligned}
\epsilon_{10}=0 & \dot{\omega}=H+R+\epsilon_{2}+\epsilon_{s} \exp \left(\epsilon_{6} t+\epsilon_{7} t^{2}\right) \\
\epsilon_{10}>0 & \dot{\omega}=\left\{\begin{array}{l}
H+\epsilon_{10} \\
H+R\left(t_{m}{ }^{*}\right)+t_{m} \leq 0 \\
t_{m}=t-\left(t_{s}+\epsilon_{6}\right) \quad \xi-\exp \left(\epsilon_{6} t_{m}+\epsilon_{7} t_{m}^{2}\right), t_{m} \geqslant 0
\end{array}\right.
\end{aligned}\right.
$$

The outlet nodes will be at saturated conditions for most of the consuctered transients. consequently the temperature proves depend directly on the pressure. If the pressure is prescribed 
COMBUSTION ENGINEERING

NUCLEAR POWER DEPARTMENT

for the particular transient, the associated saturation temperature es deterred. Curve fits en the form. of $2(4)$ on $2(b)$ would be used. If superheated steam exists in the outlet region, a polynomial curve fit for enthalpy-tempesature at a given pressure must bi used. Curve fat in the form of (1) above would be emplaned.

Tor normal transients the pressure well be very. near the $100 \%$ load operating level and the conespondung saturation temperature is apposiomaty $676.5^{\circ} \mathrm{F}$. One of thine forms may be used

a) $\epsilon_{1}=$ - (connecting node number, pos, 206, 0207 )

$\epsilon_{6}=676.5$ all other $\epsilon^{\prime}=0$

b) $\varepsilon_{1}=-369$

all $\epsilon^{\prime} s=0$ except one $\epsilon-676.5$

*.c) $\epsilon_{1}=0$

$\epsilon_{2}=676.5$, all other $\epsilon^{2}=0$ 


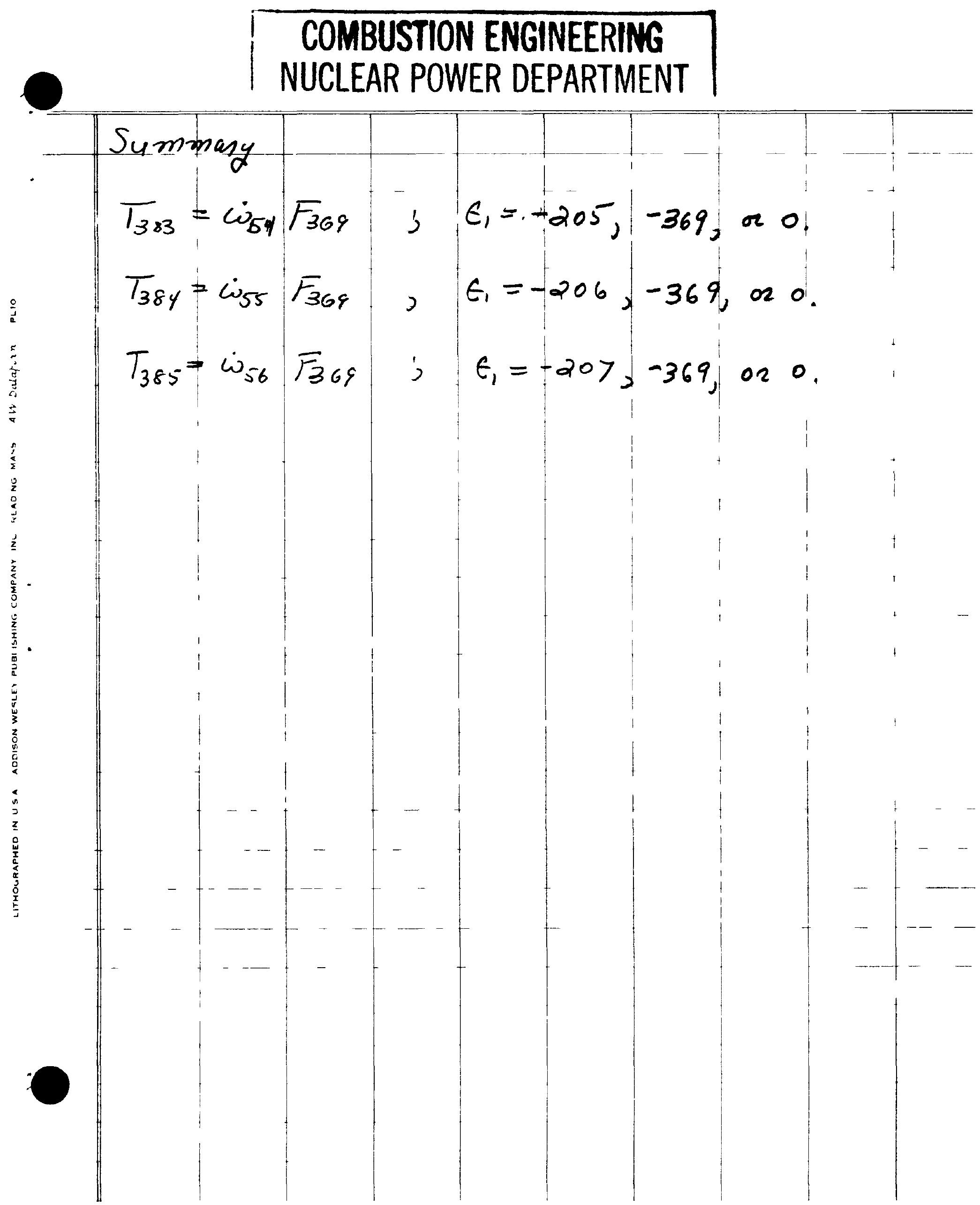


COMBUSTION ENGINEERING

NUCLEAR POWER DEPARTMENT

Sodium Peng: $S H \rightarrow E V$

Energy balance for pope and sodium nodes

$$
-(U 1)\left(T_{p}-T_{N_{a}}\right)=(\rho \vee C)_{p} \frac{d T_{p^{p}}}{d t}
$$

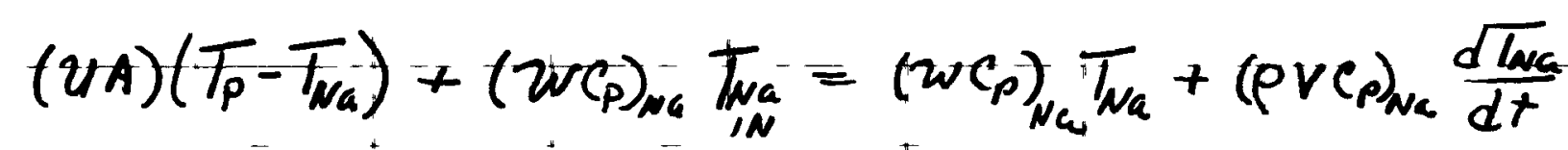

In standard format

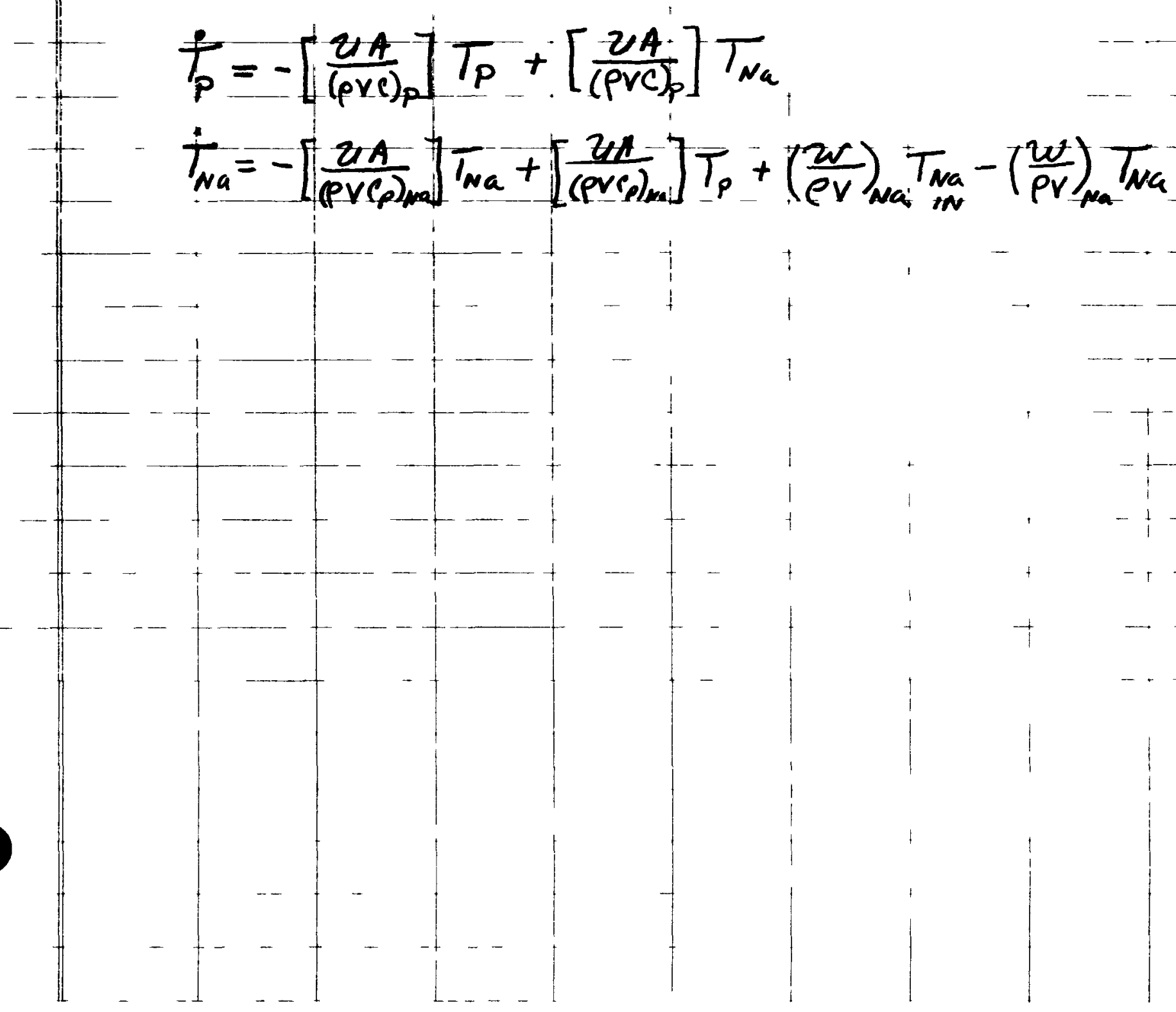


COMBUSTION ENGINEERING NUCLEAR POWER DEPARTMENT

$212^{\prime \prime}$ standard pipes $\left(24 G-1 M_{0}\right)$

$$
\begin{gathered}
D_{l}=12.0^{\prime \prime}, D_{0}=12.75^{\prime \prime}, L_{D e v}=45.6^{\prime} \\
w_{N a}=4.353 \times 10^{\circ} / 2_{1}=2.177 \times 10^{6} \mathrm{lbm} / \mathrm{he}=604.6 \mathrm{lbm} / \mathrm{sec}
\end{gathered}
$$

Properties are evaluated at temperature for full load.

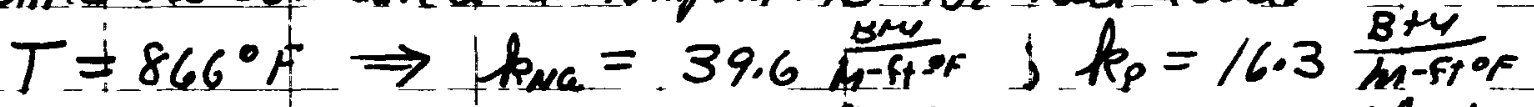

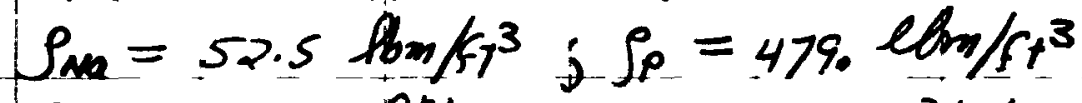

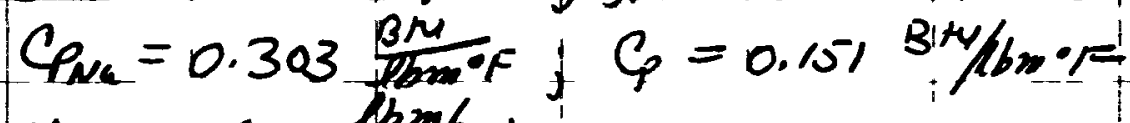

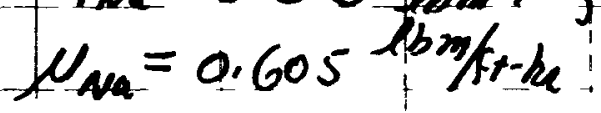

Thee nodal sets.

Wheat transfer coefficients

$$
\begin{aligned}
& \text { 1) } G_{N a}=\frac{W_{\text {Na }}}{A}=\frac{2.177 \times 10^{6}}{\frac{\pi}{4}(1)^{2}}=2.771 \times 10^{6} \frac{\mathrm{lbn}}{\mathrm{m}-\mathrm{f}^{2}} \\
& V_{N_{a}}=\frac{G}{\rho}=\frac{\left(\frac{\left.1.47 \times 10^{6}\right) / 3600}{52.5}\right.}{5.5}=14.67 \mathrm{st} / \mathrm{sec} \\
& R_{e}=\frac{G b_{i}}{\mu}=\frac{\left(2.77 \times 10^{6}\right)(1)}{.605}=4.581 \times 10^{6} \\
& P_{e}=R_{e} \frac{\mu C_{e}}{k}=\left(4.58 \times 10^{6}\right) \frac{0.605(.303)}{39.6}=21204 \\
& h_{\text {Na }}=\frac{k_{w_{G}}}{D_{l}}\left[5.0+.025 P^{8} P^{8}\right]=\frac{39.6}{(1)}\left[5.0+.025(21200)^{8}\right]
\end{aligned}
$$

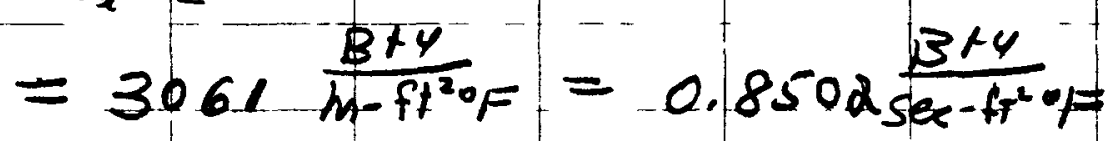

$$
\begin{aligned}
& \Rightarrow-\bar{D}=\left(\frac{D_{0}^{2}+D_{6}^{2}}{2}\right)^{1 / 2}=\left(\frac{12 \cdot 75^{2}+12^{2}}{2}\right)^{1 / 2}=12.38^{\prime \prime}
\end{aligned}
$$


COMBUSTION ENGINEERING NUCLEAR POWER DEPARTMENT

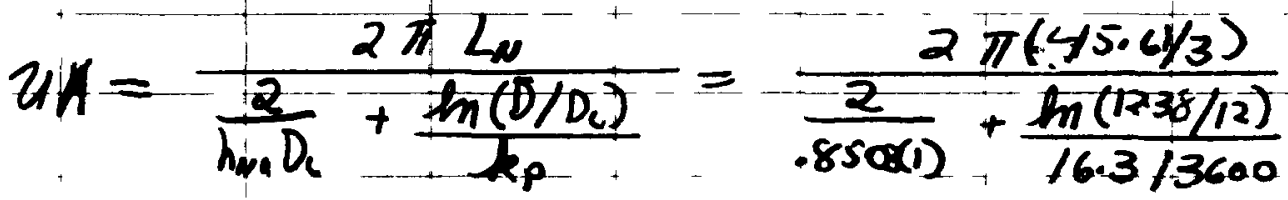

$$
\begin{aligned}
& =10.39 \frac{\mathrm{B}+4}{\mathrm{sec}^{\circ} \mathrm{F}} \text { per pup }
\end{aligned}
$$

Volumes

$$
\begin{aligned}
& V_{p}=\frac{\pi}{4}\left(D_{0}^{2}-D_{c}^{2}\right) L_{n}=\frac{\pi}{4} \frac{\left(20.75^{2}-12^{2}\right)}{144} \frac{45.6}{3}=1.539 \overline{F t^{3}} \text { per peps } \\
& V_{N}=\frac{\pi}{4} D_{c}^{2} L_{n}=\frac{\pi}{4}(1)^{2} \frac{45.6}{3}=11 \cdot \overline{9} \bar{F} t^{3} \text { per pipe }
\end{aligned}
$$

Coefficients:

$$
\begin{aligned}
& {\left[\frac{u A}{\left(e v()_{p}\right.}\right]=\frac{2(10.34)}{(479)_{2}(0.398)(.151)}=0.09289 \mathrm{sec}^{-1}} \\
& {\left[\frac{U A}{(\text { (Pvenou }}\right]=\frac{2(10.34)}{52.5[2(11.94)](.303)}=0.05444 \sec ^{-1}} \\
& \left(\frac{1}{e}\right)_{\mathrm{Na}}=\frac{1}{52.5(11.91)^{2}}=0.0007976 \mathrm{em} \mathrm{m}^{-1}
\end{aligned}
$$


COMBUSTION ENGINEERING NIICI EAR POWER DEPARTMENT

Summary

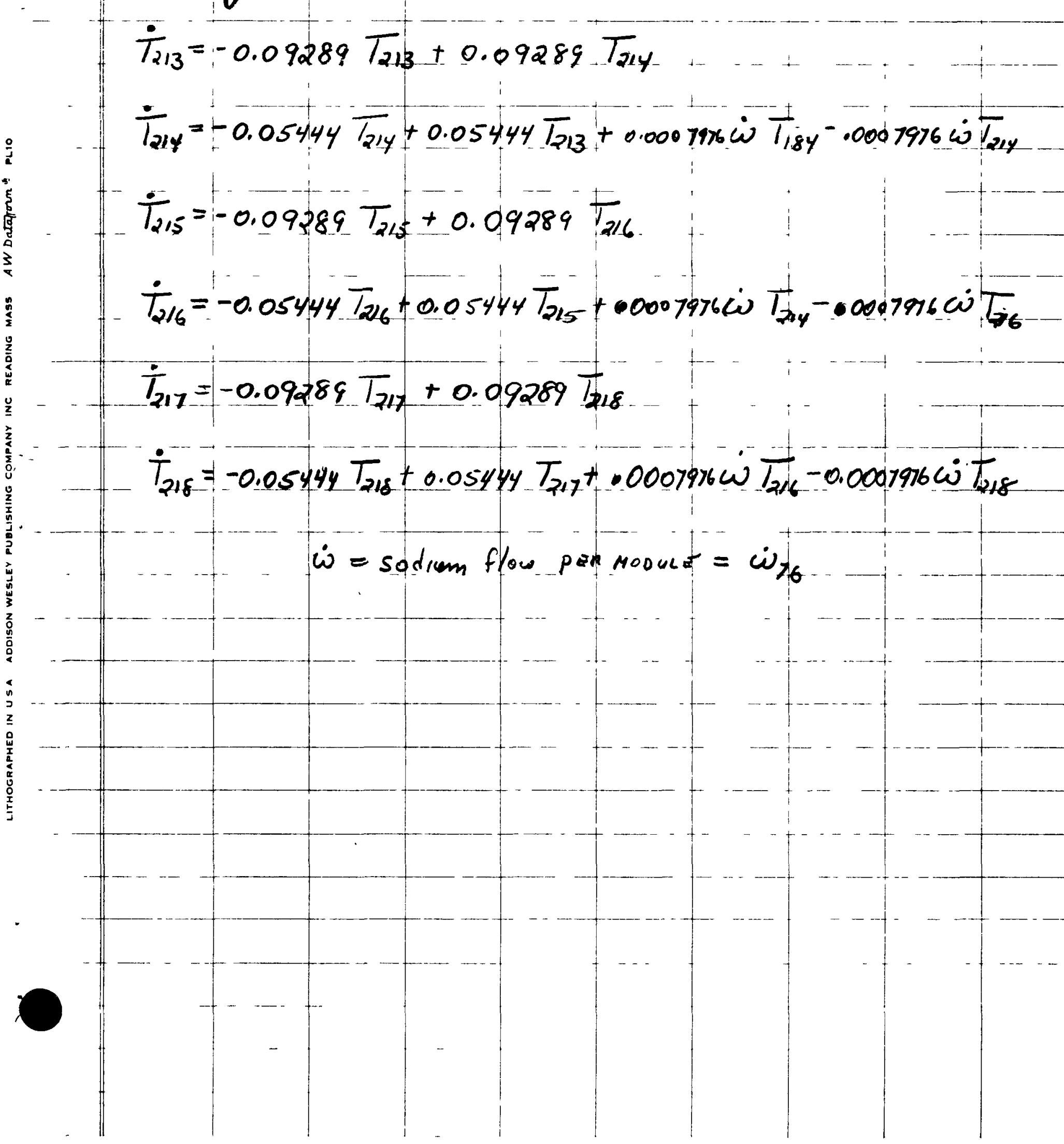


COMBUSTION ENGINEERING

NUCLEAR POWER DEPARTMENT

Saturated Stem/water Piping: $E V \rightarrow$ Dom

Energy balances for the pipe and steam footer nodes:

$$
\begin{aligned}
& \left.-(U A)\left(T_{p}-T_{\infty} / s_{p}\right)=(\bar{\rho} \bar{V})\right)_{p} \frac{d T_{p}}{d t}
\end{aligned}
$$

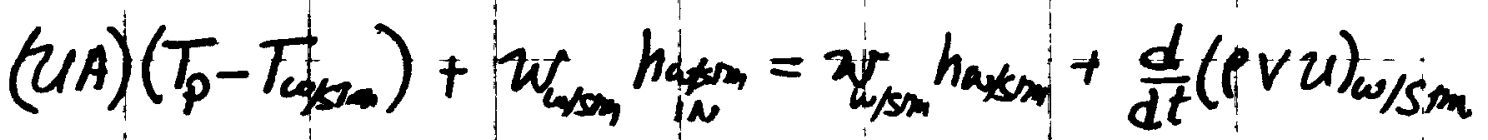

The following assumptions are made:

$$
\begin{aligned}
& \frac{d \rho}{d t}=0 \quad \text { (implead, seance continuity has not } \\
& \text { been included in the top mulation }) \\
& \frac{d p}{d t}=0 \rightarrow \frac{d(\rho u)}{d t}=\frac{d}{d t}(\rho h-p)=\frac{d}{d t}(\rho h)
\end{aligned}
$$

The results of these assumptions are sabstikited into the mingy balases. The equations are then seasoned unto stand as d format.

$$
\begin{aligned}
& \dot{T_{p}}=-\left[\frac{(U A)}{(P V C)_{p}}\right] T_{P}+\left[\frac{(U A)}{(P V C)_{p}}\right] T_{w / S T M}
\end{aligned}
$$

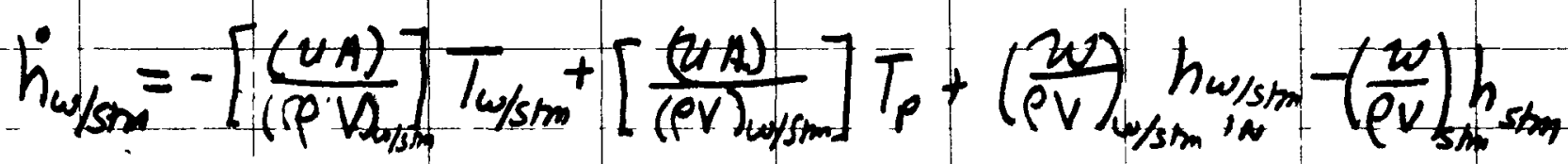

Twists and hus tm are connected by a temperatureenthalpy awe fit for a given pressure. 
Ci Ibustion Engineering. 'nc. EMGIMEERIMG DEPT.

STEAM/WATERBOILER CIRCULATION SYSTEM FOR ONE OF THREE SECONDARY SODIUM LOOPS Page No.1 1 OF 3 contract No. 7670 ... Name LMFBR STEAM GENERATOR

HEADERS, PIPING AND MISC. DATA

Quantities indicated are per boiler.

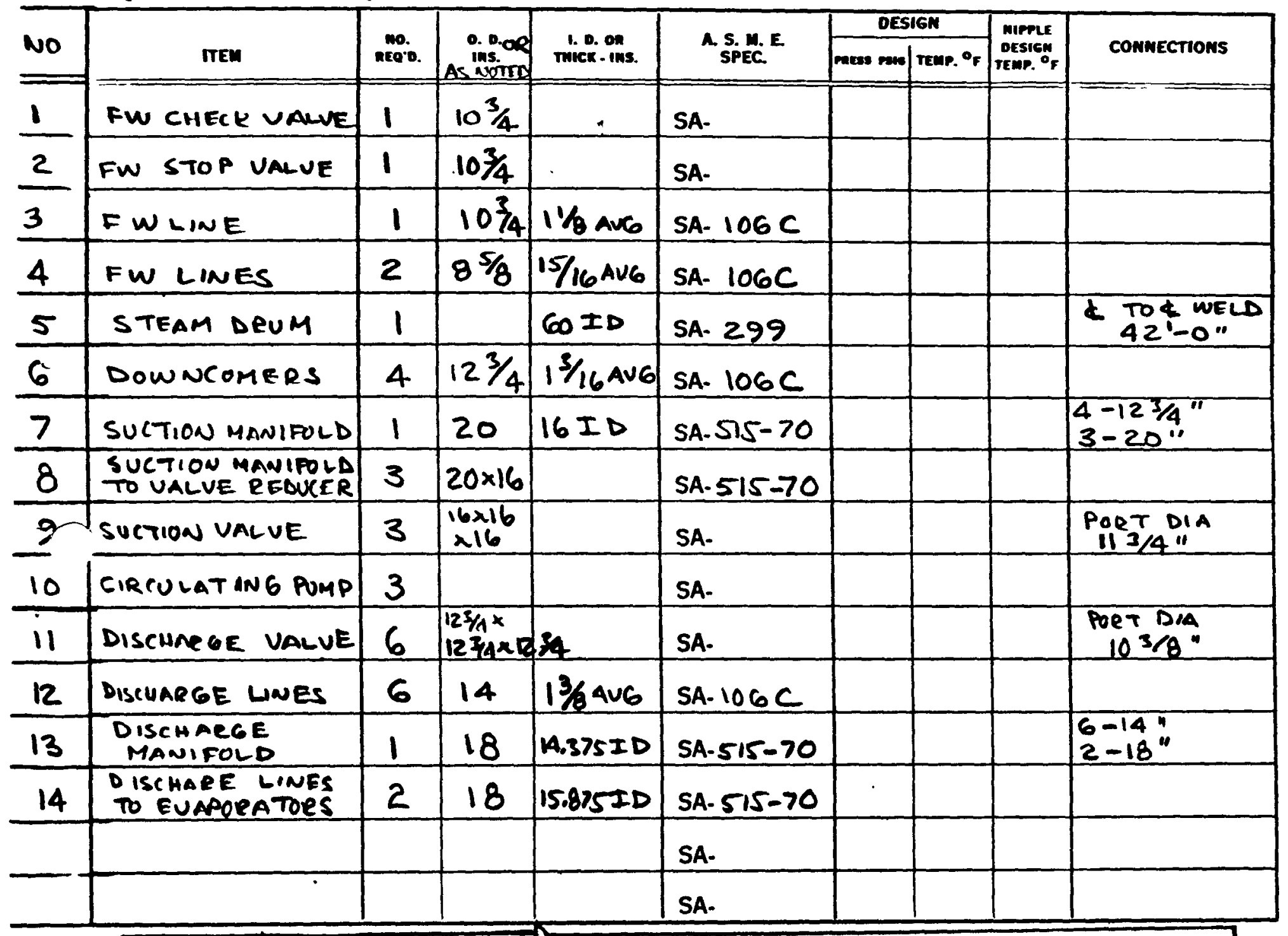

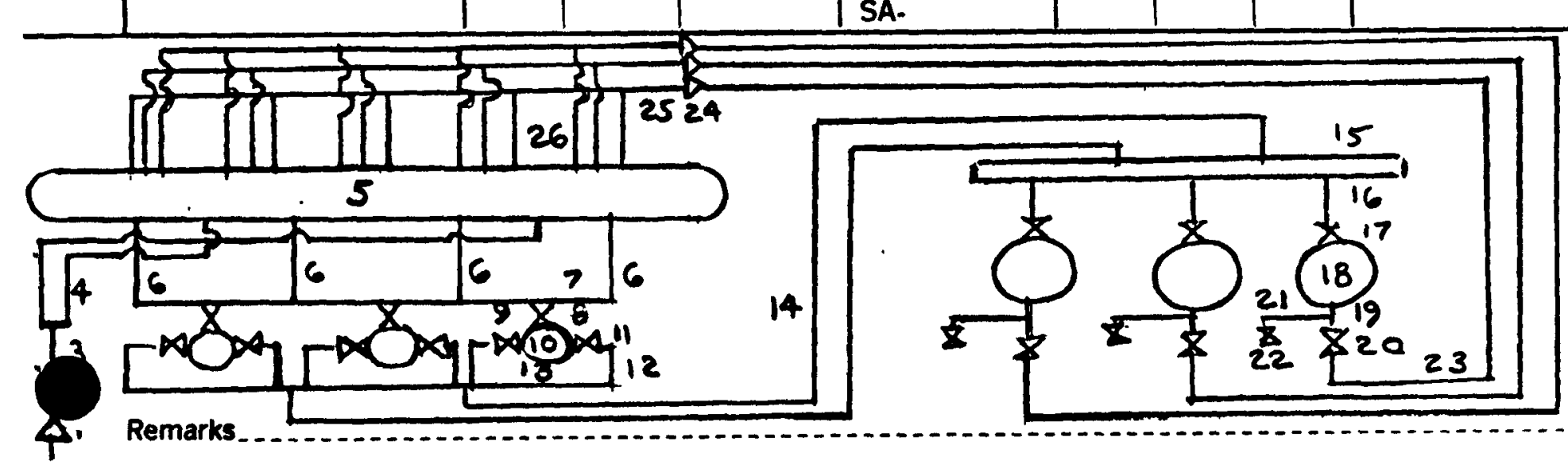

Enoinare $2 b$ Date $10 / 12 / 22$ 
Cr sbustion Engineering 'nc.

EMGINE. RI MG DEPT.

WIMOSOR, CONN.

STEAM/WATER BOILER CIRCULATION SYSTEM FOR ONE OF THEEE SECONDARY SODIUM LOOPS

Page No. $20 F 3$ contract No._76.7Q ..... Name _LMEBR _. STEAM_GENERATQR

\section{HEADERS, PIPING AND MISC. DATA}

Quantities indicated are per boiler.

\begin{tabular}{|c|c|c|c|c|c|c|c|c|c|}
\hline \multirow{2}{*}{ No } & \multirow[b]{2}{*}{ ITEM } & \multirow{2}{*}{ mo. } & \multirow{2}{*}{$\begin{array}{l}\text { O. D. } \\
\text { ins. }\end{array}$} & \multirow{2}{*}{$\begin{array}{l}\text { I. O. on } \\
\text { mick-ins. }\end{array}$} & \multirow{2}{*}{ A. S. M.E. } & \multicolumn{2}{|c|}{ DESIGN } & \multirow{2}{*}{$\begin{array}{l}\text { MIPPLE } \\
\text { DESIG } \\
\text { TEMP. }\end{array}$} & \multirow{2}{*}{ CONNECTIONS } \\
\hline & & & & & & mess.mesc| & Temr. ${ }^{\circ}$ & & \\
\hline 15 & $\begin{array}{l}\text { EUAPORATOR } \\
\text { INLET HDE. }\end{array}$ & 1 & 16 & $12.75 I D$ & SA-S75-70 & & & & $\begin{array}{l}2-18^{\prime \prime} \\
3-16^{\prime \prime}\end{array}$ \\
\hline 16 & $\begin{array}{l}\text { EUAPOPATOR } \\
\text { INLET LINES } \\
\end{array}$ & 3 & 16 & $19 / 16$ av6 & SA- $106 C$ & & & & \\
\hline 17 & $\begin{array}{l}\text { EVAPOCATOR INLET } \\
\text { QUICE CLOSINC UALUE }\end{array}$ & 3 & & & SA- $\quad \cdot$ & & & & \\
\hline 18 & EUAPORA TOE & 3 & & & SA- & & & & \\
\hline 19 & $\begin{array}{l}\text { EUAPOQATOR MUTURE } \\
\text { OUTLET }\end{array}$ & 3 & 16 & $1 \%$ AvG & SA. $106 C$ & & & & \\
\hline 20 & $\begin{array}{l}\text { EUAPOPATOR OUTLET } \\
\text { QUICK CLOSI NG UALUE }\end{array}$ & 3 & & & SA. & & & & \\
\hline 21 & $\begin{array}{l}\text { EUAPORATOR OUTLET } \\
\text { DUMP LINE }\end{array}$ & 3 & 16 & $1 \% / 16^{A} v_{6}$ & SA. $106 C$ & & & & \\
\hline 22 & $\begin{array}{l}\text { EVAPORATOR OUTLET } \\
\text { QUICK OPENIUE UALUE }\end{array}$ & 3 & & & SA. & & & & \\
\hline 27 & $\begin{array}{l}\text { EVAPORATOR OUTLT } \\
\text { LFADS TO DEUM }\end{array}$ & 3 & 16 & $1 \% / 16$ AV6 & SA. $10 G C$ & & & & \\
\hline 24 & $\begin{array}{l}\text { OUT LET LEEAD } \\
\text { REDUCER }\end{array}$ & 3 & $20 \times 16$ & & SA- $515-70$ & & & & \\
\hline 25 & $\begin{array}{l}\text { MIXTURE } \\
\text { DITEIBUTION BOTTLE }\end{array}$ & 3 & 20 & 16 FD & SA. $515-70$ & & & & $5 "-20$ \\
\hline 26 & $\begin{array}{l}\text { MIXTURE } \\
\text { DISTRIBUTION LINES }\end{array}$ & 60 & 5 & $0.500 \mathrm{HWT}$ & SA. $106 B$ & & & & \\
\hline 27 & $\begin{array}{l}\text { DRUM SAT STEAM } \\
\text { OUTLET LINES }\end{array}$ & 18 & 5 & $0.500 \mathrm{MWT}$ & SA. $106 B$ & & & & \\
\hline \multirow[t]{3}{*}{28} & $\begin{array}{l}\text { SAT STEAM } \\
\text { COLECTION HOP }\end{array}$ & 1 & 14 & $11.125 \pm 0$ & $5 A .575-70$ & & & & \\
\hline & & & & & SA. & & & & \\
\hline & & & & & SA. & & & & \\
\hline
\end{tabular}
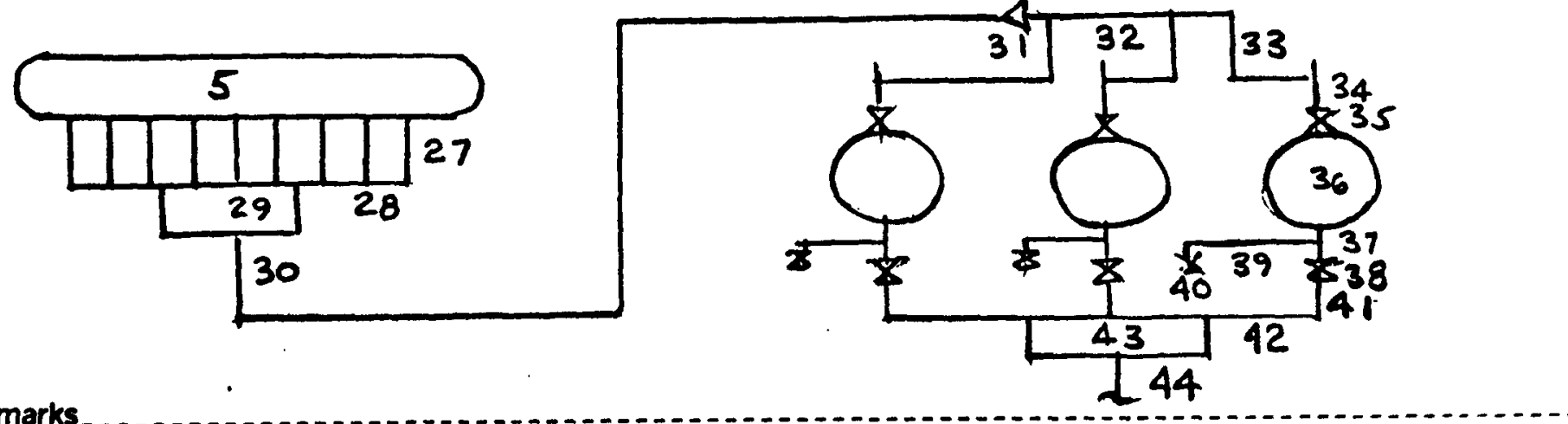

Remarks 


\section{C sbustion Engineering 'nc. \\ ENGINEERING DEPT. \\ WIMOSOR, CONM.}

STEAM/WATER BOILER CIRCULATION SYSTEM FOR ONE OF THREE SECONDARY SODIUM LOOPS

Page No.3 3 OES contract No. 7670 .... Name LMFBR STEAM GENERATOR

\section{HEADERS, PIPING AND MISC. DATA}

Quantities indicated are per boiler.

\begin{tabular}{|c|c|c|c|c|c|c|c|c|c|}
\hline \multirow{2}{*}{ vo } & \multirow[b]{2}{*}{ ITEM } & \multirow{2}{*}{ mo. } & \multirow{2}{*}{$\begin{array}{l}\text { O. } 0 . \\
\text { ims. }\end{array}$} & \multirow{2}{*}{$\begin{array}{l}\text { Sinc. on } \\
\text { rwick-oms. }\end{array}$} & \multirow{2}{*}{ A. S. M.E. } & \multicolumn{2}{|c|}{ DESIGM } & \multirow{2}{*}{ 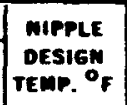 } & \multirow{2}{*}{ CONWECTIONS } \\
\hline & & & & & & mess mose & remp. of & & \\
\hline$\geq 9$ & $\begin{array}{l}\text { SHTRR INLET LEAD } \\
\text { SATCHEL HANAE }\end{array}$ & 2 & $12 \frac{3}{4}$ & $1 / / 4$ Av6 & SA- $106 C$ & & & & - \\
\hline 30 & S'H'TER INLET & 1 & 16 & $19 / 16$ & SA. $106 C$ & & & & \\
\hline 31 & $\begin{array}{l}\text { SHT'R INLET } \\
\text { LEND REDUCER } \\
\end{array}$ & 1 & $22 \times 16$ & & SA. $515-70$ & & & & \\
\hline 32 & $\begin{array}{l}\text { S'HITE INLET } \\
\text { DISTPIBUTION BOTTLE }\end{array}$ & 1 & 22 & $17.375 I D$ & SA. $575-70$ & & & & \\
\hline 33 & $\begin{array}{l}\text { S'H'TR INLET } \\
\text { LINES }\end{array}$ & 15 & 5 & $0.500 \mathrm{MwT}$ & SA-106 B & & & & \\
\hline 34 & $\begin{array}{l}\text { SUDFRHEATER } \\
\text { IVLET }\end{array}$ & 3 & 14 & $15 / 16^{A V 6}$ & SA. $106 \mathrm{C}$ & & & & \\
\hline 35 & $\begin{array}{l}\text { SH TR INLET } \\
\text { QUIIE CLOSING UALUE }\end{array}$ & 3 & & & SA- & & & & \\
\hline 36 & SUPEEHEATER & 3 & & & SA- & & & & \\
\hline $3-$ & S'H'T'R OUTLET & 3 & 14 & $10.25 I D$ & $S A .387 B$ & & & & \\
\hline 38 & $\begin{array}{l}\text { SH'T'R OUTLET } \\
\text { QUICK CLOSING VALUE }\end{array}$ & 3 & & & SA. & & & & \\
\hline 39 & $\begin{array}{l}\text { SH'TIR OUTLET } \\
\text { DUMPLINE }\end{array}$ & 3 & 14 & $10.25 \pm D$ & $S A-387 B$ & & & & \\
\hline 40 & $\begin{array}{l}\text { S'H'TR OUTLET } \\
\text { QUICK OPENIAKG VAWE }\end{array}$ & 3 & & & SA. & & & & \\
\hline 41 & \begin{tabular}{|c|}
$S^{\prime} H ' T^{\prime} R$ \\
LEAO OUTLET
\end{tabular} & 3 & 14 & 10.25 ID & $S A-387 B$ & & & & \\
\hline 42 & $\begin{array}{l}\text { S'HITR OUTLET } \\
\text { MANIEOLD }\end{array}$ & 1 & 14 & :9.75ID & SA. $387 B$ & & & & \\
\hline 43 & $\begin{array}{l}\text { S'H'7P LEAO } \\
\text { SATCAFL HANDLE }\end{array}$ & 2 & $12 \frac{3}{4}$ & $9.25 I 0$ & SA. $387 B$ & & & & \\
\hline 44 & SIH'T'R LEAD & 1 & 16 & $|11.7510|$ & SA. $387 B$ & & & & \\
\hline
\end{tabular}

GEUTRAL NOTES:

1- materials listed aeE SURUECt to fuRther Review.

Remarks 
COMBUSTION ENGINEERING NUCLEAR POWER DEPARTMENT

$W_{\text {sim /w }}=1390473 \mathrm{etm} / \mathrm{hr}$ Hew per es module $=4171419 \mathrm{l} \mathrm{lm} / \mathrm{h}$ Hear per loop

Properties are evaluated at pressure and temperature for full load.

$$
\begin{aligned}
& P_{\text {sat }}=2645 \text { psi } \Rightarrow \text { lsat }=6765^{\circ} \mathrm{F}
\end{aligned}
$$

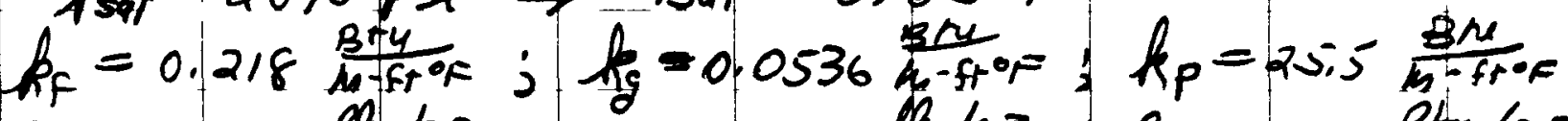

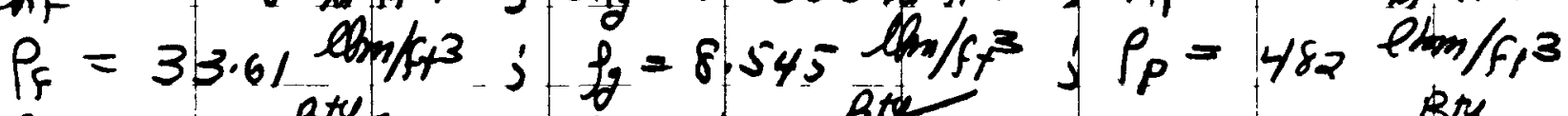

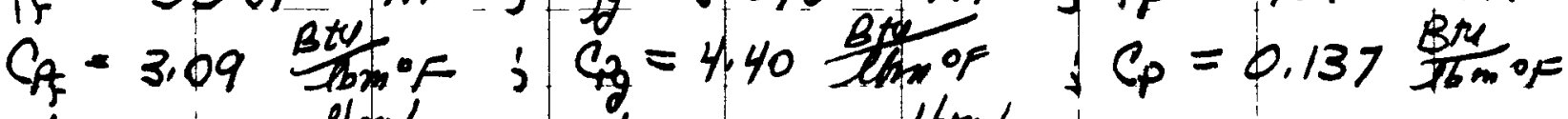

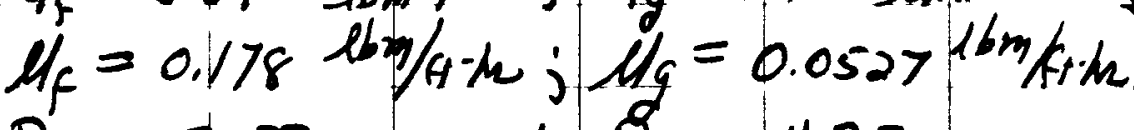

$$
\begin{aligned}
& P_{r_{f}}=2.03 \quad ; P_{r_{g}}=4.32 \\
& \bar{\rho}=\frac{\rho_{g} P_{f}}{(1-x) \rho_{g}+x \rho_{s}}=\frac{33.61(8.345)}{.714(8.345)+.286(33261)}=18.28 \frac{\rho b_{m}}{f_{T}^{3}}
\end{aligned}
$$

3 Euaponaton Outlets - Mixture distribution bottles $\&$ Reduce ns

Outlet: 16" OD, 1\$16" wall, apporemaily 16' long

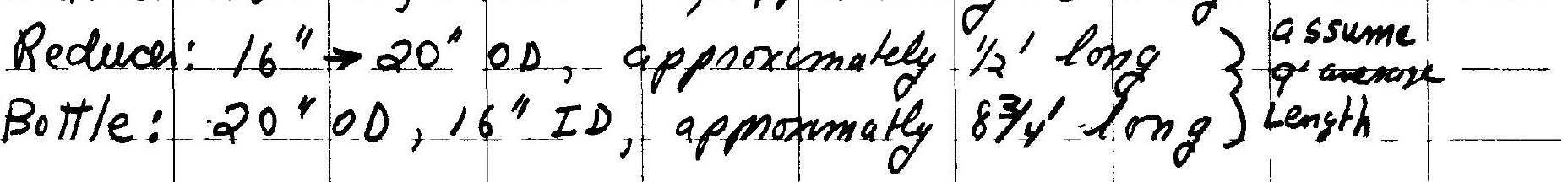

$$
\begin{aligned}
& V_{\text {netul }}=3\left[\frac{\pi}{4} \frac{\left(16^{2}-12 k^{2}\right)}{144}\right] 16+3\left[\frac{\pi}{4} \frac{\left(20^{2}-16^{2}\right)}{144}\right] 9 \\
& =2362+21.21=44.83 \mathrm{ft}^{3} \\
& V_{\text {sinew. }}=3\left[\frac{\pi}{4}\left(\frac{12 / 4}{12}\right)^{2}\right] 16+3\left[\frac{\pi}{4}\left(\frac{16}{12}\right)^{2}\right] 9 \\
& =43.40+37.70=81.10 .9 t^{3}
\end{aligned}
$$


COMBUSTION ENGINEERING

NUCLEAR POWER DEPARTMENT

Assume that the heat transfer between the stean/water mixture and the pipe es charateryed by the flow in the outlet pipes. The mystery How is, gepresally, under achabatis conditions. The heat transfer cuefferent, under these circumstances, sepusents a potential to titans. heat. Since boiling or condensation is not ocquising: in the pope uncles design conditions, this heat trons fa potential is assumed to be characterized on a two

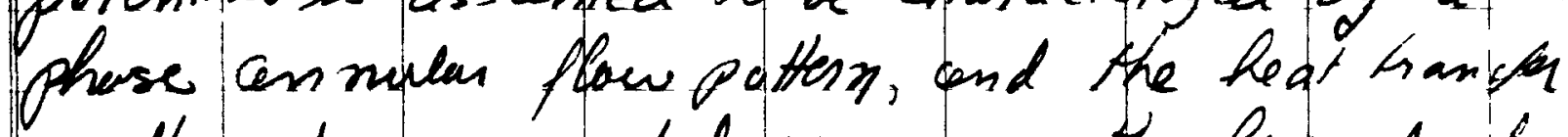
coefreicut is computed ass ann ing the liquid those Slows alone.

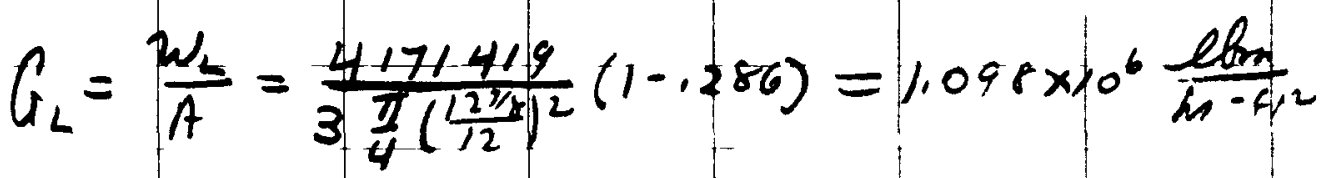

$$
\begin{aligned}
& R_{R_{L}}=\frac{Q_{-L} D}{\mu_{L}}=\frac{\left(1.098 \times 10^{6}\right)\left(\frac{\left.1 M^{\frac{1}{2}}\right)}{T_{2}}\right)}{.178}=6.619 \times 10^{6} \\
& h_{L}=\frac{k_{2}}{a_{2}}\left[.023 R_{e_{L}} P_{r_{1}}^{.4}\right]=\frac{0.311}{127 / 12}\left[.023\left(6.619 \times 10^{6}\right)^{.8}(2.33)_{1}^{19}\right] \\
& =1938 \frac{B+4}{m-f t^{20}}
\end{aligned}
$$

$$
\begin{aligned}
& \bar{D}_{0}=\left(\frac{a^{2}+D_{0}^{2}}{2}\right)^{1 / 2}=\left(\frac{27 / \gamma^{2}+16^{2}}{2}\right)^{\prime / 2}=14.52^{\prime \prime} \\
& \bar{D}_{H}=\left(\frac{16^{2}+10^{2}}{2}\right)^{1 / 2}=18.1{ }^{\prime \prime}
\end{aligned}
$$

The overall heat transfer coefficient 4 the sum of the coefficient ale duro pipe sections. 
COMBUSTION ENGINEERING

NUCLEAR POWER DEPARTMENT

$$
\begin{aligned}
& U_{A}=\frac{2 \pi L_{0}}{h \frac{2}{D_{c}}+\frac{h(D / D)}{h_{D}}}+\frac{2 \pi 4}{\frac{2}{h D_{i}}+\frac{\ln \left(3 / D_{D_{n}}\right)}{h_{D}}}
\end{aligned}
$$

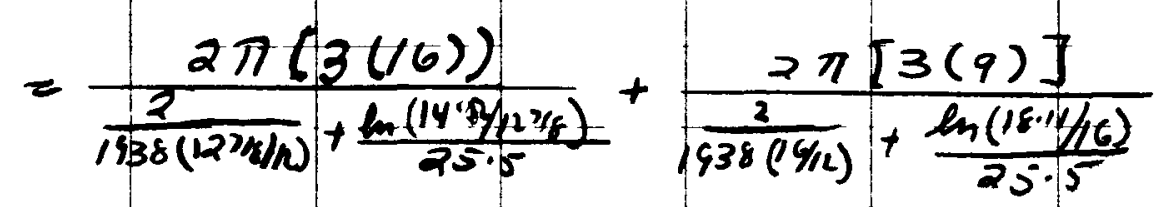

$$
\begin{aligned}
& =83247 \frac{\beta+4}{h_{1}-0 \%}=23.12 \frac{3+4}{\sec 012}
\end{aligned}
$$

Coefficients

$$
\begin{aligned}
& {\left[\frac{u A}{(\rho+C)_{p}}\right]=\frac{23.12}{(482)(44.83)(.137)}=1007810 \mathrm{sec}^{-1}} \\
& {\left[\frac{u_{A}}{\left(\mathcal{C} V v_{s / \omega}\right.}\right]=\frac{23.12}{(18.28)(81.10)}=0.01560 \mathrm{sec} 4} \\
& \left(\frac{1}{\rho v}\right)_{s / w}=\frac{1}{(1828)(81.10)}=0.000674 \mathrm{eth}^{-1}
\end{aligned}
$$

2) 2 sets (306-307\& $38 \mathrm{~L}$ and $308-309 \$ 382$ )

3 sets of 20 outlet leads to the separation chum. Each lead has a 5"00, 1/2" wall, and a typal length of 56" is assumed.

$$
\begin{aligned}
& U_{\text {Metal }}=3\left\{20\left[\frac{\pi}{4} \frac{\left(5^{2}-4^{2}\right)}{144}\right] 28\right\}=82.47 \mathrm{ft}^{3} \\
& Z_{\mathrm{sm} / \mathrm{H}}=3\left\{20\left[\frac{\pi}{4}\left(\frac{4}{12}\right)^{2}\right] 28\right\}=146.6 \mathrm{ft}^{3}
\end{aligned}
$$

The heat thonsfec coefficient for the mixture is computed 
COMBUSTION ENGINEERING

NIIII FAR POWIFR DEPARTMENT

based on the model descried above.

$$
\begin{aligned}
& G_{L}=\frac{w_{C}}{d}=\frac{4171+19(1-286)}{60 \frac{\pi}{4}\left(\frac{4}{2}\right)^{2}}=5.688 \times 10^{5} \frac{2 \mathrm{bm}}{h_{\mathrm{s}}-\mathrm{rr}^{2}} \\
& R_{e_{1}}=\frac{G_{L} D}{\mu_{L}}=\frac{\left(5.688 \times 10^{5}\right)\left(\frac{4}{8}\right)}{0.778}=1.065 \times 10^{6} \\
& h_{L}=\frac{k_{1}}{D}\left[.023 \beta_{p_{l}}^{.8} P_{r_{2}}^{.4}\right]=\frac{0.218}{(4 / 1 / 2)}\left[.023\left(1.065 \times 10^{6}\right)^{.8}(2.03)^{14}\right] \\
& =1447 \frac{B(4}{h-f^{2} t^{20}}=
\end{aligned}
$$

Position of the pipe node

$$
\bar{D}=\left(\frac{D^{2}+p^{2}}{2}\right)^{1 / 2}=\left(\frac{4^{2}+s^{2}}{2}\right)^{1 / 2}=4.5281
$$

The overall frat transfer coefferent

$$
\begin{aligned}
& U A=\frac{2 \pi 4 \text { io }}{\frac{2}{n D_{l}}+\frac{\ln (D / D)}{k_{p}}}=\frac{-2 \pi[60(28)]}{\frac{2}{1447(1 / 12)}+\frac{\ln (4.928 / 4)}{25.5}} \\
& =1172000 \frac{B E Y}{M O F}=325.5 \frac{B F 4}{\sec ^{\circ} \mathrm{F} F} \\
& \text { Coefperients } \\
& {\left[\frac{U A}{(P V C)_{P}}\right]=\frac{325.5}{(482)(82.47)(.137)}=0.05977 \mathrm{sec}} \\
& {\left[\frac{4 A}{(\rho v)_{\text {A. }}}\right]=\frac{325.5}{(18.28)(146.6)}=0.1275 \mathrm{sec}^{-1}} \\
& \left(\frac{1}{e y}\right)_{\text {mix }}=\frac{1}{(18.28)(146.6)}=0.0003732 \mathrm{etm}^{-1}
\end{aligned}
$$


COMBUSTION ENGINEERING

NUCLEAR POWER DEPARTMENT

Summary

$$
\begin{aligned}
& \dot{T}_{304}=-(.007810) T_{304}+(.007810) T_{380} \\
& \dot{h}_{305}=-(0.01560) T_{380}+(0.01560) T_{304} . \\
& \pm(.0006745) \dot{\omega}_{r} h_{205}-(.0006745) \dot{\omega}_{r} h_{305} \\
& \dot{T}_{306}=-(.05977) T_{306}+(.05977)-T_{381} \\
& \dot{h}_{307}=-(.1215) T_{381}+(.1215) T_{306} \\
& +(.000373 p) \dot{\omega}_{r} h_{305}-(.0003732) \dot{\omega}_{r} h_{307} \\
& \dot{T}_{308}=-(.05977) T_{308}+(.05977) T_{382} \\
& \hbar_{309}=-(.1215) T_{322}+(.1215) T_{308} \\
& +(.0003732) \dot{\omega}_{r} h_{307}-(10003732) \dot{\omega}_{r} h_{300}
\end{aligned}
$$$$
\dot{\omega}_{.}=\text {nexus flow pe loop }=\dot{\omega}_{85}
$$ 
COMBUSTION ENGINEERING III FAR POWER DEPARTMENT

The nodes representating the temperature of the steam f water mixture in the piping connecting the euaposato with the steam separation drum are connected to the corresponding enthalpy mode by "How equations". These equations can be used as appsopiote curve fits, he. phegnosials in h or a function of tome.

In general

$$
k_{1}=\epsilon_{1} ; z=F_{|k|}=\text { modal value }
$$

1) $k<0$

$$
\begin{aligned}
\dot{c}=\epsilon_{2} z & +\bar{\epsilon}_{3 z^{2}}+\frac{\epsilon_{4}}{z}+\frac{\epsilon_{5}}{z^{2}} \\
& +\epsilon_{6}+\epsilon_{7} z^{3}+\epsilon_{8} z^{4}+\epsilon_{9} z^{5}+\epsilon_{10} z^{6}
\end{aligned}
$$

2) $k \geqslant 10$

a) $\epsilon_{0}=0$

$$
\dot{v}=H+R+\epsilon_{2}+\epsilon_{5} \exp \left(\epsilon_{6} t+\epsilon_{7} t^{2}\right)
$$

b) $6,0>0$

$$
\begin{aligned}
& \dot{w}=\left\{\begin{array}{l}
H+\epsilon_{10}, t_{m} \leqslant 0 \\
H+R\left(t_{m}^{*}\right)+\epsilon_{2}+\epsilon_{5} \exp \left(\epsilon_{0}+\epsilon_{m} t_{m}^{2}\right), t_{m} \geqslant 0
\end{array}\right. \\
& t_{m}=t-\left(t_{s}+\epsilon_{\delta}\right) ; \quad t_{m}^{*}=\epsilon_{q}-t_{m}
\end{aligned}
$$

The pope modes well be at saturated conditions fin most of the considered transients. Consequently the temperature nodes depend directly on the messur. 
COMBUSTION ENGINEERING "MIn' FAP POWER DEPARTMENT

If the pressure as pesescibed for the particular transient, the associated saturation temperature is: determined. Curve fits in the form of pea) a pub) would be used. If superheated stem exist in the outlet region, a polynomial curve fit for enthalpy -temperature at a given pressure must be used. Curve fits in the form of (1) clonk would be used.

To nomad transients the popssure well be ven near the full load operating level and the crusponding saturation temperature is appoxprately 676.5 of. Ope of thee forms may be used.

a) $\epsilon_{1}=-$ (convecting node number, $\left.-305,-307,-309\right)$

$\epsilon_{6}=676,5$, all then $\epsilon^{\prime} s=0$

b) $\epsilon_{1}=-369$

all $\epsilon^{2}=0$ except one $\epsilon=676.5$

c) $G_{1}=0$

$\epsilon_{2}=676.5$, all other $\epsilon_{s}=0$ 
COMBUSTION ENGINEERING

NUCLEAR POWER DEPARTMENT

Summary

$$
\begin{aligned}
& T_{380}=\dot{\omega}_{51} F_{369} ; \\
& T_{381}=\dot{\omega}_{52} \mid F_{369} ;
\end{aligned}
$$

$$
\epsilon_{1}=-305,-369,00
$$

$\frac{ْ}{2}$

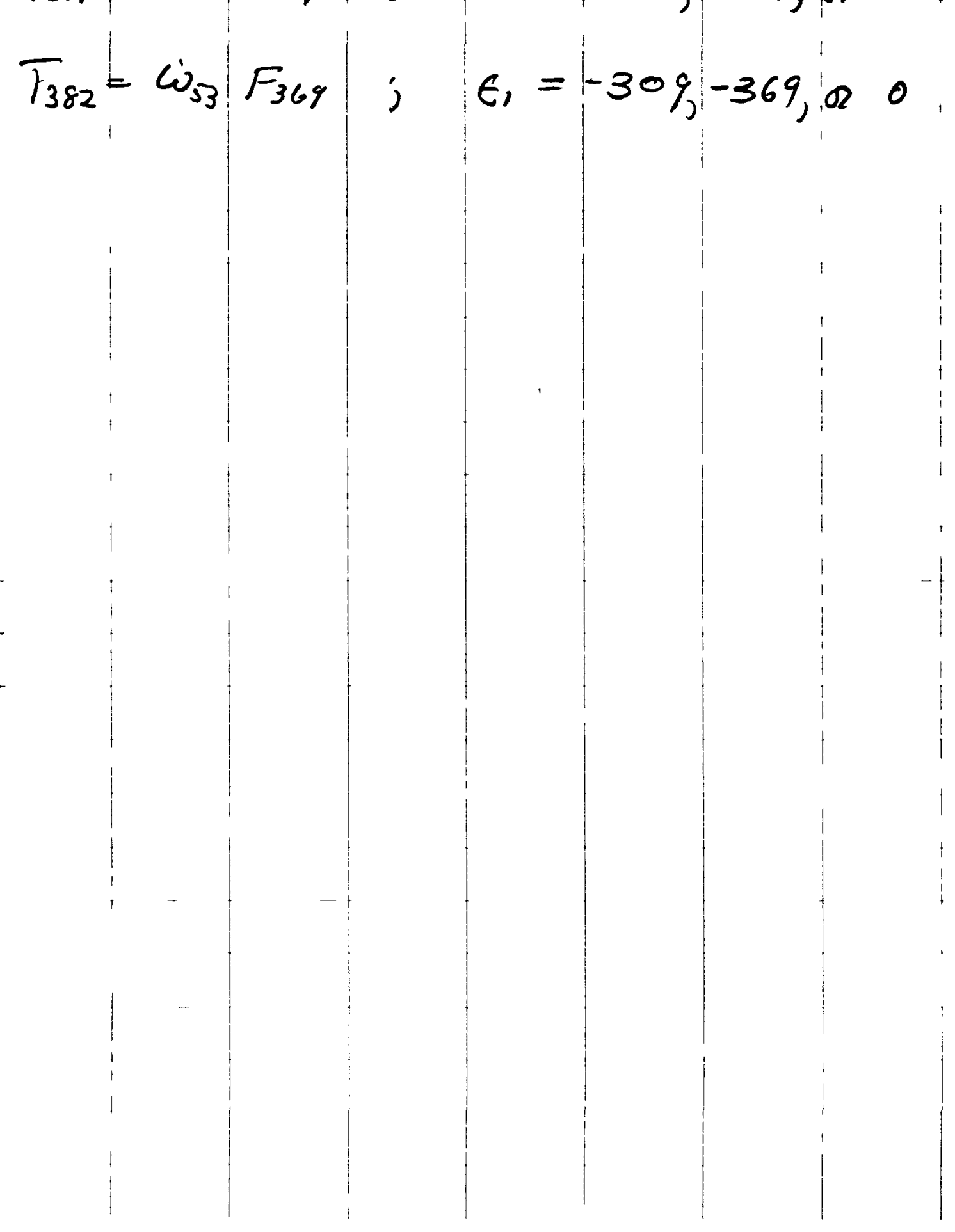


COMBUSTION ENGINEERING NUCLEAR POWER DEPARTMENT

Sarunated Steam Piping: Dave $\rightarrow$ SH

Energy balances fop pye and steams nodes

$$
\begin{aligned}
& -(U A)\left(T_{p}-T_{s t m}\right)=(\rho \vee C)_{p} \frac{d T_{p}}{d t} \\
& (U A)\left(T_{p}=T_{s m_{m}}\right)+W_{s m} h_{s_{N}}=W_{s m} h_{s m m}+\frac{d}{d t}(\rho \vee U)_{s m m}
\end{aligned}
$$

The following assumptions are made:

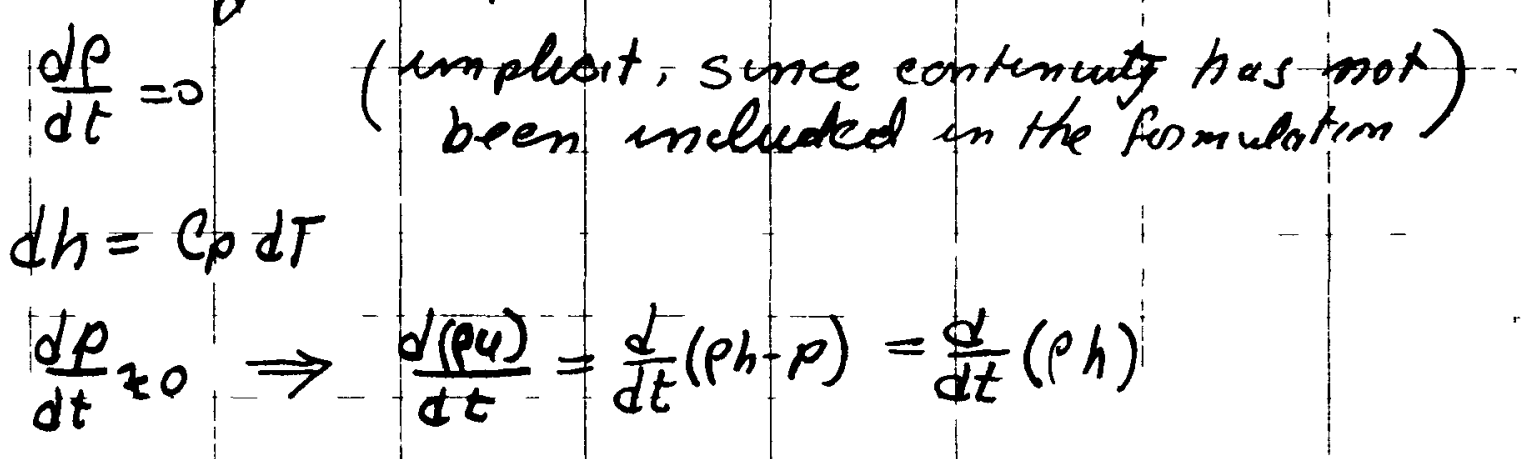

The results of these assumptions are substituted into the energy bulanoes. The equations ape then seassanged into standard format

$$
\begin{aligned}
& \dot{T}_{p}=-\left[\frac{(U A)}{(P V C)_{p}}\right] T_{P}+\left[\frac{(U A)}{(P \vee C)_{p}}\right] T_{s t m}
\end{aligned}
$$

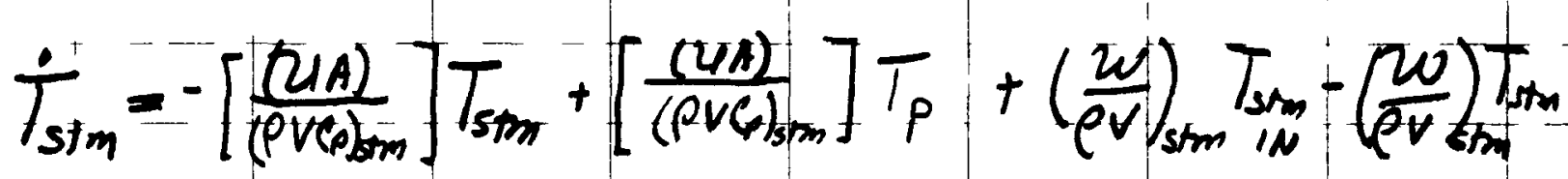


COMBUSTION ENGINEERING NUCLEAR POWER DEPARTMENT

$w_{s}=397278$ ld ml Flow per SH module $=191834$ lbm/n

Properties are evaluated at pressure and temperature for full load

$$
\begin{aligned}
& P_{\text {sat }}=2612 \text { psia } \Rightarrow T=674.6^{\circ} \mathrm{F}
\end{aligned}
$$

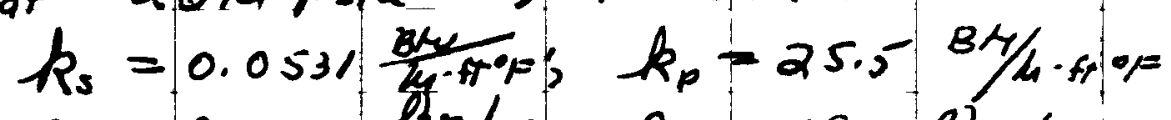

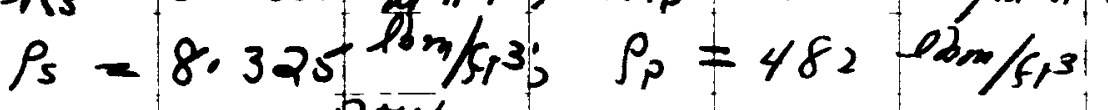

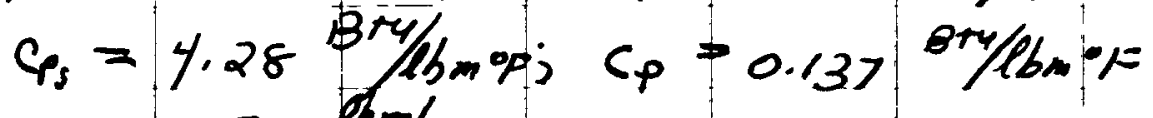

$$
\begin{aligned}
& \mu_{s}=.0526 \mathrm{em} / \mathrm{m}-\mathrm{fr} \\
& P_{r_{s}}=.4 .24
\end{aligned}
$$

3 Nodal sets

1) 1 set $(333-334)$

18 outlet lings form the chan to a collection header. Each line is 5" OD, $1 / 2$ " wall, and a typical length of $21^{\prime}$ is assumed.

$$
\begin{aligned}
& v_{\text {petal }}=18\left[\frac{\pi}{4} \frac{\left(\frac{5^{2}-4^{2}}{14}\right)}{1^{4}}\right] 21=18.56 \mathrm{ft}^{3} \\
& V_{\$ \mathrm{tm}}=18\left[\frac{\pi}{4}\left(\frac{4}{12}\right)^{2}\right] 21=32.99 \mathrm{ft}^{3}
\end{aligned}
$$

The steam heat toans/en cueflucient

$$
\begin{aligned}
& G_{s}=\frac{W_{s}}{A_{s}}=\frac{119183 \mathrm{y}}{18 \frac{\pi}{4}\left(\frac{4}{12}\right)^{2}}=7587 \times 10^{5} \frac{\mathrm{mbm}}{\mathrm{m}-\mathrm{Fst}^{2}} \\
& V_{s}=\frac{G_{s}}{\rho_{s}}=\frac{1.587 \times 10^{5} / 3600}{83^{2} 5}=25.32 \mathrm{ft} / \mathrm{sec}
\end{aligned}
$$


COMBUSTION ENGINEERING NUCLEAR POWER DEPARTMENT

$$
\begin{aligned}
& R_{e_{5}}=\frac{C_{S} D}{\mu_{s}}=\frac{7.587 \times 10^{5}\left(\frac{4}{12}\right)}{.0526}=4.008 \times 106 \\
& h_{s}=\frac{A_{s}}{D_{c}}\left[.023 R_{e}{ }^{8} P_{r_{2}} \cdot 4\right]=\frac{.0531}{4 / 12}\left[.023(4.008+10)^{-8}(4.24)^{-.4}\right] \\
& =1447 \frac{d+4}{m-s^{2} T_{0}=}
\end{aligned}
$$

position of pipe socle

$$
\bar{D}=\left(\frac{D^{2}+p_{0}^{2}}{2}\right)^{2}=\left(\frac{5^{2}+4^{2}}{2}\right)^{1 / 2}=4.528^{\prime \prime}
$$

The retral hit transfer coefficient

$$
\begin{aligned}
& \text { aAA } \\
& \frac{2 \pi L_{\text {rot }}}{+\frac{\ln (5 / D)}{k p}}=\frac{2 \pi[(18)(21)]}{\frac{2}{1447\left(\frac{1}{2}\right)}+\frac{\ln (4.521 / 4)}{25.5}} \\
& =263600 \frac{B H}{x_{1}-0 . F}=73.23 \frac{B / 4}{\sec \text { of }} \\
& {\left[\frac{\partial A}{(\rho)(C)_{\rho}}\right]=\frac{73.23}{(482)(18.56)(.137)}=0.05975 \mathrm{sec}^{-1}} \\
& {\left[\frac{y A}{(9 \vee 8) s}\right]=\frac{73.23}{(8.325)(32.99)(4.28)}=0.06230 \mathrm{sec}^{-1}} \\
& \left(\frac{1}{\rho v}\right)_{s}=\frac{1}{(8.325)(3299)}=0.003641 \mathrm{ebm}-1
\end{aligned}
$$


COMBUSTION ENGINEERING

NUCLEAR POWER DEPARTMENT

2) $1 \operatorname{set}(335-336)$

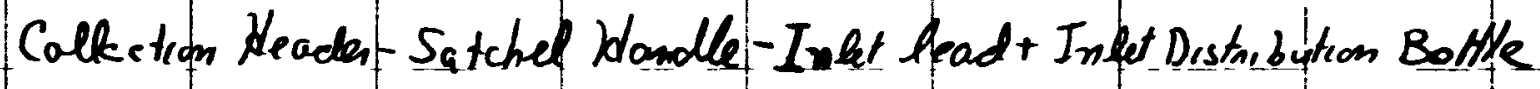

Pleader: 14" OD, 1118 "ID, 42' long

Standee: 2, 123/4"00, 4"1" wall, approximately 15' developed length

LEAD: 16" OD, 19/1 wall, approximately 18' developed length

Reduce n: $16^{\prime \prime} \rightarrow 22^{\prime \prime} D D$, approximately "I: long 3 assume

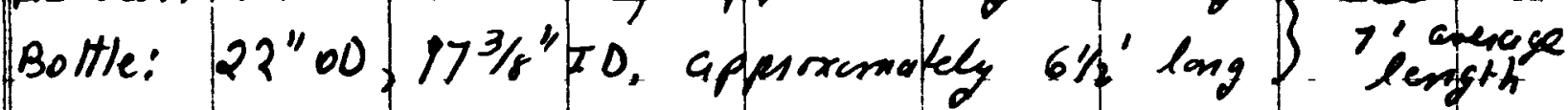

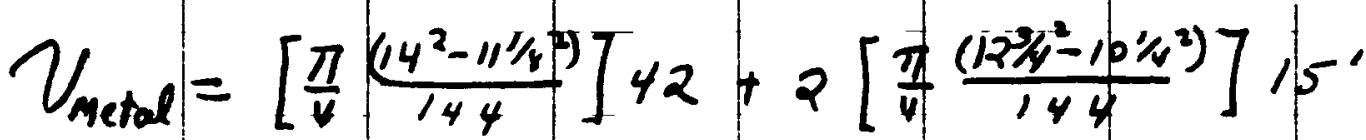

$$
\begin{aligned}
& +\left[\frac{\pi}{4} \frac{\left(16^{2}-12^{2} / 7^{2}\right)}{144}\right] 18+\left[\frac{\pi}{4} \frac{\left.\left(\sqrt\left[32^{2}-1\right)^{3}\right]{144}\right)}{14}\right] \\
& =41.77 \mathrm{ft}^{3} \\
& V_{\text {str }}=\left[\frac{\pi}{4}\left(\frac{\pi / 4}{12}\right)^{2}\right] 42+2\left[\frac{\pi}{4}\left(\frac{10 \pi / 4}{12}\right)^{2}\right] 15+\left[\frac{\pi}{4}\left(\frac{1275}{12}\right)^{2}\right] 18 \\
& +\left[\frac{\pi}{4}\left(\frac{17^{3 / 4}}{12}\right)^{2}\right] 7 \\
& =73.36 \mathrm{Ft}^{3}
\end{aligned}
$$

The heat transfer coeffuient is computed for the How confuter in the satchel handle. This section has the lower steam zelouty and the thigh flo resistance.

$$
\begin{aligned}
& G_{s}=\frac{W_{s}}{A_{s}}=\frac{119183 \mathrm{y}}{2 \frac{\pi}{4}\left(\frac{10 / 4}{12}\right)^{2}}=1.040 \times 10^{6} \frac{\mathrm{lbm}}{\frac{\mathrm{ft}^{2} \mathrm{~h}}{2}} \\
& V_{s}=\frac{G_{s}}{P_{s}}=\frac{1.040^{\circ} \times 1.0 \% 3600}{8325}=34.70 \mathrm{f} / \mathrm{sec}
\end{aligned}
$$


COMBUSTION ENGINEERING

NIIII FAR POWER NFPARTMFNT

$$
\begin{aligned}
& R_{e_{5}}=\frac{G_{S S} D}{\mu_{s}}=\frac{\left(1.040 \times \times 0^{6}\right)\left(\frac{1040}{4}\right)}{.0526}=1.689 \times 10^{7} \\
& h_{s}=\frac{R_{s}}{D}\left[.023 R_{S}^{.8} P_{s}^{.4}\right]=\frac{.053 j}{10 \% / 102}\left[.023\left(1.689 \times 19^{7}\right)^{.8}(4.24)^{.4}\right] \\
& =1543 \frac{B \times 4}{10-f^{2} 0 \%}
\end{aligned}
$$

Nodal position of pipe sections

$$
\begin{aligned}
& D_{H_{1}}=\left(\frac{D_{0}^{2}+D_{0}^{2}}{2}\right)^{1 / 2}=\left(\frac{1 \gamma^{2}+p^{1 / 8}{ }^{2}}{2}\right)^{1 / 2}=12.64^{\prime \prime} \\
& \vec{D}_{5 H}=\left(\frac{123 / y+10^{3} / y^{2}}{2}\right)^{2}=1.507 \\
& \vec{D}_{2}=\left(\frac{6^{2}+12 z_{2}^{2}}{2}\right)^{1 / 2}=14.52^{4} \\
& \bar{D}_{B}=\left(\frac{77^{3 / r^{2}+22^{2}}}{2}\right)^{1 / 2}=19.82^{\prime \prime}
\end{aligned}
$$

The overall heat transfer coefficient is the sum of the dual coefferenta is each pipe section.

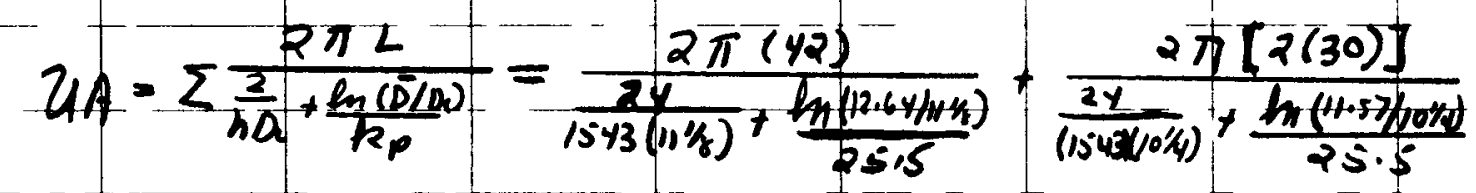

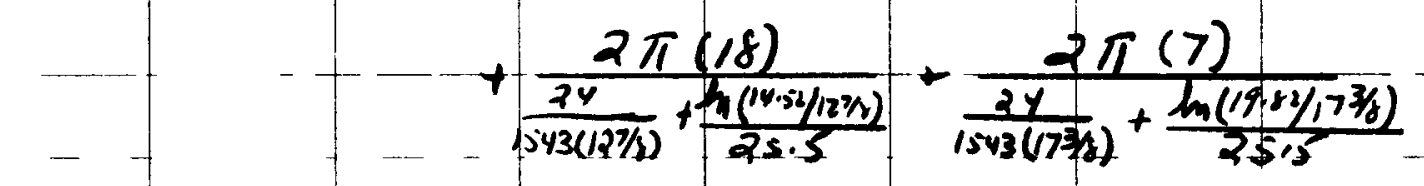

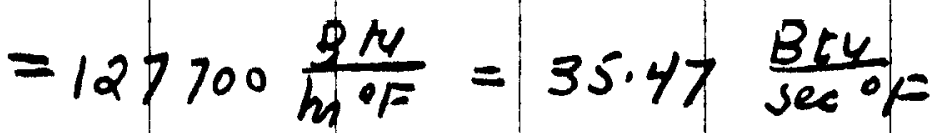

$$
\begin{aligned}
& \text { Coeffurents } \\
& {\left[\frac{y A}{(e v)_{p}}\right]=\frac{35.47}{482(41.77)(1.137)}=0.01286 \mathrm{sec}^{-1}}
\end{aligned}
$$


COMBUSTION ENGINEERING NUCLEAR POWER DFPARTMFNT

$$
\begin{aligned}
& {\left[\frac{u A}{\left(\rho v p_{s}\right.}\right]=\frac{35.47}{(8.335)(73.35)(y \cdot 2 y)}=0.01370 \sec -1} \\
& \left(\frac{1}{\rho v}\right)_{s}=\frac{1}{(8.375)(73.36)}=0.001637 \mathrm{lbm}-1 \\
& \text { 3) } 1 \text { set }(337-338)
\end{aligned}
$$

In let lines - Inlet Distribution Bole \& Reduces - Inlets

Lines: 15. 5" 00 , 1/2" wall, typical developed length = 30 ? Bottle! $316^{\prime \prime} 00,19 / 10$ wall, apporentaky 43/1 long $\}$ assceme

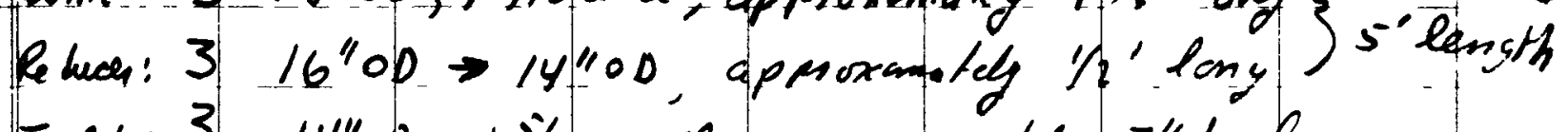

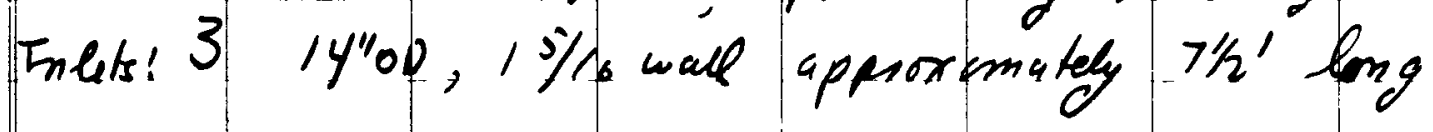

$$
\begin{aligned}
& V_{\text {metal }}=15\left[\frac{\pi}{4} \frac{\left(5^{2}-4^{2}\right)}{144}\right] 30+3\left[\frac{\pi}{4} \frac{\left(16^{2}-12^{2} z^{2}\right)}{144}\right] 5 \\
& +3\left[\frac{\pi}{4} \frac{\left(14^{2}-1 / 3 / z^{2}\right)}{144}\right]>\% \\
& =37.65 \mathrm{Fr}^{3} \\
& V_{s i 2 n}=15\left[\frac{\pi}{4}\left(\frac{4}{12}\right)^{2}\right] 30+3\left[\frac{\pi}{4}\left(\frac{12 / 8}{12}\right)^{2}\right] 5+3\left[\frac{\pi}{4}\left(\frac{113 / 4}{12}\right)^{2}\right] 7 \% \\
& =68.71 \mathrm{Fr}^{3}
\end{aligned}
$$

The steam flow heat transfer coefficient is computed for the flow in the 15 inlet lines.

$$
G_{s}=\frac{2 \omega_{3}}{A}=\frac{119183 y}{15 \frac{\pi}{4}\left(\frac{4}{12}\right)^{2}}=9.104 \times 10^{5}
$$


COMBUSTION ENGINEERING ?UCLEAR POWER DEPARTMENT

$$
\begin{aligned}
& \begin{array}{l}
V_{s}=\frac{C_{s}}{\rho_{s}}-\frac{9.104 \times 10^{5} \beta 600}{8.325}=30.38 \frac{\mathrm{ft}}{\mathrm{sec}} \\
R_{e_{s}}=\frac{C_{s} D}{U_{s}}=\frac{\left(9.104 \times 10^{5}\right)\left(\frac{4}{12}\right)}{.0596}=5.770 \times 10^{6}
\end{array} \\
& h_{s}=\frac{h_{s}}{D}\left[.023 R_{s}^{.8} P_{s}^{-4}\right]=\frac{.0531)}{(4 / 12)}\left[.023\left(5.770 \times 10^{6}\right)^{-8}(4,24)^{.4}\right] \\
& =1674^{\circ} \frac{\text { By }}{h_{n}-f^{2} 0^{2}=}
\end{aligned}
$$

$$
\begin{aligned}
& \bar{D}_{L}=\left(\frac{D_{L^{2}+D_{0}^{2}}^{2}}{2}\right)^{1 / 2}=\left(\frac{4^{2}+5^{2}}{2}\right)^{1 / 2}=4,528^{\prime \prime} \\
& \bar{D}_{B}=\left(\frac{17^{2} / /^{2}+16^{2}}{2}\right)^{\prime / 2}=14.52^{\prime \prime} \\
& \bar{D}_{\Sigma}=\left(\frac{11 \gamma_{8}^{2}+14^{2}}{2}\right)^{1 / 2}=12.76^{\prime \prime}
\end{aligned}
$$

The overall heat trams fa cueffuerent is the sum of the local real coefficients.

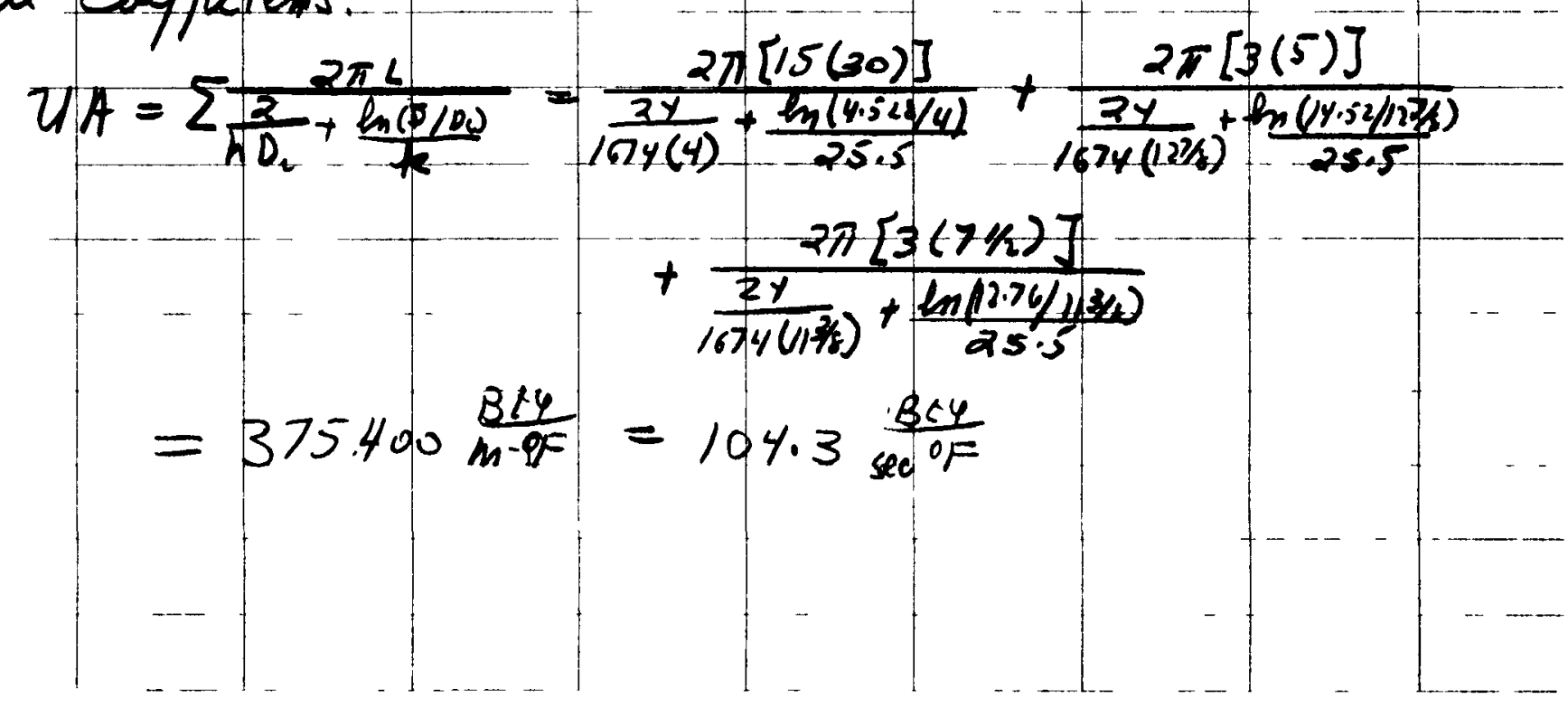




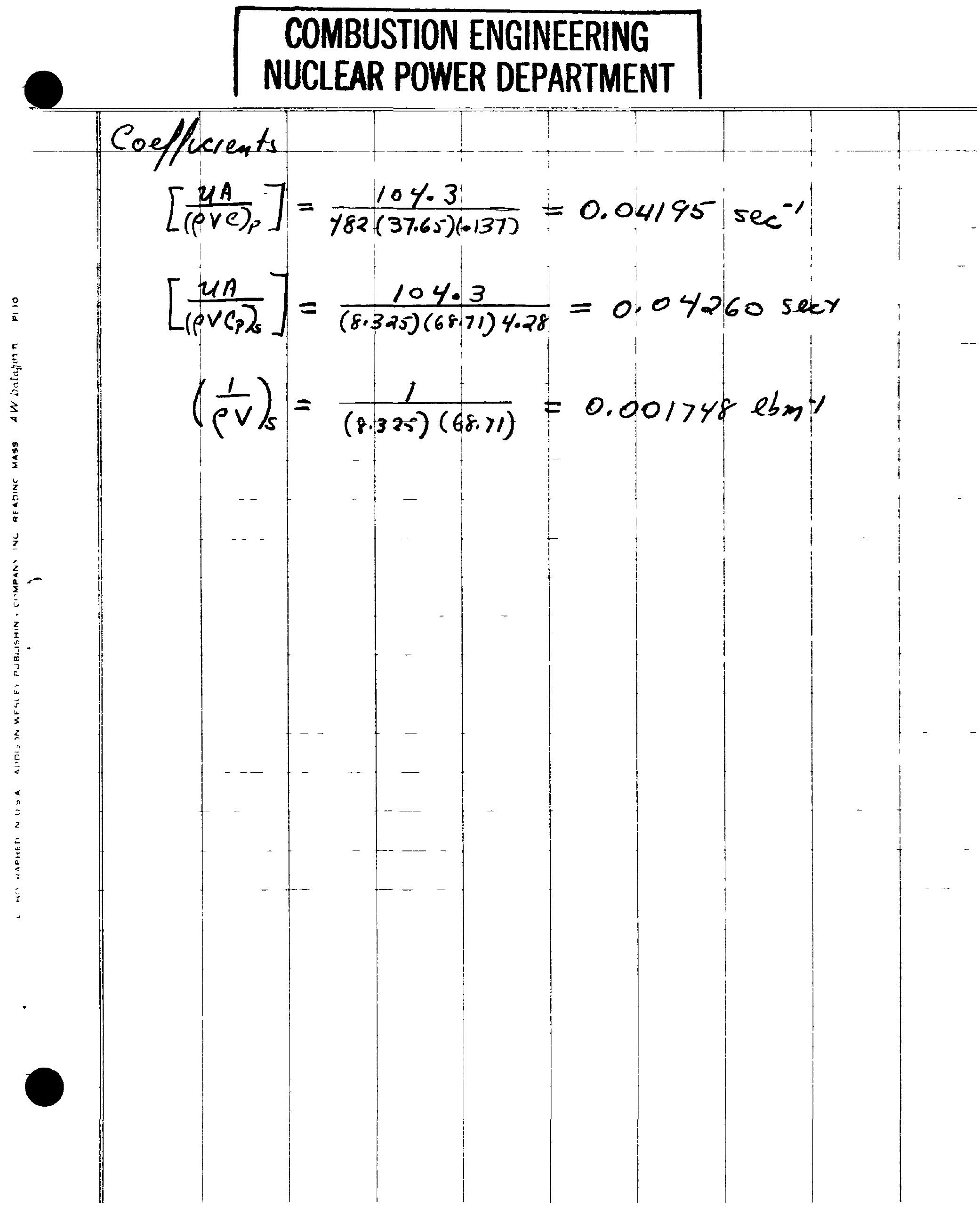


COMBUSTION ENGINEERING NUCLEAR POWER DEPARTMENT

Summary

$$
\begin{aligned}
& \dot{T}_{333}=-(0.05975) T_{333}+(0.05975) T_{334} \\
& \dot{T}_{334}=-(0.06230) T_{334}+(0.06230) T_{333}+(0.003641) \dot{\omega}_{3} T_{362} \\
& -(0.003641) \text { is T334 } \\
& \dot{T}_{335}=-(0.01286) \bar{T}_{335}+(0.01286) T_{336} \\
& \dot{T}_{336}=-(0.01370) T_{336}+(0.01370) T_{335}+\left(0.001637 p \dot{\omega}_{5} T_{334}\right. \\
& f(0,00 / 637) \dot{0}_{s} T_{336} \\
& \dot{T}_{337}=-(0.04195) T_{337}+(0.04 / 95) T_{338} \\
& \dot{T}_{338}=-(0.04260) T_{338}+(0.04260) T_{332}+(0.001748) \dot{u}_{5} T_{336} \\
& -(0.001748) \dot{\omega}_{s} T_{338} \\
& \dot{\omega}_{s}=\text { steam Flow per loop }=\dot{\omega}_{81}
\end{aligned}
$$


COMBUSTION ENGINEERING

NUCLEAR POWER DEPARTMENT

Recirculated Water Piping: Drum $\rightarrow$ Pump; Pump $\rightarrow$ EN

Energy balances for the pipe and water nodes

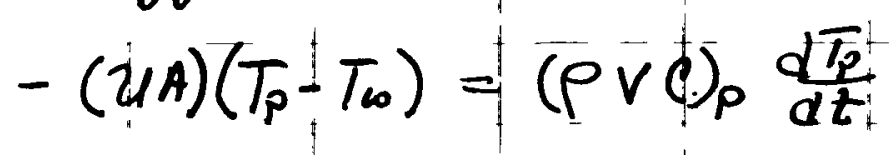

$(U A)\left(T_{P}-T_{\omega}\right)+\left(W C_{P}\right)_{\omega} T_{\omega N}=\left(w \omega C_{\rho}\right)_{\omega} T_{\omega}+\left(p \vee C_{\rho}\right)_{\omega} \frac{d T_{\omega}}{d r}$

In standard format

$$
\begin{aligned}
& \dot{T}_{p}=-\left[\frac{(U A)}{(\rho \vee C)_{p}}\right] T_{p}+\left[\frac{(U A)}{(P \vee C)_{p}}\right] T_{\omega} \\
& \dot{T_{\omega t}}=-\left[\frac{(U A)}{\left(\rho v(\rho)_{\omega}\right.}\right] T_{\omega}+\left[\frac{(U A)}{\left(\rho V C_{\rho}\right)_{\sigma}}\right] T_{\rho}+\left(\frac{\partial v}{\rho v}\right)_{\omega} T_{\omega \omega}-\left(\frac{w}{\rho v}\right)_{\omega} T_{\omega}
\end{aligned}
$$


COMBUSTION ENGINEERING

NUCLEAR POWER DEPARTMENT

$W_{\text {ca }}=1390473 \mathrm{lbm} / \mathrm{p}$ How pe lv module

$=4171419$ lamas flow pes flop

Properties are evaluated at pressure and temperature for full load. $p=2663$ psi, $T=634,5$ of

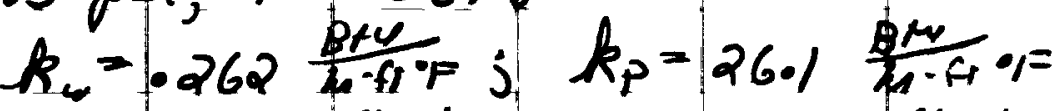

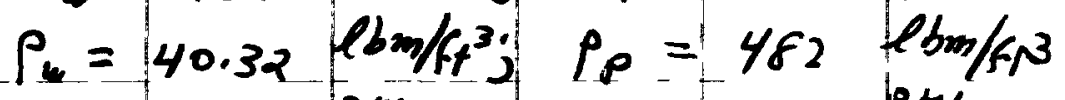

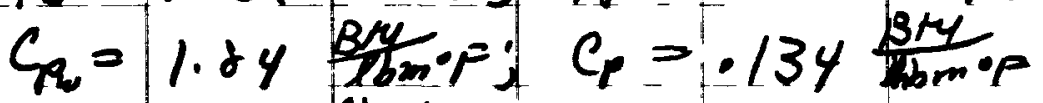

$$
\begin{aligned}
& \mu_{\omega}=192 \text { loro/fth } \\
& P_{r_{m}}=1.35
\end{aligned}
$$

Drum $\rightarrow$ Pump: 2 Nodal sets $(3 / 0-3 / 1$ and 3/2-3/3)

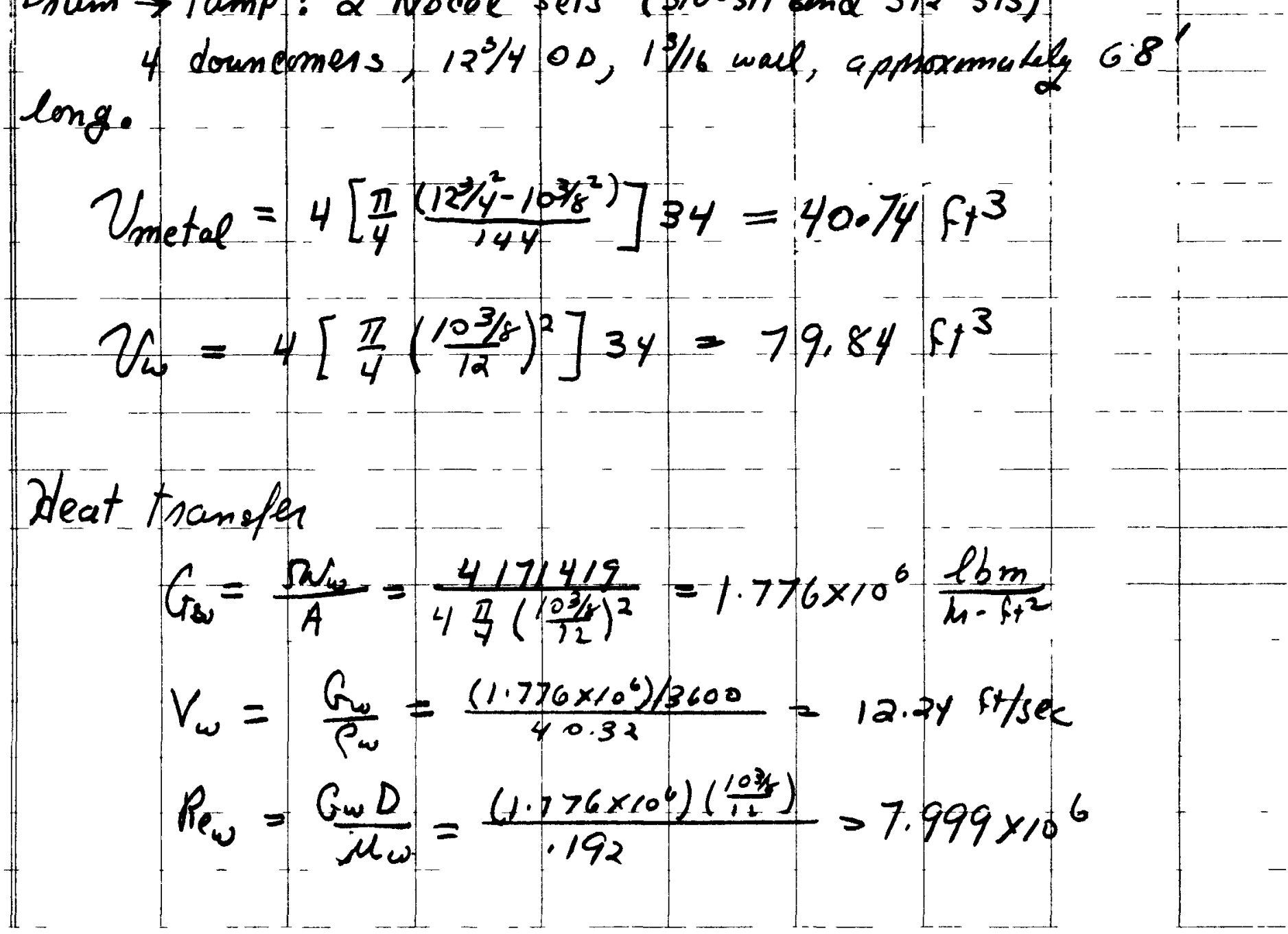


COMBUSTION ENGINEERING

NUCLEAR POWER DEPARTMENT

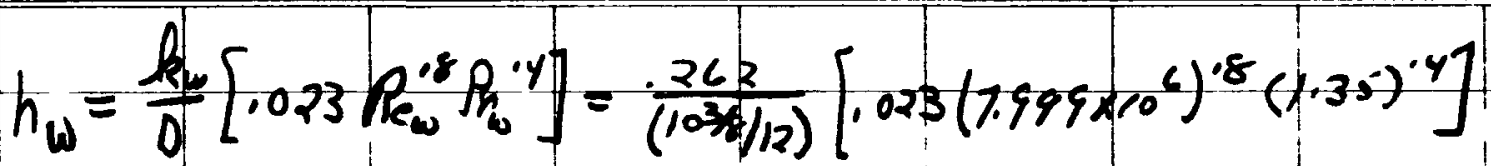

$$
\begin{aligned}
& =2617 \frac{B t y}{2-f t^{2} \mathrm{~F}}
\end{aligned}
$$

The avenge chamete of the peps

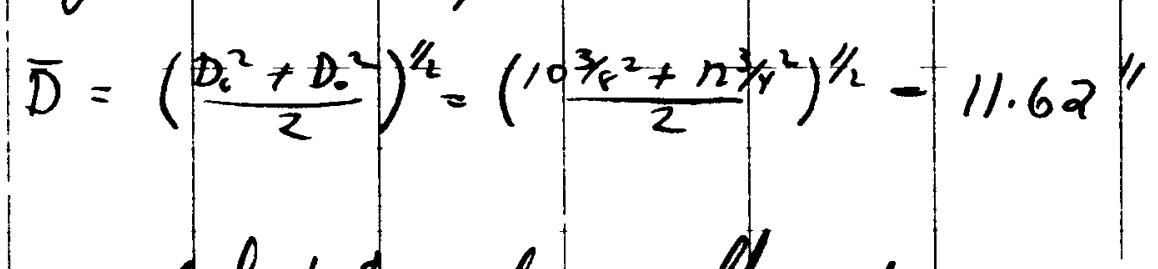

The overall hat tarsier coefficient

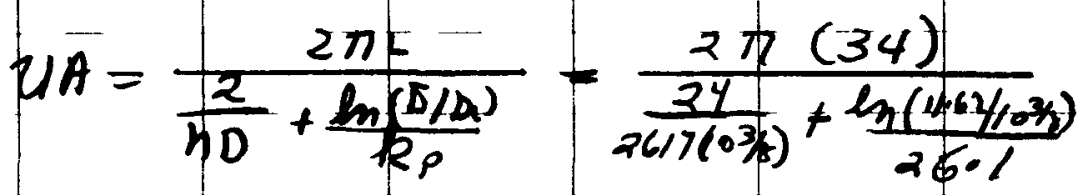

$$
\begin{aligned}
& =40880 \frac{B+4}{L_{0}=0 \%}=11.35 \frac{B+4}{\sec 01=}
\end{aligned}
$$

Coefficients

$$
\begin{aligned}
& {\left[\frac{u A}{(\rho \operatorname{Pr})_{p}}\right]=\frac{t 1.35}{(482)}=0.004316 \sec ^{7} 7} \\
& {\left[\frac{24}{(\rho \vee 0)_{6}}\right]=\frac{11.35}{40.32(79.84)(1.84)}=0.001916 \mathrm{sec}^{-1}} \\
& \left(\frac{1}{c_{v}}\right)_{\omega}=\frac{1}{(40.32)(79.84)}=0.0003106 \mathrm{ebm}^{-1}
\end{aligned}
$$


COMBUSTION ENGINEERING

NUCLEAR POWER DEPARTMENT

$$
\begin{aligned}
& h_{\omega}=\frac{k_{\omega}}{D}\left[.023 R_{e^{2}} R_{\omega} \cdot y\right]=\frac{.262}{(1034 / 12)}\left[.023\left(7.999 \times 10^{6}\right)^{.8}(1.35)^{14}\right] \\
& =2617 \frac{\beta+4}{h-f t^{2} \sigma F}
\end{aligned}
$$

the avenge cha meter of the peps

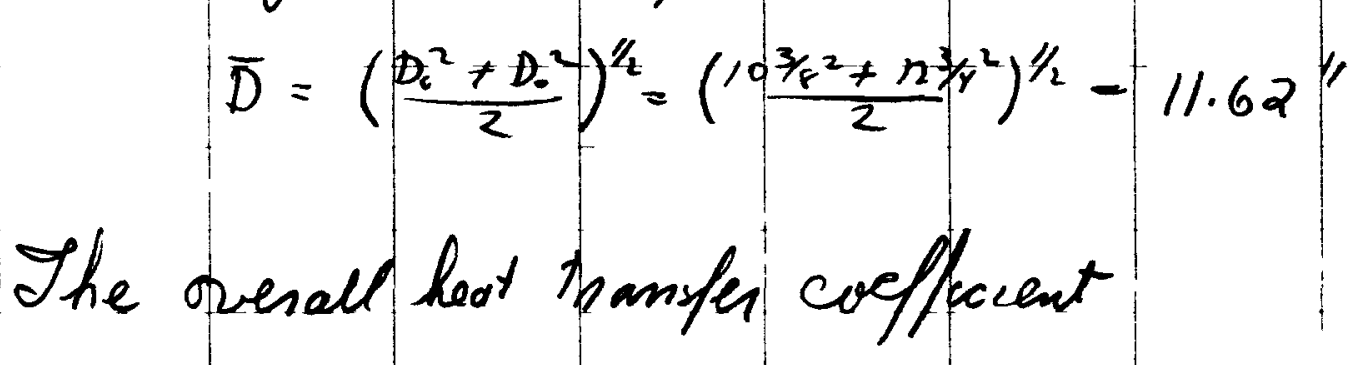

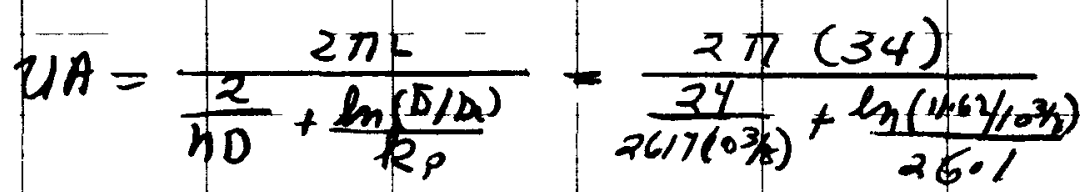

$$
\begin{aligned}
& =40880 \frac{B+4}{L_{1}-0.9}=11.35 \frac{B+4}{\sec 01=} \\
& \text { Coeffuents } \\
& {\left[\frac{\psi A}{(\text { evcle }}\right]=\frac{1 / .35}{(482)}=0.004316 \mathrm{sec} 7} \\
& {\left[\frac{\overline{u A}}{(\rho \vee v)_{\omega}}\right]=\frac{11.35}{40.32(79.84)(1.84)}=0.001916 \mathrm{sec}^{-1}} \\
& \left(\frac{1}{e_{v}}\right)_{\omega}=\frac{1}{(40.32)(79.84)}=0.0003 .106 \mathrm{ebm}^{-1}
\end{aligned}
$$


COMBUSTION ENGINEERING

NUCLEAR POWER DEPARTMENT

Pump $\rightarrow$ Exp: 3 Nodal sets

1)' Set (339-3\%)

Discharge limes - Discharge manifold

Lives: 6, 14" 00 , 13/6" wall, typal length $36^{\prime}$

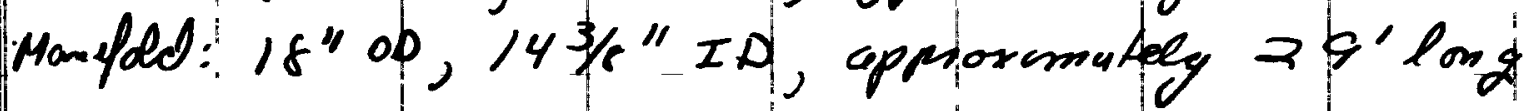

$$
\begin{aligned}
& V_{\text {metal }}=6\left[\frac{\pi}{4} \frac{\left(14^{2}-11^{2}\right)}{144}\right] 36+\left[\frac{\pi}{4} \frac{\left(18^{2}-14^{3}\right)^{2}}{148}\right] 29 \\
& =100.4 \mathrm{ft}^{3} \\
& V_{w}=6\left[\frac{\pi}{4}\left(\frac{11 / 4}{12}\right)^{2}\right] 36+\left[\frac{\pi}{4}\left(\frac{14 / 4}{12}\right)^{2}\right] 29 \\
& =181.8 \mathrm{Ft}^{3}
\end{aligned}
$$

Assume the water film coefficient is that computed in the discharge lines..

$$
\begin{aligned}
& G_{\omega}=\frac{W_{w}}{A}=\frac{4171419}{6 \frac{\pi}{4}\left(\frac{11 / 4}{12}\right)^{2}}=1.007 \times 10^{6} \frac{\frac{16 \mathrm{~m}}{2}-6 / 2}{m^{2}} \\
& V_{\omega}=\frac{G_{\omega}}{\rho_{\omega}}=\frac{\left(1,007 \times 10^{0}\right) / 3600}{40.32}=6.939 \mathrm{fr} / \mathrm{sec} \\
& R_{e_{\omega}}=\frac{G_{\omega} D}{\mu_{\omega}}=\frac{\left(1.007 \times 10^{2}\right)\left(\frac{11 \pi_{4}}{12}\right)}{.192}=4.918 \times 10^{6} \\
& \left.h_{\omega}=\frac{R_{w}}{D}\left[.023 R_{e_{w}} P_{\omega_{\omega}}^{14}\right]=\frac{.262}{(11 / 4 / 12)}\left[.023\left(4.916 \times 10^{9}\right)^{8}(1.35)^{4}\right)^{4}\right] \\
& =1635 \frac{B+4}{m-f i f^{\circ}}
\end{aligned}
$$


COMBUSTION ENGINEERING

NUCLEAR POWER DEPARTMENT

average chametus of the pipe

$$
\begin{aligned}
& \bar{D}_{L}=\left(\frac{D_{L}^{2}+P_{0}^{2}}{2}\right)^{\prime \prime}=\left(\frac{11^{\prime \prime} y^{2}+14^{2}}{2}\right)^{1 / 2}=12.70^{17} \\
& D_{M}=\left(\frac{4 z^{2}+18^{2}}{2}\right)^{\prime}=16.29^{\prime \prime}
\end{aligned}
$$

The overall heat transfer colfuerent is the sam of the local caffecients in the rio sections.

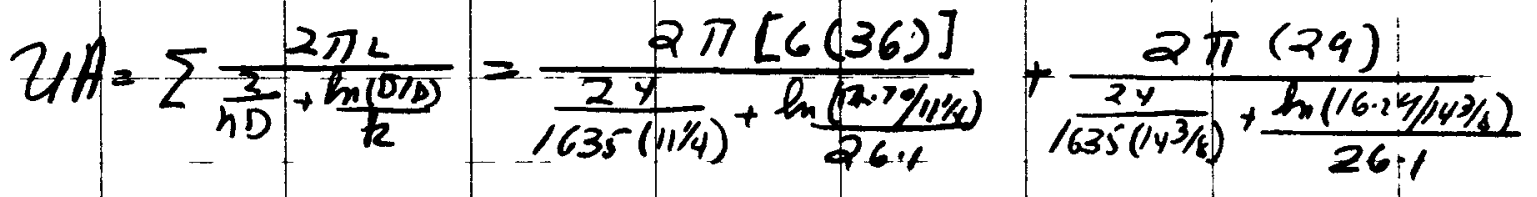

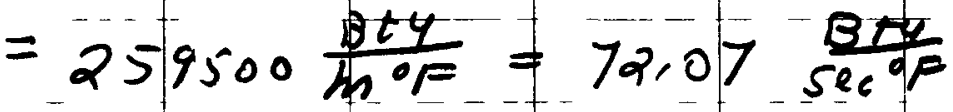

$$
\begin{aligned}
& \text { Coefjucients } \\
& {\left[\frac{2 \mathrm{At}}{(\rho \mathrm{rc})_{p}}\right]=\frac{72.07}{482(100.4)(1 / 34)}=0.01117 \mathrm{sec}^{-1}}
\end{aligned}
$$

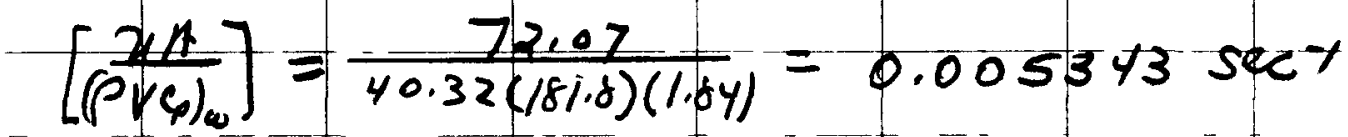

$$
\begin{aligned}
& \left(\frac{1}{\rho V}\right)_{10}=\frac{1}{(40.32)(181.8)}=10001364 \mathrm{eb} \mathrm{m}^{-1} \\
& \text { 2) } 1 \operatorname{set}(341-342) \\
& \text { Discharge hines to evaporator in let heocle: } 2,18 \text { " OD, } \\
& \text { 157k" ED, appsoxamately 84.6.' long } \\
& V_{\text {metal }}=2\left[\frac{\pi}{4} \frac{\left(18^{2}-i 5^{2} / 8^{2}\right)}{144}\right] 84.6=66.43 \mathrm{fr}
\end{aligned}
$$


COMBUSTION ENGINEERING NUCLEAR POWER DEPARTMENT

$$
v_{\omega}=2\left[\frac{\pi}{4}\left(\frac{157 / 8}{12}\right)^{2}\right] 84.6=232.6 \mathrm{Fr} 3
$$

Heat Thassfe coefficient

$$
\begin{aligned}
& G_{\omega}=\mid \frac{w_{\omega}}{A}=\frac{4171419}{2 \frac{\pi}{4}\left(\frac{15^{5} / 2}{12}\right)^{2}}=1.517 \times 10^{6} \frac{l b_{m}}{m_{1}-5^{2}} \\
& V_{w}=\frac{G_{\omega}}{\rho_{w}}=\frac{\left.(1.5) 7 \times 10^{\circ}\right) / 3600}{40.32}=10.45 \mathrm{FT} / \mathrm{sec} \\
& R_{e_{\omega}}=\frac{G_{\omega} D}{\mu_{\omega}}=\frac{\left(1.517 \times 10^{\circ}\right)\left(\frac{15 \%}{T^{2}}\right)}{.192}=1046 \times 10^{7} \\
& \left.h_{\omega}=\frac{k_{\omega}}{D}\left[.023 R_{e}{ }^{8} P_{\eta} \cdot 4\right]=\frac{.262}{(15 \% / 2)}\left[1.023\left(1.046 \times 10^{7}\right)^{.8}(1.35)^{4}\right]\right] \\
& =2119 \frac{B+4}{\left.H_{1}-f\right)^{2} \circ \sigma_{F}}
\end{aligned}
$$

Average diameter of the pipe

$$
\bar{D}=\left(\frac{D_{0}^{2}+D_{2}^{2}}{2}\right)^{1 / 2}=\left(\frac{15^{2}{ }^{2}+18^{2}}{2}\right)^{1 / 2}=16.97^{\prime \prime}
$$

The viral heat Trooper coefficient

$$
\begin{aligned}
& U A=\frac{2 \pi L}{\frac{2}{h D}+\frac{\ln (B 1 D)}{k}}=\frac{2 \pi[2(89.6)]}{2119(15 \%)}+\frac{\ln (16.62(1.27)}{26.1}
\end{aligned}
$$

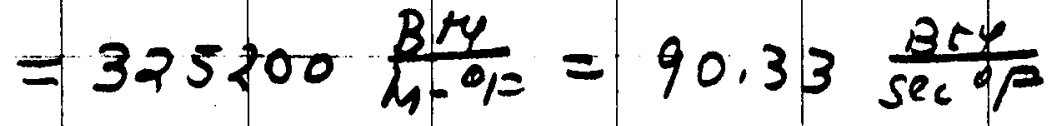

$$
\begin{aligned}
& \text { Coeffuents } \\
& {\left[\frac{y \|}{(P V C)_{p}}\right]=\frac{90.33}{(482)(66.43)(134)}=0.02105 \mathrm{sec} 7}
\end{aligned}
$$


COMBUSTION ENGINEERING

NUCLEAR POWER DEPARTMENT

$$
\begin{aligned}
& {\left[\frac{u A}{\left(\rho v_{0}\right)_{0}}\right]=\frac{90.33}{(40.32)(232.6(1.84)}=0.0052355 \mathrm{sec}^{-1}} \\
& \left(\frac{1}{\rho v}\right)_{\omega}=\frac{1}{(40.32)(232.6)}=.0001066 \mathrm{elm}^{-1}
\end{aligned}
$$

Evaposator Thlet header - Eraporato inlet hries Headen: 16" 00, 12 3/1" ID, appoximately 3s" long Lines: 3, 16"OD, 19/16 wall, appox mpstely a $41 / 2$ " lpng

$$
\begin{aligned}
& V_{m}=\left[\frac{\pi\left(1 / 6^{2}-12^{3} 3 / 2\right)}{144}\right](35)+3\left[\frac{\pi}{4} \frac{\left(16^{2}-12^{2} /^{2}\right)}{144}\right] 24 / 2 \\
& =54,01 \mathrm{FH}^{3} \\
& V_{\omega}=\left[\frac{\pi}{4}\left(\frac{12^{3 / 4}}{12}\right)^{2}\right]\left(35^{5}\right)+3\left[\frac{7}{4}\left(\frac{127 / 6}{12}\right)^{2}\right] 24 / 2 \\
& =97,48
\end{aligned}
$$

Wleat Zransfer coefferent

$$
\begin{aligned}
& G_{\omega}=\frac{w_{\omega}}{A}=\frac{4171419}{3\left[\frac{\pi}{4}\left(\frac{12 / 2}{12}\right)^{2}\right]}=1.538 \times 10^{6} \frac{\mathrm{llm}}{\mathrm{f}^{2} / \mathrm{m}} \\
& V_{\omega}=\frac{G_{\omega}}{\rho_{\omega}}=\frac{1.538 \times 10^{6} / 3600}{40.32}=10.60 \mathrm{ft} / \mathrm{sec} \\
& R_{e_{\omega}}=\frac{G_{\omega} D}{N_{\omega}}=\frac{0.505 \times 10^{6}\left(\frac{122 / 1}{12}\right)}{192}=8.594 \times 10^{6} \\
& h_{\omega}=\frac{f_{\omega}}{D}\left[.023 R_{e_{\omega}}^{.8} P_{r_{\omega}} \cdot 4\right]=\frac{.262}{(1276 / 6 / 2)}\left[.023(8.594 \times 10)^{18}(1.35)^{14}\right] \\
& =2233 \text { Bry/m.ft } 0 / 2
\end{aligned}
$$


COMBUSTION ENGINEERING

NUCLEAR POWER DEPARTMENT

Average diameter of the two sections

$$
\begin{aligned}
& \bar{D}_{H}=\left(\frac{D^{2}+D_{0}^{2}}{2}\right)^{1 / 2}=\left(\frac{13^{3 / 2}+16}{2}\right)^{k}=14.47^{\prime \prime} \\
& \bar{D}_{2}=\left(\frac{127^{2}+160^{2}}{2}=14.52^{\prime \prime}\right.
\end{aligned}
$$

The overall coefficient is the sum of the tar local coefficients.

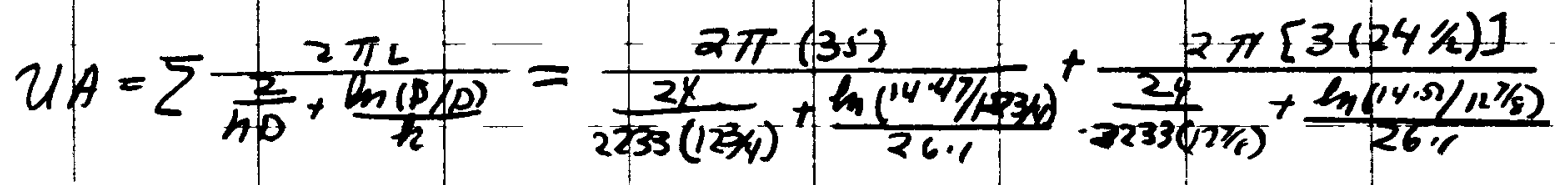

$$
\begin{aligned}
& =123500 \frac{\beta \mu \mu}{11-6 F}=34.31 \frac{B \mu g}{\sec \%}
\end{aligned}
$$

Coeffurents.

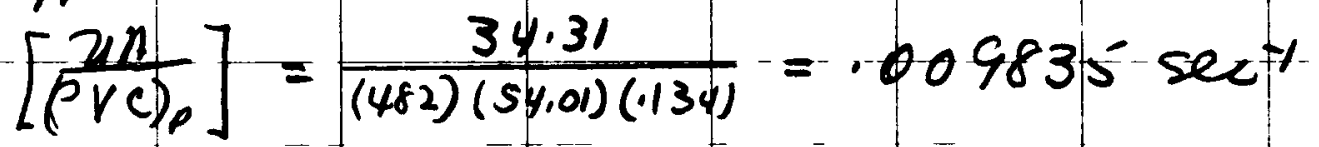

$$
\begin{aligned}
& {\left[\frac{21}{(e v(c) .0}\right]=\frac{34.31}{(40.32)(93.48)(1.84)}=.004744 \mathrm{sec}^{-1}}
\end{aligned}
$$

$$
\left(\frac{1}{f v}\right)_{10}=\frac{1}{(40.32)(52.46)}=.0002544 \mathrm{lbm}-1
$$


COMBUSTION ENGINEERING NUCLEAR POWER DEPARTMENT

$$
\begin{aligned}
& \text { Summary } \\
& \dot{T}_{3 / 0}=-(0.001916) T_{3 / 0}+(0.001916) T_{310}+(0.0003106) \dot{\omega}_{\mu} T_{363} \\
& \dot{T}_{311}=-(0.004316) T_{311}+(0.0043 / 6) T_{310} \\
& \dot{T}_{312}=-(0.001916) T_{3 / 2}+(0.001916) T_{313}+(0.0003106) \dot{\omega}_{r} T_{310} \\
& -(0.0003106) \dot{\omega}_{n} T_{3 / 2} \\
& T_{313}=-(0.004316) T_{3,3}+(0.0043 / 6) T_{312} \\
& \dot{T}_{339}=-\left(0.005343 p \bar{T}_{339}+(0.005343) T_{340}+(0.0001364) \dot{\omega}_{r} T_{r w}\right. \\
& -(0.060 / 364) \omega_{r} T_{339} \\
& \dot{T}_{340}=-(0.01111) T_{340}+(0.01111) T_{339} \\
& \dot{T}_{341}=-(0,005235) T_{341}+(0.005235) T_{312}+(0.0001066) \omega_{r} T_{395} \\
& -(0.0001066) \dot{\omega}_{n} T_{3} \psi \\
& \dot{T}_{3 y 2}=-(0.02105) \bar{T}_{342}+(0,02105) T_{341} \\
& \dot{T}_{343}=-(0.004744) T_{343}+(0.004744) \bar{z}_{44}+\left(0.0002 p_{44}\right) \dot{w}_{n} \bar{\xi}_{44} \\
& -(0.0002544) \text { in } T_{343} \\
& \dot{T}_{344}=-(0.009835) T_{344}+(0.009835) T_{343} \\
& \omega_{n}=\text { tatum secien flow per loop }=\dot{\omega}_{85}
\end{aligned}
$$


COMBUSTION ENGINEERING

VIII FAR POWER DEPARTMENT

Recirculation Pump

Energy balance for the water with on the pump: The walk is assumed to be bounded by adrabate. walk.

$$
(w C p)_{\omega} T_{\omega_{1 N}}=\left(w C_{p}\right)_{\omega_{0}} T_{\omega}+\left(P V C_{p}\right)_{\omega} \frac{d T_{\omega}}{d t}
$$

In standard format

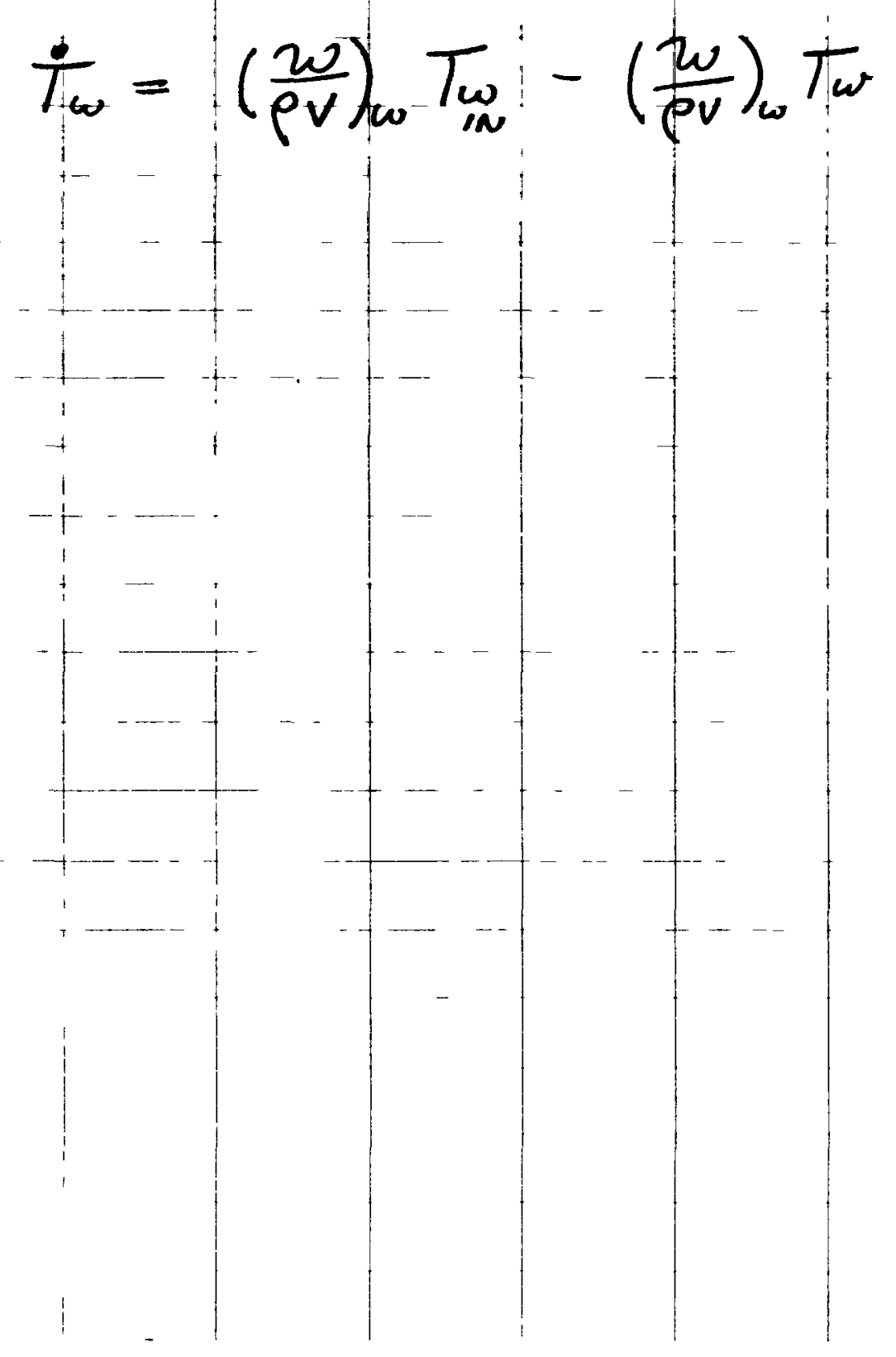


COMBUSTION ENGINEERING

NUCLEAR POWER DEPARTMENT

$$
\begin{aligned}
\omega_{w} & =1390473 \mathrm{lbm} / \mathrm{h} \text { flow per es module } \\
& =4171415 \mathrm{ltm} / \mathrm{m} \text {. Slow per lop }
\end{aligned}
$$

Properties are evaluated at pressure and temperature fo fell l lowed.

$$
\begin{aligned}
& p=2663 \text { psi, } T=634.5 \text { of }
\end{aligned}
$$

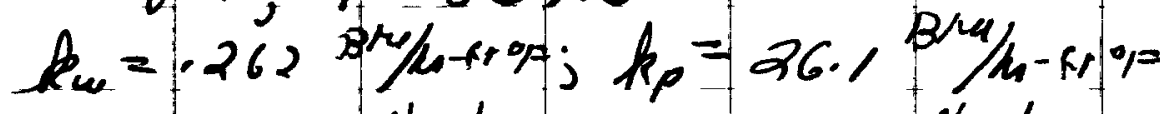

$$
\begin{aligned}
& \rho_{\omega}=40.32 \mathrm{lbm} / \mathrm{m} ; \quad \rho_{c}=482 \mathrm{lhm} / \mathrm{s}, 3
\end{aligned}
$$

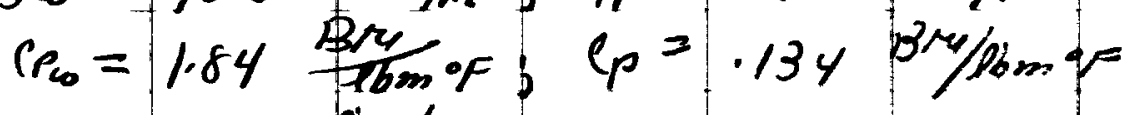

$$
\begin{aligned}
& \mu_{w}=.192 \mathrm{pbm} / \mathrm{ss} \mathrm{h}_{2} \\
& p_{r_{w}}=1.35
\end{aligned}
$$

Pump - include suctun manifold 5 values, un let lines. A gross estimate of the total volume capump plus :- additional stans is assumed to be

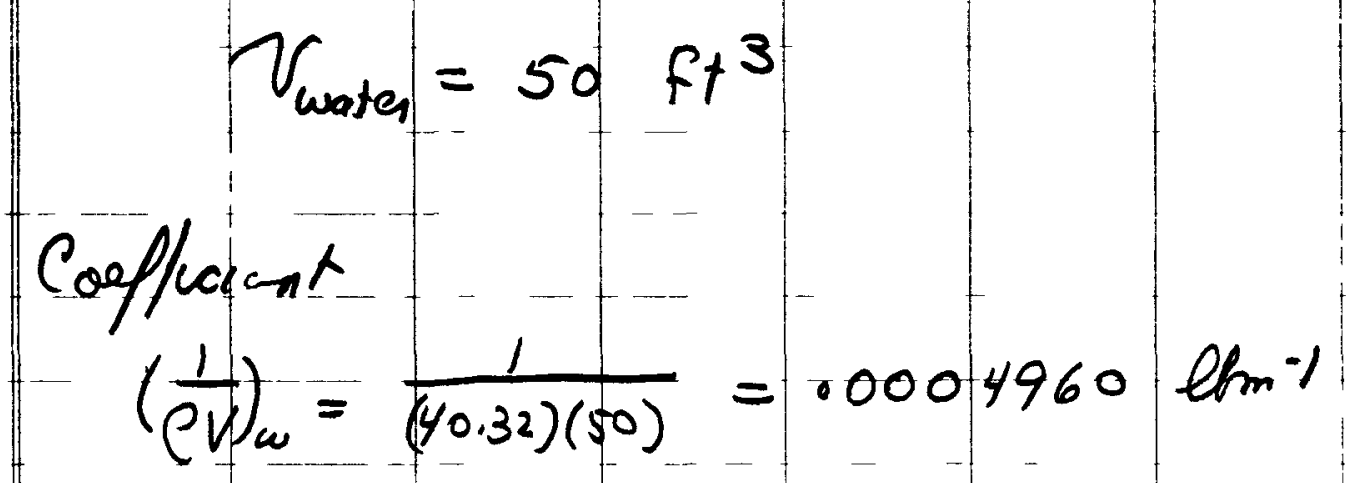


COMBUSTION ENGINEERING

NUCLEAR POWER DEPARTMENT

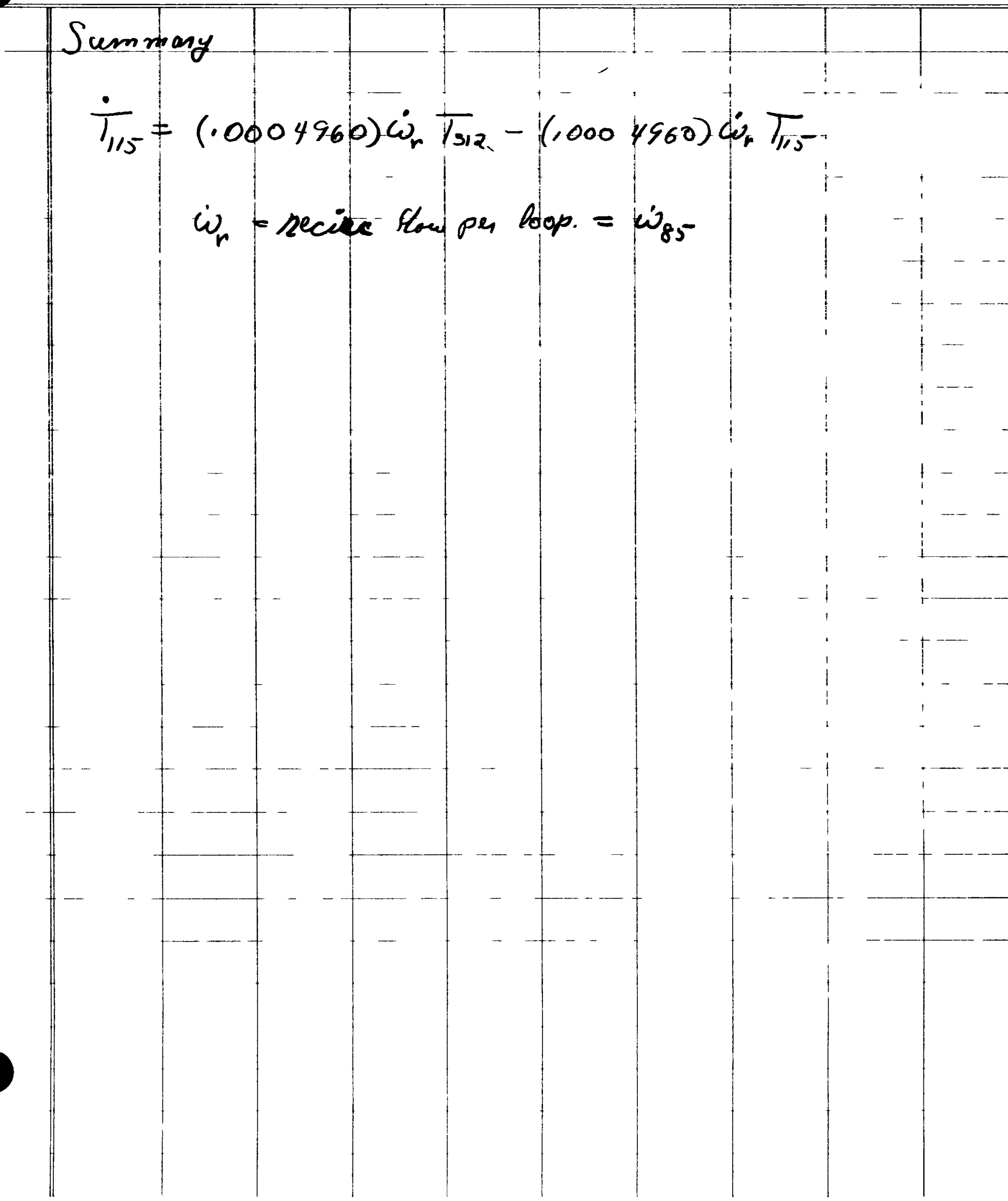


COMBUSTION ENGINEERING

NUCLEAR POWER DEPARTMENT

Drain

The chum seckeves \& stearp/wate mixture from the pipe, separates. The two phases, and mires the separated water wi th the feedruater.

st ram quality

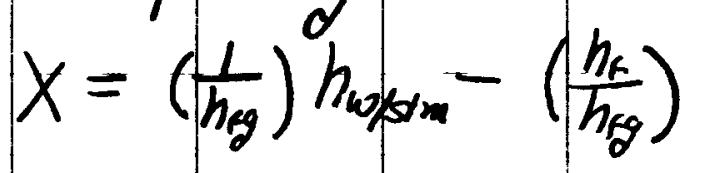

f where $h_{f,} h_{g} h_{k g}=h_{g}-h_{f}$, the specific enthalpies of the saturated states, depend on the drum opening pressure.

The separated steam flow and the separated water flow are

$$
\begin{aligned}
& W_{s t m}=\omega_{r} x=w_{s i n} \\
& W_{w}=\omega_{r}(1)-w_{r} x=w_{w}
\end{aligned}
$$

During a transient the hychaule conditions downstream of the dim dictate the instanteaus demand for steam. Slow. If the steam productions is insuffuerent, the drum pressure would dip thus causing Placing of steam in the section connecting the expiator and the chum and in the evaporator itself. This hychamlic model of the chum has not been included in the thermal transient model. Instead, the feedwater flow and diem pressie as functions of time 
COMBUSTION ENGINEERING

NUCLEAR POWER DEPARTMENT

provided in the series of cure defining the transients were assured cipplecable. In addition the steam flow was assumed to be the same a the feechuaten flow, and the separated water How was computed from this.

$P, w_{s}, w_{\text {seed }}$ assumed

$$
w_{\omega}=w_{r}-w_{s}
$$

The thamodynamic properties That, $h_{f}, h g$ ware assume to od just to tho new pressure level instantaneously. The ratio of zs to us at any tore should gie the quality at that time. Since the pressure curve was assured and the hum hydraulic adyustonent assured a pori, tit noterpected that quality calculation to ane. The calculations of $X, W_{w}, W_{s}$, described above, bused on exit enthalpy are still performed, but they are not used in any fin the colailations.

The energy balances for the upper portion of the drum (1.e. that past which is above the normal waterledel):

$-(u A)\left[T_{D_{n}}-T_{s+m}\right]=\left(\rho \vee c_{1}\right)_{D_{n}} \frac{d T_{D_{n}}}{d t}$

$(U A)\left[T_{D r}-T_{s t m}\right]+w_{s t m} h_{s x_{m}}=w_{s r_{m}} h_{s r_{m}}+\frac{d}{d t}(\rho v u)$ 
COMBUSTION ENGINEERING

WII! FAR POWER NFPARTMFNT

The follow ing assumptions are made:

$\frac{d p}{d t} \approx 0 \quad$ (implant, since confunuly has mot $)$

$$
\frac{d p}{d t} \tau_{0} \Rightarrow \frac{d}{d t}(\rho u)=\frac{d}{d t}(\rho h-p)=\frac{d(e h)}{d t}
$$

Combing these assumptions with the energy balances and seassanging the equations ito standard format

$$
\begin{aligned}
& \dot{T_{D r}}=-\left[\frac{u A}{(\rho v)_{D r}}\right] T_{D r}+\left[\frac{u r}{(\rho v C)_{D r}}\right] T_{s t m a}
\end{aligned}
$$

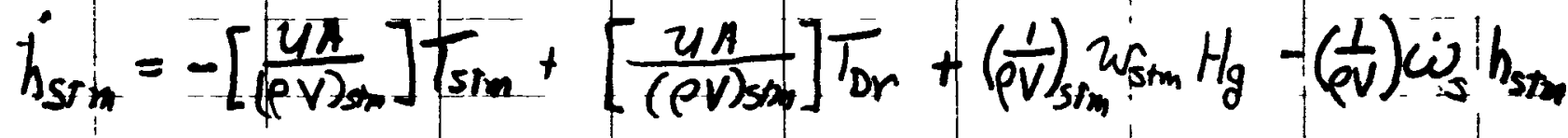

Sunivarly, fo the flower portion of the drum

$$
\begin{aligned}
& -(U / A)\left[T_{D_{r}}-T_{\phi j}\right]=(\rho \vee c)_{D n} \frac{d T_{D_{n}}}{d t} \\
& (U A)\left[T_{\text {Dr }}-T_{\omega}\right]+w_{w} h_{w / D}+w_{k} h_{\text {read }}=w_{\text {oc }} h_{w}+\frac{d}{d r}(P v U)
\end{aligned}
$$

Doting the above assumptions and neassengung

$$
\begin{aligned}
& \dot{T}_{D r}=-\left[\frac{u A}{(\rho Y C)_{p r}}\right] T_{D r}+\left[\frac{4 A}{\left(\rho \vee c_{D_{a}}\right.}\right] T_{\omega}
\end{aligned}
$$

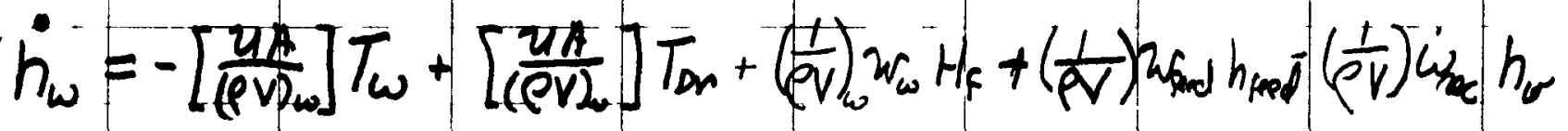

In addition Twi $h_{w}$ and $T_{s m}, h_{3} t_{m}$ as e connected by cure Fits for the given operating pressure. 
COMBUSTION ENGINEERING NUCLEAR POWER DEPARTMENT

$\left.\begin{array}{rl}W_{n} & =1390473 \text { lbon/he permodule } \\ & =4 \mathrm{~V} 71419 \text { lom/h pertloop }\end{array}\right\}$ secure flow

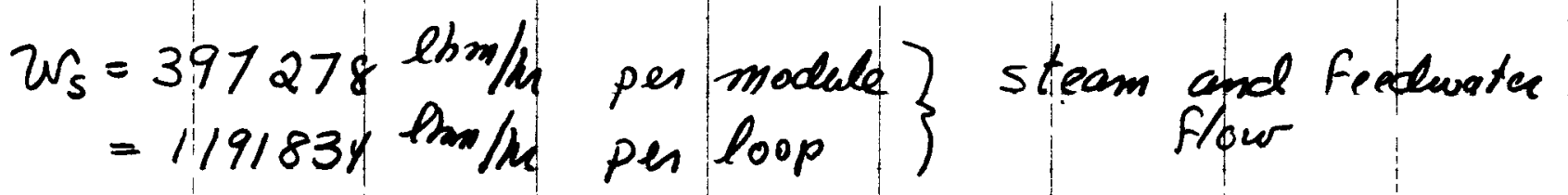
Properties are evaluated at pressure and temperature Fo full load.

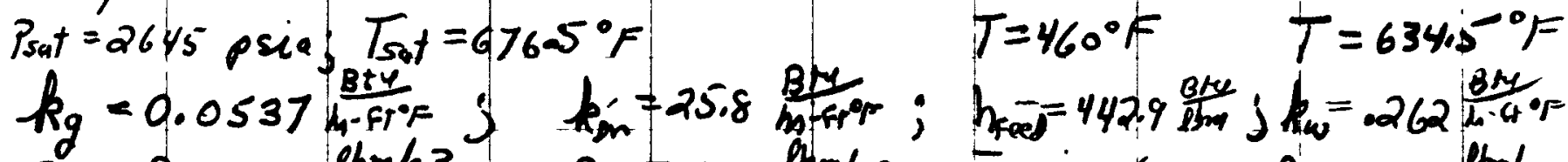

$$
\begin{aligned}
& \rho_{g}=8.545 \mathrm{lbm} / \mathrm{ft}^{3} ; \quad \rho_{\text {or }}=482 \mathrm{lbm} / \mathrm{fr}^{3} ; \quad C_{p}=0.963 \quad \rho_{\omega}=40.32 \mathrm{lbm} / \mathrm{H}^{3}
\end{aligned}
$$

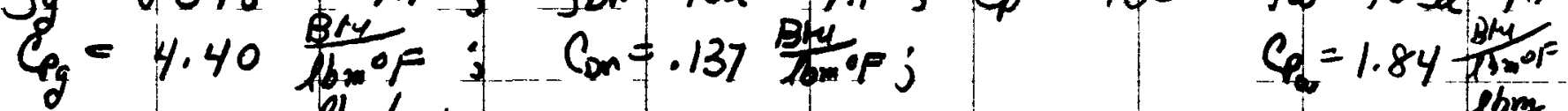

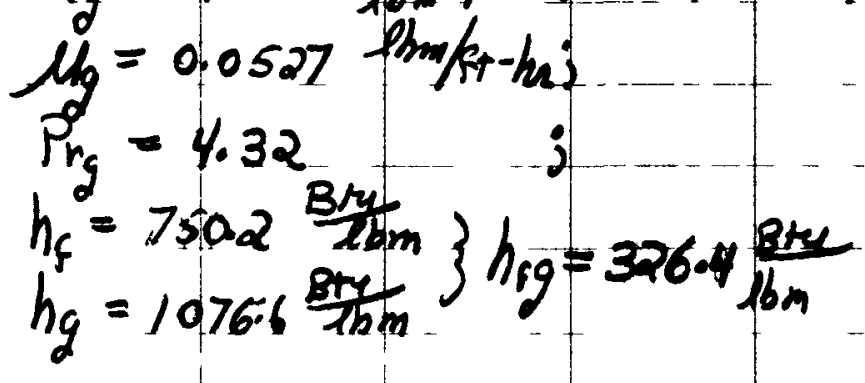

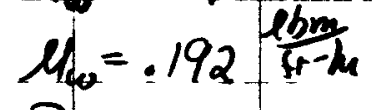

$$
\begin{aligned}
& P_{\eta_{w}}=1.35
\end{aligned}
$$
is nominally $0.8^{\prime}$ below the center hongontal plane. The internal structure of the chum is not conscolesed.

$$
\begin{aligned}
& V_{\text {Motel }}=\frac{\pi}{4} \frac{\left(73^{2}-60^{2}\right)}{144} 42+\frac{4}{3} \pi \frac{\left(36^{3} y^{3}-30^{3}\right)}{1728}=467.7 \mathrm{ft}^{3} \\
& V_{\text {Tor at }}=\frac{\pi}{4}\left(\frac{60}{12}\right)^{2} t 2+\frac{4}{3} \pi\left(\frac{30}{12}\right)^{3}=890.1 \mathrm{ft}^{3}
\end{aligned}
$$


COMBUSTION ENGINEERING NUCLEAR POWER DEPARTMENT

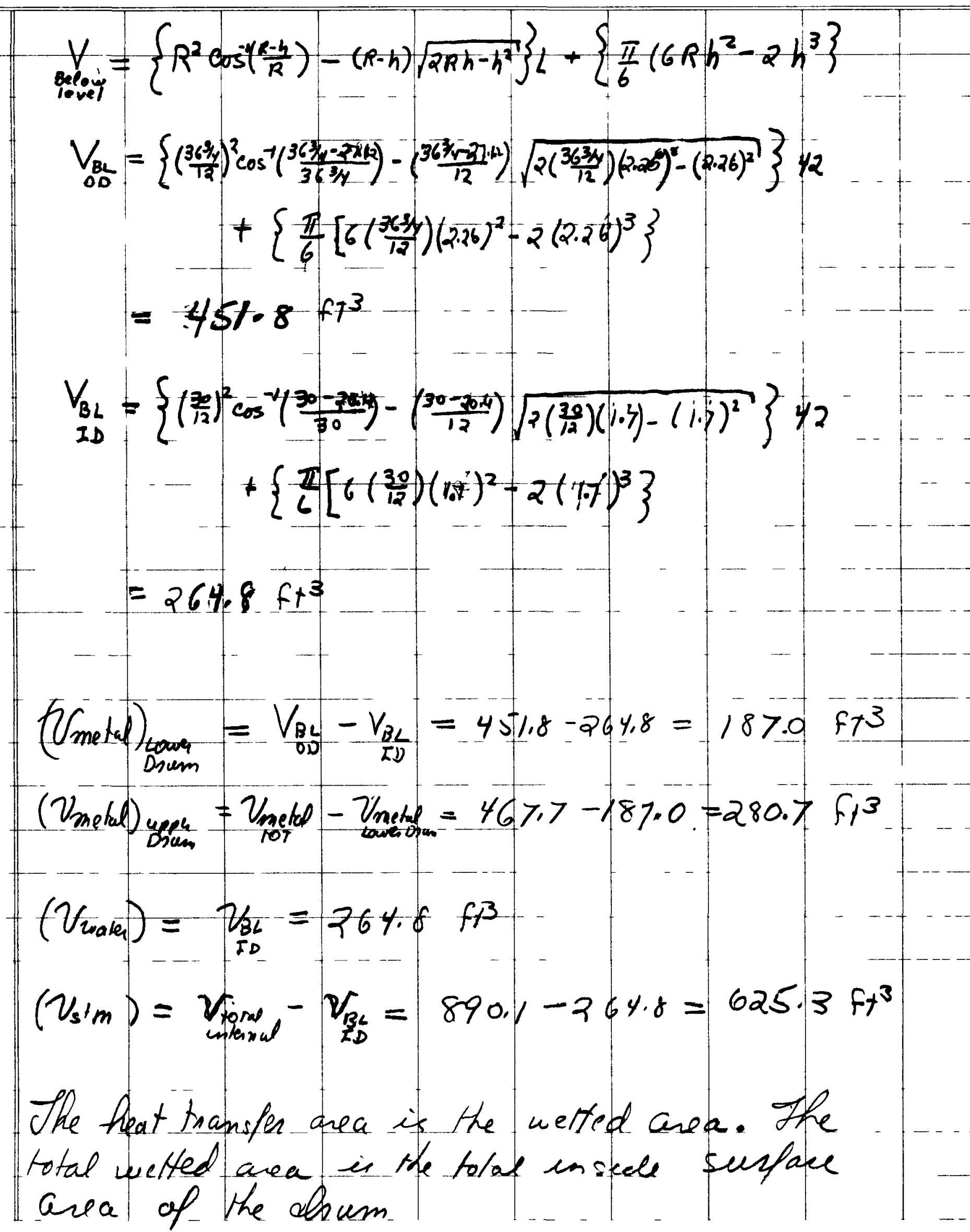


COMBUSTION ENGINEERING NUCLEAR POWER DEPARTMENT

$$
\begin{aligned}
& \begin{aligned}
A_{\text {TOT }} & =\pi D_{L} L+\pi D^{2}=\pi \\
& =\mid 738.3 f \mathrm{~F}^{2} \\
\text { The axes wettrd by the water } &
\end{aligned} \\
& A_{\omega}=D\left\{\cos ^{-1}\left(\frac{R-h}{R}\right)\right\} L+\pi D h=(5)\left\{\cos ^{-1}(.32)\right\} 42+r(5)(1.7) \\
& =288.2 \mathrm{fy}^{2}
\end{aligned}
$$

The area witted by the steam

$$
A_{s m}=A_{7}-A_{w}=738.3-288 . \overline{2}=450.1 \mathrm{Rt}^{2}
$$

The radial position of the Dom node is

$$
\bar{D}=\left(\frac{\phi_{0}^{2}+D_{0}^{2}}{2}\right)^{1 / 2}=\left(\frac{60^{2}+733^{2}}{2}\right)^{1 / 2}=67.05^{\prime \prime}
$$

The thermal resistance of the chum ran be written as

$$
R=\frac{D_{c}}{2 k} \frac{\ln \left(\bar{D} / D_{c}\right)}{\text { Altered }}
$$

cylenchical secreting in assumed charucterstat!

So

$$
\begin{aligned}
& R_{s+m}=\frac{5}{2(25.8)} \frac{\ln (67.09 / 60)}{450.1}=.00002398 \frac{h+.0 F}{B+4} \\
& R_{\omega}=\frac{5}{2(25.8)} \frac{\ln (67.0 \%)}{288.2}=.00003747 \frac{\mathrm{M}-0 F}{B^{2} 4}
\end{aligned}
$$


COMBUSTION ENGINEERING

NUCLEAR POWER DEPARTMENT

Fleat thans fer Coefferent.

The heat transfer coeffuer ents for the woter-dium and for the steam-chum interactions ase computpd assicemeng. pratural convection. The courelations for horogental plates pccommonded by Mic Aolams will be used. These should yold high thermal zescstinces id hech is

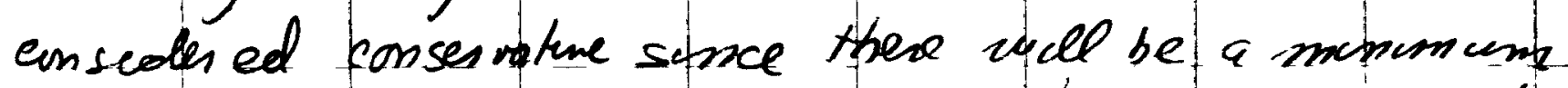
of modenation of a toansucht betaves the estapostion and supenheater.

In addetion assume to calculational rasposes the lollowing quartily

$\beta_{\text {stm }}=0.011_{0.1}-\beta_{\text {wak }}=.005$ or $=-1 ; \Delta T=1{ }^{\circ} \mathrm{F}$ $L=3.0^{\prime}$, chanacterstic length, an average width of the walu level

$$
\begin{aligned}
& G_{r}=\frac{\rho^{2} g \beta}{\mu^{2}} \Delta T L^{3}
\end{aligned}
$$

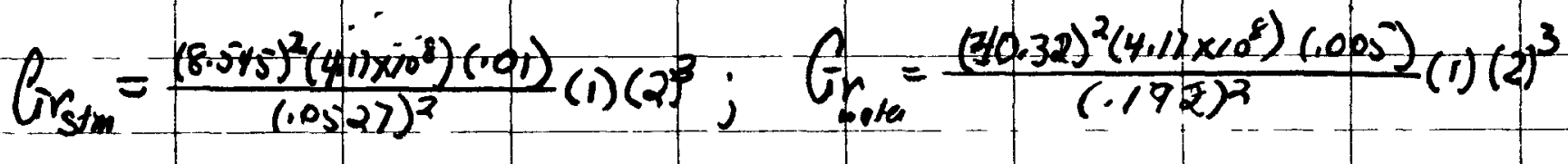

$$
\begin{aligned}
& =8.77 \times 10^{11}+\frac{1}{1.36 \times 10^{11}} \\
& \begin{aligned}
h_{s t_{n}} & =\frac{k_{s}(.27)}{L}\left(G_{n} P_{r}\right)^{25} \\
& =\frac{.0537}{2}(1.27)\left[\left(6.77 \times 10^{4}\right)(4.32)\right]^{\prime 25}
\end{aligned} \\
& h_{0}=\frac{k_{u}}{L}(., y)\left(C_{r} P_{r}\right)^{1 / p^{\prime}} \\
& =\frac{.26}{2}(.14)\left[\left(7.36 \times 10^{\prime \prime}\right)\left[1.35^{\circ}\right)\right]^{4 / 3} \\
& =10.1 \frac{B+y}{\lambda_{1}-A^{2} T^{2} C} \\
& =18.3 \frac{B t 4}{m-F T^{20} F}
\end{aligned}
$$


COMBUSTION ENGINEERING

NUCLEAR POWER DEPARTMENT

Finally the overall coefficient is given by

$$
\begin{aligned}
& U A=\frac{1.0}{\frac{1}{h A}+R} \\
& \left(U A_{s m}=\frac{1.0}{\frac{1}{(0.1)(450.1)}+0.00002398}=4099^{\frac{B+y}{h_{1} 0.5}}=1.139 \frac{\beta A y}{\sec \%}\right.
\end{aligned}
$$

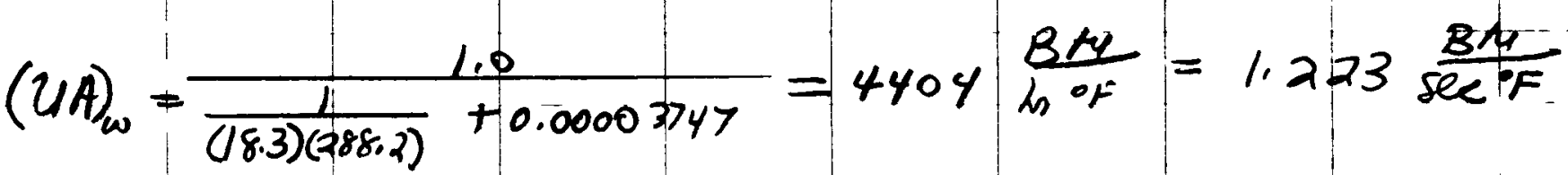

$$
\begin{aligned}
& \text { Coefficients } \\
& \text { a) upper drum } \\
& {\left[\frac{U A}{(P V C)_{0 r}}\right]=\frac{-1.139}{(462)(280.7)(.137)}=0.00006145 \mathrm{sec}^{-1}} \\
& {\left[\frac{U_{A}}{\left(P V_{s m}\right.}\right]=\frac{1.139}{(8: 545)(625: 3)}=0.0002132 \frac{B \mathrm{mu} / \mathrm{lbm}}{\mathrm{sec} / \mathrm{F}}} \\
& \left(\frac{1}{\rho v}\right)=\frac{1.0}{(8.575)(6.25 \cdot 3)}=0.0001872 \quad \text { lan" } \\
& \text { b) Loves dom } \\
& {\left[\frac{z_{A}}{(\text { evclon }}\right]=\frac{1.223}{(482)(187.0)(137)}=0.00009904 \mathrm{sec}^{-1}} \\
& {\left[\frac{\overline{u A}}{(\mathrm{VV})_{w}}\right]=\frac{1.223}{(40.32)(264.8)}=0.0001145 \frac{\mathrm{Bru} / \mathrm{pm}}{\mathrm{sec}-\mathrm{p}}}
\end{aligned}
$$

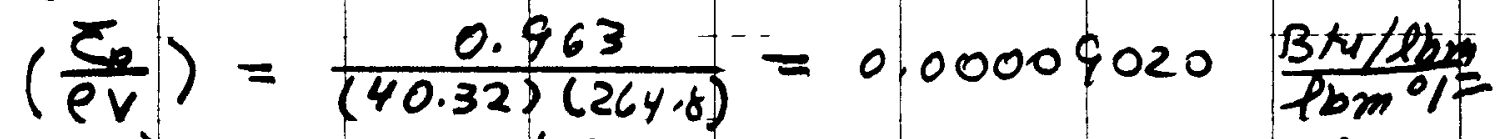

$$
\begin{aligned}
& \left(\frac{1}{\rho v}\right)=\frac{1.0}{(40.32)(264.8)}=0.00009366\left|86 \mathrm{~m}^{-1}\right|
\end{aligned}
$$


COMBUSTION ENGINEERING

NUCLEAR POWER DEPARTMENT

Summing

$$
\begin{aligned}
& \dot{h}_{48}=-(0.0002132) T_{362}+(0.0002132) T_{49} \\
& +(0.0001872) 2_{5} H_{356}-(0.0001872) w_{5} h_{48} \\
& \dot{T}_{49}=-(0.00006145) T_{49}+(0.00006145) T_{\text {Ff }} \\
& \left.h_{50}=-(0.0001 / 45) T_{363}+(0.0001145) T_{5}\right) \\
& +(4.00004366) w_{\text {pred }} h_{\text {fend }} \text {. }(0,00009366) w_{w} H_{357} \\
& \text { - }(0.00009366) \omega_{r} h_{50}
\end{aligned}
$$$$
\dot{T}_{51}=-(0.00009904) T_{51}+(0.00009904) T_{363}
$$$$
\dot{\omega}_{s}=\text { steam flow per loop }=\dot{\omega}_{81}
$$$$
\dot{\omega}_{\text {feed }}=\text { Foedwater flow per loop }=\dot{\omega}_{\text {sa }}
$$$$
\dot{\omega}_{n}=\text { total secenculated flow per loop }=\dot{\omega}_{85}
$$$$
H_{30}=\text { saturated vapor enthalpy }=h_{g}=\dot{\omega}_{s 0}
$$$$
h_{307}=\text { steterated liquid enthalpy }=h_{F}=w_{57}
$$$$
\omega_{\omega}=\text { separated water flow per loop }=\dot{\omega}_{y 7}
$$

The algebraic equation for the saturation enthalpies are

$$
\begin{aligned}
& H_{356}=(1,0) \omega_{86} F_{364} ; F_{369}=1.0 \\
& H_{357}=(1,0) \omega_{87} F_{33},
\end{aligned}
$$


COMBUSTION ENGINEERING

NUCLEAR POWER DEPARTMENT

The algebraic nodes for the hum

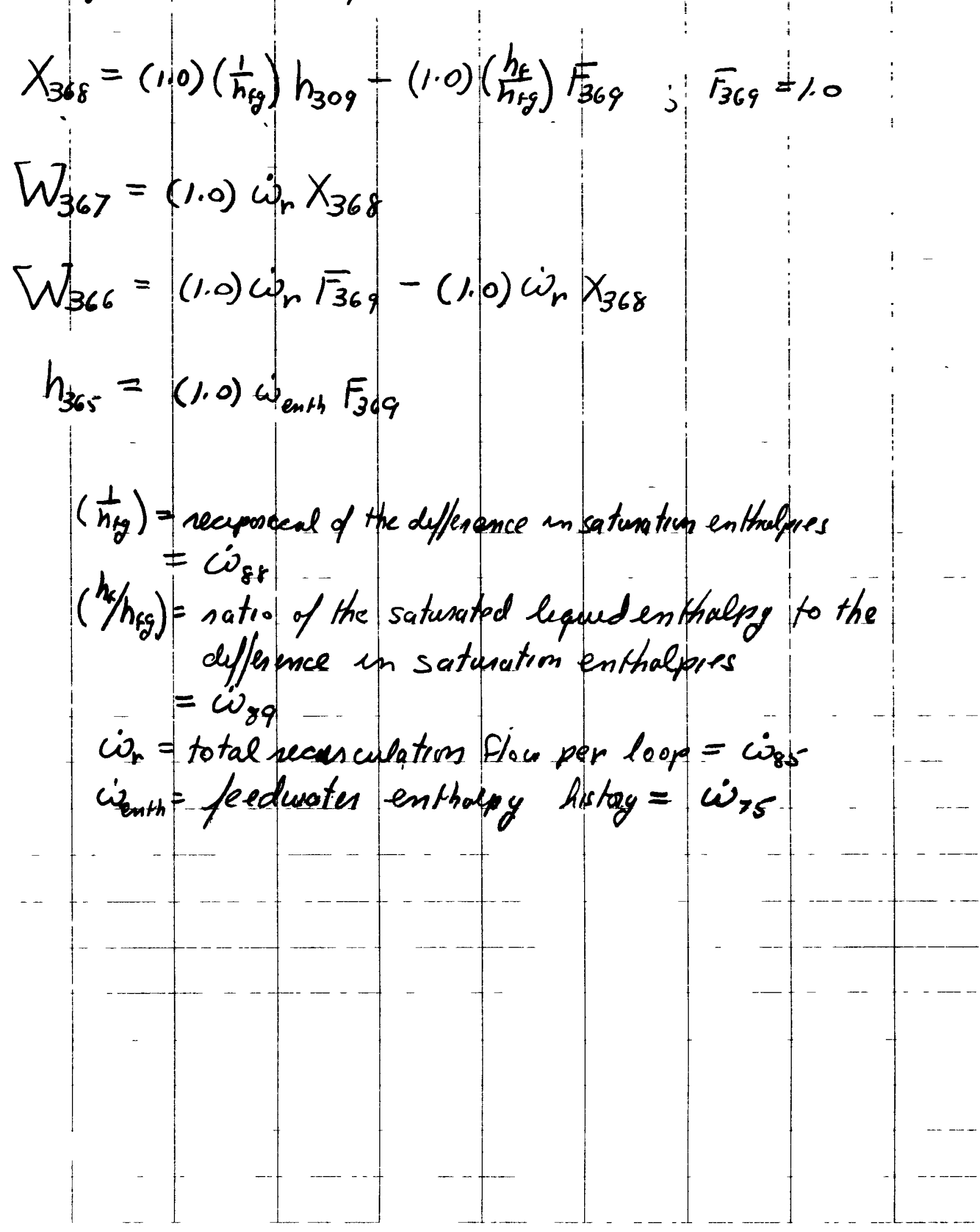


COMBUSTION ENGINEERING

NUCLEAR POWER DFPARTMFNT

The sides pepresentung the temperature of the steam and crater in the drum are connected to the corresponding enthalpy node by "flow equations". These equations can be used as appropriate curve Fits, tee. polynomials in $h$ or as a function of time.

In general

$$
k=\epsilon_{1} ; z=T_{1 / 1}=\text { pedal value }
$$

1) $k<0$

$$
\begin{array}{r}
\dot{\omega}=\epsilon_{2} z+\epsilon_{3} z^{2}+\frac{\epsilon_{4}}{z}+\frac{\epsilon_{5}}{z^{2}} \\
+\epsilon_{6}+\epsilon_{7} z^{3}+\epsilon_{8} z^{4}+\epsilon_{5} z^{5}+\epsilon_{10} z^{6} \\
H=\left\{\begin{array}{l}
0, k=0 \\
z, k>0
\end{array}, \quad R=\left\{\begin{array}{c}
0, t \leq 0 \\
\epsilon_{3} t+\epsilon_{4} t^{2}, t \geqslant 0
\end{array}\right.\right.
\end{array}
$$

2) $k \geqslant 0$

a) $\epsilon_{10}=0$

$$
\dot{\omega}=H+R+\epsilon_{2}+\epsilon_{5} \exp \left(\epsilon_{6} t+\epsilon_{7} t^{2}\right)
$$

b) $\epsilon_{10}>0$

$$
\begin{aligned}
& \dot{\omega}=\left\{\begin{array}{l}
H+\epsilon_{10}, t_{m} \leqslant 0 \\
H+R\left(t_{m}^{k}\right)+\epsilon_{2}+\epsilon_{s} \exp \left(\epsilon_{\theta} t_{m}+\sigma_{g} t_{m}^{2}\right), t_{m} \geqslant 0
\end{array}\right. \\
& t_{m}=t-\left(t_{s}+\epsilon_{8}\right) ; t_{m}^{*}=\epsilon_{q}-t_{m}
\end{aligned}
$$

The steam node will be at saturated conditions for most of the conscolered transients. Consequently the temperature modes depend directly on the pressure. If the pressure is prescribed for the particular transient, the associated saturation Temperature is determined. Curve fits in the 
COMBUSTION ENGINEERING NUCLEAR POWER DEPARTMENT

form $2(a)$ of $2(b)$ would be used to normal transients the pressure will be very near the full load operating level and the cospespondeng saturation tempenture is approximately 676.5 F. one of the following forms may be used.

a)

$$
\begin{aligned}
& \epsilon_{1}=-48 \\
& \epsilon_{6}=676.5 \text {, que other } \epsilon^{\prime}=0
\end{aligned}
$$

b) $\epsilon_{1}=-369$

all $\epsilon^{\prime} s=0$ except one $\epsilon=676.5$

*c) $e_{1}=0$

$$
\epsilon_{2}=676.5 \text {, all other } E^{\prime} 5=0
$$

Fo stomgent conditions. that deviate from the above special considerations must be made.

The coates rode will be at a subrooled conditur. The temperature wall be a function of enthalpy for a given pressure. Curve fit in the form (1) is used.

The selected pressure is 2645 psia when is the pressure at the ext of the man heat transfer region of the evaporator and ven y nearly the pressure in the hum. The effect blue to pressure. variation well be small since properties of composed water aye a weak function of pressure.

The values of temperatuse-enthalpy were 
COMBUSTION ENGINEERING

NUCLEAR POWER DEPARTMENT

obtained finn the GE mask II steam tables cure fits to Keenan $\$$ Leges steam tables). GE mark 7 program POKFZT was then used to obtain the coefficients in a polynomial cusk e fit.

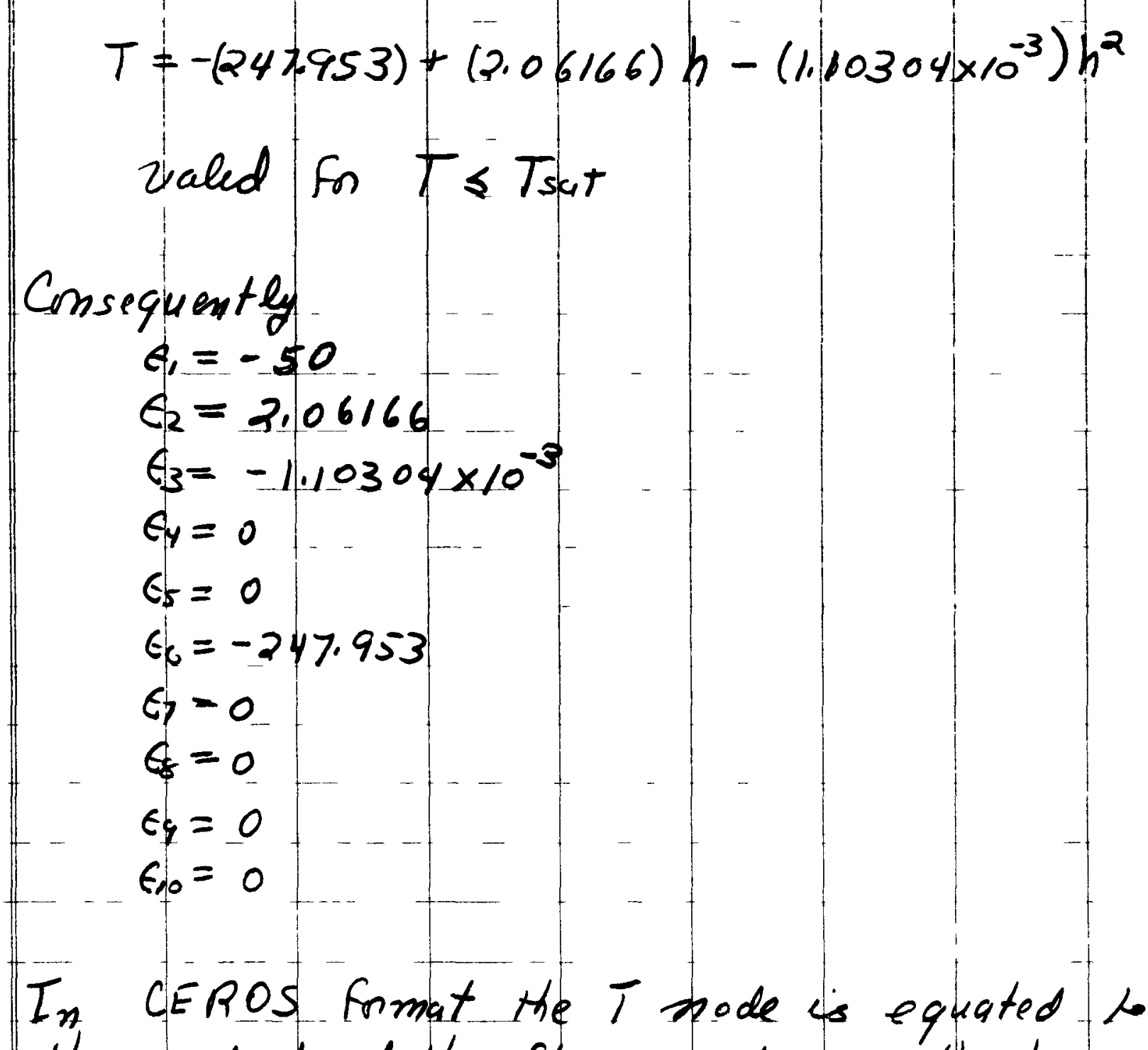
the product of the flow equation with the unity node. 


$$
\text { COMBUSTION ENGINEERING }
$$

NUCLEAR POWER DEPARTMENT

Sum many

$$
\begin{array}{ll}
T_{362}=(1.0) \omega_{32} F_{369} ; & \epsilon_{1}=-48,-369,000 \\
T_{363}=(1.0) \omega_{13} F_{369} ; & \epsilon_{1}=-50
\end{array}
$$


COMBUSTION ENGINEERING. INC.

WINDSOR. CONN.

CONT. No

MADE BY

DATE

DWG. No.

Chr' Dr

Dare

The curve defining each transient were rendered into approximate arialytial form uscg the functions available in the CERDS slow equations. The time varying form of these equations cire as follows:

$$
\begin{gathered}
\left.\epsilon_{1 \text { (integral) }} \geqslant 0 \Rightarrow Z=F_{\epsilon_{1}} \begin{array}{r}
\text { (modal } \\
\text { cha }
\end{array}\right) \\
H=\left\{\begin{array}{l}
0, \epsilon_{1}=0 \\
Z, \epsilon_{1}>0
\end{array}\right. \\
R(t)=\left\{\begin{array}{c}
0, t \leqslant 0 \\
\epsilon_{3} t+\epsilon_{4} t_{0}^{2} t \geqslant 0
\end{array}\right.
\end{gathered}
$$

a)

$$
\begin{aligned}
& \epsilon_{10}=0 \\
& \dot{\omega}=H+R(\bar{t})+\epsilon_{2}+\epsilon_{5} \exp \left(\epsilon_{6} t+\epsilon_{7} t^{2}\right) \\
& \quad \bar{t}=t+\epsilon_{9} ; \quad \epsilon_{8}=0
\end{aligned}
$$

b)

$$
\begin{aligned}
& \epsilon_{10}>0 \\
& \dot{\omega}=\left\{\begin{array}{l}
H+\epsilon_{10} \quad t_{s} \leq 0 \text { and } t_{m} \leq 0 \\
H+R\left(t_{m}^{*}\right)+\epsilon_{2}+\epsilon_{5} \exp \left(\epsilon_{6}+\epsilon_{7} t^{D}\right)
\end{array}\right. \\
& t_{m}=t-\left(t_{s}+\epsilon_{\delta}\right) \text { ts olelmed during CEROS } \\
& t_{m}^{*}=t_{m}+\epsilon_{q}
\end{aligned}
$$

The $10 \mathrm{\epsilon}$ 's completely define these flow equations. In order to simulated pastrowar transient curve the $E$ 's are specualyed to a curve fit. 
COMBUSTION ENGINEERING, INC.

WINDSOR, CONN.

CONT. No

Made Br

Dare

DWG. No.

Chr' Br

DATE

LOCATION

Steady State values for flaw equations.

$\dot{w}_{50}, \dot{\omega}_{57} \rightarrow \dot{\omega}_{71}, \dot{\omega}_{33}$ are curve fits connecting temperature and enthalpy nodes. Those well not be changed during the transient.

$$
\begin{aligned}
& \dot{\omega}_{y\rangle}=\omega_{\omega}=\delta 21.3 \\
& \dot{\omega}_{51}=\dot{w}_{52}=\dot{\omega}_{s 3}=\dot{\omega}_{s y}=\dot{w}_{s 5}=\dot{\omega}_{s 6}=\dot{\omega}_{32}=T_{s, r}=676.5 \\
& \dot{\omega}_{74}=T_{\text {MG }}=960 \\
& \dot{\omega}_{75}=h_{\text {peed }}=442.9 \\
& \dot{\omega}_{x 6}=\dot{\omega}_{\text {Mar pu module }}=1209 \\
& \dot{\omega}_{77}=w_{\text {ia }} \text { pen } S H \text { tube }=8.061 \\
& \dot{\omega}_{78}>w_{\text {int }} \text { cher EV tube }=3.182 \\
& \dot{\omega}_{79}=w_{s} \text { per module }=112.6 \\
& \dot{\omega}_{\text {go }}=\omega_{\text {s pes }} 5 \mathrm{Hl} \text { time }=0.750 \mathrm{Y} \\
& \omega_{\delta_{1}}=\omega_{s} \text { per loop }=337.7 \\
& \dot{\omega}_{82}=\text { used ph loop }=337.7 \\
& \dot{\omega}_{\delta 3}=w_{n} \text { per module }=386.2 \\
& \dot{\omega}_{\text {gl }}=\omega_{n} \text { per } \varepsilon_{V} \text { tube }=1.016 \\
& \omega_{\text {iss }}=w_{r} \text { pes loop }=1159 \\
& \dot{\omega}_{\delta 6}=h g=1076.6 \\
& \dot{c}_{81}=h_{f}=750.2 \\
& c_{\text {cos }}=1 / h_{\text {hg }}=0.003064 \\
& \omega_{89}=h_{\text {A }} / h_{\text {gl }}=2.298
\end{aligned}
$$

In all the above equations $\epsilon_{2}=$ particular value, all ot hen $G$ 's are 0 . 
COMBUSTION ENGINEERING, INC.

WINDSOR. CONN.

ramen

CONT. No

Made Br__ Date

LOCATION

DWG. No.

Chromo BY

Date

1) Nonrural Scram

$$
\begin{aligned}
T_{\text {Ma }}= & 960+0.20 t \\
& \omega_{7 y}: \epsilon_{2}=960, \epsilon_{3}=0.20, \text { all others } 0 .
\end{aligned}
$$

$h_{\text {peed }}=442.9$

$\omega_{75}: \epsilon_{2}=442.9$, all others 0 .

same as steady state

$$
\begin{aligned}
& w_{N a}=0.95 e^{-0.09005 t}+0.05 \quad \text { (nomalyed) } \\
& \omega_{76}: \epsilon_{2}=0.45, \epsilon_{5}=1149 ; \epsilon_{6}=-0.09005 \\
& \omega_{77}: \epsilon_{2}=0.4031, \epsilon_{5}=7.568, \epsilon_{6}=-0.09005 \\
& \omega_{78}: \epsilon_{7}=0.1591, \epsilon_{5}=3.0229, \epsilon_{6}=-0.09005
\end{aligned}
$$

$$
w_{s}=w_{\text {reed }}=0.96 e^{-0.06539 t}+0.04 \quad \text { (nomalyed) }
$$

$\omega_{79}: \epsilon_{2}=4.003, \epsilon_{5}=108.1, \epsilon_{6}=-0.06539$

$\omega_{80}: \epsilon_{2}=0.03002, \epsilon_{5}=0.7204, \epsilon_{6}=-0.06539$

$w_{81}: \epsilon_{2}=13.508, \epsilon_{5}=324.2, \epsilon_{6}=-0.06539$

$\omega_{12}: \epsilon_{2}=13.508, \epsilon_{5}=324.2, \epsilon_{6}=-0.06539$

$W_{\omega}=1145,5-324.2 e^{-0.065995}$

$\omega_{47}: \epsilon_{2}=1145.5, \epsilon_{5}=-324.2, \epsilon_{6}=-0.06539$

$$
P(t)=2447+198 e^{-0.1333 t}
$$

Assuming an immediate adjust rent to equalibicum and Us cong the 1969 ASME steam 
Combustion Enemiaghing, INC.

WINDSOR, CONN.

CONT. No

Made Br

Date

LOCation

Die. No.

CHico

Date

tables, the follow ny analytical expressions for Tsars $h_{f}, h_{y}, h_{f g}$ are obtaundo.

$$
\begin{aligned}
& T_{\text {sat }}=664.9+11.6 e^{-0.1333 t} \\
& \begin{array}{l}
\dot{w}_{51} \rightarrow \dot{c}_{56}: \epsilon_{2}=664.9, \epsilon_{5}=11.6, \epsilon_{6}=-0.1333 \\
\text { and } \dot{\omega}_{72}
\end{array} \\
& h_{g}=1099-22.4 e^{-0.1333 t} \\
& \dot{w}_{36}: \epsilon_{2}=1099, \epsilon_{3}=-22.4, \epsilon_{6}=-0.1333 \\
& h_{f}=724.9+25.3 e^{-0.1333 t} \\
& \dot{\omega}_{87}: \epsilon_{2}=724.9, \epsilon_{5}=25.3, \epsilon_{6}=-0.1333 \\
& 1 / h_{\text {sg }}=0.002673+0.0003910 e^{-0.1323 t} \\
& \dot{\omega}_{\delta \delta}: \epsilon_{2}=0.002673, \epsilon_{5}=0.0003910, \epsilon_{6}=-0.1333 \\
& h_{\text {thy }}=1.938+0.360 e^{-0.13336} \\
& \dot{\omega}_{59}: \epsilon_{2}=1.938, \epsilon_{5}=0.360, \epsilon_{6}=-0.1323
\end{aligned}
$$
All other flow equation constant at their steady
state values.

2) Secure of one Second any Pump with Scram J hes transient is colentical with normal scram with the following exceptions.

$$
T_{\text {wa }}=960
$$

$\dot{w}_{74}: \epsilon_{2}=960$, (same as steady state) 
COMBUSTION ENGINEERING. INC.

WINDSOR, CONN.

CONT. No

Made Br____ DATE

Location

DWG. No.

ChK'd BY

DATE

$$
\begin{aligned}
& \omega_{\mu_{a}}=0.95 e^{-0.1689 t}+0.05 \\
& \dot{\omega}_{76:} \epsilon_{2}=60.45, \epsilon_{5}=1149, \epsilon_{6}=-0.1689 \\
& \dot{\omega}_{77}: \epsilon_{2}=0.4031, \epsilon_{5}=7.568, \epsilon_{6}=-0.1689 \\
& \dot{\omega}_{78}: \epsilon_{7}=0.1591, \epsilon_{5}=3.0229, \epsilon_{6}=-0.1689
\end{aligned}
$$

3) Single primary pump secure with scram

This transient is selentecal with normal scone with the following single exception.

$$
T_{N a}= \begin{cases}960 & 0 \leqslant t \leqslant 100 \\ 960-2.87 t \quad 100 \leqslant t \leqslant 200 \\ 673 \quad t \geqslant 200\end{cases}
$$

In order to implements this 2 plow equations are needed. why is added to the already used $\omega_{74}$

$$
T_{\text {Na }}=F_{364}=(1.0) \omega_{74} F_{369}+(1.0) \omega_{49} F_{369} j F_{369}=1.0
$$

is the new algebraic equation required. Node 220 which represents time is also added. Provision in a "Reactor Scram" at are mode j this will define $t_{s}=+\infty 0^{2}$

$$
\begin{aligned}
& \dot{\omega}_{74}: \epsilon_{2}=960, \epsilon_{3}=-2.87, \epsilon_{0}=960
\end{aligned}
$$

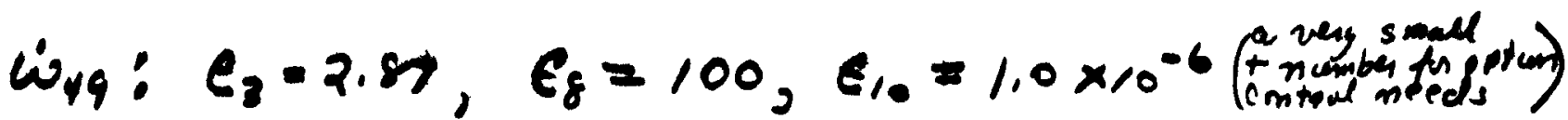

$\dot{w}_{74}$ is a pomp down delayed by $t_{5}=100$ sec. $\dot{w}_{49}$ is a ramp tor delayed by $c_{3}+t=200 \mathrm{sec}$. conseguanty often 200 sec the two sumps add to cancel further

- changes in TN a. 
COMBUSTiON ENGINEERING. INC.

WINDSOR, CONN.

CONT. No

MADE Br

Date

LOCATION

DWG. No.

CHK'D B

Date

4) Loss of one circulation pump

One pump goes $\mathscr{H}$ o line in 3 seconds and the How reduces to 66\%. A 15 second delay at $66 \%$ How is assumed, and then the standby pump cuts in. The flow returns to $100 \%$ in 12 seconds. All other flow equations remaining at the 100\% load steady state.

$$
w_{r}=\left\{\begin{array}{lr}
1-0.1133 t & 0 \leq t \leq 3 \\
0.66 & 3 \leq t \leq 18 \\
0.66+0.02833 t & 18 \leq t \leq 30 \\
1.0 & t \geqslant 80
\end{array}\right.
$$

To ease of implementation node 355 is add and coupled to 4 new the equations $41,42,43,44$. This well gere the nommened circulation flow. Tl ow equations $83,64,85$ are coupled to 355 with the appropriate constant to adjust the flow to module, cucponatstute, and bop beet. In addition node 220, sepsesenteng time is coupled to the "Reactor serin" option to define ts $=0$.

$$
F_{355}=(1.0) \omega_{11} F_{369}+(1.0) \omega_{12} F_{369}+(1.0) \omega_{43} F_{699}+(1.0) w_{x y} F_{369}
$$

when e $\bar{F}_{36}, \equiv 1$.

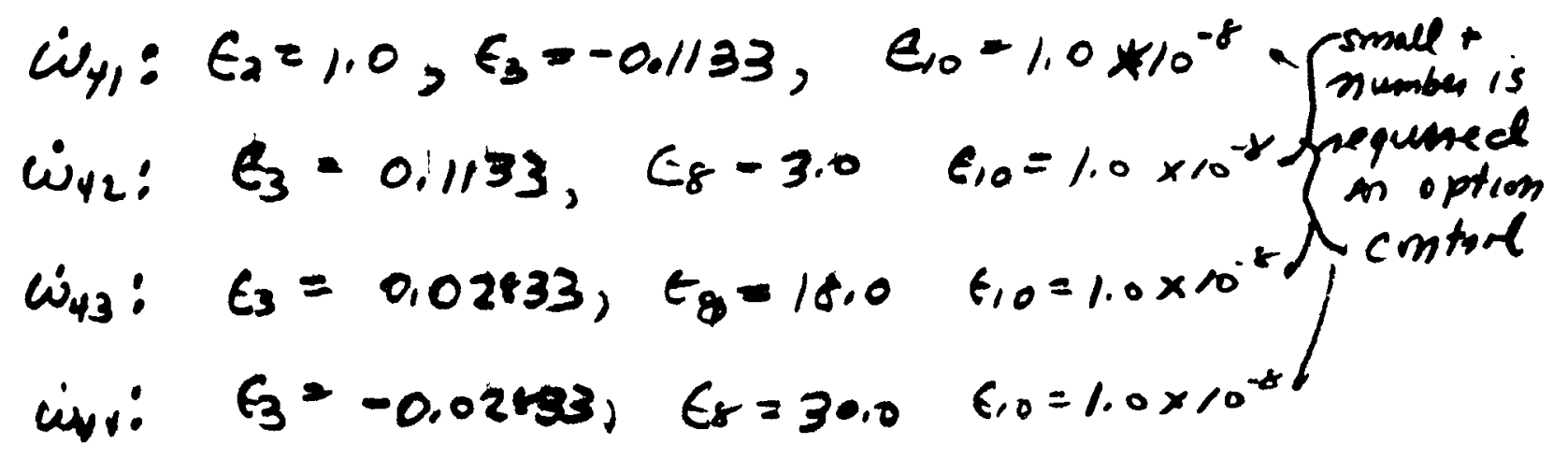

Ot the apmoprate delay ties, $G_{t}$ new flow equations - arg entiodure to courthact reveres changes os to Elect new changes. 
COMBUSTION ENGINEERING. INC.

WINDSOR, CONN.

romes

CONT. No

Made ar

Dare

Location DNG. No. CMK. Br Dare

$\omega_{83}: \epsilon_{1}=-355 ; \epsilon_{2}=386.2$

$\omega_{84}: \epsilon_{1}=-355 ; \epsilon_{2}=1.016$

$\omega_{85}: \epsilon_{1}=-355 ; \epsilon_{2}=1159$

$\epsilon_{1}$ is supertax as - 2 . for option control and 355 to s coupling to the appropriate mode.

5) Power ramp from $100 \%$ load to $40 \%$ load.

Node 220 representing tune is coupled to the "Re actor Scrams" option to define $t_{s}=0$.

$$
T_{\text {Na }}= \begin{cases}960-0.03 t & t \leq 1200 \\ 924 & t>1200\end{cases}
$$

An additional flaw equation is sequined

$$
\begin{aligned}
& T_{1 w}=F_{36 y}=(1.0) \omega_{3 y} F_{369}+(1.0) \omega_{y 9} F_{369} \\
& \omega_{2 y}: \varepsilon_{2}=960, \epsilon_{3}=-0.03 \text {, } \\
& \epsilon_{10}=1,0 \times 10^{-8} k \\
& \omega_{49}: \epsilon_{3}=0.03, \epsilon_{8}=1200, \quad \epsilon_{10}=110 \times 10^{-k} k \\
& h_{\text {reed }}= \begin{cases}442.4-0.08008 t & t \leq 1200 \\
346 & t>1200\end{cases}
\end{aligned}
$$

An conditional flow equation is sequined

$$
\begin{aligned}
& h_{\text {reed }}=F_{365}=(1.0) \omega_{75} F_{369}+(1.0) \omega_{48} F_{369} \\
& \omega_{35}: \epsilon_{2}=44.2 .9, \epsilon_{3}=-0.08008, \epsilon_{10}=1.0 \times 10^{-8 k} \\
& \omega_{08}: \epsilon_{3}=0.08008, \epsilon_{8}=1200 \quad \epsilon_{10}=1.0 \times 10^{-8 k}
\end{aligned}
$$


COMBUSTION ENGINEERING, INC.

WINDSOR, CONN.

CONT. NO

MADE BY_ DATE

DWG. No

Cuk'D Br

Date

LOCATION

$$
w_{s}=w_{\text {seed }}= \begin{cases}1-.000525 t & t \neq 1200 \\ 0.37 & t>1200\end{cases}
$$

Node 355 is add ut to compute the nosmalyed value of wis, wrap. This value is coupled in to the aphopigite flaw equation with the cost scale factor.

$$
\begin{aligned}
& F_{355}=(1.0) \omega_{45} F_{369}+(1.0) \omega_{44} F_{369} \\
& \omega_{47}: \epsilon_{2}=110, \epsilon_{0}=0.000525, \epsilon_{10}=1.0 \times 10^{.4} \\
& \omega_{45}: \epsilon_{3}=0.000525, \epsilon_{8}=1200, \epsilon_{10}=1.0 \times 10^{.8 \mathrm{~K}}
\end{aligned}
$$

and

$$
\begin{aligned}
& \omega_{79}: \epsilon_{1}=-355, \epsilon_{2}=112.6 \\
& \omega_{50}: \epsilon_{2}=-355, \epsilon_{2}=0756 y \\
& \omega_{11}: \epsilon_{1}=-355, \epsilon_{2}=337.7 \\
& \omega_{52}: \epsilon_{1}=-3.55, \epsilon_{2}=337.7
\end{aligned}
$$

$C_{1}$ is selected as -355 for option control and proper coupling to node.

$$
w_{\omega}= \begin{cases}821.3+0.1773 t & t \leqslant 1200 \\ 103410 & t \geqslant 1200\end{cases}
$$

Node so must be coupled to bott flow equations defining ww.

$$
\begin{gathered}
h_{30}=F_{50}=\cdots+(1.0) \omega_{47} F_{357}+(1.0) \omega_{46} F_{357} \\
F_{357}=h_{g}
\end{gathered}
$$


Combuomon EnOMEdNing. Inc.

WMDSOR, CONN.

CONT. No.

MADE BY

Dare

LOCATION

OWG. No. Ciao By Dare

$$
\begin{aligned}
& \omega_{46}: \epsilon_{2}=871.3, \epsilon_{3}=0.1773, \epsilon_{10}-1.0 \times 10^{-8 *} \\
& \omega_{47}: \epsilon_{3}=-0.1773, \epsilon_{8}=1200, \quad \epsilon_{10}=1.0 \times 10^{-8 *} \\
& \omega_{\text {Na }}= \begin{cases}1.0-0.0005042 t & t \leqslant 1200 \\
0.395 & t>1200\end{cases}
\end{aligned}
$$

nock $35 y$ adds the taw require flow equations. Then the sodurm flow coupled into the popes equations with appoperate scale factors

$$
\begin{aligned}
& w_{w_{1}}=F_{354}=(1.0) \omega_{42} F_{369}+(1.0) \omega_{43} F_{369} \\
& \omega_{42}: \epsilon_{2}=1.0, \epsilon_{3}=-0.0005042, \epsilon_{10}=1.0 \times 10^{-8} \\
& \omega_{43}: \epsilon_{3}=0.000,042, \epsilon_{8}=1200, \epsilon_{10}=1.0 \times 10^{-8} k
\end{aligned}
$$

and

$w_{16}: \epsilon_{1}=-3 s^{-} y, \epsilon_{2}=1209$

$w_{77}: G=-3+4, \epsilon_{2}=8.061$

wis: $\epsilon_{1}=-35 y, \epsilon_{3}=3.182$

* $E_{10}=1.0 \times 10^{*}$ us used for option control on by. 